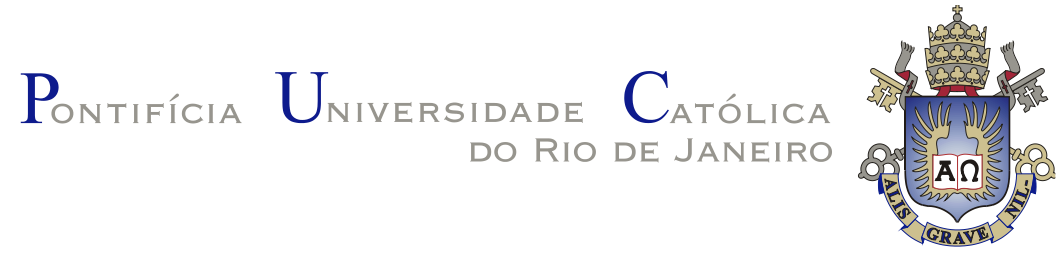

Luana Caroline da Silveira Nascimento

\title{
Fundamentos da Sorção de Neodímio em Palygorskita: Aspectos termodinâmicos e cinéticos
}

Dissertação de Mestrado

Dissertação apresentada como requisito parcial para obtenção do grau de Mestre pelo Programa de PósGraduação em Engenharia de Materiais e de Processos Químicos e Metalúrgicos do departamento de Engenharia Química e de Materiais PUC-Rio.

Orientadores: Prof Maurício Leonardo Torem

Dra. Ellen Cristine Giese

Rio de Janeiro

setembro de 2019 


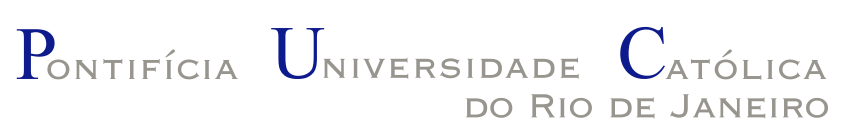

Luana Caroline da Silveira Nascimento

\title{
Fundamentos da Sorção de Neodímio em Palygorskita: aspectos termodinâmicos e cinéticos
}

\begin{abstract}
Dissertação apresentada como requisito parcial para obtenção do grau de Mestre pelo Programa de PósGraduação em Engenharia de Materiais e de Processos Químicos e Metalúrgicos do departamento de Engenharia Química e de Materiais PUC-Rio.
\end{abstract}

Prof. Maurício Leonardo Torem

Orientador

Departamento de Engenharia Química e de Materiais - PUC- RIO

Dr. Ronald Rojas Hacha

Departamento de Engenharia Química e de Materiais - PUC-RIO

Dr. Luiz Carlos Bertolino

CETEM

Prof. Rodrigo Fernandes Magalhães de Souza

Departamento de Engenharia Química e de Materiais - PUC-RIO 
Todos os direitos reservados. É proibida a reprodução total ou parcial do trabalho sem autorização da universidade, da autora e do orientador.

\section{Luana Caroline da Silveira Nascimento}

Graduou-se em engenharia de Petróleo na Universidade Federal do Rio Grande do Norte, Natal, Brasil em 2017.

Ficha Catalográfica

Fundamentos da sorção de neodímio em palygorskita: aspectos termodinâmicos e cinéticos / Luana Caroline da Silveira Nascimento; orientadores: Maurício Leonardo Torem, Ellen Cristine Giese. - 2019.

146 f. : il. color. ; $30 \mathrm{~cm}$

Dissertação (mestrado)-Pontifícia Universidade Católica do Rio de Janeiro, Departamento de Engenharia Química e de Materiais, 2019.

Inclui bibliografia

1. Engenharia Química e de Materiais - Teses. 2. Palygorskita. 3. Adsorção. 4. Neodímio. 5. Isotermas. 6. Potencial Zeta. I. Torem, Maurício Leonardo. II. Giese, Ellen Cristine. III. Pontifícia Universidade Católica do Rio de Janeiro. Departamento de Engenharia Química e de Materiais. IV. Título. 
Aos meus pais Wellington e Fátima, Pelo amor e educação; e aos meus tios Maria e Sérgio por todo o apoio prestado. 


\section{Agradecimentos}

A Deus pelo dom da vida, e por me ajudar nos momentos mais difíceis nos quais duvidei que não fosse possível continuar.

Ao Professor Doutor Maurício Leonardo Torem, meu orientador, pela confiança, paciência, boa vontade e compreensão oferecidas durante a orientação e pelo enorme aprendizado, que foi proporcionado ao compartilhar de sua experiência.

A minha Co-orientadora Doutora Ellen Cristine Giese, por todas as dicas, paciência, confiança e resiliência em ser minha co-orientadora. Obrigada por se fazer presente.

Ao Doutor Luiz Carlos Bertolino obrigada pela paciência, carinho e orientação, incentivo, contribuição científica, disponibilidade, palavras de motivação. Serei sempre eternamente grata por todo o apoio prestado. Sem dúvida foi indispensável para a realização deste trabalho.

Ao Doutor Antônio Gutierrez Merma pelas considerações e aporte indispensáveis para a condução desta dissertação.

Ao querido professor José Yvan Pereira Leitte (in memoriam) que me impulsionou a continuar e abriu portas para que eu continuasse. Sou grata e feliz por ter sido sua aluna.

Aos meus pais Wellington e Fátima que nunca mediram esforços para proporcionar a mim e aos meus irmãos Paulo (in memoriam) e Rafael a melhor herança que os pais podem deixar aos seus filhos: Educação e resiliência. Sem dúvida meus maiores incentivadores e os verdadeiros mestres.

Aos meus tios Maria e Sérgio, e irmãos de coração Rodrigo e Ricardo pela companhia, paciência e amor. Sou eternamente grata por tudo.

A toda família pela união, sorrisos e companhia que tornaram esta jornada mais leve e descontraída. Dividir a vida com vocês me faz ter a certeza que a família é o bem mais precioso que temos.

Aos amigos da vida Jéssica Sena, Rafael Neves, Jânio Costa, Tayse Gomes, Luciano Dantas, Alana Melo, Cinara Marculino, Fernanda Amorim, Monaliza 
Fernandes, Raffaela Soares, Isabella Rodrigues, Inês Cavalcanti e Hiago Henry obrigada pela torcida, apoio, confiança e principalmente pela amizade verdadeira.

Aos amigos do grupo de pesquisa do CETEM Bruna Lemos, Karla Arguelles, Rayssa Furlanetto, Patrícia Viana, Victor Campos, Victor Brandão e especial a Nathália Oliveira por ter aceitado esse desafio junto comigo e por estar sempre disposta a ajudar na realização desta pesquisa.

Aos colegas da PUC-Rio, professores e pesquisadores pelos ensinamentos, orientações e sugestões para minha formação e crescimento profissional. Em especial aos amigos de coração Carolina Simões, Jesana Moura, Francescca Fornasier, Marcelo Carneiro, Thiago Ribeiro e Ronald Rojas por compartilhar os momentos difíceis e multiplicar as alegrias.

Ao Centro de Tecnologia Mineral - CETEM, por toda a infraestrutura laboratorial e a todos seus servidores, técnicos e colaboradores pelo suporte técnico e científico para a realização deste trabalho.

Ao CNPq e a PUC-Rio pelo apoio financeiro para a realização deste trabalho 


\section{Resumo}

Nascimento, Luana Caroline da Silveira; Torem, Maurício Leonardo. Fundamentos da Sorção de Neodímio em Palygorskita: Aspectos termodinâmicos e cinéticos. Rio de Janeiro, 2019. 146. Dissertação de Mestrado - Departamento de Engenharia Química e de Materiais, Pontifícia Universidade Católica do Rio de Janeiro.

Nas últimas décadas a demanda por elementos terras raras (ETRs) cresceu consideravelmente devido a sua importância estratégica. Os ETRs são amplamente utilizados em diferentes setores, tais como, medicina, engenharia química, eletrônica e fabricação de computadores. Entre os ETRs, está o Neodímio, que é um dos metais mais valiosos utilizados em ligas, componentes eletrônicos e filtros ópticos. A necessidade da alta pureza dessas espécies requer a separação seletiva, e entre os métodos disponíveis, a adsorção ganhou maior atenção devido à sua simplicidade, alta eficiência e baixo custo. Neste trabalho foi avaliado o argilomineral palygorskita como potencial sorvente para remoção de $\mathrm{Nd}$ (III) de soluções aquosas através de ensaios em batelada. Para este propósito, a amostra proveniente da região de Guadalupe (Piauí) foi beneficiada e estudada a composição química e mineralógica com o intuito de utilizar no processo adsortivo a amostra com maior grau de pureza. A composição química apresenta teores de óxidos, sendo os principais, $\mathrm{SiO}_{2}, \mathrm{Al}_{2} \mathrm{O}_{3}$ e $\mathrm{MgO}$ corroborando a presença de palygorskita na amostra. Os estudos de potencial zeta apontam que o argilomineral apresenta carga superficial negativa em toda faixa de $\mathrm{pH}$, além disso, a elevada área superficial de $118 \mathrm{~m}^{2} / \mathrm{g}$ justificam a aplicação como adsorvedor de cátions. Diferentes tipos de isotermas de adsorção e modelos cinéticos foram utilizados para descrever o comportamento do $\mathrm{Nd}$ (III) na adsorção e os resultados experimentais que melhor se ajustaram são referentes ao modelo de Langmuir, e a capacidade máxima de captação foi de $15,39 \mathrm{mg} / \mathrm{L}$ avaliada em pH 5. A cinética de adsorção para o $\mathrm{Nd}$ (III) foi modelada pela equação de pseudo segunda ordem. A adsorção foi encontrada e sugere-se que o processo é endotérmico e espontâneo $(\Delta \mathrm{H}=17,12 \mathrm{KJ} / \mathrm{mol} ; \Delta \mathrm{G}=-26,3 \mathrm{KJ} / \mathrm{mol})$ em relação aos parâmetros termodinâmicos obtidos. Os resultados gerais sugerem que este adsorvente demonstrou ser um potencial sorvente para separação de $\mathrm{Nd}(\mathrm{III})$ a partir de soluções aquosas.

\section{Palavras-chave}

Palygorskita; Adsorção; Neodímio; Isotermas; Potencial Zeta 


\section{Abstract}

Nascimento, Luana Caroline da Silveira; Torem, Maurício Leonardo (Advisor). Fundamentals of Neodymium sorption in palygorskite: Thermodynamics and kinetic aspects. Rio de Janeiro, 2019. 146p. Dissertação de Mestrado - Departamento de Engenharia Química e de Materiais, Pontifícia Universidade Católica do Rio de Janeiro.

In recent decades, the rare-earth elements (REEs) demand has considerably grown because of its strategic importance. REEs are widely used in different hightech sectors such as nuclear power, metallurgy, medicine, chemical engineering, electronics and computer manufacturing. Among REEs, is Neodymium, which is one of the most valuable metals used in alloys, electronic components and optical filters. The need for the high purity of these species requires selective separation, between the available methods, adsorption has earned greater attention due to its simplicity, high efficiency and low cost. The removal of metal ions is a complex task due to the high cost of treatment methods. Contributed to the intensification of research for low-cost adsorbent materials, reusable alternatives were added to the adsorption process. In this work was evaluated the clay mineral palygorskite as a sorbent potential for $\mathrm{Nd}$ (III) removal from aqueous solutions by batch trials. For this purpose, the sample from Guadalupe (Piauí) was benefited and the composition of the chemical and mineralogical was studied in order to use the sample with the highest purity in the adsorptive process. The samples were found to be essentially composed of palygorskite, kaolinite, quartz and diaspore. The chemical composition presents oxide contents, the main ones being $\mathrm{SiO}_{2}, \mathrm{Al}_{2} \mathrm{O}_{3}$ and $\mathrm{MgO}$, corroborating the presence of palygorskite in the sample. Zeta Potential studies point out that the clay mineral has a negative surface charge in the whole $\mathrm{pH}$ range, in addition, the high surface area of $118.43 \mathrm{~m}^{2} / \mathrm{g}$ justifies the cation adsorber application. Different types of adsorption isotherms and kinetics models were used to describe the behavior of $\mathrm{Nd}$ (III) in adsorption and the best experimental results set refer to the Langmuir model and pseudo second order model, respectively, with the maximum uptake capacity was $15.39 \mathrm{mg} / \mathrm{L}$ evaluated at $\mathrm{pH}$ 5. Adsorption was found as an endothermic and spontaneous process $(\Delta \mathrm{H}$ $=17.12 \mathrm{KJ} / \mathrm{mol} ; \Delta \mathrm{G}=-26.3 \mathrm{KJ} / \mathrm{mol}$ ) in relation to thermodynamic parameters obtained. Overall results suggest that this adsorbent has been shown to be a potential sorbent for enrichment and separation of $\mathrm{Nd}$ (III) from aqueous solutions.

\section{Keywords}

Palygorskite; Adsorption; Neodymium; Isotherms; Zeta Potential 


\section{Sumário}

$\begin{array}{lr}1 \text { Introdução } & 18\end{array}$

2 Justificativa e Relevância $\quad 20$

3 Objetivos $\quad 21$

3.1. Objetivos Gerais 21

$\begin{array}{ll}\text { 3.2. Objetivos específicos } & 21\end{array}$

4 Revisão Bibliográfica $\quad 22$

4.1. Elementos terras -raras $\quad 22$

4.1.1. Características Gerais $\quad 24$

4.1.2. Neodímio 26

4.1.3. Aplicação estratégica do neodímio 27

4.2. Métodos de concentração e separação de ETRs 28

4.2.1. Precipitação química 28

4.2.2. Extração por solventes $\quad 29$

4.2.3. Troca iônica 29

4.2.4. Adsorção 30

4.3. Argilas 31

4.3.1. Palygorskita 32

4.3.2. Estrutura e propriedades da palygorskita 33

4.3.3. Palygorskita como adsorvente de metais $\quad 36$

$\begin{array}{ll}\text { 4.4. Tipos de adsorção } & 37\end{array}$

4.4.1. Adsorção específica 37

$\begin{array}{ll}\text { 4.4.2. Adsorção não específica } & 37\end{array}$

4.5. Adsorção de ETRs 38

4.6. Variáveis que influenciam a adsorção 39

4.6.1. Concentração do adsorvente 40

4.6.2. $\mathrm{pH} \quad 41$

4.6.3. Temperatura 42

4.6.4. Concentração do íon metálico 43

4.7. Carga elétrica da superfície 43 
4.7.1. Dupla Camada elétrica 43

4.7.2. Caracterização da carga de superfície- Potencial Zeta 45

4.8. Isotermas de adsorção $\quad 47$

4.9. Parâmetros termodinâmicos

4.10. Cinética de adsorção 59

5 Materiais e métodos $\quad 64$

5.1. Preparação da amostra 64

5.2. Caracterização da palygorskita $\quad 67$

5.2.1. Distribuição granulométrica $\quad 67$

5.2.2. Difratometria de raios $X(D R X) \quad 68$

5.2.3. Espectrometria de fluorescência de raios X- (FRX) 69

5.2.4. Microscopia eletrônica de Varredura - (MEV) 70

$\begin{array}{ll}\text { 5.2.5. Capacidade de troca catiônica - (CTC) } & 71\end{array}$

5.2.6. Determinação da área superficial - (BET) 72

5.2.7. Análise Termogravimétrica TG-DTG 73

5.2.8. Medidas de carga superficial (potencial Zeta) 73

5.2.9. Espectroscopia no infravermelho- (FTIR) 74

$\begin{array}{ll}\text { 5.3. Preparo da solução estoque } & 74\end{array}$

5.4. Ensaios de adsorção 76

5.4.1. Influência da concentração do adsorvente 76

$\begin{array}{ll}\text { 5.4.2. Influência do } \mathrm{pH} & 77\end{array}$

5.4.3. Influência da concentração do íon metálico 78

5.4.4. Tempo de equilíbrio e cinética de adsorção 79

$\begin{array}{ll}\text { 5.4.5. Influência da temperatura } & 79\end{array}$

6 Resultados e discussões 81

6.1. Caracterização da palygorskita 81

6.1.1. Distribuição granulométrica 81

6.1.2. Difratometria de raios X-DRX 82

6.1.3. Fluorescência de raios X- FRX 83

6.1.4. Microscopia eletrônica de varredura - MEV 85

6.1.5. Capacidade de troca catiônica - CTC 85

6.1.6. Propriedades texturais 86

6.1.7. Análise Termogravimétrica (TG-DTG) 86

6.1.8. Potencial Zeta 88

6.1.9. Espectroscopia no infravermelho por transformada de Fourier (FTIR) 92 
$\begin{array}{ll}\text { 6.2. Ensaios de adsorção } & 94\end{array}$

6.2.1. Influência da concentração do adsorvente 94

6.2.2. Influência do pH 96

6.2.3. Influência da concentração inicial do íon metálico 102

$\begin{array}{ll}\text { 6.3. Cinética de adsorção e tempo de equilíbrio } & 119\end{array}$

$\begin{array}{ll}\text { 6.3.1. Influência da temperatura } & 123\end{array}$

$\begin{array}{ll}\text { 6.3.2. Parâmetros termodinâmicos } & 128\end{array}$

7 Conclusões 131

8 Recomendações para trabalhos futuros $\quad 134$

9 Referências bibliográficas 135 


\section{Lista de tabelas}

Tabela 1-Produção mundial de ETRs. (Fonte: USGS,2019)

Tabela 2- Elementos das terras raras divididos de acordo com a sua classificação ETRs leves e ETRs pesadas (Fonte: Lide,2004)

Tabela 3- Características entre adsorção de origem física e adsorção de origem química

Tabela 4-Capacidade de captação de diferentes adsorventes e condições

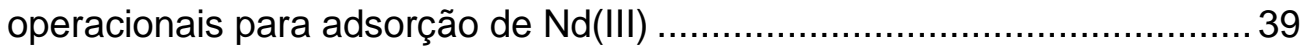

Tabela 5-Tipos de porosidade e tamanho de poros. 41

Tabela 6- Revisão dos modelos cinéticos que melhor se ajustam aos dados experimentais para a adsorção de metais utilizando diferentes adsorventes

Tabela 7- Parâmetros do plasma para o ICP …........................................... 75

Tabela 8- Parâmetros do método utilizado ..................................................... 75

Tabela 9-Condições experimentais para avaliação do efeito dosagem de adsorvente na adsorção do $\mathrm{Nd}$ (III) 77

Tabela 10-Condições experimentais para avaliar o efeito do $\mathrm{pH}$ no processo de sorção do $\mathrm{Nd}$ (III)

Tabela 11-Condições experimentais para avaliação do efeito da concentração do íon metálico na adsorção do $\mathrm{Nd}$ (III)

Tabela 12-Condições experimentais para avaliação do efeito do tempo de contato no processo de sorção do Nd (III). .79

Tabela 13-Condições experimentais para avaliação do efeito da temperatura no processo de sorção do $\mathrm{Nd}$ (III) 80

Tabela 14- Composição química elementar da palygorskita $(<20 \mu \mathrm{m})$ 84

Tabela 15- Grupos funcionais correspondentes as bandas de absorção apresentados no espectro de FTIR ................................................ 94

Tabela 16- Constantes de adsorção para Neodímio a 30 C .......................... 107

Tabela 17- Constantes de adsorção de Freundlich para neodímio a $30^{\circ} \mathrm{C}$....... 110

Tabela 18- Constantes de adsorção de Temkin para neodímio a $30^{\circ} \mathrm{C}$ 112

Tabela 19- Constantes de adsorção de Dubinin- Radushkevich para neodímio a $30^{\circ} \mathrm{C}$

Tabela 20- Constantes de adsorção de Sips não linear para neodímio a $30^{\circ} \mathrm{C} 116$ 
Tabela 21 Constantes de adsorção de Redlich-Peterson não linear para

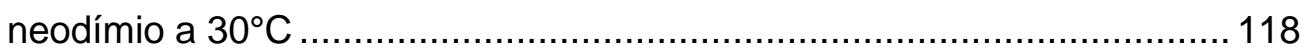

Tabela 22- Resumo dos parâmetros das isotermas utilizadas ........................ 119

Tabela 23- Parâmetros referentes a cinética de pseudo primeira ordem .......... 122

Tabela 24- Parâmetros referentes a cinética de pseudo segunda ordem ........ 122

Tabela 25- Parâmetros relacionados a cada temperatura referentes ao modelo cinético de pseudo segunda ordem em sua forma linearizada ................ 125

Tabela 26- Parâmetros referentes a cada temperatura estudada .................... 129

Tabela 27- Parâmetros termodinâmicos ....................................................... 130 


\section{Lista de figuras}

Figura 1- Distribuição do raio atômico dos ETRs. Adaptado de Shannon (1976).

Figura 2- Modelo esquemático de um argilomineral genérico. Em (a)grupo tetraédrico (b) folha tetraédrica. Fonte: Adaptado de Chang et al (2016) ... 32

Figura 3- Estrutura da palygorskita. Adaptado de Chen et al (2011) .33

Figura 4- Presença de canais na estrutura física da palygorskita. Adaptado de

Chang et al (2016)

Figura 5- Representação esquemática do esquema de colapso da estrutura da

palygorskita durante tratamento térmico. Adaptado de González et

al.,(1993)

Figura 6- Classificação do tamanho de poro segundo a União Internacional de

Química Pura e Aplicada - IUPAC (1982)....

Figura 7- Modelo Stern-Grahame para dupla camada. Adaptado de Wills (2015)

Figura 8-Desenho esquemático de um sistema de adsorção em equilíbrio.

Adaptado de Veneu (2010) ..... 48

Figura 9- Classificação dos tipos de isotermas. Adaptado de Guiles et al.,(1974).

Figura 10 - Frente da lavra da Mina Boa Vista II, local onde foi coletada a amostra de palygorskita

Figura 11- Fluxograma de beneficiamento da palygorskita.

Figura 12- Desenho esquemático do funcionamento do DRX. Fonte: Gobbo,2009

Figura 13-Desenho esquemático da adsorção realizada em batelada utilizando

como adsorvente a palygorskita. 76

Figura 14- Curva de distribuição granulométrica da amostra BV II após

beneficiamento. 82

Figura 15-Difratogramas de raios X das amostras Run of mine (ROM) e $<20 \mu \mathrm{m}$

Figura 16- Imagens obtidas por MEV da palygorskita antes da adsorção .85

Figura 17- Formação do halo para o azul de metileno para estimativa do valor de

Capacidade de troca catiônica .86 
Figura 18- Curva termogravimétrica (TG) e sua derivada (DTG) da amostra de palygorskita

Figura 19- Potencial zeta da palygorskita in natura para três concentrações de eletrólitos indiferentes

Figura 20-Potencial zeta do óxido de neodímio para três concentrações de eletrólitos indiferentes

Figura 21- Curva de potencial zeta antes e após a adsorção com diferentes concentrações de neodímio ( $\mathrm{pH}: 5$; tempo de contato:60 min; velocidade de agitação:150 rpm)

Figura 22-FTIR espectro da palygorskita antes e após o contato com o Nd (III) 93

Figura 23- Influência da concentração do adsorvente. 95

Figura 24- Diagrama de distribuição de espécies do $\mathrm{Nd}$ (III) em solução aquosa na concentração de $1,7 \times 10^{-3} \mathrm{~mol} / \mathrm{L}$ .98

Figura 25- Diagrama de distribuição de espécies do Nd (III) em solução aquosa na concentração de $4,8 \times 10^{-3} \mathrm{~mol} / \mathrm{L}$ .98

Figura 26- Diagrama de distribuição de espécies do Nd (III) em solução aquosa na concentração $6,2 \times 10^{-3} \mathrm{~mol} / \mathrm{L}$ .99

Figura 27- Influência do pH na adsorção do Nd (III) 100

Figura 28- Isoterma de adsorção em função da concentração de equilíbrio do $\mathrm{Nd}$ (III). (pH: 5 ; concentração inicial de palygorskita: $2 \mathrm{~g}$; temperatura: $30^{\circ} \mathrm{C}$; Tempo de contato: $60 \mathrm{~min}$ ) 104

Figura 29- Isoterma de Langmuir para o neodímio na forma não linearizada $\mathrm{pH}$ :

5; Concentração inicial de palygorskita: $2 \mathrm{~g}$; temperatura: $30^{\circ} \mathrm{C}$; tempo de contato: $60 \mathrm{~min}$ ) 106

Figura 30-Isoterma de Langmuir linearizada para neodímio $(\mathrm{pH}$ : 5; Concentração inicial de palygorskita: $2 \mathrm{~g}$; temperatura: $30^{\circ} \mathrm{C}$; tempo de contato: $\left.60 \mathrm{~min}\right) 106$

Figura 31- Isoterma de Freundlich para o neodímio na forma não linearizada pH:

5; Concentração inicial de palygorskita: $2 \mathrm{~g}$; temperatura: $30^{\circ} \mathrm{C}$; tempo de contato: $60 \mathrm{~min}$ ) 109

Figura 32-Isoterma de Freundlich para o neodímio na forma linearizada $\mathrm{pH}: 5$;

Concentração inicial de palygorskita: $2 \mathrm{~g}$; temperatura: $30^{\circ} \mathrm{C}$; tempo de contato: $60 \mathrm{~min}$ ) 109

Figura 33 Isoterma de Temkin para o neodímio na forma não linearizada $(\mathrm{pH}: 5$; Concentração inicial de palygorskita: $2 \mathrm{~g}$; temperatura: $30^{\circ} \mathrm{C}$; tempo de contato: $60 \mathrm{~min}$ ) 
Figura 34 Isoterma de Temkin para o neodímio na forma linearizada $(\mathrm{pH}: 5$; Concentração inicial de palygorskita: $2 \mathrm{~g}$; temperatura: $30^{\circ} \mathrm{C}$; tempo de contato: $60 \mathrm{~min}$ )

Figura 35 Isoterma de Dubinin-Radushkevich para o neodímio na forma não linearizada $(\mathrm{pH}$ : 5; Concentração inicial de palygorskita: 2g; temperatura: $30^{\circ} \mathrm{C}$; tempo de contato: $60 \mathrm{~min}$ )

Figura 36- Isoterma de Dubinin-Radushkevich para o neodímio na forma linearizada ( $\mathrm{pH}$ : 5; Concentração inicial de palygorskita: 2g; temperatura: $30^{\circ} \mathrm{C}$; tempo de contato: $60 \mathrm{~min}$ ). 114

Figura 37 Isoterma de sips para o neodímio na forma não linearizada $(\mathrm{pH}: 5$;

Concentração inicial de palygorskita: $2 \mathrm{~g}$; temperatura: $30^{\circ} \mathrm{C}$; tempo de contato: $60 \mathrm{~min}$ )

Figura 38 Isoterma de sips para o neodímio na forma linearizada $(\mathrm{pH}: 5$;

Concentração inicial de palygorskita: $2 \mathrm{~g}$; temperatura: $30^{\circ} \mathrm{C}$; tempo de contato: $60 \mathrm{~min}$ )

Figura 39 Isoterma de Redlich-Peterson para o neodímio na forma não

linearizada $(\mathrm{pH}$ : 5; Concentração inicial de palygorskita: 2g; temperatura:

$30^{\circ} \mathrm{C}$; tempo de contato: $60 \mathrm{~min}$ )

Figura 40 Isoterma de Redlich-Peterson para o neodímio na forma linearizada

$\left(\mathrm{pH}\right.$ : 5; Concentração inicial de palygorskita: $2 \mathrm{~g}$; temperatura: $30^{\circ} \mathrm{C}$; tempo de contato: $60 \mathrm{~min}$ )

Figura 41 - Influência do tempo de equilíbrio na adsorção de $\mathrm{Nd}$ (III) por palygorskita. (Concentração inicial de íon metálico: $2 \times 10^{3} \mathrm{mg} / \mathrm{L} ; \mathrm{pH}: 5$; concentração inicial de palygorskita: $2 \mathrm{~g}$; temperatura: $30^{\circ} \mathrm{C}$ ) 120

Figura 42- Modelo cinético de pseudo-primeira ordem linearizado aplicado a adsorção de $\mathrm{Nd}$ (III) adsorvido por palygorskita.

Figura 43- Modelo cinético de pseudo-segunda ordem linearizado aplicado a adsorção de $\mathrm{Nd}$ (III) adsorvido por palygorskita.

Figura 44- Influência da temperatura no processo de adsorção de Nd (III) utilizando palygorskita como adsorvente em diferentes temperaturas

Figura 45- Modelo cinético de pseudo segunda ordem linearizado aplicado a adsorção de neodímio utilizando a palygorskita como adsorvente a diferentes temperaturas 125

Figura 46- Curva de Arrhenius para o Neodímio 127 
Figura 47- Relação entre a constante de equilíbrio de Langmuir ( $/ \mathrm{mol})$ e temperatura na adsorção de $\mathrm{Nd}$ (III) em palygorskita............................... 129 


\section{1 \\ Introdução}

Nas últimas décadas a demanda por elementos terras- raras (ETRs) aumentou, e a necessidade da alta pureza desses elementos requer a separação seletiva dos lantanídeos, o que ainda é de grande interesse e importância. Os ETRs pertencem a um grupo multiplicável e são utilizados extensivamente em muitos campos de alta tecnologia, tais como catalisadores, ligas, ímãs, eletrônica, ótica e laser, e imagem, devido à sua singularidade propriedades fotoeletromagnéticas, permitem a aplicação em lâmpadas fluorescentes, baterias, lasers, super-imãs, supercondutividade de alta temperatura, armazenamento de informações, conservação e transporte de energia (Eliseeva,2011). China, Estados Unidos da América (EUA) e Austrália são os principais produtores de ETRs, com a China detendo aproximadamente $90 \%$ da produção mundial (Feng,2006).

Entre os ETRs, destaca-se o neodímio, sendo classificado como ETR leve. Utilizado em ligas, componentes eletrônicos, vidros, filtros ópticos, o neodímio desempenha um papel importante em ímãs permanentes de alta resistência. Os ímãs permanentes apresentam grande desempenho na indústria eletrônica em aplicações como motores elétricos, discos rígidos de computador e poderosos geradores de eletricidade, o que chama a atenção do aspecto da fabricação de turbinas eólicas, por exemplo, para melhoria da eficiência energética.

Por um lado, o aumento da demanda, paralelamente ao esgotamento dos recursos naturais dos ETRs, somado com as reservas estratégicas em alguns países, em especial a China, tornam a separação e recuperação de ETRs particularmente importante. Alguns fluxos de resíduos industriais contendo ETRs têm sido considerados como recursos secundários importantes.

Por outro lado, publicações recentes relataram os efeitos tóxicos de ETRs em bactérias, plantas e animais. Embora esses metais não representem uma ameaça tóxica comum, pode-se prever que a introdução de muitos íons metálicos no meio ambiente por meio de várias vias poderá resultar em problemas ambientais nas próximas décadas e que regulamentações mais rígidas provavelmente serão impostas. Portanto, um processo eficaz e econômico para remover os íons de ETRs das águas residuais é necessário não apenas do ponto 
de vista da utilização dos recursos, mas também para a proteção do meio ambiente.

A separação de lantanídeos é uma tarefa difícil devido às similaridades químicas e propriedades físicas. Nos últimos anos, com a crescente demanda por ETRs de alta pureza e seus compostos, a purificação dos íons individuais ganhou considerável atenção (Tian et al,2012). Existem muitos métodos que são aplicados para separar, purificar e concentrar estes elementos, tais como adsorção, extração por solvente, precipitação química e troca iônica (Zhu et al,2015). Entre eles, a adsorção tem sido reconhecida como um dos métodos mais promissores devido à sua simplicidade, alta eficiência e ampla disponibilidade (Anastopoulos et al,2016).

Denominada como uma operação de transferência de massa, a adsorção, estuda a habilidade de sólidos em concentrar-se em substâncias em fluidos gasosos ou líquidos, possibilitando a possível posterior separação. Dessa maneira, quanto maior é a superfície por unidade de massa, o fenômeno da adsorção torna-se mais favorável.

Nos últimos anos pesquisas vêm sendo realizadas com o objetivo de desenvolver adsorventes de baixo custo tais como materiais naturais, biossorventes, resíduos sólidos da agricultura que otimizam o processo de adsorção. Entre eles, os argilominerais são reconhecidos como materiais excepcionalmente promissores (Cheng et al,2011).

A palygorskita que é um silicato de alumínio e magnésio hidratado, apresenta propriedades físico-químicas diferenciadas que se comparadas a outros argilominerais como a caulinita ou montmorilonita a distinguem para ser utilizada no campo da adsorção. A presença da sua natureza alongadas com a presenta de microporos conferem a este argilomineral elevada área superficial (Singer et al,2011).

Substituições isomórficas existentes na estrutura cristalina como por exemplo de $\mathrm{Si}^{4+}$, nos tetraedros por cátions trivalentes $\mathrm{Al}^{3+}$ ou $\mathrm{Fe}^{3+}$ e de $\mathrm{Al}^{3+}$, nos octaedros, por cátions divalentes de $\mathrm{Mg}^{2+}$ ou $\mathrm{Fe}^{2+}$ levando a uma consequente deficiência de cargas positivas e um potencial negativo na superfície da palygorskita, confere a este argilomineral uma boa capacidade de captação de cátions metálicos. 


\section{2 \\ Justificativa e Relevância}

No cenário de alianças geopolíticas, a situação da oferta de ETRs causa preocupação entre os governos e entidades privadas. Relatórios do governo do gabinete de contabilidade dos EUA reportam um quadro de exploração de ETRs, enquanto as agências de notícias publicam notícias salientando a importância das ETRs nas tecnologias energéticas alternativas e no consumo de eletrônicos. Este trabalho busca elucidar a importância da captação e concentração dos íons $\mathrm{Nd}$ (III), que representa um ETR estratégico no que tange as suas propriedades ópticas e aplicabilidade industrial. Outro fator relevante, é que nas pesquisas, não foram encontrados diagramas de especiação referentes às espécies de neodímio, o que levou a construção destes diagramas para o melhor entendimento do comportamento do íon metálico. Kosmulski (2016), reporta em seu estudo que o ponto isoelétrico das espécies de neodímio não é bem documentado, esta janela de oportunidade permitiu a verificação do PIE do óxido de neodímio. Além disso, a inovação de propor adsorção de um ETR em um argilomineral é um processo inédito que dá luz a novas possibilidades de remover íons metálicos de soluções aquosa. 


\section{3 \\ Objetivos}

\section{1.}

\section{Objetivos Gerais}

O objetivo geral do presente trabalho é avaliar a capacidade de sorção do Neodímio- Nd (III) em solução aquosa utilizando o argilomineral palygorskita como material adsorvente.

\section{2.}

\section{Objetivos específicos}

$\checkmark$ Realizar o beneficiamento e caracterização da palygorskita promovendo o aumento da pureza do minério com o objetivo de alcançar melhores resultados e conhecimento da amostra a ser estudada;

$\checkmark$ Avaliar a capacidade de adsorção do argilomineral por meio de ensaios de adsorção em batelada para remoção de íons metálicos, $\mathrm{Nd}$ (III) contidos em solução aquosa;

$\checkmark$ Avaliar o efeito da concentração do adsorvente, do pH, concentração do íon metálico, temperatura e tempo de contato para recuperação do Neodímio;

$\checkmark$ Determinar os modelos de isotermas que melhor se ajustam aos dados experimentais e parâmetros termodinâmicos;

$\checkmark$ Avaliar a cinética de sorção do neodímio em palygorskita assim como determinar qual modelo cinético melhor se ajusta aos dados experimentais. 


\section{4 \\ Revisão Bibliográfica}

\section{1. Elementos terras -raras}

Elementos terras - raras (ETRs) são um grupo de 17 metais, incluindo 15 lantanídeos, ítrio (Y) e escândio (Sc). A demanda por ETRs aumentou na última década devido à sua importância em aplicações ecológicas e de alta tecnologia. Turbinas eólicas exigem ímãs fortes, bem como carros elétricos. Para iluminação com eficiência energética, são necessários fósforos contendo ETRs. Aplicações militares incluem mísseis, jatos de combate, sensores e munições guiadas, entre outros. A indústria da saúde usa ETRs em imagens médicas. De um modo geral, ETRs nos permitem ter produtos ecológicos rápidos, leves, duráveis e de alto desempenho, que é a questão-chave mundo moderno.

Metais que demandam interesse tecnológico vêm ganhando crescente interesse no que diz respeito as etapas de concentração e separação devido ao seu alto valor agregados e/ou alta demanda de fabricação de aparatos tecnológicos que utilizam estes ETRs, como lâmpadas fluorescentes, satélites, fósforos, catalisadores para craqueamento de petróleo, lasers, supercondutores.

O elemento Cério $(\mathrm{Ce})$ que é o mais abundante dos ETRs, apresenta tanta abundância quanto o Zinco (Zn). Já o ETRs Túlio (Tm) que é o menos abundante na crosta terrestre apresenta mais ocorrência que a prata $(\mathrm{Ag})$. Dessa maneira, aproximadamente $0,01 \%$ é a porcentagem média da ocorrência de ETRs na crosta terrestre (Lide,2004).

Ainda que existam minas e suprimentos necessários, esses metais críticos apresentam na atualidade perigo de escassez. Um deles é o neodímio, que é amplamente utilizado em ímãs. Os outros são elementos pesados de terras-raras aplicados em vários setores tecnológicos, incluindo európio, térbio, disprósio e ítrio. Substituições para metais de terras-raras não são tão eficientes quanto o ETR genuíno.

Mais de $90 \%$ do ETRs são encontrados em depósitos de placer primário ou subproduto, como areias aluviais nas praias ou ao longo dos leitos dos rios. Minerais de ocorrência frequente contendo ETRs são monazita (fosfato), 
bastnasita (fluorocarbonato) e xenotímio (fosfato) (Beauford,2010). ETRs mais leves são mais abundantes e perfazem $80-99 \%$ do depósito total. A principal fonte de ETRs leves é proveniente da monazita, e xenotima incorpora principalmente os ETRs pesados. ETRs podem ainda ser encontradas em depósitos de argila, onde os elementos são adsorvidos nas partículas de argila. Esta fonte compreende um pequeno percentual do mercado total de ETRs, mas é importante porque fornece alguns dos ETRs pesados. Muitas vezes, os ETRs ocorrem em uma forma de subproduto da mineração e processamento de fosfatos de $\mathrm{Cu}, \mathrm{Au}$, U.

Os primeiros minérios de ETRs foram encontrados na Suécia, em 1787. O uso industrial começou apenas depois de um século. Os primeiros produtores de ETRs foram o Brasil e a Índia. Austrália e Malásia ingressaram na exportação do ETRs em 1940. Os EUA começaram a extrair ETRs da Mina de Mountain Pass e, em 1960, tornaram-se líderes na produção desses metais. No entanto, em 1980 a China rapidamente alcançou o lugar dominante na produção mundial.

Atualmente, a China detém $85 \%$ da produção mundial de ETRs, com a Austrália e Estados Unidos da América sendo o segundo e terceiro maiores produtores. A Europa não tem minas de ETRs em uso. A dependência da importação de ETRs de uma única fonte é uma incerteza indesejável para a União Europeia.

Mesmo considerando uma queda significativa em relação a 2010, a China ainda controla a maior parte do mercado de ETRs. A segunda maior fonte após o bastnasita é a monazita, que é extraída na Austrália, no Brasil, China, Índia e Malásia. Na Tabela 1, a produção e as reservas mundiais de minas são mostradas (USGS,2019). 
Tabela 1-Produção mundial de ETRs. (Fonte: USGS,2019)

\begin{tabular}{cccc}
\hline País & $\begin{array}{c}\text { Produção em 2014 } \\
\text { [t] }\end{array}$ & $\begin{array}{c}\text { Produção em 2015 } \\
\text { [t] }\end{array}$ & $\begin{array}{c}\text { Reserva } \\
\text { [t] }\end{array}$ \\
\hline EUA & 5400 & 4100 & 1800000 \\
Austrália & 8000 & 10000 & 3200000 \\
Brasil & 0 & 0 & 22000000 \\
China & 105000 & 105000 & 55000000 \\
Índia & - & - & 3100000 \\
Malásia & 240 & 200 & 30000 \\
\hline
\end{tabular}

\subsection{1.}

\section{Características Gerais}

Todos os ETRs podem ser divididos em dois grupos: ETRs leves e ETRs pesados (Tabela 2). Esta divisão é baseada na configuração eletrônica de átomos do metal.

Tabela 2- Elementos das terras raras divididos de acordo com a sua classificação ETRs leves e ETRs pesadas (Fonte: Lide,2004).

\begin{tabular}{ccccc}
\hline Elemento & Símbolo & $\begin{array}{c}\text { Número } \\
\text { atômico }\end{array}$ & $\begin{array}{c}\text { Peso } \\
\text { molecular }\end{array}$ & $\begin{array}{c}\text { Abundância mundial } \\
\text { (Parte por milhão) }\end{array}$ \\
\hline Lantânio & $\mathrm{La}$ & 57 & 138,91 & 39 \\
Cério & $\mathrm{Ce}$ & 58 & 140,12 & 66,5 \\
Praseodímio & $\mathrm{Pr}$ & 59 & 140,91 & 9,2 \\
Neodímio & $\mathrm{Nd}$ & 60 & 144,24 & 41,5 \\
Samário & $\mathrm{Sm}$ & 62 & 150,36 & 7,05 \\
Európio & $\mathrm{Eu}$ & 63 & 151,96 & 2,0 \\
Gadolínio & $\mathrm{Gd}$ & 64 & 157,25 & 6,2 \\
\hline & & Terras raras pesadas & 33 \\
\hline Ítrio & $\mathrm{Y}$ & 39 & 88,91 & 1,2 \\
Térbio & $\mathrm{Tb}$ & 65 & 158,92 & 5,2 \\
Disprósio & $\mathrm{Dy}$ & 66 & 162,50 & 1,3 \\
Hólmio & $\mathrm{Ho}$ & 67 & 164,93 & 3,5 \\
Érbio & $\mathrm{Er}$ & 68 & 167,26 & 0,52 \\
Túlio & $\mathrm{Tm}$ & 69 & 168,93 & 3,2 \\
Itérbio & $\mathrm{Yb}$ & 70 & 173,04 & 0,8 \\
Lutécio & $\mathrm{Lu}$ & 71 & 174,97 & \\
\hline
\end{tabular}


Os ETRs são geralmente encontrados juntos na crosta terrestre pois compartilham uma carga trivalente $\left(\mathrm{ETRs}^{3+}\right)$ e raio iônico similar. Exceções à carga trivalente são o cério, que pode ocorrer em um estado de valência Ce(IV), e európio, que pode existir como Eu(II). Os lantanídeos (lantânio a lutécio) têm uma propriedade única. Com o aumento no número atômico em todo o grupo, um elétron é adicionado a uma subcamada incompleta interna (4f) ao invés de um nível externo.

O ítrio está no grupo de ETRs pesados, mas o escândio (Sc) não pertence a nenhum grupo, com base no raio iônico e nas propriedades químicas. Esta propriedade de preencher seletivamente os níveis internos resulta em diminuição progressiva do raio iônico dos íons lantanídeos trivalentes de La(III) para Lu(III),(Figura 1) referido como "contração de lantanídeos".

A diminuição sistemática de raios iônicos através do grupo dos lantanídeos tem duas consequências: (a) afeta o fracionamento dos ETRs em um alto grau, o que permite sua separação individual em ambientes geológicos e no processamento de minério, e (b) confere ao ETR propriedades químicas e físicas incomuns e úteis, como propriedades magnéticas e/ou óticas únicas.

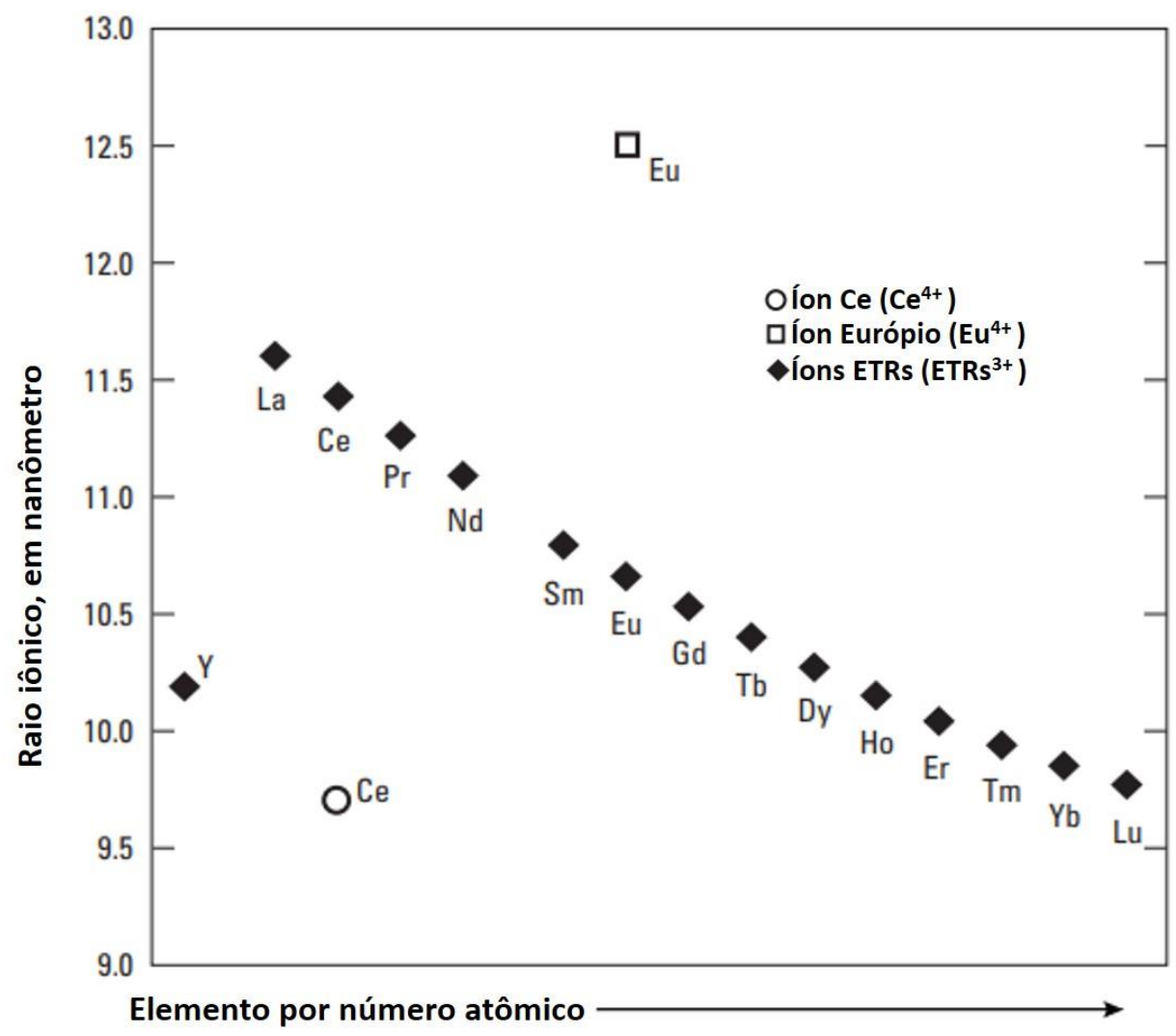

Figura 1- Distribuição do raio atômico dos ETRs. Adaptado de Shannon (1976). 
ETRs são bastante abundantes na crosta terrestre, embora não concentrados, o que os torna difíceis de extrair e separar uns dos outros. Esse recurso é a razão pela qual os ETRs são assim chamados. A palavra "raro" é usada no sentido antigo aqui, significando "difícil".

Como são elementos de transição interna, com predominância de íons trivalentes na camada eletrônica mais externa $\left(5 s^{2}, 5 p^{6}\right)$ apresentando pequena diferença entre o raio iônico, faz com que elementos se encontrem na natureza de maneira misturada tornando-os de difícil separação.

\subsection{2.}

\section{Neodímio}

Descoberto em 1885 pelo cientista austríaco Carl Auer von Welsbach o neodímio é um metal com estado de oxidação $3^{+}$que mancha no ar. Os principais minerais contendo $\mathrm{Nd}$ são bastnasita e monazita. Amplamente distribuído na crosta terrestre, com uma concentração aproximada de $4 \times 10^{-5} \mathrm{~kg} / \mathrm{kg}$ (Wedepohl,1995) apresenta abundância semelhante ao Co, Ni e Cu.

Assim como os outros ETRs, ele não existe como um único metal, e geralmente um método de separação é necessária para extrair $\mathrm{Nd}$ (III) de uma mistura de lantanídeos.

O neodímio tem sete isótopos naturais, entre os quais o mais abundante $(27,13 \%)$ é o 142Nd (Encyclopaedia Britannica Online,2013). Entre os minérios contendo $\mathrm{Nd}$, estão a monazita tem $17-18 \%$ de fosfatos de neodímio em composição enquanto a bastnasita contendo $12-19 \%$ de carbonatos de neodímio em peso, (USGS, 2013). Apesar de ter uma porcentagem maior a monazita é menos comumente comparada a bastnasita pois contém tório, que apresenta altos níveis de radiação (Humphries,2010). Atualmente a produção de Nd (III) está nos países da China, Estados Unidos, Brasil e Austrália.

O neodímio forma compostos intermetálicos como $\mathrm{Nd}_{2} \mathrm{Fe}_{14} \mathrm{~B}$ ou $\mathrm{NdFeB}$ com - metal de transição Fe. O Neodímio apresenta configuração eletrônica $1 s^{2} 2 s^{2} 2 p^{6} 3 s^{2} 3 p^{6} 4 s^{2} 3 d^{10} 4 p^{6} 5 s^{2} 4 d^{10} 5 p^{6} 6 s^{2} 4 f^{4}$. Suas propriedades conferem e dão destaque ao $\mathrm{Nd}$ (III) como um dos ETRs mais eficientes luminescentes tendo como campo de aplicação o infravermelho podendo ser utilizado especialmente em dispositivos lasers e amplificadores ópticos em fibras ópticas.

No relatório da Estratégia de Materiais Críticos lançado pelo Departamento de Energia dos EUA em 2011, o neodímio permanece na categoria de material crítico com alta importância para energia limpa e risco de suprimento 
relativamente alto no futuro, tanto na análise de curto quanto médio prazo (Chu,2011).

\subsection{3.}

\section{Aplicação estratégica do neodímio}

Os produtos químicos com neodímio aparecem inicialmente como aditivos de vidro em 1927 e ainda são usados para esse fim. O neodímio também é aplicado em lasers de estado sólido. Outra aplicação popular está produzindo ligas para ímãs poderosos, que são usados em dispositivos de áudio, vídeo, bem como discos rígidos. Motores elétricos de baixo peso são eficientes para carros híbridos, geradores para aeronaves além disso turbinas eólicas também usam ímãs Nd.

Os ímãs NdFeB podem alcançar produtos energéticos de $400 \mathrm{~kJ} / \mathrm{m}^{3}$ ou mais e permanecem como materiais de escolha para a minimização de tamanho, como em dispositivos portáteis (Cullity \& Graham,2008).Introduzida em 1983 esta liga é agora amplamente utilizado em dispositivos portáteis (telefones móveis, microfones, discos rígidos, etc.), bombas de combustível, vidros, catalisadores, motores e também em turbinas eólicas (Emsley,2011).

Além de turbinas eólicas, os fortes imãs baseados em Nd permitem o design miniaturizado de aplicações como pequenos alto-falantes e discos rígidos. Motores elétricos de veículos híbridos, e veículos elétricos também são os principais interesses do uso de ímãs permanentes (Schüler et al.,2011).

O neodímio também desempenha um papel significativo na produção de baterias NiMH quando se trata de design de veículos elétricos e híbridos. No geral, aplicações de motores elétricos para veículos, utilização de turbinas eólicas e discos rígidos seriam os principais fatores que determinam significativamente a demanda futura de ímãs permanentes (Schüler et al.,2011).

Atualmente, as aplicações relacionadas a ímãs são responsáveis por uma participação de cerca de $20 \%$ no volume total global de aplicações de ETRs, (Schüler et al.,2011). Uma análise dos investimentos globais (por aplicação) de ETRs em 2007 demonstra que os estoques totais de Nd em uso foram de 137.000 toneladas, que compartilharam aproximadamente $31 \%$ do total de estoques totais de ETRs.

Somente no mesmo ano, 14.800 toneladas de neodímio foram utilizadas. O estoque total de $\mathrm{Nd}$ reside principalmente em aplicações de computadores com 40.000 toneladas (29\%), sistemas de áudio com 31.000 toneladas (22.6\%), turbinas eólicas com 18.000 toneladas (13\%), aplicações relacionadas ao 
automóvel também até $13 \%$ com 18.000 toneladas de material (Du \& Graedel,2011).

Com toda a pressão e riscos do fornecimento futuro, os cientistas estão procurando maneiras de poupar os ETRs em algumas áreas. Um dos principais focos é procurando alternativas para ETRs. Geralmente, isso inclui pesquisa em materiais alternativos ou pesquisa em projetos de produtos alternativos. Mas é difícil encontrar materiais mais abundantes ou comuns para substituir o neodímio, que é ao mesmo tempo leve e poderoso, na aplicação do imã permanente.

\section{2. \\ Métodos de concentração e separação de ETRs}

A separação e a concentração de ETRs pode tornar-se uma difícil empreitada devido a pequenas diferenças entre propriedades físicas e químicas desses elementos. O consequente aumento do número de aplicações de ETRs leva a um profundo interesse em novas fontes e técnicas para separação desses elementos (Krishnamurthy \& Gupta,2004).

Métodos hidrometalúrgicos oferecem vantagens como menor consumo de energia, poluição do ar e capital, quando comparados a outros como a pirometalurgia. Além de permitir o processamento de dados complexos e matérias-primas de qualidade e controle constante de emissões.

A separação seletiva de ETRs foi um problema clássico na química por muitos anos. A complexidade disso decorre do fato de que todos os lantanídeos têm propriedades e minerais de ETRs sempre contêm a mistura de ETRs. Todos os métodos de separação invariavelmente utilizam uma pequena diferença na basicidade resultante da diminuição do raio iônico (Moeller,2013).

\subsection{1.}

\section{Precipitação química}

A precipitação química é a tecnologia mais comum usada na remoção de metais dissolvidos (iônicos) de soluções, como águas residuais de processo contendo metais tóxicos. Os metais iônicos são convertidos em uma forma insolúvel (partícula) pela reação química entre os compostos metálicos solúveis e o reagente de precipitação. As partículas formadas por esta reação são removidas da solução por sedimentação e/ou filtração. As operações unitárias normalmente exigidas nesta tecnologia incluem neutralização, precipitação, coagulação/ floculação, separação de sólidos/líquido e desidratação. 
A eficácia de um processo de precipitação química depende de vários fatores, incluindo o tipo e a concentração de metais iônicos presentes na solução, o precipitante utilizado, as condições da reação (especialmente o pH da solução) e a presença de outros constituintes que podem inibir a reação de precipitação. (Lewinsky,2007).

\subsection{2.}

\section{Extração por solventes}

A extração por solvente é um processo comum de extração química usando solvente orgânico. Este método é comumente usado em combinação com outras tecnologias, como solidificação/estabilização, incineração ou lavagem de solo, dependendo das condições específicas do local. Este método também pode ser usado como uma tecnologia independente em alguns casos. Metais organicamente ligados podem ser extraídos juntamente com os contaminantes orgânicos alvo, criando assim resíduos com requisitos especiais de manuseio.

Pode ser eficaz no tratamento de sedimentos, lamas e solos contendo principalmente contaminantes orgânicos e resíduos de petróleo. O processo demonstra ser aplicável para a separação dos contaminantes orgânicos em resíduos de tinta, resíduos de processos de borracha sintética, resíduos de alcatrão de carvão, lamas de perfuração, resíduos de tratamento de madeira, lamas de separação, resíduos de pesticidas/inseticidas e resíduos oleosos de refinaria de petróleo (Lewinsky,2007).

Riano \& Binnemans (2015) reportam o uso da extração por solventes para recuperação de neodímio e disprósio dos imãs de $\mathrm{NdFeB}$

\subsection{3.}

\section{Troca iônica}

O processo de troca iônica é comumentemente consagrado por ser eficaz para remoção de metais pesados das águas residuais. Sendo facilmente recuperadas e reutilizadas por operações de regeneração, as resinas de troca iônica são utilizadas no processo com o objetivo de remover esses metais (AboFarha,2009). Íons em solução são transferidos para uma matriz sólida nesse processo, que pode liberar diferentes tipos de íons de carga similar (Zewail \& Yousef,2015). É um processo de separação física onde os íons trocados não são quimicamente alterados. As principais vantagens da troca iônica são a recuperação do valor do metal e a seletividade. Além disso, a resina de troca iônica pode ser categorizada com base em grupos funcionais, como resinas de 
troca catiônica, resinas de troca aniônica e resina de troca quelante (Lee, Kuan \& Chern,2007).

\subsection{4. \\ Adsorção}

ETRs podem ser também encontrados em sucata eletrônica ou resíduos de mineração. No entanto, as concentrações de ETR em materiais residuais são baixas e, por enquanto, a extração não é economicamente viável. Novas formas eficientes de recuperar ETRs de materiais residuais são necessárias. Entre os outros métodos para separação de ETRs, a adsorção é considerada promissora.

A adsorção é um processo no qual um componente se acumula no limite comum de duas fases. O componente acumulador da fase gasosa ou líquida é chamado adsorvato e o material que irá adsorver é o adsorvente (Sposito,2004). Nos últimos trinta anos, a tecnologia de adsorção tornou-se uma operação unitária importante usada em indústrias petroquímicas, produção de gases industriais, e purificação do ar e da água (Zhou,2007). A modelagem do equilíbrio de adsorção, assim como da cinética, tornou-se cada vez mais importante para o entendimento do processo ser bem-sucedido (Asnin, et al.,2007).

Moléculas de uma substância são capazes de adsorver na superfície adsorvente de duas maneiras diferentes. Quando cada molécula está em contato apenas com o sítio ativo da superfície adsorvente e não tem conexões com outras moléculas, é a adsorção ocorre em monocamada. No caso da presença de várias camadas de moléculas na superfície adsorvente, quando nem todas as moléculas estão em contato com o adsorvente, ocorre a adsorção multicamada (Sing,1985).

Como é bastante difícil determinar o mecanismo exato de adsorção antes do estudo detalhado, geralmente o processo de acumulação de uma substância na superfície do material é chamado de sorção. Informações sobre a estrutura e a composição química de um adsorvente oferecem uma oportunidade para avaliação preliminar do mecanismo de sorção.

Christmann (2011) reportou que o processo de quimissorção frequentemente ocorre nas superfícies heterogêneas, enquanto a adsorção de origem física ou fisissorção é mais significativa nos processos de separação próximos aos limites da fase. A comparação entre os tipos físicos e químicos de adsorção é representada na Tabela 3. 
Tabela 3- Características entre adsorção de origem física e adsorção de origem química

\begin{tabular}{cc}
\hline $\begin{array}{c}\text { Adsorção de origem } \\
\text { física }\end{array}$ & $\begin{array}{c}\text { Adsorção de origem química } \\
\text { Forças de Van der Waals } \\
\text { Não há transferência de } \\
\text { elétrons } \\
\text { Calor de adsorção 2 6 } \\
\text { kcal.mol }{ }^{-1} \\
\text { Lenta /rápida } \\
\text { Adsorvente é pouco } \\
\text { afetado } \\
\text { Monocamada ou } \\
\text { multicamadasones covalentes }\end{array}$ \\
\hline Fonte: (Zhang,2016) & Calor de adsorção 10 200 ${\text { kcal.mol }{ }^{-1}}^{\text {Instantânea }}$ \\
\hline
\end{tabular}

Segundo Alves (2014), a estrutura dos poros pode ser fator limitante das dimensões das moléculas que podem ser adsorvidas enquanto a área superficial disponível limita a quantidade de íon metálico que pode ser adsorvido. Dessa maneira, o volume de poros e a área superficial são fatores que afetam a adsorção.

\section{3.}

Argilas

Abreu (1973), define argila como sendo uma rocha de granulometria fina e constituída essencialmente por argilominerais. Na geologia a palavra argila é usada de duas maneiras: primeiro como uma classificação de rocha que geralmente implica um material de grão fino que desenvolve plasticidade na mistura com quantidade limitada de água. A outra definição, é referente ao termo de partícula, que descreve as argilas como minerais que têm um tamanho de partícula $<37 \mu \mathrm{m}$.

Como geomateriais naturalmente abundantes e altamente reativos, minerais argilosos têm sido usados desde os tempos pré-históricos para uma variedade de propósitos. Por exemplo, as argilas foram usadas na nutrição de animais de fazenda como agentes de ligação e aditivos alimentares para promover o 
crescimento e a saúde, e como um suplemento para tratar desordens gastrintestinais; às vezes, mulheres grávidas consumiam argilas para compensar a deficiência mineral em alimentos (Gomes \& Silva,2007; Slamova et al.,2011)

As argilas também são usadas na produção de cerâmicas, tijolos, cerâmica e medicamentos (Choy et al.,2007; Gomes \& Silva,2007; Newman \& Cragg,2007; Floody et al.,2009).

Os argilominerais são classificados segundo semelhanças na composição química e na estrutura. Folhas tetraédricas de silício e octaédrica de alumínio aparecem na estrutura cristalina dos argilominerais como ilustrado na Figura 2 (a) e (b). Essas folhas são comumentemente chamadas de folhas tetraédricas e octaédricas, respectivamente (Coelho,2007).

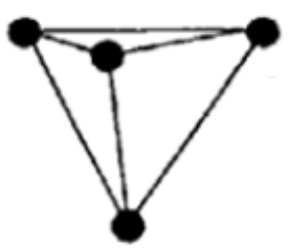

(a)

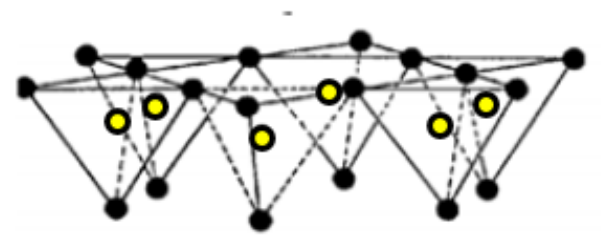

(b)

Oxigennios-ou-hidroxilas

O Aluminio, ferro-e/ou-aluminio

- Silicios

Figura 2- Modelo esquemático de um argilomineral genérico. Em (a)grupo tetraédrico (b) folha tetraédrica. Fonte: Adaptado de Chang et al (2016)

\subsection{1.}

\section{Palygorskita}

A palygorskita, também conhecida por atapulgita, é um argilomineral que desperta grande interesse comercial devido uma série de aplicações industriais e ambientais e isso se deve a sua estrutura peculiar, a natureza alongada das suas partículas, a alta superfície específica e a sua alta capacidade de sorção (Murray,2000).

Em Monteis Urais, União Soviética são datadas as primeiras ocorrências de palygorskita foram descobertas em 1861. No ano de 1935 foi chamada de atapulgita uma "terra fuller" descoberta em Attapulgus, Geórgia (EUA) por achar que essa espécie mineral era diferente da palygorskita (Nasedkin et al.,2009, 
Guggenheim \& Krekeler,2011). Entretanto, foi concluído através da utilização de técnicas mais modernas como a difração de raios $X$ que palygorskita e atapulgita dizem respeito a uma mesma espécie de mineral (Murray,2000). Esta denominação é hoje aceita pela comunidade científica e persiste o nome atapulgita na literatura americana (Huggins et al.,1962).

A palygorskita é formada em três tipos de ambientes geológicos: i) Sedimentos de ordem química em mares e em lagos continentais e epicontinentais, ii) Oceanos, devido à alteração hidrotermal de vidro basáltico e de sedimentos vulcânicos, iii) Solos calcários, devido à cristalização. Entretanto, podem ocorrer em outros tipos de ambientes, sendo necessário que o meio seja alcalino e que ocorra em clima árido ou semiárido e que os teores de $\mathrm{Si}$ e $\mathrm{Mg}$ sejam elevados, e baixo teor de alumínio (Heivilin \& Murray,1994).

\subsection{2.}

\section{Estrutura e propriedades da palygorskita}

A palygorskita é um argilomineral lamelar hidratado de hábito fibroso, onde sua composição química é dada por $(\mathrm{Mg}, \mathrm{Al})_{5} \mathrm{Si}_{8} \mathrm{O}_{20}\left(\mathrm{OH}_{2}\right)_{4} \cdot 4 \mathrm{H}_{2} \mathrm{O}$ Como representado na Figura 3. É um filossilicato 2:1, que apresenta uma estrutura cristalina porosa, constituída por dupla camada composta de tetraedros de silício e oxigênio ligadas por uma folha octaédrica com íons de magnésio, pertencente ao grupo das "hormitas" (palygorskita ou sepiolita).

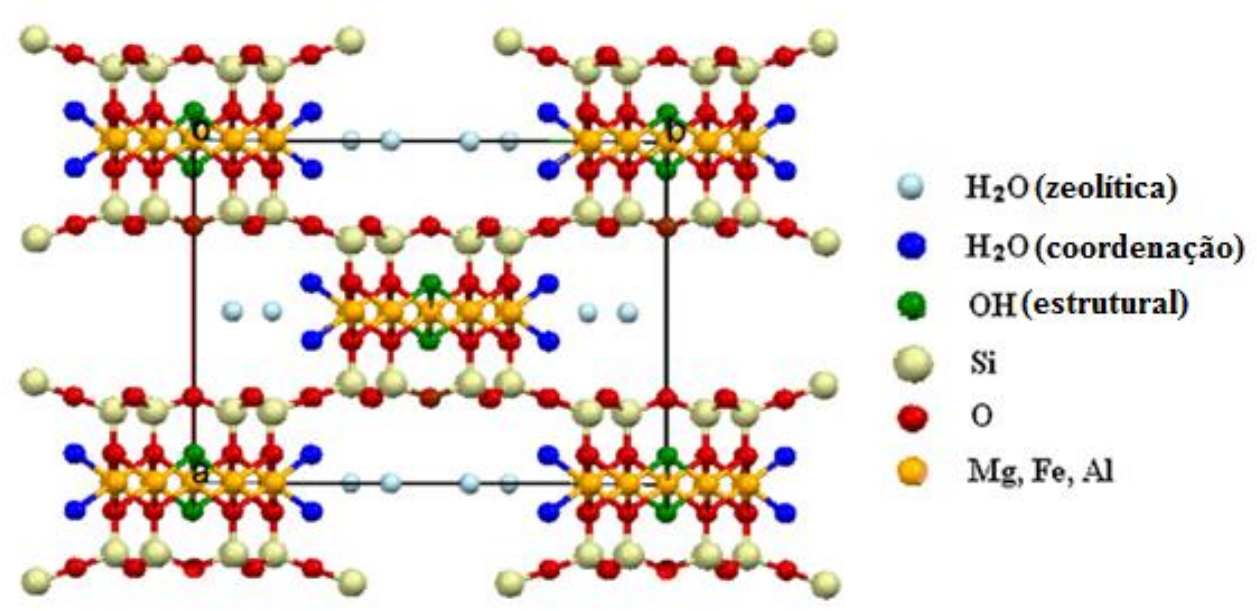

Figura 3- Estrutura da palygorskita. Adaptado de Chen et al (2011) 
A palygorskita apresenta um excesso de carga negativa na sua superfície devido às substituições por íons de menor valência, por exemplo, íons $\mathrm{Al}^{3+}$ substituindo os íons de $\mathrm{Si}^{4+}$ das folhas tetraédricas, ou ainda a substituição de $\mathrm{Al}^{3+}$ por $\mathrm{Mg}^{2+}$ nas folhas octaédricas.(Heivelin \& Murray,1994, Huang et al.,2007, Suárez \& Garcia-Romero,2006).

Os canais presentes na estrutura do argilomineral, bem como sua elevada área superficial e a sua granulometria fina promovem uma alta capacidade de adsorção de vários tipos de compostos, tornando-o eficaz em diversas aplicações industriais. Um fator importante no que tange as aplicações industriais da palygorskita é a tendência das partículas finas se aglomerarem. As propriedades deste material podem variar dependendo do estado de aglomeração (Galan \& Singer, 2011).

Dessa estrutura cristalina peculiar resulta uma morfologia fibrosa com espaços ocos sob forma de canais como ilustra a Figura 4. Tais substituições, entretanto, são consideradas isomórficas por não causarem distorção na estrutura cristalina, uma vez que estes íons possuem tamanhos similares. Além disso, estes argilominerais possuem elevada densidade de grupos silanol (-SiOH) na superfície externas das bordas das camadas, o que explica sua hidrofilia acentuada. As fibras são ripiformes com comprimentos de até $5 \mu \mathrm{m}$ e largura de 50 a $100 \AA ̊$ e os canais de 5,6 a 11,0 Å (Vágvölgyi et al.,2008).

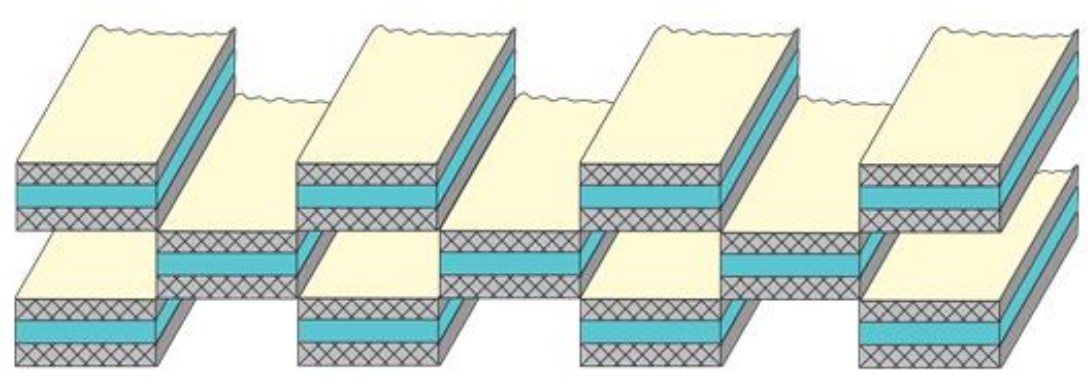

Figura 4- Presença de canais na estrutura física da palygorskita. Adaptado de Chang et al (2016)

A presença de microporos e canais na estrutura da palygorskita, bem como a natureza alongada das partículas e a sua granulometria fina, conferem uma alta superfície específica e capacidade de sorção de diferentes tipos de espécies. A palygorskita apresenta capacidade catiônica entre 20 e 50 miliequivalentes $/ 100 \mathrm{~g}$ e grande área superficial, estimada em torno de 125 a $210 \mathrm{~m}^{2} / \mathrm{g}$ (Murray,2000). Devido a estas propriedades esse mineral é utilizado em diferentes áreas, tais 
como: carreador de fertilizantes e defensivos agrícolas, condicionador de solos, cama de animais domésticos (pet litter), refino e processamento químico de derivados de petróleo, indústria de cimento, absorvente de óleo e graxa, indústria de tinta, aplicações têxteis, revestimento de piso cerâmico, adesivos, entre outros (Silva et al.,2013).

Cada célula unitária cristalina do argilomineral contém normalmente oito moléculas de água. A perda de água estrutural irá provocar uma mudança na estrutura durante a qual produz-se o colapso ou "folding" estrutural por rotação em torno de um eixo das ligações $\mathrm{Si}-\mathrm{O}-\mathrm{Si}$ que ligam as camadas tetraédricas invertidas da palygorskita (Preisinger,1961).

As propriedades de adsorção da palygorskita podem ser afetadas principalmente por mudanças estruturais provocadas pelo tratamento térmico no argilomineral. González et al., 1993, examinaram as modificações estruturais da palygorskita por análise térmica sob o vácuo. Os autores afirmaram que o colapso estrutural começa a ocorrer na temperatura de $125^{\circ} \mathrm{C}$, temperatura na qual a porosidade diminui. $\mathrm{O}$ colapso é reversível até a temperatura de $300^{\circ} \mathrm{C}$. Acima desta temperatura de tratamento térmico a modificação estrutural é irreversível. Na Figura 5 é demonstrado o esquema estrutural antes e após o colapso.
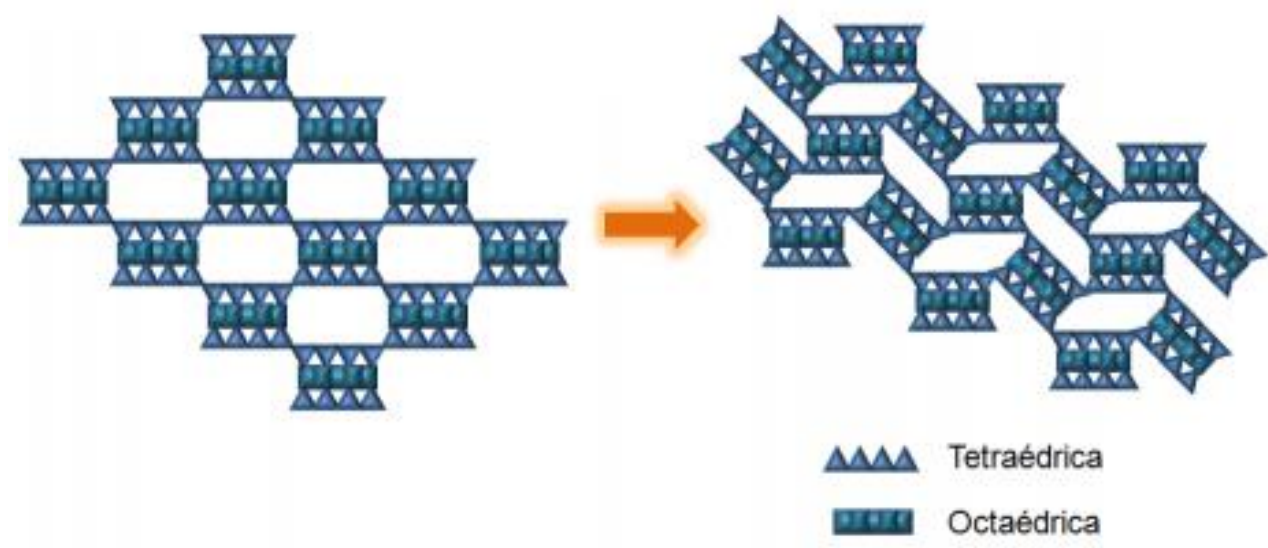

Figura 5- Representação esquemática do esquema de colapso da estrutura da palygorskita durante tratamento térmico. Adaptado de González et al.,(1993).

A distribuição do íon ferro é importante na determinação da origem da palygorskita e também na sua aplicação industrial. A palygorskita usada na indústria farmacêutica e de cosmético requer um elevado grau de pureza do mineral o que faz com que a diminuição de impurezas como essas sejam importantes do ponto de vista da sua aplicabilidade (Carretero \& Pozo,2009; Silva et al.,2011). 


\subsection{3. \\ Palygorskita como adsorvente de metais}

Alguns dos métodos convencionais para a remoção de metais pesados de soluções aquosas, geralmente apresenta um custo elevado. Portanto, é necessário investigar alternativas tecnicamente eficazes e de baixo custo. $A$ adsorção é uma alternativa, e vem sendo utilizada para remoção desses metais.

Um material adsorvente alternativo que vem despertando interesse são os argilominerais devido suas propriedades (carga superficial negativa em ampla faixa de $\mathrm{pH}$, e elevada área superficial) que favorecem a captação de íons metálicos. Além disto, é um material atóxico e com custo relativamente baixo, o que associado à sua elevada disponibilidade, torna estas matérias-primas uma alternativa para a remoção de íon metálicos (Uddin,2017; Malamis \& Katsou,2013; Sharifipour,2015).

Bourliva et al.,(2018), estudaram a eficiência da palygorskita e da vermiculita no processo de adsorção de $\mathrm{Cu}(\mathrm{II})$ e $\mathrm{Ni}(\mathrm{II})$ de soluções aquosas. Os efeitos de alguns parâmetros como tempo de contanto, concentração dos adsorventes e pH foram testados. Os autores também realizaram o estudo cinético para propor mecanismos de adsorção. A capacidade máxima de adsorção para o Cu(II) foi de $12,53 \mathrm{mg} / \mathrm{L}$ e $32,68 \mathrm{mg} / \mathrm{L}$ para a palygorskita e vermiculita, respectivamente. Foram obtidos dados correspondentes para Ni(II) de $11,57 \mathrm{mg} / \mathrm{L}$ e $37,85 \mathrm{mg} / \mathrm{L}$.

Simões (2017), beneficiou e caracterizou uma amostra de palygorskita da região de Guadalupe-PI para avaliar a eficiência do argilomineral na remoção de íons de $\mathrm{Pb}$ (II) e de $\mathrm{Cd}$ (II) em efluentes sintéticos por processo em batelada. A amostra de palygorskita apresentou capacidade de troca catiônica de 35,5 meq/100g e área superficial de $71,29 \mathrm{~m}^{2} / \mathrm{g}$. Referente aos testes de adsorção a palygorskita estudada apresentou percentual de remoção de 98 e $91 \%$ para os íons de $\mathrm{Pb}(\mathrm{II})$ e $\mathrm{Cd}(\mathrm{II})$, respectivamente. Em relação ao equilíbrio, o modelo de isoterma de Langmuir mostrou ser o que melhor se ajustou aos dados experimentais para ambos os metais estudados. A capacidade máxima de adsorção foi de $21,65 \mathrm{mg} / \mathrm{L}$ e 11,0 mg/L para os íons de $\mathrm{Pb}$ (II) e de Cd (II), respectivamente. 


\section{4.}

\section{Tipos de adsorção}

\subsection{1. Adsorção específica}

Neste tipo de adsorção os íons se tornam especificamente adsorvidos quando interações de curto alcance entre elas e a interface se tornam importantes. Acredita-se, então, que eles penetram na camada interna e podem (mas não necessariamente) entrar em contato com a superfície. Eles geralmente são assumidos para formar uma monocamada parcial ou completa. Dessa maneira, neste tipo de adsorção a camada de hidratação é perdida, consequentemente ocasionando maior aproximação e estabelecendo contato direto com a superfície diminuindo a mobilidade dos íons. A adsorção específica ocorre de forma mais lenta, ocasionalmente dificultando o equilíbrio e tornando sua reversão mais difícil.

Dispersões contendo apenas óxido metálico e eletrólito inerte raramente são encontradas em problemas práticos, e a maioria das aplicações do mundo real envolve adsorção específica de espécies iônicas (Kosmulski,2016).

Segundo Parks (1965), neste tipo de adsorção os mecanismos predominantes não dependem da atração eletrostática, dessa maneira os íons adsorvidos podem realizar as alterações a carga elétrica do sólido.

\subsection{2. \\ Adsorção não específica}

Neste tipo de adsorção predominam o estabelecimento de ligações mais fracas entre as moléculas, tais quais as forças de van der Waals e as provenientes de natureza eletrostática. Como característica, este tipo de adsorção apresenta reversibilidade, configurando-se como um processo rápido, usualmente limitado pelos fenômenos de difusão.

A seletividade ou a preferência de um íon por outro é outro fator predominante neste tipo de adsorção. Isso quer dizer que o processo relacionase com o raio iônico e com a energia de hidratação dos cátions que tenham a mesma valência. 


\section{5. \\ Adsorção de ETRs}

Como visto anteriormente, na literatura são reportados diversos métodos para separação de metais. Dependendo do objetivo que se deseja alcançar, esses métodos podem não ser atraentes do ponto de vista econômico (Anastopoulos et al.,2016). Dessa maneira, a adsorção tem atraído a atenção nas últimas décadas como uma maneira possível de recuperar o metal de maneira eficiente, simples e relativamente com baixo custo.

Gok (2014) utilizou a nano-hidroxiapatita magnética como novo adsorvente para a captação de íons $\mathrm{Nd}(\mathrm{III})$. A adsorção que obteve maior capacidade de captação ocorreu em pH 5,0 e os principais mecanismos presentes foram adsorção química e troca iônica. Estudos de regeneração foram realizados usando soluções de $\mathrm{HCl}$ e $\mathrm{NaOH}$. Após três ciclos de adsorção-dessorção, não foram relatadas alterações significativas do $\mathrm{Nd}$ (III) adsorvido.

Naser et al.,(2015) adsorveram $\mathrm{Nd}$ (III) em uréia-formaldeído à base de sílica $\left(\mathrm{SiO}_{2} / \mathrm{UF}\right)$ impregnada com material constituinte do extrator organofosforado. $\mathrm{O}$ equilíbrio foi alcançado em 120 min e a adsorção aumentou conforme $\mathrm{opH}$ aumentou de 1 para 6 . Aumentar a temperatura de 25 para $50^{\circ} \mathrm{C}$ levou a melhorar a capacidade de remoção.

Wang et al.,(2013) utilizaram géis híbridos de alginato de cálcio (ALG) e alginato de cálcio-ácido glutâmico (ALG-PGA) como adsorventes e reportaram que eles foram satisfatoriamente examinados quanto à sua capacidade de adsorção para remoção de $\mathrm{Nd}(\mathrm{III})$. Em comparação com o ALG, o adsorvente ALG-PGA pareceu exibir maior capacidade de adsorção. Experimentos cinéticos revelaram que o tempo de equilíbrio para ambos os sorventes foi atingido em $6 \mathrm{~h}$.

Palmieri (2000) relatou a biossorção de Nd (III) por microrganismos e carvão ativado. A biossorção máxima foi obtida utilizando a microalga Monoraphidium $s p$. (1511 mg/L de células), seguido de levedura de Baker (313 mg/L de células), Penicillium sp. (178 mg/L de células) e carvão ativado (61 mg/L).

A importância da adsorção devido à sua simplicidade, ampla aplicabilidade e possibilidade de uso mesmo com baixas concentrações de ETRs foi reportada por diversos autores e sumarizada na Tabela 4. 
Tabela 4-Capacidade de captação de diferentes adsorventes e condições operacionais para adsorção de $\mathrm{Nd}(\mathrm{III})$

\begin{tabular}{|c|c|c|c|c|c|c|c|}
\hline \multirow[b]{2}{*}{ Metal } & \multirow[b]{2}{*}{ Adsorvente } & \multicolumn{5}{|c|}{ Condicões Operacionais } & \multirow[b]{2}{*}{ Referência } \\
\hline & & $\begin{array}{c}\mathrm{qe}_{\mathrm{e}} \\
(\mathrm{mg} / \mathrm{L})\end{array}$ & $\mathrm{pH}$ & $\begin{array}{c}\mathrm{T} \\
\left({ }^{\circ} \mathrm{C}\right)\end{array}$ & $\begin{array}{c}\mathrm{C}_{\mathrm{M}} \\
(\mathrm{mg} / \mathrm{L})\end{array}$ & $\begin{array}{l}C_{a} \\
(g)\end{array}$ & \\
\hline $\mathrm{Nd}(\mathrm{III})$ & Alginato de cálcio & 194,73 & 3,6 & 25 & 25 & 0,04 & $\begin{array}{l}\text { Wang et } \\
\text { al.,(2013) }\end{array}$ \\
\hline $\mathrm{Nd}(\mathrm{III})$ & $\begin{array}{l}\text { Géis híbridos de } \\
\text { ácido glutâmico } \\
\text { de alginato de } \\
\text { cálcio }\end{array}$ & 238 & 3,6 & 25 & 25 & 0,04 & $\begin{array}{l}\text { Wang et } \\
\text { al.,(2013) }\end{array}$ \\
\hline $\mathrm{Nd}(\mathrm{III})$ & $\mathrm{SiO}_{2}$ & $\begin{array}{c}0,18 \\
\mathrm{meq} / \mathrm{g}\end{array}$ & 3 & n.a & 10 & 0,1 & $\begin{array}{c}\text { Naser et al } \\
\text { (2015) }\end{array}$ \\
\hline $\mathrm{Nd}(\mathrm{III})$ & $\begin{array}{l}\mathrm{SiO}_{2} \text { empregnado } \\
\text { com extratante } \\
\text { organo fosforado }\end{array}$ & $\begin{array}{c}2,8 \\
\mathrm{meq} / \mathrm{g}\end{array}$ & 3 & n.a & 10 & 0,1 & $\begin{array}{c}\text { Naser et al } \\
\text { (2015) }\end{array}$ \\
\hline $\mathrm{Nd}(\mathrm{III})$ & Pó de osso & 10,9 & n.a & 25 & 25 & 1 & $\begin{array}{c}\text { Butnariu et } \\
\text { al (2015) }\end{array}$ \\
\hline $\mathrm{Nd}(\mathrm{III})$ & $\begin{array}{c}\text { Nano } \\
\text { hidroxiapatita } \\
\text { magnética }\end{array}$ & 323 & 5 & 25 & 25 & 0,025 & Gok (2014) \\
\hline
\end{tabular}

\section{6.}

Variáveis que influenciam a adsorção

Além de fatores físico-químicos como o pH, a presença de outros ânions e cátions, a especiação dos metais, a concentração e propriedades do adsorvente, concentração do íon metálico, temperatura do sistema tais como as condições operacionais podem influenciar o processo de adsorção (Gadd,2009; Park \& Tavlarides,2010). 


\subsection{1. \\ Concentração do adsorvente}

Selecionar um adsorvente para uma determinada aplicação representa talvez uma das tarefas mais importantes. Em princípio, um adsorvente pode ser escolhido com base em vários fatores, incluindo a capacidade de adsorção, a seletividade do adsorvente, a regenerabilidade, compatibilidade com as condições operacionais e não menos importantes, o custo.

A concentração do adsorvente juntamente com a concentração dos íons metálicos apresenta-se como uma variável operacional que influencia na sorção de metais de forma que o processo seja dependente dessas variáveis.

Um aumento na concentração de adsorvente pode aumentar a quantidade de soluto adsorvido devido ao aumento do número de sítios ativos disponíveis. Por outro lado, quando os íons metálicos presentes na solução são adsorvidos, a adsorção de metal diminui, consequentemente o número de sítios ativos desocupados aumenta, o que resulta na diminuição da capacidade de adsorção do adsorvente (Zhang et al.,2016).

Ou seja, a concentração do adsorvente pode afetar a eficiência de adsorção com uma redução na sorção por unidade de peso ocorrendo com o aumento do adsorvente. Portanto, uma baixa concentração de adsorvente com uma maior captação do metal pode ser atribuída a concentração na solução que pode se ligar ao máximo de grupos funcionais do adsorvente.

Segundo Vijayaraghavan \& Yun (2008), o tamanho da partícula também é um fator que altera o processo de sorção, já que partículas que apresentam dimensões menores têm uma maior área de superfície, o que consequentemente favorece a adsorção e resulta um menor tempo de equilíbrio.

Outro fator que é determinante é a natureza físico-química do adsorvente já que a captação dos íons metálicos é dependente do volume específico de poros, da área superficial e distribuição do tamanho de poros, dos grupos funcionais presentes na superfície (Domingues,2005).

O tamanho do microporo determina a capacidade das moléculas de soluto de acessá-lo, de tal modo que a distribuição de tamanho do poro é outra propriedade importante para a caracterização dos adsorventes por meio da adsortividade. Com relação à porosidade, os poros podem ser classificados em três categorias, segundo as normas da IUPAC (1982), como é mostrado na Tabela 5. 
Tabela 5-Tipos de porosidade e tamanho de poros

\begin{tabular}{cc}
\hline Tipo de porosidade & Tamanho de poro \\
\hline Microporo & Poro de largura interna menor que $2 \mathrm{~nm}$ \\
Mesoporo & Poro de largura interna entre 2 e $50 \mathrm{~nm}$ \\
Macroporo & Poro de largura interna maior que $50 \mathrm{~nm}$ \\
\hline
\end{tabular}

Microporos contribuem, principalmente, para a adsorção de moléculas pequenas, tais como gases e solventes comuns, os mesoporos são importantes para a adsorção de moléculas grandes, tais como os corantes e proporcionam a maioria da área superficial para carvões impregnados com produtos químicos, já os macroporos são normalmente considerados sem importância para a adsorção. A função dos macroporos é permitir que as moléculas do adsorvato tenham acesso aos poros menores situados no interior do adsorvente (Figura 6).

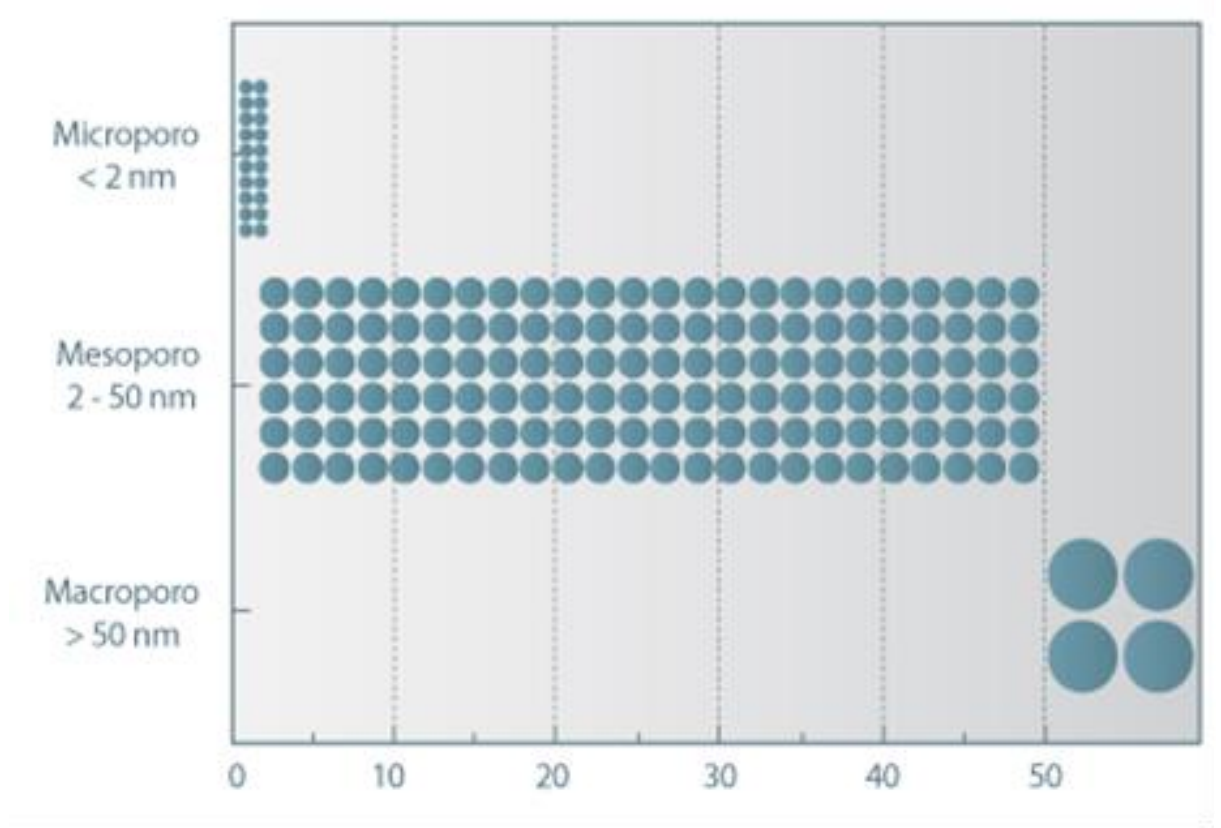

Figura 6- Classificação do tamanho de poro segundo a União Internacional de Química Pura e Aplicada - IUPAC (1982).

\subsection{2.}

$\mathrm{pH}$

Dos fatores físico-químicos, o pH é possivelmente o mais importante das variáveis. A adsorção dos metais tem mostrado ser fortemente dependente do $\mathrm{pH}$ (Vijayaraghavan et al,2008).

$\mathrm{O}$ pH é fator determinante do processo pois determina o grau de distribuição das espécies químicas. A concentração de prótons influencia a especiação do 
metal, que afeta as interações metal/adsorvente, a especiação influencia a solubilidade e mobilidade de espécies metálicas afetando o desempenho da sorção.

Além disso, ele pode afetar as propriedades superficiais do sorvente (protonação e desprotonação de grupos reativos) e a especiação de espécies metálicas (formação de espécies ou complexos hidrolisados). No caso de íons metálicos de elementos terra raras em soluções simples (sem ligantes adicionais) a especiação não é substancialmente alterada e a maior parte do efeito do $\mathrm{pH}$ prosseguirá através da alteração da carga global do sorvente e mais especificamente da desprotonação da amina e dos grupos carboxílicos.

Íons metálicos estão presentes sob a forma de $\mathrm{Nd}(\mathrm{III})$ em soluções ácidas e tendem a formar espécies hidrolisadas catiônicas (tais como $\mathrm{Nd}(\mathrm{OH})^{2+}, \mathrm{Nd}(\mathrm{OH})_{2}$ ) quando aumentamos o pH. Por outro lado, a um pH mais elevado (isto é, acima de $\mathrm{pH}$ 6) podem aparecer espécies tais como $\mathrm{Nd}(\mathrm{OH})_{3}$ e a alta concentração de íons metálicos começam a precipitar. Como consequência, em soluções levemente ácidas, espécies metálicas catiônicas podem coexistir sob diferentes formas (a depender de fatores como o pH e da concentração do metal).

\subsection{3.}

\section{Temperatura}

O efeito da temperatura sobre o sistema afeta os processos de sorção de modo que um incremento dela pode ocasionar um amento da energia cinética e mobilidade das espécies do adsorvato (Jimenez et al.,2004). Desde que a entalpia global das interações não seja zero, ocorrerá uma dependência da temperatura na adsorção de íons metálicos. A mudança de temperatura afeta vários fatores, como a estabilidade das espécies de íons metálicos inicialmente colocadas em solução e a estabilidade do complexo adsorvente-metal, dependendo dos locais de adsorção (Sag \& Kutsal,2000). O aumento da temperatura também pode produzir uma desobstrução de poros no interior da estrutura do adsorvente, permitindo a penetração de moléculas maiores do adsorvato.

A temperatura geralmente aumenta a captação de ions metálicos já que é variado a energia cinética do adsorvato, contudo um incremento dela também pode danificar a estrutura física do adsorvente.

O calor de adsorção tem papel fundamental, para predição do tipo de adsorção (química ou física). A constante de equilíbrio termodinâmica é representada pela Equação 1: 


$$
K=\exp \left(\frac{-\Delta H^{\circ}+T \Delta S^{\circ}}{R T}\right)
$$

Segundo Veneu (2010), a adsorção não é necessariamente exotérmica. Se o $\Delta \mathrm{H}^{\circ}<0$, pode-se afirmar que a adsorção é exotérmica e a temperaturas elevadas, é favorecida, já quando acontece o contrário, ou seja $\Delta \mathrm{H}^{\circ}>0$ é endotérmica e favorecida a temperaturas elevadas (Akzu,2002).

\subsection{4.}

\section{Concentração do íon metálico}

A concentração inicial do íon metálico em solução a ser adsorvido apresenta um papel chave como força motriz para superar a resistência de transferência de massa entre a fase líquida e a fase sólida. Portanto, é esperado que, com o aumento de íons metálicos, a adsorção dos metais vá aumentar.

A capacidade de sorção, portanto, é limitada pelo número de sítios ativos presentes no adsorvente. A baixas concentrações do íon metálico, são necessárias pequenas concentrações de adsorvente para atingir a capacidade máxima de captação. Segundo Sandau et al (1996) em concentrações mais altas, o número de íons competindo pelos sítios ativos disponíveis na superfície do adsorvente aumenta, e a capacidade de captação (mg de metal/g de adsorvente) também é aumentada.

\section{7.}

\section{Carga elétrica da superfície}

\subsection{1. Dupla Camada elétrica}

A fundamentação da teoria da dupla camada elétrica encontra-se, eventualmente, no estudo da distribuição dos íons e seu eventual potencial elétrico, que estão presentes na superfície carregada do colóide em estudo. Segundo Shaw (1975), partículas compreendidas em um intervalo entre $1 \mathrm{~nm}$ a $1 \mu \mathrm{m}$ são interpretadas pela ciência dos colóides. Isso significa que a esses sistemas é atribuído tanto moléculas grandes como a pequenas. 
Segundo Adamson et al.,(1967) a distribuição espacial das cargas livres sejam elas iônicas ou eletrônicas é dependente do estado elétrico da superfície. Dessa maneira, a idealização desta distribuição é atribuída a teoria da dupla camada elétrica. (Kellly et al.,1982).

A compreensão desta teoria é de extrema relevância para o entendimento de sistemas coloidais que contem partículas carregadas, já que estas são propriedades experimentais referentes a propriedades eletrocinéticas, por exemplo.

Sabe-se que em meio aquoso, partículas estão submetidas a um campo elétrico e obtém carga elétrica superficial. Os mecanismos do surgimento dessas cargas podem ser provenientes de dissolução ou adsorção de íons, defeitos na rede cristalina dos minerais e até mesmo ionização da superfície. Duncan (1975), atribui a esta carga superficial a distribuição no meio os quais os íons estão próximos. Dessa maneira, denomina-se como camada de Stern a camada rígida adjacente ao redor da superfície do colóide, que é formada a partir da atração dos íons positivos. A atração de mais íons positivos pelos colóides de carga negativa, podem fazer com que estes de carga positiva sejam repelidos da camada de Stern, resultando desta maneira em um equilíbrio dinâmico que consequentemente resulta na formação de uma camada difusa de contra-íons, como está demonstrado na Figura 7. 


\section{Superfície da partícula}
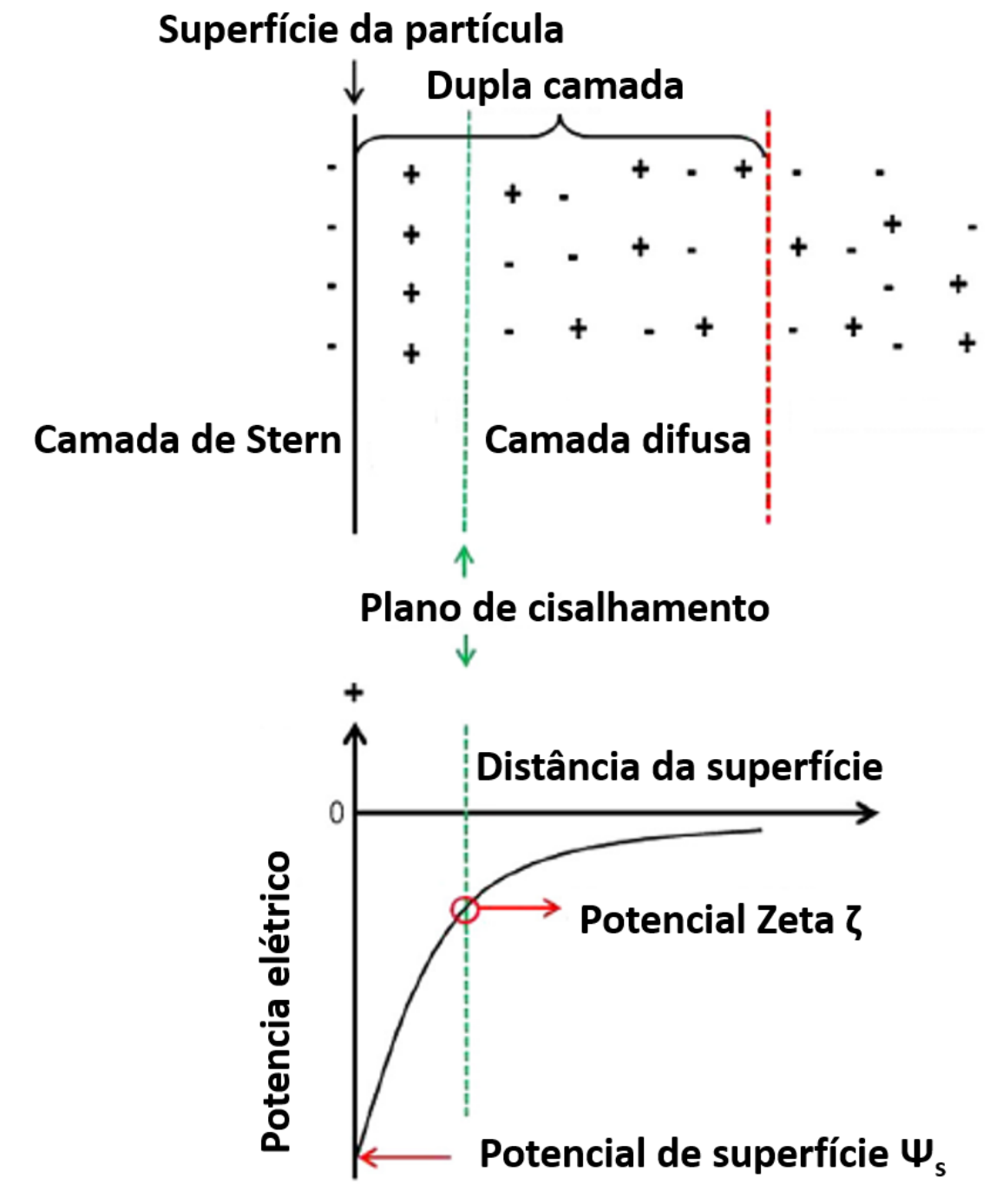

Figura 7- Modelo Stern-Grahame para dupla camada. Adaptado de Wills (2015)

\subsection{2.}

\section{Caracterização da carga de superfície- Potencial Zeta}

Circunstancialmente, partículas que são mantidas em contato em meio aquoso são submetidas a um campo elétrico e consequentemente portará carga elétrica positiva, negativa ou até mesmo neutra. Botero \&Torem (2008) citam que o deslocamento da partícula no campo elétrico como potencial zeta que está associado ao plano de cisalhamento. Sua medida é obtida experimentalmente em fenômenos eletrocinéticos que são decorrentes da movimentação das partículas dispersas no meio provocando o rompimento da dupla camada elétrica (DCE), no plano de cisalhamento (Pino,2005). Este parâmetro é considerado como indicador 
de carga e é de extrema relevância sua compreensão nos estudos de química de superfície, pois sua utilização pode prever e controlar a estabilidade de suspensões ou emulsões coloidais (Bueno,2008).

Os estudos relacionados aos fenômenos eletrocinéticos compreendem os seguintes campos:

(1) Eletroforese;

(2) Eletrosmose;

(3) Potencial de escoamento;

(4) Potencial de sedimentação;

A eletroforese é uma das técnicas mais reportadas para medição do potencial Zeta $(\zeta)$ sendo este o mais adequado para ser utilizado no presente estudo. Dessa maneira, a mobilidade eletroforética pode ser expressa a partir da Equação 2 denominada de expressão de Helmholtz - Smoluchowski (Hunter,2013).

$$
Z_{p}(\zeta)=\frac{4 \pi \mu v}{\varepsilon}
$$

Onde $Z_{p}$ é o potencial zeta $(\mathrm{mV}), \mu$ é a viscosidade do fluido, $v$ é a mobilidade eletroforética $\left(\mu \mathrm{m} \cdot \mathrm{s}^{-1} \cdot \mathrm{v}^{-1} \cdot \mathrm{cm}\right), \varepsilon$ é a constante dielétrica. Tem-se que para a água a $25^{\circ} \mathrm{C}(\varepsilon=78,4$ e $\mu$ 0,0089 P), é obtida a Equação 3:

$$
\zeta=12,83 v
$$

A determinação do parâmetro de potencial zeta em extensa faixa de $\mathrm{pH}$ permite dá a obtenção das curvas de potencial zeta, e a consequente avaliação da carga superficial das partículas em estudo. Além desta medida, há a possibilidade da obtenção do ponto isoelétrico (PI), comumentemente denominado logaritmo negativo da atividade da espécie determinadora do potencial correspondente ao potencial zeta nulo, na presença de eletrólito indiferente. O ponto isoelétrico se distingui do ponto de carga zero (PCZ), no ponto de carga zero, a carga da superfície é zero.

A magnitude do potencial zeta ( $\zeta$ ) determina a estabilidade de um sistema coloidal. As partículas em suspensão que possuem um alto valor de potencial zeta 
(ל), positivo ou negativo usualmente tendem a se repelir umas as outras, fazendo assim com que as partículas não apresentem tendência a flocular.

O parâmetro que mais afeta o potencial zeta (ל) é o $\mathrm{pH}$. Em meio básico, a tendência de uma partícula em suspensão é de apresentar um potencial zeta negativo. Já em meio ácido é adicionada a suspensão, chegará um ponto em que a carga negativa pode vir a ser neutralizada. É qualquer adição de ácido, pode levar a um acréscimo de carga positiva (Sondi et al.,1997). A afinidade do adsorvente a espécies metálicas depende em grande parte da força iônica da solução aquosa, assim como a variação do pH.

\section{8. \\ Isotermas de adsorção}

A fim de organizar, estabelecer e compreender um modelo de projeto adequado para a remoção de metais de ETRs em meios aquosos, a compreensão de estudos das isotermas também são pré-requisitos básicos essenciais para obtenção de informações sobre a adsorção. (Kedari; et al.,2001).

Ao entrar em contato com o adsorvente, as moléculas ou íons do adsorvato tendem a fluir do meio aquoso para a superfície do adsorvente, até que a concentração do soluto na fase líquida $\left(C_{e}\right)$ permaneça constante. $A$ capacidade de adsorção do adsorvente $\left(q_{e}\right)$ é alcançada quando o sistema atinge o estado de equilíbrio. Dessa maneira, é possível plotar a capacidade de adsorção (q) versus $\mathrm{C}_{\mathrm{e}}$ a partir dos dados experimentais (Cooney,1998).

Estas curvas representam a relação entre a quantidade de metal adsorvido no adsorvente $\left(q_{e} \mathrm{em} \mathrm{mg} / \mathrm{g}\right)$ e a quantidade de metal remanescente na fase líquida $\left(\mathrm{C}_{e}\right.$ em $\left.\mathrm{mg} / \mathrm{L}\right)$ a uma temperatura fixa e sob condições de equilíbrio como pode ser representado pela Figura 8. 


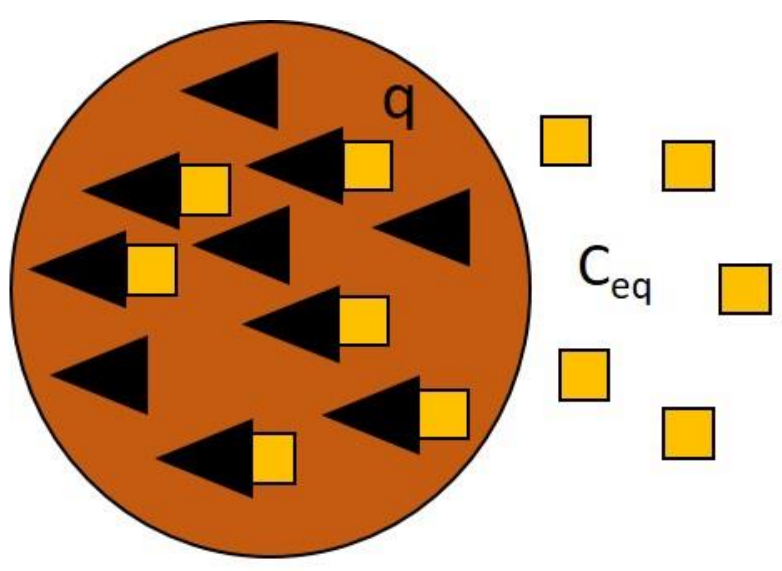

Sítios de adsorção

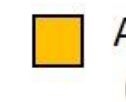

Adsorvato

(íons metálicos)

adsorvente

Figura 8-Desenho esquemático de um sistema de adsorção em equilíbrio.

Adaptado de Veneu (2010)

A forma dessas curvas pode fornecer informações sobre o mecanismo de adsorção. Além disso, a partir das isotermas pode-se obter a máxima capacidade de captação do metal na adsorção de um determinado adsorvente, através da Equação 4:

$$
q=\frac{V\left(C_{i}-C_{e q}\right)}{M}
$$

Onde:

$q$ = Capacidade de captação do metal (mg de metal $/ \mathrm{g}$ de adsorvente);

$C_{i}=$ Concentração inicial do metal ( $\mathrm{mg}$ de metal/ $\mathrm{L}$ de solvente);

$C_{e q}=$ Concentração do metal no equilíbrio ( $\mathrm{mg}$ de metal/L de solvente);

$M=$ Massa do adsorvente $(\mathrm{g})$

Segundo Giles et al.,(1974), existem quatro diferentes formas de isotermas são comumente observadas na Figura 9 (Limousin et al.,2007). A isoterma do tipo C (partição constante) é uma linha que passa pela origem (Figura 9 a). Refere-se a um sistema em que a relação entre a concentração do composto em solução e adsorvida no sólido é a mesma em todo o intervalo de concentração. Na prática, esse tipo de isoterma só pode ser obtido para uma faixa estreita de concentrações ou baixas concentrações. $A$ isoterma do tipo $L$ (Langmuir) propõe uma saturação progressiva do sólido com ou sem estrato estrito (Figura 9 b). A maioria das equações isotérmicas são desse tipo. $A$ isoterma do tipo $H$ (alta afinidade) é um 
caso especial da isoterma do tipo L (Figura 9 c) com uma inclinação inicial muito alta indicando fortes interações adsorvente-adsorvente (Covelo et al.,2007). Finalmente, a isoterma do tipo $S$ (Stype), embora muito raramente observada, mostra uma baixa afinidade de adsorção em baixas concentrações de adsorvato e adsorção aumentada após o ponto (ponto de inflexão, Figura 9 d) no qual alguma adsorção já ocorreu.

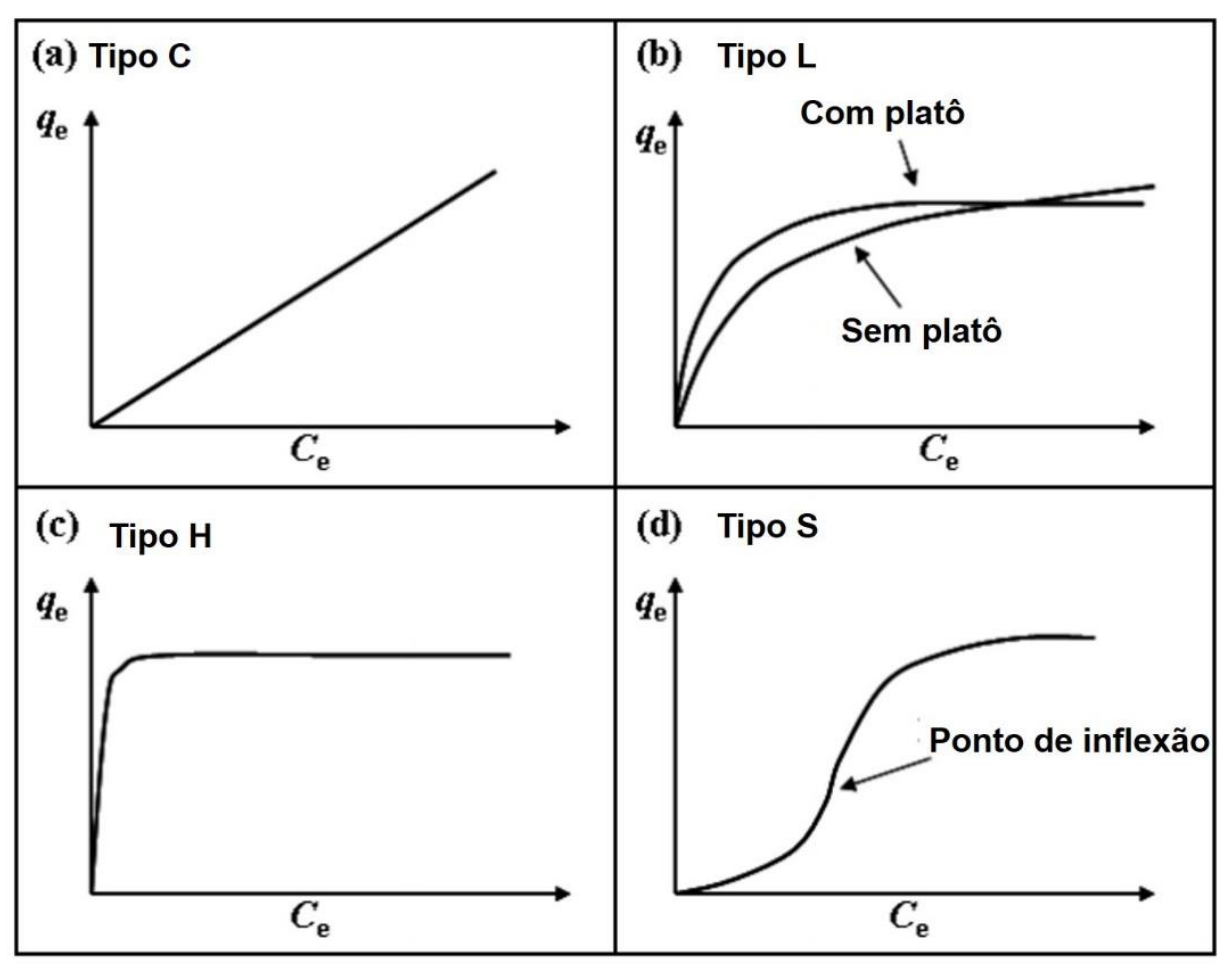

Figura 9- Classificação dos tipos de isotermas. Adaptado de Guiles et al.,(1974).

Dentre os principais modelos teóricos e empíricos de isoterma que descrevem o comportamento de adsorção e dessorção de acordo com determinados parâmetros os mais utilizados são os de Langmuir, Freundlich, Temkin,Dubinin-Radushkevich (DR), Sips e Redlich-Peterson (Chen et al.,2009; Febrianto et al.,2009; Wang et al.,2013, :Unlü \& Ersoz,2006).

\section{ISOTERMA DE LANGMUIR}

Dentre os modelos mais comumentemente utilizados, encontra-se a isoterma de Langmuir para a representação dos processos de adsorção. Originalmente derivada de estudos sobre a adsorção de gás ao carvão ativado (Gadd,2009) também pode ser aplicado a adsorção a partir da solução de uma substância $B$ num local de um adsorvente insolúvel $A$ a temperatura fixa, como 
mostra a Equação 5, onde $A \cdot B_{(s)}$ indica a ligação dos íons metálicos com o adsorvente e $\mathrm{K}$ é a constante de equilíbrio para adsorção.

$$
A_{(s)}+B_{(s)} \leftrightharpoons A B_{(s)} \quad K
$$

A fração $\theta$ de sítios adsorventes ocupados por B é dada pela Equação 6, onde $[B]$ é a concentração de $B$ não adsorvido em solução em equilíbrio.

$$
\theta=\frac{K[B]}{1+K[B]}
$$

A isoterma de Langmuir baseia-se em suposições, a saber: a sorção é limitada à cobertura em monocamada, todos os sítios superficiais são semelhantes e só podem acomodar um átomo adsorvido e a capacidade de uma molécula ser adsorvida em um determinado local é independente de sua ocupação, dentro do modelo de Langmuir, a capacidade de saturação $q_{\text {máx }}$ deve coincidir com a saturação de um número fixo de locais de superfície idênticos, dessa maneira os íons são adsorvidos em uma única camada na superfície, onde ocorrerá a adsorção máxima, a energia de adsorção é constante em toda a superfície e independente da superfície coberta, e as espécies adsorvidas não interagem.

Geralmente, é preferível a representação em termos de quantidade $Q_{e}$, ao invés da quantidade de $\theta$ como fora apresentado na Equação 6 . Basicamente a equação da isoterma de Langmuir tem uma forma hiperbólica:

$$
Q_{e}=\frac{q_{\max } K_{L} C_{e}}{1+K_{L} C_{e}}
$$

Onde:

$Q_{e}$ é a quantidade de metal adsorvido no adsorvente no equilíbrio (mg/g);

$q_{\max }$ parâmetro de Langmuir relativo à capacidade máxima de adsorção $(\mathrm{mg} / \mathrm{g})$;

$K_{L}$ Constante de Langmuir relacionada à energia de adsorção $(\mathrm{L} / \mathrm{mg})$;

$C_{e}$ Concentração do íon em solução no equilíbrio (mg/L). 
Este é o valor máximo que $Q_{e}$ pode atingir com o aumento de $C_{e}$, o que leva conclusão de que a cobertura da superfície $\theta$ é igual à relação $Q_{e} / q_{\max }$, e portanto, $\theta=1$ quando $Q_{e}=q_{\max }$.

Para os valores de $K_{\mathrm{L}}$ e $q_{\max }$ a Equação 7 é frequentemente rearranjada para sua forma linear como demostrado na Equação 8.

$$
\frac{C_{e}}{q_{e}}=\frac{1}{q_{\max } K_{L}}+\frac{C_{e}}{q_{\max }}
$$

Dessa maneira a construção do gráfico $\left(C_{e} / q_{e}\right)$ em função de $C_{e}, q_{\max }$ e $K_{L}$ são determinadas quando uma linha reta é obtida, que é geralmente arranjada através de um ajuste linear pelo método dos mínimos quadrados. Ao conhecer os valores da inclinação e a interceptação, é possível calcular os valores dos parâmetros $\mathrm{K}_{\mathrm{L}}$ e $\mathrm{q}_{\max }$, através dos coeficientes angular e linear da reta, respectivamente (Barros,2000).

\section{ISOTERMA DE FREUNDLICH}

Considerada uma isoterma de adsorção empírica para uma adsorção não ideal em superfícies heterogêneas. Proposta por Freundilich (1907), para a adsorção de gases em superfícies sólidas é utilizada para descrever atualmente as características em soluções aquosas. Representada pela Equação 9.

$$
q=K_{f} C e^{\frac{1}{n}}
$$

Onde:

$q=$ quantidade de metal adsorvido no adsorvente no equilíbrio $(\mathrm{mg} / \mathrm{g})$;

$K_{f}=$ é a concentração do íon em solução $(\mathrm{L} / \mathrm{mg})$;

$C e=$ Concentração do íon em solução em equilíbrio $(\mathrm{mg} / \mathrm{L})$;

$n=$ Constante que indica a intensidade de adsorção.

Este modelo considera a captação em multicamadas, e não prevê a saturação da superfície baseada no processo de adsorção. Considerando o sólido heterogêneo, é aplicado uma distribuição exponencial com o objetivo de 
caracterizar os vários tipos de sítios de adsorção, que podem possuir energias adsortivas (Febrianto et al.,2009).

A Equação 9 pode ser representada na forma linearizada representada pela Equação 10:

$$
\ln q_{e}=\ln K_{f}+\frac{1}{n} \ln C_{e}
$$

Onde:

$q_{e}=$ quantidade de soluto adsorvido $(\mathrm{mg} / \mathrm{g})$;

$C_{e}=$ Concentração de equilíbrio em solução $(\mathrm{mg} / \mathrm{L})$;

$K_{f}=$ Constante de capacidade de adsorção de Freundlich (L/mg).

Dessa maneira, a determinação dos parâmetros $\mathrm{K}_{\mathrm{f}}$ e 1/n são obtidos através de regressão linear, portanto, um gráfico q versus log $C_{e}$ fornece uma inclinação de $1 / n$ e log $K_{F}$ (Febrianto, et al.,2009).

Segundo Cooney (1998) o modelo de Freundlich é incapaz de prever os dados de equilíbrio de adsorção quando as faixas de concentração são elevadas.

\section{ISOTERMA DE TEMKIN}

A distribuição uniforme de energias de ligação e as interações adsorventeadsorvato são dois parâmetros levados em consideração para o modelo de Temkin (Foo \& Hameed,2010). Considerando os efeitos de interação indiretas do adsorvato/adsorvato sobre as isotermas de adsorção, Temkin representou este modelo através da Equação 11.

$$
q_{e}=\frac{R T}{b} \ln \left(A C_{e}\right)
$$

Onde:

$A=$ Constante da isoterma de Temkin (L/mg);

$C_{e}=$ Concentração no equilíbrio $(\mathrm{mg} / \mathrm{L})$;

$q_{e}=$ Captação no equilíbrio $(\mathrm{mg} / \mathrm{g})$;

$R=$ Constante dos gases $8,314\left(\mathrm{~J} \cdot \mathrm{mol}^{-1} \cdot \mathrm{K}^{-1}\right)$

$T=$ Temperatura absoluta $(\mathrm{K})$;

$b=$ Constante relacionada para o calor de adsorção (J.g.mol-2) 
Compreendido como uma extensão do modelo de Langmuir em superfícies homogêneas e heterogêneas, o modelo criado em 1941 por Mikhail Temkin assume que as moléculas primeiro adsorvem no local com maior calor de adsorção (energia), portanto o calor de adsorção diminui linearmente com o preenchimento dos sítios. No entanto, essa diminuição também pode acontecer na superfície homogênea, devido às interações das moléculas adsorvidas.

Segundo Kim et al.,(2004) a descrição de processos de adsorção pela isoterma de Temkin é mais adequada em meios gasosos, pois alguns fatores como a organização das moléculas na superfície do adsorvente e o pH não são considerados.

O modelo em sua forma linearizada é representado pela Equação 12 e o parâmetro pode ser dado pela Equação 13.

$$
q_{e}=B \ln A_{T}+B \ln C_{e}
$$

Onde B é:

$$
B=\frac{R T}{b_{T}}
$$

$q_{e}=$ Captação no equilíbrio $(\mathrm{mg} / \mathrm{g})$;

$C_{e}=$ Concentração no equilíbrio $(\mathrm{mg} / \mathrm{L})$;

$A_{T}=$ Constante de equilíbrio isotérmico de Temkim;(L/mg);

$B=$ Constante relacionada ao calor de sorção $(\mathrm{J} / \mathrm{mol})$;

$b_{T}=$ Constante de Temkin;

$T=$ Temperatura absoluta K;

Segundo Vijayaraghavan et al.,(2008) se o valor de $\mathrm{b}_{\text {T }}$ aumenta com o incremento da temperatura, indica que a adsorção é endotérmica, caso contrário, isto é, se "bT" diminui com o aumento da temperatura, a adsorção pode ser considerada exotérmica. 


\section{ISOTERMA DE DUBININ-RADUSHKEVICH}

Esta isoterma é geralmente aplicada para expressar o mecanismo de adsorção com uma distribuição de energia gaussiana sobre uma superfície heterogênea. Apesar de ser mais satisfatória para adsorventes sólidos em fase gasosa. Representando uma curva característica de adsorção que está relacionada à estrutura porosa do adsorvente, a Equação 14 representa a isoterma de Dubinin-Radushkevich e a Equação 16 o potencial de Polayni:

$$
q_{e}=q_{s} \exp \left\lfloor-\beta\left(R T \ln \left(1+\frac{1}{C_{e}}\right)\right)^{2}\right\rfloor
$$

Essa abordagem é usualmente aplicada para distinguir a adsorção física e química de íons metálicos através da energia de adsorção $(\mathrm{KJ} / \mathrm{mol})$ e é relacionado para $\beta$ pelo uso da Equação 15.

$$
E_{s}=\frac{1}{\sqrt{2 \beta}}
$$

Onde $E_{s}$ representa a energia livre de adsorção. Segundo Wang et al., (2006), a $E_{s}$ está relacionada com o fenômeno de adsorção que acontece no sistema adsorvente-adsorvato. Sabe-se que se:

$\mathrm{E}_{\mathrm{s}}<8 \mathrm{KJ} / \mathrm{mol}$ a adsorção pode ser considerada de natureza física; se 8 $\mathrm{KJ} / \mathrm{mol}<\mathrm{E}_{\mathrm{s}}<16 \mathrm{KJ} / \mathrm{mol}$ adsorção acontece por troca iônica; Se $\mathrm{E}_{\mathrm{s}}<16 \mathrm{KJ} / \mathrm{mol}$ a adsorção é considerada de natureza química. (özcan et al.,2005, Chen et al., 2009; Tripathy \& Raichur,2008)

A Equação 14 pode ser expressa de forma linearizada através de:

$$
\ln q_{e}=\ln q_{\max }-\beta F^{2}
$$

Onde:

$$
F=R T \ln \left(1+\frac{1}{C_{e}}\right)
$$


$q_{e}=$ Captação no equilíbrio $(\mathrm{mol} / \mathrm{g})$;

$\beta=$ Constante relacionado à energia de sorção $\left(\mathrm{mol}^{2} . \mathrm{KJ}^{-2}\right)$;

$\mathrm{F}=$ Potencial de Polayni $(\mathrm{J} / \mathrm{mol})$;

$\mathrm{R}=$ Constante dos gases $\left(8,314 \mathrm{~J} \cdot \mathrm{mol}^{-1} \cdot \mathrm{K}^{-1}\right)$;

O modelo vem sendo utilizado e obtido êxito em meios de concentrações de soluto de média a elevada, mas não tem muito sucesso na previsão da lei de Henry quando se trata de baixas pressões. (Altin et al.,1998).

\section{ISOTERMA DE SIPS}

A equação de sips é comumentemente utilizada como uma variação do modelo de Langmuir-Freundlich. Em um estudo da distribuição de energias de adsorção nos sítios na superfície de um catalisador Sips propôs uma isoterma empírica que é frequentemente expressa através da Equação 18:

$$
q_{e}=\frac{K_{s} C_{e}^{n s}}{1+a_{s} C_{e}^{n s}}
$$

Os dados podem ser ajustados ao modelo isotérmico de Freundlich a baixas concentrações de adsorvato.

Onde:

$K_{S}=$ Constante de Sips $(\mathrm{L} / \mathrm{g})$;

$a_{s}=$ Coeficiente de afinidade

$n_{S}=$ Coeficiente de heterogeneidade da superfície do adsorvente;

$C_{e}=$ Concentração no equilíbrio $(\mathrm{mg} / \mathrm{L})$.

Sua forma linearizada pode ser representada através da Equação 19:

$$
\ln \left[q_{e}\left(1+a_{s} C_{e}^{\beta_{s}}\right)\right]=\ln K_{s}+\beta_{s} \ln C_{e}
$$

Onde $\beta_{s}$ é considerado o expoente isotérmico de sips. Quando $\beta_{\mathrm{s}}$ está próximo de 1 em altas concentrações de adsorvato, o ajuste dos dados é comumentemente mais próximo ao modelo de Langmuir característico de monocamada. Por outro lado, os dados podem ser ajustados ao modelo de 
Freundlich a baixas concentrações de adsorvato não obedecendo a lei de Henry (Choundhrary \& Paul,2018).

\section{ISOTERMA DE REDLICH-PETERSON}

Representa um modelo empírico de três parâmetros que inclui as características das isotermas de Langmuir e Freundlich e explica os dados de equilíbrio de sorção obtidos a partir de uma ampla faixa de concentração de soluto. $A$ isoterma de Redlich-Peterson é descrita pela Equação 20 de maneira não-linear da seguinte forma:

$$
q_{e}=\frac{K_{R P} C_{e}}{1+a_{R P} c_{e}^{\beta_{R P}}}
$$

Onde:

$K_{R P}=$ Constante de Redlich- Peterson (L/g);

$a_{R P}=$ Constante de Redlich-Peterson (L/mg);

$\beta_{R P}=$ expoente do modelo de Redlich-Peterson

$C_{e}=$ Concentração no equilíbrio $(\mathrm{mg} / \mathrm{L})$

$\mathrm{O} \beta_{\mathrm{RP}}$ é um expoente que varia entre valores de 0 a 1 . Em cobertura superficial baixa $\left(\beta_{R P}=0\right)$, a Equação 20 toma a forma da equação da lei de Henry Equação 21 , enquanto que em cobertura superficial alta $\left(\beta_{R P}=1\right)$ a mesma equação se reduz a isoterma de Langmuir. (Equação 22)

$$
\begin{gathered}
q_{e}=\frac{K_{R P} C_{e}}{1+a_{R P} C_{e}} \\
q_{e}=\frac{K_{R P} C_{e}}{1+a_{R P}}
\end{gathered}
$$

\section{ISOTERMAS DIVERSAS}

$\mathrm{Na}$ literatura são encontrados outros tipos de isotermas como a de Jovanovic (1969), que considera a possibilidade de alguns contatos mecânicos entre as moléculas de adsorvato e faz as mesmas suposições do modelo de Langmuir. 
O modelo de Toth (1971) é considerado outro modelo que modificou a equação de Langmuir para melhorar a predição dos dados, além disso é aplicável simultaneamente a sistemas de sorção heterogênea.

A equação associada ao modelo de Khan (Khan et al.,1996) é sugerida para soluções puras e a correlação do modelo tem uma característica única ao cobrir ambos os extremos das equações de Langmuir e Freundlich.

Hill (2010) descreve a ligação de diferentes adsorvatos a substratos homogêneos. De acordo com o modelo, a sorção é um fenômeno cooperativo, com a capacidade de ligação do ligante em um local da macromolécula, que pode influenciar diferentes locais funcionais da mesma (Foo and Hameed,2010).

Koble-Corrigan (1952) incorpora as características do modelo de Langmuir e Freundlich. Apesar da grande variedade de modelos de isotermas mais sofisticados relatados na literatura, é notável que a maioria deles são variações dos modelos de Langmuir e Freundlich o que faz com que nenhum desses modelos ofereçam apenas suposições sobre os mecanismos de sorção envolvidos nos processos, além disso, muitos deles não são sensitivos para as variáveis do processo ( $\mathrm{pH}$, força iônica,etc) (Cayllahua,2008).

\section{9. \\ Parâmetros termodinâmicos}

A análise dos parâmetros termodinâmicos é muito importante para fornecer informações adicionais sobre alterações energéticas inerentes associadas ao processo de adsorção. As equações mais comuns relacionam parâmetros termodinâmicos, como mudança na energia livre de gibs $\left(\Delta \mathrm{G}^{\circ}\right)$, entalpia $\left(\Delta \mathrm{H}^{\circ}\right)$, e entropia $\left(\Delta S^{\circ}\right)$ (M.J. Ahmed,2016).

Um valor negativo de $\Delta \mathrm{H}$ implica que o fenômeno de adsorção é exotérmico, enquanto um valor positivo implica que o processo de adsorção é endotérmico. $O$ processo de adsorção no sistema sólido-líquido é uma combinação de dois processos: (a) a dessorção das moléculas de solvente (água) previamente adsorvida, e (b) a adsorção das espécies do adsorvato. Em um processo endotérmico, a espécie adsorvida tem que deslocar mais de uma molécula de água para sua adsorção e isso resulta na endotermicidade no processo de adsorção. Portanto, $\Delta \mathrm{H}$ será positivo. Em um processo exotérmico, a energia total absorvida na quebra de ligação é menor que a energia total liberada na ligação entre o adsorvato e o adsorvente, resultando na liberação de energia extra na forma de calor. Portanto $\Delta \mathrm{H}$ será negativo. A magnitude de $\Delta \mathrm{H}$ pode dar uma idéia 
sobre o tipo de sorção. O calor desenvolvido durante a adsorção física é da mesma ordem de grandeza que os aquecedores de condensação, isto é, (2,1$20,9 \mathrm{KJ} / \mathrm{mol}$ ) enquanto que os aquecedores de quimissorção geralmente caem numa faixa de $80-200 \mathrm{KJ} / \mathrm{mol}$.

Já a um valor positivo de $\Delta S$ reflete a afinidade do adsorvente pelas espécies metálicas. Além disso, um valor positivo de $\Delta S$ sugere maior ordem de aleatoriedade na interface sólido/solução com algumas mudanças estruturais no adsorvato e no adsorvato. As moléculas de solvente adsorvidas, que são deslocadas pelas espécies de adsorvato, ganham mais entropia de translação do que a perdida pelos íons/moléculas de adsorvato, permitindo assim a prevalência de aleatoriedade no sistema. $O$ Valor de $\Delta S$ positivo também corresponde a um aumento no grau de liberdade das espécies adsorvidas. Um valor negativo de mudança de entropia $\Delta S$ também implica uma diminuição da desordem na interface sólido/líquido durante o processo de adsorção, fazendo com que os íons de adsorvato migrem da fase sólida para a fase líquida. Portanto, a quantidade de adsorvato que pode ser adsorvida diminuirá.

O fluxo de energia entre sistema e vizinhança pode ser empregado com critério de espontaneidade. Segundo Bansal \& Goyal (2005), geralmente os fenômenos adsortivos são processos espontâneos e exotérmicos com uma diminuição na entropia.

Sendo assim, valores de $\Delta G<0$, mostram indícios que o processo ocorrerá espontaneamente, embora não se possa prever o tempo necessário em que ele ocorrerá. Os parâmetros termodinâmicos de sorção mais explorados podem ser obtidos pelas Equações 23, 24 e 25.

$$
\begin{gathered}
\frac{\partial\left(\ln K_{a d s}\right)}{\partial\left(T^{-1}\right)}=-\frac{\Delta H_{a d s}}{R} \\
\ln K_{a d s}=\frac{\Delta S_{a d s}}{R}-\frac{\Delta H_{a d s}}{R T} \\
\Delta G_{a d s}=-R T \ln K_{a d s}
\end{gathered}
$$

Em que ( $\left(K_{\text {ads }}\right)$, $\left(\Delta G_{a d s}\right)$ e $\left(\Delta H_{\text {ads }}\right)$ são respectivamente os valores de constante de equilíbrio, variação da energia livre de Gibs e entalpia no processo de adsorção, em que T é a temperatura absoluta dada em (K), R é a constante dos 
gases $\left(8,314\left(\mathrm{~J} \cdot \mathrm{mol}^{-1} \cdot \mathrm{k}^{-1}\right)\right.$ e $\mathrm{K}_{\text {ads }}(\mathrm{L} / \mathrm{g})$ é a constante de equilíbrio. Estes parâmetros podem ser estimados a partir dos dados experimentais de equilíbrio. Os valores de $\Delta H_{\text {ads }}$ e $\Delta S_{\text {ads }}$ são avaliados respectivamente a partir da inclinação e interceptação linear do gráfico entre $\ln K_{\text {ads }}$ e $1 / T$.

\subsection{0.}

\section{Cinética de adsorção}

A avaliação da cinética apresenta-se como sendo fundamental nos processos de sorção. Para este propósito, curvas da quantidade de metal adsorvido no adsorvente juntamente com o tempo (t, min) são utilizadas. A partir das curvas cinéticas, é possível verificar a rapidez com que ocorre a adsorção e examinar o mecanismo de transferência de massa.

A cinética de adsorção é uma curva ou linha que descreve a taxa de retenção ou liberação de um soluto de um ambiente aquoso para a interface de fase sólida a uma determinada dose de adsorventes, temperatura, vazão e pH.

Durante a adsorção, dois processos principais estão envolvidos; físico (fisissorção) ou químico (quimissorção). A adsorção física é resultado de forças de atração fracas (van der Waals), enquanto a quimissorção envolve a formação de uma forte ligação entre o soluto e o adsorvente que envolve a transferência de elétrons.

Diversos modelos cinéticos têm sido aplicados para examinar o mecanismo de controle da adsorção de metais em solução aquosa. Nesse sentido, obter informações sobre equilíbrio e cinética são de extrema relevância para a determinação desses dados. Porém respostas dos dados termodinâmicos só irão informar sobre os estados iniciais e finais do sistema, de modo que quem irá determinar como as variações das taxas se comportam é a cinética. (Smith,1981).

Outro parâmetro importante no estudo termodinâmico é a energia de ativação, pois determina a dependência da temperatura da taxa de reação. Quimicamente, a energia de ativação é definida como a energia que deve ser superada para que uma reação ocorra. No processo de adsorção, é definida como a energia que deve ser superada pelo íon para que as moléculas do adsorvato possam interagir com os grupos funcionais na superfície do adsorvente. A energia de ativação Ea é dada em $\mathrm{KJ} / \mathrm{mol}$ para a adsorção de um íon adsorvido sobre uma superfície adsorvente em um processo de adsorção pode ser determinada a partir de medições experimentais da constante de adsorção em diferentes temperaturas de acordo com a equação de Arrhenius. 
A magnitude da energia de ativação pode fornecer informações úteis sobre o tipo de adsorção. Dois tipos principais podem ocorrer, físicos e químicos. $\mathrm{Na}$ fisissorção, o equilíbrio é geralmente alcançado rapidamente e facilmente reversível, porque os requisitos de energia são pequenos. A quimissorção é específica e envolve forças muito mais fortes do que na fisissorção. Dois tipos de quimissorção são encontradas, as ativadas e, menos frequentemente, não ativadas. A quimissorção ativada significa que a taxa varia com a temperatura de acordo com a energia de ativação finita (entre 8,4 e 83,7 KJ/mol) na equação de Arrhenius (alta Ea). No entanto, e alguns sistemas, a quimissorção ocorre muito rapidamente, sugerindo que a energia de ativação é próxima de erro. Isso é denominado como uma quimissorção não ativada.

A Tabela 6 apresenta uma sinopse dos modelos cinéticos que foram bem ajustados aos dados experimentais para adsorção de íons metálicos utilizando diferentes adsorventes.

Tabela 6- Revisão dos modelos cinéticos que melhor se ajustam aos dados experimentais para a adsorção de metais utilizando diferentes adsorventes

\begin{tabular}{|c|c|c|c|}
\hline Adsorvente & $\begin{array}{c}\text { Íon } \\
\text { metálico }\end{array}$ & $\begin{array}{l}\text { Modelo } \\
\text { cinético }\end{array}$ & Referência \\
\hline Palygorskita & $\mathrm{Fe}(\mathrm{III})$ & PS2 & Middea et al (2013) \\
\hline Palygorskita & $\mathrm{Ni}(\mathrm{II})$ & PS2 & Bourliva et al (2018) \\
\hline Vermiculita & $\mathrm{Cu}(\mathrm{II})$ & PS2 & Bourliva et al (2018) \\
\hline Casca de Toranja & $\mathrm{Ce}(\mathrm{III})$ & PS2 & Torab et al (2015) \\
\hline Casca de caranguejo & $\mathrm{Ce}(\mathrm{III})$ & PS2 & Varshini et al (2015) \\
\hline $\begin{array}{l}\text { Biohydrogel modificado com } \\
\text { esporopollenin }\end{array}$ & $\mathrm{Ce}(\mathrm{III})$ & PS2 & Varshini et al (2014) \\
\hline EDTA- $\beta$-ciclodextrina & $\mathrm{Ce}(\mathrm{III})$ & PS2 & Zhao et al (2016) \\
\hline Stichococcus bacillaris & $\mathrm{La}(\mathrm{III})$ & PS1 & Birungi et al (2014) \\
\hline Hidroxiapatita & $\mathrm{Eu}(\mathrm{III})$ & PS2 & $\begin{array}{c}\text { Granados-correa et } \\
\text { al (2012) }\end{array}$ \\
\hline Óxido de grafeno & $\mathrm{Eu}(\mathrm{III})$ & PS2 & Yao et al (2016) \\
\hline Chlorella vulgaris & $\mathrm{La}(\mathrm{III})$ & PS2 & Birungi et al (2014) \\
\hline Alginato de cálcio & $\mathrm{Nd}(\mathrm{III})$ & PS2 & Wang et al (2014) \\
\hline $\begin{array}{l}\mathrm{SiO}_{2} / \mathrm{UF} \text { impregnado com } \\
\text { extratante organofosforado }\end{array}$ & $\mathrm{Nd}(\mathrm{III})$ & PS2 & Naser et al (2015) \\
\hline $\begin{array}{l}\text { Sargassum wightii (alga } \\
\text { marrom) }\end{array}$ & $\operatorname{Pr}(I I I)$ & PS1 & $\begin{array}{l}\text { Vijayaraghavan et al } \\
\text { (2015). }\end{array}$ \\
\hline
\end{tabular}


PS1- Pseudo primeira ordem/ PS2- Pseudo segunda ordem

Identificar os mecanismos de sorção e a sua etapa controladora que incluem transporte de massa e processos de reações químicas, são fundamentais de maneira que modelagens cinéticas são realizadas para ajuste dos dados experimentais.

O processo de adsorção inclui algumas fases que são caracterizadas pelo movimento do íon metálico para o adsorvente e para dentro dele. É por isso que, para entender os mecanismos do processo de adsorção e descobrir o passo determinante da taxa, modelos cinéticos devem ser estudados. Da mesma forma, como no caso das isotermas de adsorção (Langmuir, Freundlich), a cinética de tem sido mais frequentemente ajustada pelos dois modelos: equações de pseudoprimeira e pseudo-segunda ordem. Esses modelos eram originalmente propostos empiricamente e só recentemente foram examinados em sua base teórica (Azizian et al.,2008). Além dos modelos pseudo-cinéticos, que assumem que a adsorção é governada pela reação de superfície, uma variedade de modelos baseados em difusão foi derivada. (Ho et al.,2000).

\section{PSEUDO PRIMEIRA ORDEM}

O modelo apresentado foi proposto por Lagergren (1898). Entretanto, somente em 1990 esse modelo foi utilizado no caso da remoção de Ni (II) pela wollastonita por Sharma et al.,(1990). O modelo também foi chamado de modelo de pseudo-primeira ordem devido ao fato de estar associado à cinética de adsorção de um sítio governada pela taxa da reação de superfície.

A principal sugestão do modelo é que não haja interações entre os íons e cada íon sorve em um local. O modelo também aprova que a cobertura não influencia a energia de adsorção e a concentração de uma substância é constante. Essa teoria projeta o processo de adsorção como uma monocamada na superfície adsorvente (Largitte \& Pasquier,2016). Reações de pseudo primeira ordem são bem modeladas aos dados experimentais quando a concentração de um determinado reagente for muito maior que a de outro. Geralmente, acontece quando as reações são em fase aquosa e um dos componentes participa como reagente e diluente ao mesmo tempo. A equação da taxa do modelo de pseudoprimeira ordem (Ajmal et al, 2000) é definida pela Equação 26. 


$$
\frac{d q_{t}}{d t}=k_{1}\left(q_{e}-q_{t}\right)
$$

Onde $q_{t}$ é a quantidade de adsorvato retido no tempo "t" (mg/L);

$q_{e}$ é a quantidade de adsorvato retido $\mathrm{n}$ equilíbrio ( $\left.\mathrm{mg} / \mathrm{L}\right)$;

$k_{1}$ é a constante da reação de pseudo primeira ordem $\left(\mathrm{min}^{-1}\right)$;

Ao integrar a Equação 26 nas seguintes condições de contorno $t=0$ até $t=t$ e $q_{t}=q_{t}$ obter-se á uma forma linear do modelo de pseudo primeira ordem:

$$
\ln \left(q_{e}-q_{t}\right)=\ln q_{e}-k_{1} t
$$

O plote linear de $\ln \left(q_{e}-q_{t}\right)$ versus t pode sugerir uma possível aplicação deste modelo. A constante $k_{1}$. Ao aplicar o logaritmo decimal, a Equação 27 pode ser descrita como:

$$
\log \left(q_{e}-q_{t}\right)=\log q_{e}-\frac{k_{1}}{2,303} t
$$

\section{PSEUDO SEGUNDA ORDEM}

Blanchard et al.,(1984) propuseram a Equação para o modelo de segunda ordem. Inicialmente, este modelo foi utilizado para descrever a remoção de metais pesados da água pelas zeólitas. As premissas do modelo de pseudo segunda ordem assemelham-se as sugestões do primeiro modelo. No entanto, a principal diferença entre eles é que neste utiliza-se a taxa de segunda ordem na Equação 29. Deve-se mencionar que a constante da taxa de pseudo segunda ordem é igual à concentração inicial de uma substância em uma solução (Azizian et al.,2009).

A Equação 29 representa o modelo de pseudo-segunda ordem. As formas lineares e não lineares do modelo foram obtidas pela integração da equação inicial.

$$
\frac{d q_{t}}{d t}=k_{2}\left(q_{e}-q_{t}\right)^{2}
$$


Onde $q_{t}$ é a quantidade de adsorvato retido no tempo "t" (mg/L);

$q_{e}$ é a quantidade de adsorvato retido $\mathrm{n}$ equilíbrio ( $\left.\mathrm{mg} / \mathrm{L}\right)$;

$k_{2}$ é a constante de velocidade da reação de pseudo segunda ordem (g.mg $\left.{ }^{1} \cdot \min ^{-1}\right)$;

Ao integrar a Equação 29 nas seguintes condições de contorno $t=0$ até $t=t$ e $q_{t}=0$ até $q_{t}=q_{t}$ obter-se a Equação 30:

$$
\frac{1}{\left(q_{e}-q_{t}\right)}=\frac{1}{q_{e}}+k_{2} t
$$

A equação acima é apresentada na forma linearizada pela Equação 31:

$$
\frac{t}{q_{t}}=\frac{1}{k_{2} q^{2}}+\frac{1}{q_{e}}
$$

Observa-se que a partir da Equação 31 o plote linear de $\left(\mathrm{t} / \mathrm{q}_{\mathrm{t}}\right)$ versus t mostra uma relação linear, apresentando como coeficiente angular $\left(1 / \mathrm{q}_{\mathrm{e}}\right)$ e coeficiente linear $\left(1 / k_{2} q_{e}^{2}\right)$.

O modelo de pseudo segunda é capaz de estimar muito bem os valores experimentais de $q_{e}$ e não é muito sensível à influência dos erros aleatórios (Plazinski et al.,2009). Esta é também uma das razões pelas quais o modelo de segunda ordem é geralmente melhor ajustado aos dados experimentais do que 0 modelo de primeira ordem. 


\section{5 \\ Materiais e métodos}

Neste item serão descritos os materiais, equipamentos e procedimentos utilizados no estudo do processo de adsorção para remoção de $\mathrm{Nd}$ (III) usando a palygorskita como adsorvente bem como a metodologia experimental desenvolvida para o estudo em questão.

À posteriori será apresentada a metodologia empregada para a realização das condições operacionais do estudo da influência das variáveis estudadas nesta pesquisa.

A metodologia adotada visa determinar os constituintes mineralógicos da palygorskita e avaliar os fatores que interferem na qualidade do minério. Durante o desenvolvimento do estudo foi determinada a distribuição granulométrica, difratometria de raios $-X(D R X)$, espectrometria de fluorescência de raios $X(F R X)$, capacidade de troca catiônica (CTC), análise termogravimétrica (TG-DTG), medidas referentes a carga superficial (potencial zeta), Espectroscopia vibracional no infravermelho, microscopia eletrônica de varredura (MEV), determinação da área superficial (BET).

\section{1.}

\section{Preparação da amostra}

Esta pesquisa foi realizada com amostra oriunda do município de Guadalupe localizado no Piauí/Brasil onde encontram-se os principais depósitos de palygorskita no Brasil. A amostra representativa de aproximadamente, $2 \mathrm{~kg}$ foi coletada na mina Boa Vista II pertencente à Mineração Coimbra Ltda (Figura 10) e enviada ao Centro de Tecnologia Mineral (CETEM/MCTI) para o desenvolvimento desta pesquisa. 


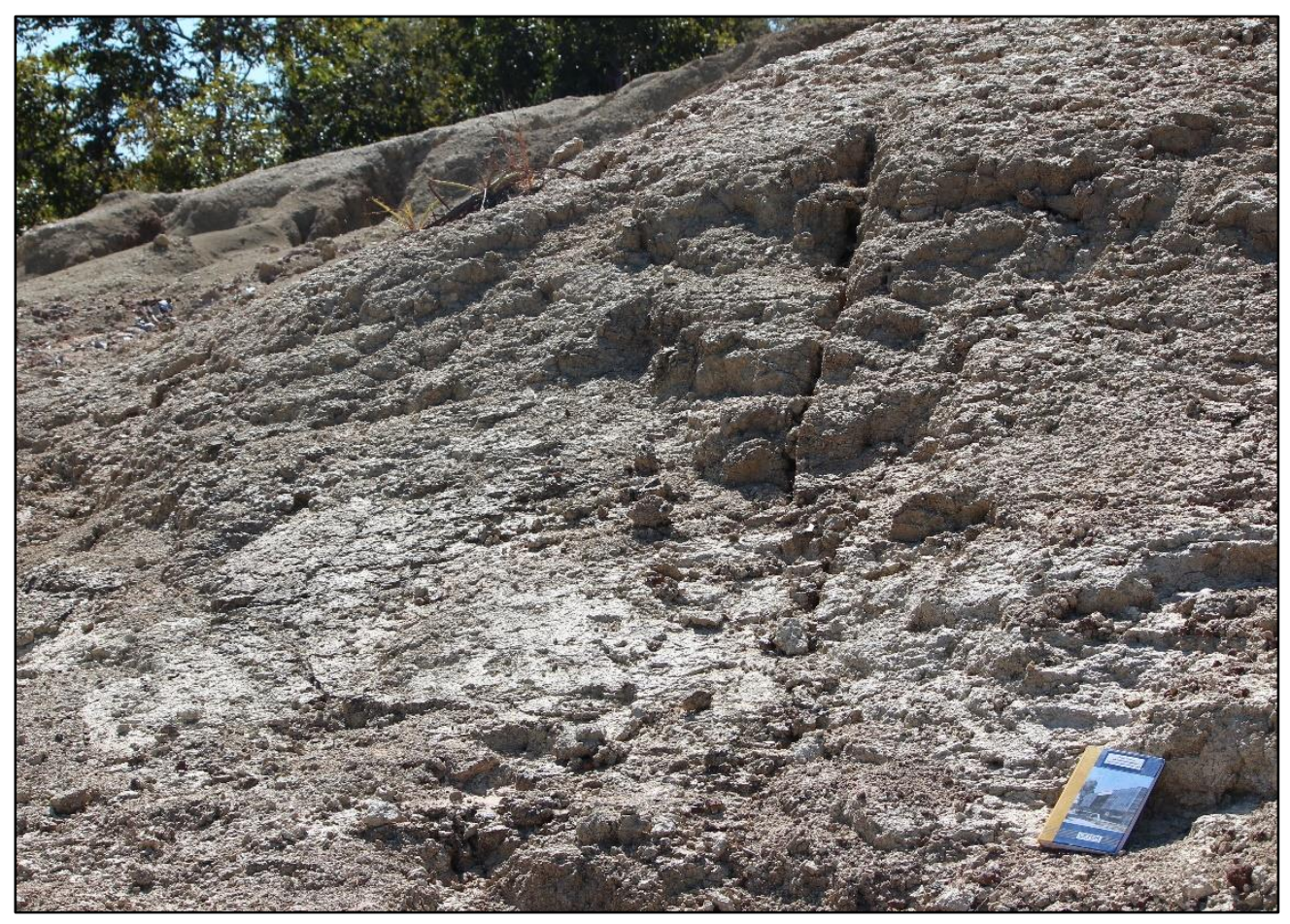

Figura 10 - Frente da lavra da Mina Boa Vista II, local onde foi coletada a amostra de palygorskita

A amostra ROM (rum of mine) de aproximadamente $2 \mathrm{~kg}$ foi submetida a várias etapas de concentração e beneficiamento físico visando eliminar as impurezas mineralógicas presentes no minério e concentrar 0 mineral palygorskita. Incialmente, a amostra foi britada em um britador de mandíbula de alta frequência com, aproximadamente $0,4 \mathrm{~mm}$ de abertura, para a desagregação da amostra e posteriormente, homogeneizada em pilha prismática. Em seguida uma alíquota da amostra foi submetida a etapa de moagem à úmido (polpa 1:1amostra: água), em moinho de barras de aço inoxidável, contendo 10 barras de 20 mm de diâmetro, a 88 rpm por 30 min.

Em seguida foi realizada classificação granulométrica à úmido, em um peneirador vibratório, operando a, aproximadamente, 684,5 rpm, equipado com um conjunto de peneiras de 300,212,150,106,75,53 e $45 \mu \mathrm{m}$. As frações correspondentes a cada peneira foram secas em estufa a $50^{\circ} \mathrm{C}$.

A fração da amostra abaixo de $45 \mu \mathrm{m}$ foi filtrada em filtro prensa a uma pressão de 5 bar e, posteriormente submetida à secagem em estufa $\left(50^{\circ} \mathrm{C}\right)$, após ser retirada da estufa e resfriada, foi desagregada em moinho de disco.

Para a análise química, as alíquotas precisam apresentar granulometria abaixo de $106 \mu \mathrm{m}$, portanto foi necessária a cominuição das alíquotas com granulometria acima de $106 \mu \mathrm{m}$, isto é, 300,212 e $150 \mu \mathrm{m}$, assim como a amostra 
ROM. A moagem foi realizada em moinho de disco, no tempo de 1 minuto, operando em circuito fechado com uma peneira de abertura de $106 \mu \mathrm{m}$.

A separação magnética à úmido foi realizada com a amostra de granulometria abaixo de $45 \mu \mathrm{m}$, em separador magnético BOXMAG RAPID com campo de alta intensidade, da ordem de $15 \mathrm{kGauss,} \mathrm{e} \mathrm{matriz} \mathrm{ferromagnética.} \mathrm{Após}$ a separação magnética, a fração magnética (BVII-MAG) e não magnética (BVIINMAG) foram filtradas em filtro prensa ( 5 bar) e secas em estufa $\left(50^{\circ} \mathrm{C}\right)$. Após a secagem, as frações foram desagregadas e homogeneizadas em pilhas prismática para a retirada de alíquotas representativas de ambas as frações, e então, caracterizadas pelas técnicas de Difratometria de raios $X(D R X)$ e fluorescência de raios $X$ (FRX).

A fração não magnética foi desagregada em moinho de disco (800 rpm) por dois minutos e submetida a uma nova classificação granulométrica à úmido com o uso da peneira de $20 \mu \mathrm{m}$. A fração abaixo de $20 \mu \mathrm{m}$ (BVII) foi filtrada, em seguida, submetida à secagem em estufa a $60^{\circ} \mathrm{C}$. Desagregou-se a fração, cuidadosamente com auxílio de pistilo e grau e em moinho planetário. A fração não magnética com granulometria acima de $20 \mu \mathrm{m}$ (BVII- MAG >20 $\mu \mathrm{m}$ ) foi estocada.

A amostra BV II foi caracterizada pelas técnicas de DRX, FRX, determinação da CTC pelo método de azul de metileno, TG-DTG, medidas de carga superficial (potencial zeta), FTIR, MEV, análise texturais e distribuição granulométrica.

No fluxograma da Figura 11 é possível observar as etapas envolvidas no processo de beneficiamento, bem como as técnicas de caracterização utilizadas na amostra BV II. 


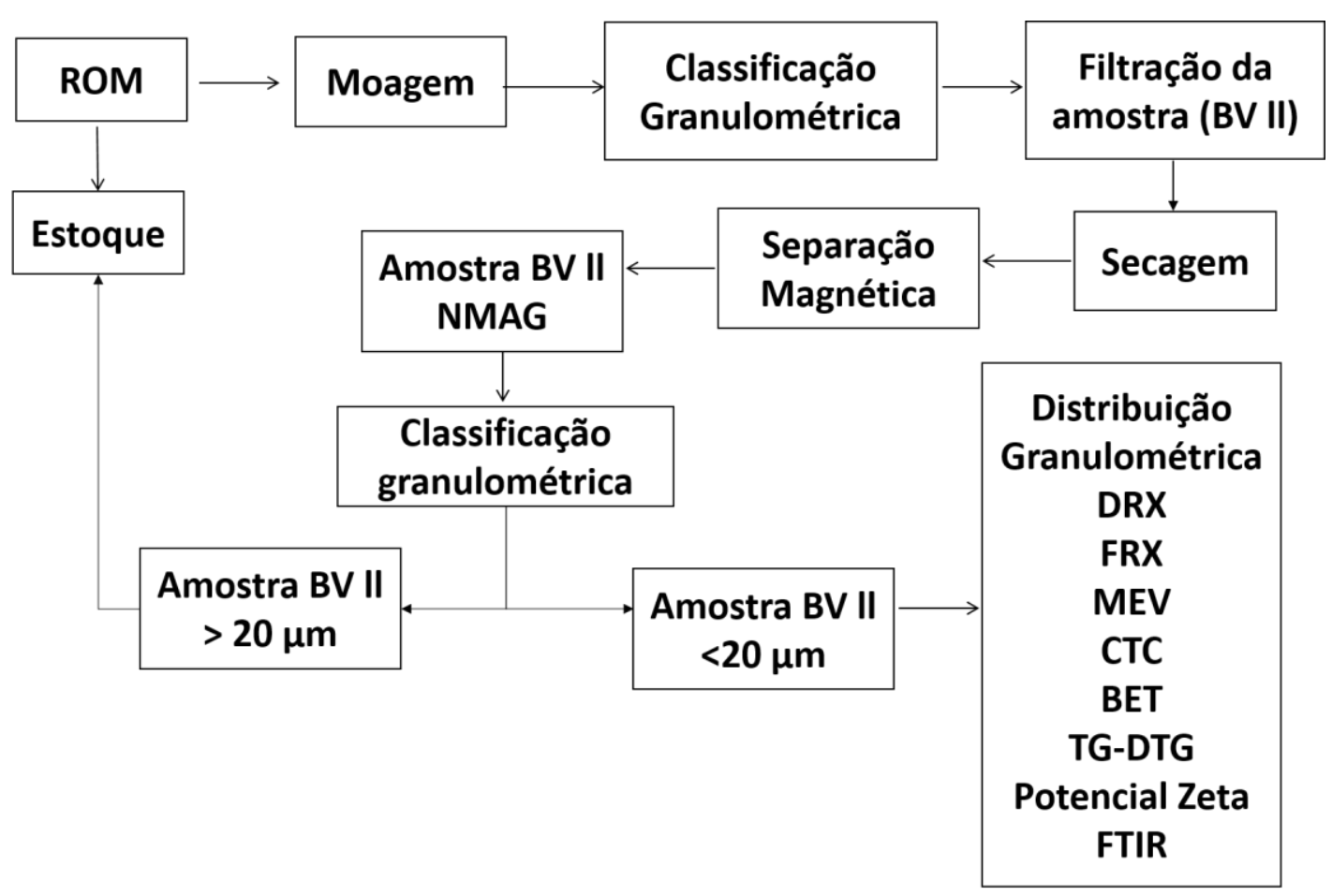

Figura 11- Fluxograma de beneficiamento da palygorskita

\section{2.}

\section{Caracterização da palygorskita}

A amostra ROM foi caracterizada por meio da técnica de DRX. Já a amostra BV II, fração mais pura obtida após as etapas de beneficiamento, foi caracterizada pelas técnicas que seguem.

\subsection{1.}

\section{Distribuição granulométrica}

A difração à laser mede as distribuições de tamanho por medição da variação angular na intensidade da luz difundida à medida que um feixe de laser interage com as partículas dispersas da amostra.

A análise de distribuição granulométrica à laser foi realizada no equipamento Mastersize 2000, da marca Malvern sendo a análise realizada no CETEM. A amostra foi dispersa em água deionizada para desagregação das partículas e posteriormente foi colocada no equipamento. A técnica do equipamento determina o volume das partículas por meio da difração a laser. 


\subsection{2. \\ Difratometria de raios $X(D R X)$}

A técnica de difração de raios $X$ (DRX) é uma das mais utilizadas para determinação de fases cristalinas e é considerada favorável para caracterização microestrutural, pois é simples, rápida e tem um ótimo grau de confiabilidade. Os perfis obtidos nessa análise caracterizam uma fase cristalina. (Albers et al,2002).

$\mathrm{O}$ princípio físico da análise por Difratometria de raios $\mathrm{X}$ utiliza os raios $\mathrm{x}$ para determinar propriedades químicas das amostras. No caso do DRX os raios $X$ interagem com a superfície das amostras e nesta interação ocorre o fenômeno da difração. Os raios $X$ que tem determinado comprimentos de onda, passam pelos planos cristalográficos das moléculas formadoras das amostras (que tem determinada distância) e formam um ângulo entre os raios $X$ difratados e o plano cristalográfico. Desta forma, a difração de raios $X$ é uma análise usada na identificação de estruturas cristalinas como mencionado anteriormente. Uma vez que planos de difração, distâncias interplanares e densidades são características singulares de cada estrutura cristalina a difração gerada na interação também será única (Erdócia et al.,2011).

A Lei de Bragg demonstra a relação entre comprimento da onda, distância interplanar e ângulo formado entre o plano cristalográfico e os raios $X$ (Cullity \& Graham,2011).

Diversas variáveis influenciam na intensidade do feixe difratado e no alargamento dos mesmos. Considerando condições ideais nas quais o cristal fosse perfeito e que os raios $X$ fossem monocromáticos não haveria alargamento no perfil de difração. A Figura 12 representa esquematicamente o funcionamento do equipamento de DRX (Gobbo, 2009).

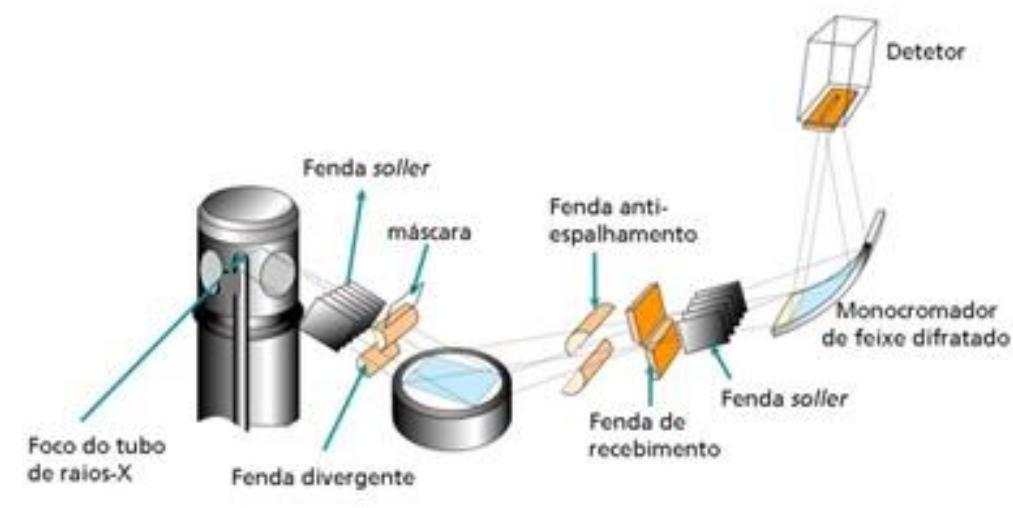

Figura 12- Desenho esquemático do funcionamento do DRX. Fonte: Gobbo,2009 
O resultado da análise por DRX são difratogramas que representam as intensidades obtidas em ângulo $2 \theta$ que correspondem a difração de um feixe de raios $X$ nas estruturas interplanares dos diversos minerais formadores da rocha. A distribuição dos picos no difratograma é devido aos diferentes ângulos de cada mineral, o que permite identifica-los.

Obtidos pelo método do pó, os difratogramas de raios $X$ das amostras de palygorskita foram coletadas pelo equipamento Bruker-D4 Endeavor, nas condições operacionais que seguem: radiação Co Ka (40 kV/40 mA); velocidade do goniômetro de $0,02^{\circ}(2 \theta)$ por passo com tempo de contagem de $0,5 \mathrm{~s}$ por passo e coletados de 5 a $70^{\circ}(2 \theta)$. Através do software Bruker AXS Diffrac Plus foi possível realizar as interpretações qualitativas do espectro por meio de comparação com padrões contidos no banco de dados PDF02 (ICDD, 2006). As interpretações dos picos foram efetuadas por comparação com padrões contidos no banco de dados do software do CETEM.

\subsection{3.}

\section{Espectrometria de fluorescência de raios X- (FRX)}

A espectrometria de fluorescência de raios $X(F R X)$ é um método de análise química instrumental, com grande aplicabilidade na geoquímica e para análise de grande quantidade de elementos químicos diferentes em amostras de minério. Este método é usado rotineiramente para caracterização de amostras em estado sólido, com alta precisão analítica em suas determinações. (Yamamoto et al.,2008).

O princípio físico da análise de FRX é embasado na teoria de que através de uma fonte de energia externa (seja por tubo ou radionuclídeos), elétrons mudam de camadas na estrutura da eletrosfera. Quando um elétron de uma camada mais externa ocupa a vacância deixada por um elétron de uma camada mais interna (salto quântico) há liberação de energia (fóton). Esta onda eletromagnética (raios $\mathrm{X}$ ) tem um comprimento de onda característico, isto é, intrínseco a cada elemento químico (Varela et al.,2005). Isto permite a identificação dos elementos químicos e suas concentrações nas amostras.

Esta análise é considerada quali-quantitativa, uma vez que determina não só a presença dos elementos químicos como também a concentração dos mesmos (Nascimento \& Virgílio,1999). Entretanto, alguns equipamentos permitem análise semi-quantitativa na curva universal, que foi a utilizada neste trabalho. 
A metodologia de preparação das amostras deve levar em consideração fatores que corroborem com a certeza de suas respostas. Ou seja, a exatidão das análises será dependente da calibração, preparação e representatividade da amostra. Dessa forma, as amostras analisadas passaram previamente pelas etapas de quarteamento e homogeneização adequadas para otimização dos resultados.

A amostra pode ser prensada na sua preparação para a análise por FRX, este método é bastante utilizado por sua rapidez. O tamanho das partículas influencia a análise por FRX de forma significativa (Criss,1976).

Portanto, como a palygorskita tem granulometria fina, a amostra foi preparada com o auxílio do aglomerante ácido bórico $\mathrm{H}_{3} \mathrm{BO}_{3}$ na proporção $0,3 \mathrm{~g}$ do ácido e $2,0 \mathrm{~g}$ da amostra seca à $100^{\circ} \mathrm{C}$ em prensa automática de modelo VANEOX (molde de $20 \mathrm{~mm}$ ) da Fluxana do CETEM com as seguintes condições operacionais: pressão de 20 toneladas de pressão e $30 \mathrm{~s}$. As análises foram realizadas em espectrômetro por fluorescência de raios $X$, modelo AXIOS MAX panalytical.

\subsection{4. \\ Microscopia eletrônica de Varredura - (MEV)}

A microscopia eletrônica de varredura é uma técnica utilizada para a análise micro estrutural em amostras sólidas (Dedavid et al,2007). Mesmo sendo um equipamento de alta complexidade de seus mecanismos o resultado obtido é uma imagem de clara interpretação. O MEV mostra uma imagem tridimensional, podendo, em alguns casos, combinar a análise micro estrutural com a microanálise química, e até análise de fraturas, isso é suficiente para entendermos a importância dessa tecnologia nas análises das argilas.

Permitir analisar qualitativamente, semi quantitativa e quantitativa a partir da emissão de raios $X$ característicos através de um sistema chamado de EDS (Espectroscopia de Energia Dispersiva) da composição química de partículas com pontos de até $2 \mu \mathrm{m}$ de diâmetro, correlação entre a composição química e morfológica da amostra é uma das vantagens de se utilizar o MEV.

Por não serem condutoras de corrente elétrica, as amostras devem ser previamente metalizadas com um material condutor (ouro ou prata) sobre a superfície da amostra, para que haja a possibilidade assim da condução de corrente elétrica. (Veneu,2010). 
O microscópio eletrônico de varredura (MEV) utilizado foi o modelo FEI Quanta 250 FEG no Instituto Militar de Engenharia (IME) utilizando o programa Genesis GSR-XT instalado no microscópio. A preparação da amostra foi realizada pelo método do pó, e foram metalizadas com ouro utilizando o equipamento BACTEC-SCD005 Sputter Coater.

\subsection{5.}

\section{Capacidade de troca catiônica - (CTC)}

A capacidade de troca catiônica (CTC) mede a quantidade de cátions que um argilomineral pode adsorver e trocar. Esta medida é feita com e expressa $\mathrm{meq} / 100 \mathrm{~g}$ de amostra. Isto ocorre devido ao desequilíbrio de cargas pelas substituições isomórficas na estrutura onde a ligação de valência é quebrada e ocorre uma interação com as cargas de onde a ligação foi quebrada (Sampaio et al.,2007).

Quando o argilomineral entra em contato com a $\mathrm{H}_{2} \mathrm{O}$, facilita que cátions orgânicos ou inorgânicos infiltrem entre as partículas e lamelas, desse modo os cátions saem e entram em reações de troca catiônica sem destruição da estrutura cristalina do mineral (Guerra et al.,2007). O tamanho das partículas dos argilominerais possui uma área grande área superficial, alguns argilominerais apresentam área superficial lamelar estrutural 2:1 como as esmectitas, ou em canais abertos como de estrutura cristalina como as da palygorskita. Esta grande superfície com ligações químicas não saturadas interage com grandes variedades de substâncias, portanto possuem como característica um comportamento plástico quando misturada com água, onde ocorre o inchamento e aumento de volume. Cátions trocáveis influenciam as propriedades físico-químicas dos argilominerais (Albanez,2008).

O método mais usado para determinar a CTC consiste em saturar uma amostra do material adequado e determinar a quantidade fixada desse cátion. A CTC da amostra BV-II foi obtida segundo o método de titulação utilizando azul de metileno como reagente que em solução aquosa promove a troca catiônica, onde os cátions inorgânicos trocáveis do argilomineral (usualmente $\mathrm{Na}^{+}, \mathrm{K}^{+}, \mathrm{Ca}^{2+}, \mathrm{Mg}^{2+}$ ) Chen et al.,(2009) são substituídos pelo cátion orgânico do azul de metileno.

Para realização desta medida, cerca de $2 \mathrm{~g}$ da amostra previamente seca em estufa a $60^{\circ} \mathrm{C}$ foi adicionada em um béquer contendo $30 \mathrm{~mL}$ de água deionizada em agitador magnético para promover homogeneização. $\mathrm{O} p \mathrm{H}$ da suspensão da argila foi ajustado com o auxílio de solução de ácido sulfúrico $(0,1$ 
M) com o intuito de se estabilizar em uma faixa que ia de 2,5 a 4,0 e então iniciouse a titulação com a solução de azul de metileno $0,01 \mathrm{~mol} / \mathrm{L}$.

Adicionou-se a suspensão $10 \mathrm{~mL}$ da solução de azul de metileno, e com um auxílio de um conta-gotas a suspensão foi gotejada em papel de filtro para observação física da gota. Durante um intervalo de $1 \mathrm{~min}$ foi adicionado $1 \mathrm{~mL}$ da solução de azul de metileno até o ponto de viragem, ou seja, até que tivesse sido observada a formação de um halo azul ao redor da gota. A formação desse halo ocorre devido à saturação do azul de metileno que não é adsorvido no papel de filtro. Assim, por meio do cálculo do índice do azul de metileno (IAM), Equação 32, é possível determinar a CTC da amostra.

$$
I A M=\frac{0,01 \times V}{2} \times 100
$$

Onde $\mathrm{V}$ representa o volume utilizado na titulação.

\subsection{6. \\ Determinação da área superficial - (BET)}

A determinação da área superficial pode ser realizada com a análise de BET (Brunauer, Emmett e Teller), que é utilizada com objetivo de determinar propriedade texturais de materiais porosos, como por exemplo: tamanho de poro, sua distribuição e área superficial (Sing et al.,1985). A técnica permite a determinação da quantidade de adsorvato necessária para formar uma monocamada sobre a superfície a ser medida.

As propriedades texturais obtidas da amostra BV II de palygorskita foi realizada através da fisissorção de nitrogênio $\left(\mathrm{N}_{2}\right)$ a $-196{ }^{\circ} \mathrm{C}(77 \mathrm{~K})$. As análises foram realizadas no equipamento ASAP modelo 2000 (Micrometrics ${ }^{\circledR}$ ) do CETEM, utilizando aproximadamente $300 \mathrm{~g}$ de amostra. O pré-tratamento das amostras consistiu de secagem a $120^{\circ} \mathrm{C}$ sob vácuo de $1 \times 10^{-6} \mathrm{mmHg}$ durante o período de $24 \mathrm{~h}$ com o intuito de eliminar a água fisiossorvida. Posteriormente a esse prétratamento foi realizado a análise propriamente dita onde foram obtidas isotermas de adsorção e dessorção através da variação da pressão parcial de $\mathrm{N}_{2}$. A partir dessas isotermas, as áreas específicas foram calculadas pelo método BET e a distribuição de tamanho de poros foi obtida a partir da isoterma de dessorção de $\mathrm{N}_{2}$ pelo método B.J.H (Barret-Joyner-Halenda). 


\subsection{7.}

\section{Análise Termogravimétrica TG-DTG}

A técnica de análise térmica via termogravimetria (TG) é analítica qualitativa e quantitativa que permite avaliar as modificações no perfil da curva que podem ocorrer durante aquecimento em determinada massa da substância, objetivando estabelecer em qual faixa de temperatura a amostra sofrerá decomposição (lonashiro \& Giolito,2005). A partir das curvas de TG pode-se extrair maiores informações como por exemplo, a sua derivada (DTG), que expressa a primeira derivada da variação da massa em relação ao tempo (dm/dt), que é registrada em função do tempo ou da temperatura (Matos et al.,2009).

As curvas das análises termogravimétricas foram obtidas em balança termogravimétrica de modelo STA 449 F3 da Netzsch, utilizando como condições operacionais uma faixa de temperatura que foi variada de $25^{\circ} \mathrm{C}$ a $1000^{\circ} \mathrm{C}$, taxa de aquecimento de $10^{\circ} \mathrm{C} \cdot \mathrm{mim}^{-1}$, foi utilizada atmosfera inerte de $\mathrm{N}_{2}$, com vazão de 20 $\mathrm{mL} / \mathrm{min}$.

\subsection{8. \\ Medidas de carga superficial (potencial Zeta)}

Os argilominerais tendem a apresentar carga superficial quando presentes em suspensões aquosas. Por meio do potencial Zeta em diferentes valores de $\mathrm{pH}$ é possível obter conhecimento sobre a carga superficial da partícula (Schons,2019).

Medições de potencial zeta da amostra de palygorskita foram realizadas para determinar a carga superficial da amostra de acordo com a variação do $\mathrm{pH}$ (2 a 11) antes e depois do contato com os íons metálicos. A análise foi realizada usando o equipamento Malvern Zetasizer do CETEM com o objetivo de medir a mobilidade eletroforética das partículas, a partir da equação de Smoluchowski a qual está inserida no próprio equipamento e converte a relação entre velocidade e o campo elétrico aplicado em potencial zeta (Veneu,2010).

Para a realização das medidas, foi utilizado $10^{-3} \mathrm{M}$ de $\mathrm{KCl}$ como eletrólito indiferente. A suspensão foi acondicionada com agitação mecânica por aproximadamente 5 minutos, para posterior medição do $\mathrm{pH}$. O valor de $\mathrm{pH}$ desejado para a medição foi ajustado com soluções diluídas de $\mathrm{HCl}$ e $\mathrm{NaOH}$ Após estas medições, as soluções são introduzidas dentro da célula eletroforética, 
evitando a formação de bolhas de ar dentro desta célula. Os eletrodos são então conectados ao sistema de medição e a análise foi realizada.

\subsection{9.}

\section{Espectroscopia no infravermelho- (FTIR)}

Considerada uma técnica qualitativa a espectroscopia vibracional no infravermelho é utilizada para identificar grupos funcionais presentes em uma amostra. O princípio desta técnica baseia-se na energia necessária para ocorrer as transições vibracionais, que ocorrem na região do infravermelho do espectro eletromagnético (Silvertein et al.,1979).

As conclusões desta técnica são respaldadas pela complementação de outras técnicas de caracterização como por exemplo a fluorescência de raios $X$ (FRX), isso é explicado pelo fato de que diferentes grupos funcionais apresentam bandas de infravermelho com regiões próximas umas às outras se tornando mais várias possibilidades de interpretação (Freitas,2014).

As análises por espectroscopia vibracional no infravermelho foram realizadas no espectrofotômetro com transformada de Fourier, marca Nicolet 6700 - FTIR do Instituto de Química da UFRJ, com registros de 64 varreduras em uma faixa de comprimento de 4.000 a $400 \mathrm{~cm}^{-1}$, em uma matriz de brometo de potássio $(\mathrm{KBr})$ em uma relação de $1 \%(\mathrm{~m} / \mathrm{m})$.

\section{3.}

\section{Preparo da solução estoque}

A solução de Neodímio usada foi preparada a partir do óxido de neodímio (III) - fornecido pela Sigma Aldrich, 99,9\%, com massas estimadas para concentração de solução-estoque de TR a $5,0 \mathrm{~g} \mathrm{~L}^{-1}$. Desse modo, obtendo-se uma solução estoque de concentração conhecida e a partir da sua diluição foram preparadas outras soluções com diferentes concentrações.

Para a preparação da solução estoque, o óxido foi calcinado a aproximadamente $800{ }^{\circ} \mathrm{C}$ por 15 minutos para remoção de possíveis carbonatos contaminantes. Posterior a este procedimento, pequenas alíquotas de $\mathrm{HNO}_{3}(6 \mathrm{M})$ foram utilizadas para solubiliza-lo sob aquecimento. Para os ensaios de adsorção em batelada as soluções utilizadas foram obtidas pela diluição das soluçõesestoque, com ajuste para $\mathrm{pH} 5,0 \mathrm{com} \mathrm{HCl}$ e $\mathrm{NaOH}$ diluídos. 
A concentração de $\mathrm{Nd}$ (III) nessas soluções foi determinada por meio da técnica de espectrometria de emissão atômica com plasma indutivamente acoplado (ICP OES) modelo Ultima 2 da Horiba Jobin Yvon. Nesta análise utilizase uma solução padrão de $\mathrm{Nd}$ (III) de concentração conhecida na ordem de mg L ${ }^{1}$ para construção de uma curva de calibração obtendo a concentração de Nd (III) em $\mathrm{mg} \mathrm{L}^{-1}$ da solução desconhecida.

Nas Tabela 7 eTabela 8 encontram-se os parâmetros do plasma do Espectômetro de emissão ótica com plasma indutivamente acoplado e do método utilizado.

Tabela 7- Parâmetros do plasma para o ICP

\begin{tabular}{c|c}
\hline \multicolumn{2}{c}{ Parâmetros do Plasma } \\
\hline Potência (W) & $1100 \mathrm{~W}$ \\
Velocidade normal da bomba (rpm) & 20 \\
Fluxo do gás do plasma (L.min $\left.{ }^{-1}\right)$ & 12 \\
Fluxo do gás de revestimento(L.min ${ }^{-1}$ ) & 0,2 \\
Fluxo do gás auxiliar (L.min $\left.{ }^{-1}\right)$ & 0,01 \\
Pressão da nebulização (bar) & 2,5 \\
Uso de humidificador de argônio & SIM \\
\hline
\end{tabular}

Tabela 8- Parâmetros do método utilizado

\begin{tabular}{c|c}
\hline \multicolumn{2}{c}{ Parâmetros do método } \\
\hline Modo de análise & Normal \\
Tempo de lavagem (s) & 40 \\
Velocidade da bomba em lavagem & Rápida \\
Tempo de transferência (s) & 35 \\
Tempo de estabilização (s) & 15 \\
Velocidade da bomba em transferência & Rápida \\
Linha de emissão (nm) & 213,682 \\
Curva analítica em $\mathbf{H N O}_{3} \mathbf{3} \% \mathbf{~ v / v}$ & $0 / 1,0 / 2,4 / 5,0 / 7,5 / 10 ~ m g / L$ \\
\hline
\end{tabular}

A calibração do ICP-OES foi feita com três diferentes soluções-padrão de TR (5,0, mg L L $\left.^{-1}\right)$, com linhas de emissão em 359,260, 395,220, 398,852 e 414,311 $\mathrm{nm}$, para neodímio. A determinação da concentração de TR foi realizada por média de duplicata para cada condição. 


\section{4. \\ Ensaios de adsorção}

Os procedimentos experimentais realizados nesta pesquisa foram abordados em forma de batelada com o objetivo de obter informações relevantes a respeito da cinética, equilíbrio e termodinâmica no processo de adsorção, as quais são de extrema importância.

Foi realizado triagem das principais variáveis envolvidas e que foram analisadas são a concentração do adsorvente, $\mathrm{pH}$, concentração do íon metálico e temperatura. Para os ensaios utilizou-se suspensão de adsorvente em $50 \mathrm{~mL}$ de solução do íon metálico em frascos Erlenmeyer com capacidade de $250 \mathrm{~mL}$ a uma agitação constante de $150 \mathrm{rpm}$ a uma temperatura de $30^{\circ} \mathrm{C}$, como mostra a Figura 13.

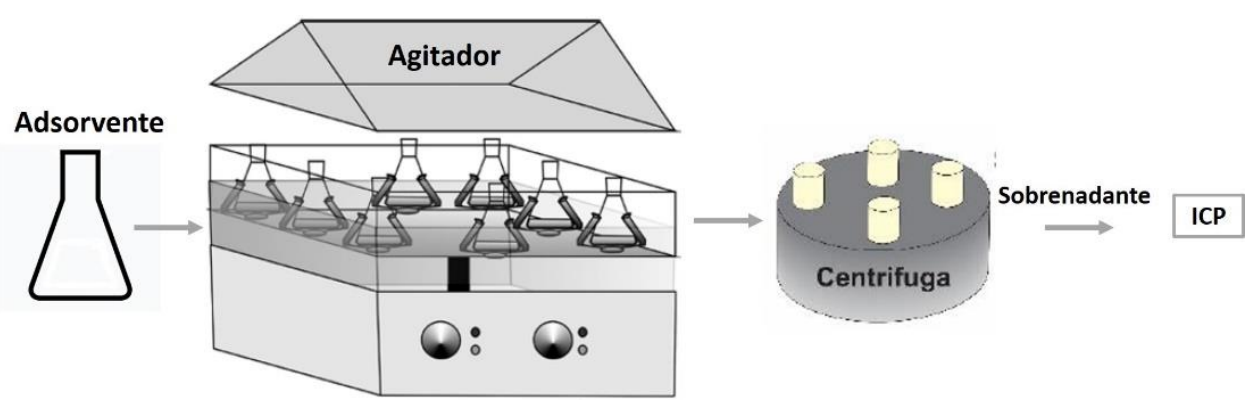

Figura 13-Desenho esquemático da adsorção realizada em batelada utilizando como adsorvente a palygorskita.

Posterior a cada ensaio a suspensão da palygorskita com o íon metálico foi concentrada por meio de centrifugação, por 15 minutos a 4000 rpm e em seguida, o sobrenadante foi encaminhado para a quantificação do íon metálico por meio da técnica de espectrometria de emissão atômica com plasma indutivamente acoplado (ICP OES). A determinação da concentração do íon metálico foi realizada por meio de duplicata para cada condição operacional.

\subsection{1.}

\section{Influência da concentração do adsorvente}

A influência da concentração do adsorvente na adsorção do $\mathrm{Nd}$ (III) em solução aquosa foi determinada, objetivando avaliar de que modo esta variável afeta no processo de adsorção, que é proporcional a área específica. Para tal ensaio, variou-se 5 diferentes concentrações iniciais em termos de massa da 
palygorskita na faixa de $0,25 \mathrm{~g}$ a 2,0 g. O efeito da dosagem do adsorvente foi avaliado a um $\mathrm{pH} 5$ e temperatura de $30^{\circ} \mathrm{C}$ e uma concentração inicial de íon metálico de $500 \mathrm{mg} / \mathrm{L}$. Na Tabela 9 está representada as condições experimentais que foram utilizadas nos ensaios.

Tabela 9-Condições experimentais para avaliação do efeito dosagem de adsorvente na adsorção do $\mathrm{Nd}$ (III)

\begin{tabular}{cc}
\hline Parâmetros & Nd(III) \\
\hline Concentração do adsorvente $(\mathrm{g})$ & 0,$25 ; 0,5 ; 1 ; 1,5 ; 2$ \\
Concentração inicial do íon metálico $(\mathrm{mg} / \mathrm{L})$ & 500 \\
Temperatura $\left({ }^{\circ} \mathrm{C}\right)$ & 30 \\
Agitação $(\mathrm{rpm})$ & 150 \\
Tempo (minutos) & 60 \\
$\mathrm{pH}$ & 5 \\
\hline
\end{tabular}

\subsection{2.}

\section{Influência do pH}

A influência do $\mathrm{pH}$ foi avaliada para determinação de qual seria o pH no qual o adsorvente apresenta maior capacidade de captação dos íons metálicos, tendo em vista que esta variável afeta a solubilidade dos íons metálicos. Dessa maneira, o efeito desta variável foi avaliado na faixa de 1-5, já que em pH maiores do que 5 existe a possibilidade de precipitação. $\mathrm{O}$ ajuste do $\mathrm{pH}$ foi realizado com soluções de $0,1 \mathrm{M}$ de $\mathrm{HCl}$ e $0,1 \mathrm{M}$ de $\mathrm{NaOH}$ até que fosse atingido o valor desejado para o ensaio. $\mathrm{O}$ volume de $50 \mathrm{~mL}$ da solução que continha o íon metálico foi mantido em contato com o adsorvente a temperatura de $30^{\circ} \mathrm{C}$, e velocidade de $150 \mathrm{rpm}$. A Tabela 10 representa as condições operacionais para este ensaio.

Tabela 10-Condições experimentais para avaliar o efeito do $\mathrm{pH}$ no processo de sorção do Nd (III)

\begin{tabular}{cc} 
Parâmetros & Nd(III) \\
\hline Concentração do adsorvente $(\mathrm{g})$ & 2
\end{tabular}


$\begin{array}{cc}\text { Concentração inicial do íon metálico }(\mathrm{mg} / \mathrm{L}) & 500 \\ \text { Temperatura }\left({ }^{\circ} \mathrm{C}\right) & 30 \\ \text { Agitação (rpm) } & 150 \\ \text { Tempo (minutos) } & 60 \\ \mathrm{pH} & 1 ; 2 ; 3 ; 4 ; 5\end{array}$

\subsection{3.}

\section{Influência da concentração do íon metálico}

A influência da concentração do íon metálico foi avaliada pois ela é função da taxa de adsorção, o que faz desta variável um importante vetor a ser considerado nos estudos de adsorção para que se alcance a captação máxima de íons metálicos e maior remoção possível. O ensaio foi realizado na faixa de concentração de 40 a $890 \mathrm{mg} / \mathrm{L}$, a valores de pH e concentração de adsorvente ótimos previamente estabelecidos nos ensaios anteriores. A suspensão do íon metálico juntamente com o adsorvente foi mantida sob agitação durante 60 min a $150 \mathrm{rpm}$. Ao final deste tempo de contato, a suspensão foi centrifugada e o sobrenadante encaminhado para análise no espectrômetro de emissão atômica com plasma indutivamente acoplado (ICP OES). Na Tabela 11 estão representadas as condições experimentais utilizadas durante o ensaio.

Tabela 11-Condições experimentais para avaliação do efeito da concentração do íon metálico na adsorção do Nd (III)

\begin{tabular}{cc}
\hline Parâmetros & Nd(III) \\
\hline Concentração do adsorvente $(\mathrm{g})$ & 2 \\
Concentração inicial do íon metálico $(\mathrm{mg} / \mathrm{L})$ & $40 ; 100 ; 250 ; 300 ;$ \\
& $500 ; 683 ; 750 ; 890$ \\
Temperatura $\left({ }^{\circ} \mathrm{C}\right)$ & 30 \\
Agitação $(\mathrm{rpm})$ & 150 \\
Tempo (minutos) & 60 \\
$\mathrm{pH}$ & 5 \\
\hline
\end{tabular}




\subsection{4.}

\section{Tempo de equilíbrio e cinética de adsorção}

O efeito do tempo de contato entre o adsorvente e o íon metálico foi avaliado objetivando reconhecer informações relevantes referentes a taxa de adsorção no processo. Foram realizados ensaios para determinação do efeito do tempo de contato na adsorção do neodímio utilizando a palygorskita, para atingir o equilíbrio, em diferentes intervalos de tempo. Foi utilizado os valores de concentrações de adsorvente e íon metálico ótimos decorrentes dos ensaios anteriores de $2 \mathrm{~g}$ e 250 $\mathrm{mg} / \mathrm{L}$ respectivamente a um $\mathrm{pH} 5$. Para os diferentes tempos as amostras eram coletadas e centrifugadas por 15 minutos em centrífuga da marca Eppendorf, modelo 5810-R a 4000 rpm e encaminhadas para ser analisada por meio da técnica de espectrometria de emissão atômica com plasma indutivamente acoplado (ICP OES). As condições experimentais estão apresentadas na Tabela 12.

Tabela 12-Condições experimentais para avaliação do efeito do tempo de contato no processo de sorção do Nd (III)

\begin{tabular}{cc}
\hline Parâmetros & Nd(III) \\
\hline Concentração do adsorvente $(\mathrm{g})$ & 2 \\
Concentração inicial do íon metálico $(\mathrm{mg} / \mathrm{L})$ & 250 \\
Temperatura $\left({ }^{\circ} \mathrm{C}\right)$ & 30 \\
Agitação $(\mathrm{rpm})$ & 150 \\
Tempo (minutos) & $5 ; 15 ; 30 ; 60 ; 120 ; 180 ; 240$ \\
$\mathrm{pH}$ & 5 \\
\hline
\end{tabular}

\subsection{5.}

\section{Influência da temperatura}

A influência da temperatura foi avaliada pois esta é uma variável que afeta a velocidade de difusão dos íons. O processo de sorção é mais favorecido em altas temperaturas devido a uma elevada atividade na superfície e energia cinética do soluto. A parte experimental para realização deste ensaio se deu de maneira similar ao do tempo de equilíbrio e cinética de adsorção. Foi utilizado os valores de concentrações de adsorvente e íon metálico que obtiveram os melhores resultados decorrentes dos ensaios anteriores de $2 \mathrm{~g}$ e $250 \mathrm{mg} / \mathrm{L}$ respectivamente 
a um $\mathrm{pH}$ 5. Para as diferentes temperaturas as amostras eram coletadas e centrifugadas por 15 minutos a 4000 rpm e encaminhadas para ser analisada por meio da técnica de espectrometria de emissão atômica com plasma indutivamente acoplado (ICP OES). As condições experimentais estão apresentadas na Tabela 13.

Tabela 13-Condições experimentais para avaliação do efeito da temperatura no processo de sorção do $\mathrm{Nd}$ (III)

\begin{tabular}{cc}
\hline Parâmetros & Nd(III) \\
\hline Concentração do adsorvente & $2 \mathrm{~g}$ \\
Concentração inicial do íon metálico $(\mathrm{mg} / \mathrm{L})$ & 250 \\
Temperatura $\left({ }^{\circ} \mathrm{C}\right)$ & $20,30,40$ \\
Agitação $(\mathrm{rpm})$ & 150 \\
Tempo (minutos) & $5 ; 15 ; 30 ; 60 ; 120 ; 180 ; 240$ \\
$\mathrm{pH}$ & 5 \\
\hline
\end{tabular}




\section{6 \\ Resultados e discussões}

Nesta sessão serão discutidos os resultados obtidos das análises experimentais realizadas.

\section{1.}

\section{Caracterização da palygorskita}

A caracterização da amostra é apresentada de forma a elucidar a metodologia experimental exibida anteriormente na qual estão representadas as características químicas e mineralógicas da amostra, para o entendimento da sua aplicação no processo de adsorção.

\subsection{1.}

\section{Distribuição granulométrica}

Após a etapa de beneficiamento e da separação magnética as partículas de frações abaixo de $20 \mu \mathrm{m}$ foram analisadas por meio do equipamento Malvern que determina o volume das partículas por meio da difração da luz. A curva de distribuição granulométrica obtida está ilustrada na Figura 14. 


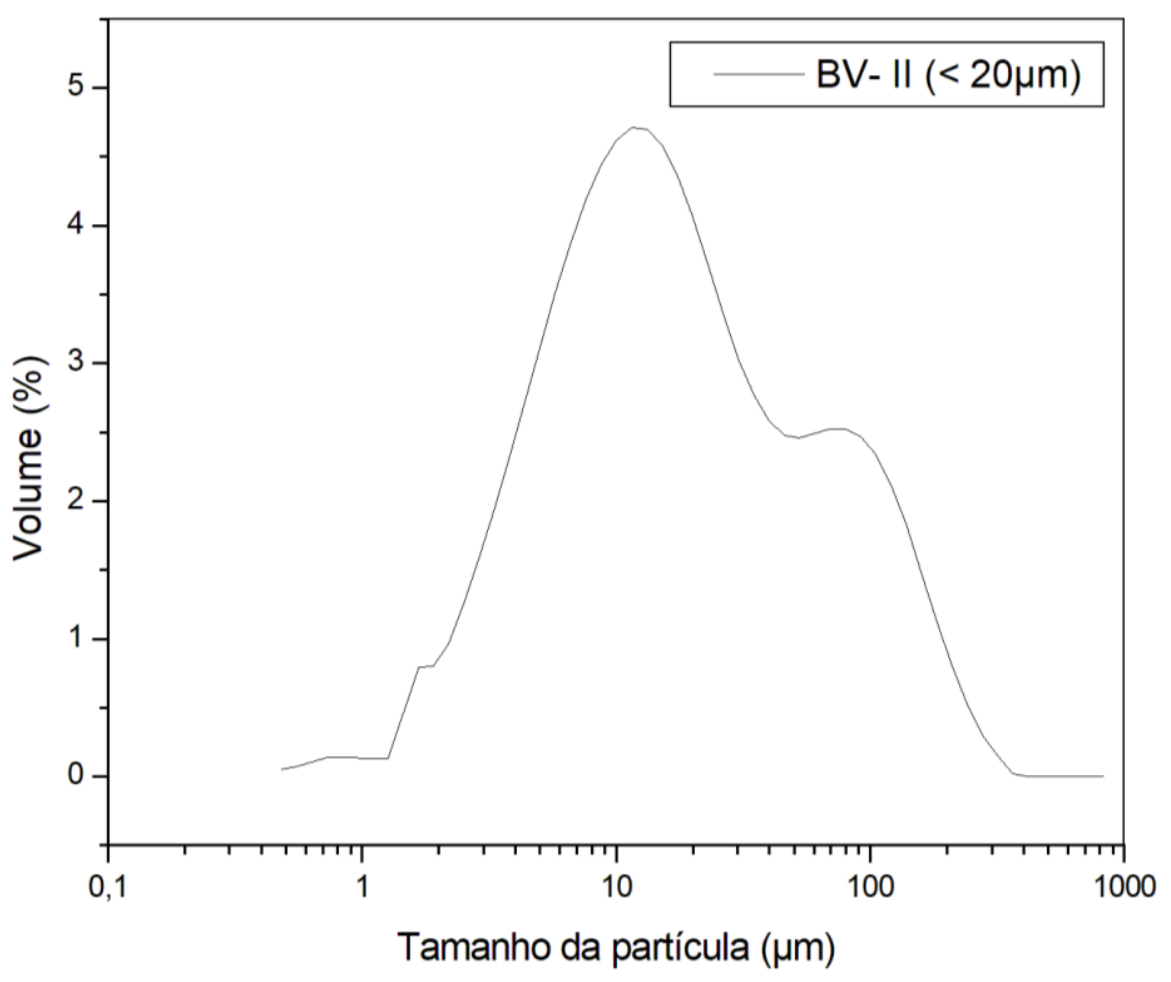

Figura 14- Curva de distribuição granulométrica da amostra BV II após beneficiamento.

Através da curva de distribuição granulométrica é possível inferir que $50 \%$ das frações com separação estão em torno de 11,32 $\mu \mathrm{m}, 10 \%$ tamanho a 2,8 $\mu \mathrm{m}$ e $90 \%$ apresentam tamanho até $20 \mu \mathrm{m}$. Esses resultados estão de acordo com o esperado, uma vez que a amostra BV II, foi pulverizada em circuito fechado com uma peneira de abertura de $20 \mu \mathrm{m}$, para que toda a amostra estivesse abaixo de $20 \mu \mathrm{m}$. O que corrobora a eficiência do processo de separação para retirada de impurezas que contém frações granulométricas maiores.

\subsection{2.}

\section{Difratometria de raios X- DRX}

A Figura 15 apresenta os difratogramas de raios $X$ da amostra de palygorskita ROM e abaixo de $20 \mu \mathrm{m}$ obtida após o beneficiamento. Através dos difratogramas identificou-se as fases mineralógicas que compõe a amostra. Foi verificado a presença de picos característicos dos minerais de palygorskita

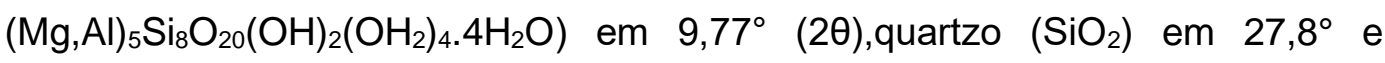
caulinita $\left(\mathrm{Al}_{4}\left(\mathrm{Si}_{4} \mathrm{O}_{10}\right)(\mathrm{OH})_{8}\right)$ em $14,33^{\circ}$, sendo estes dois minerais considerados impurezas contidas na amostra. 


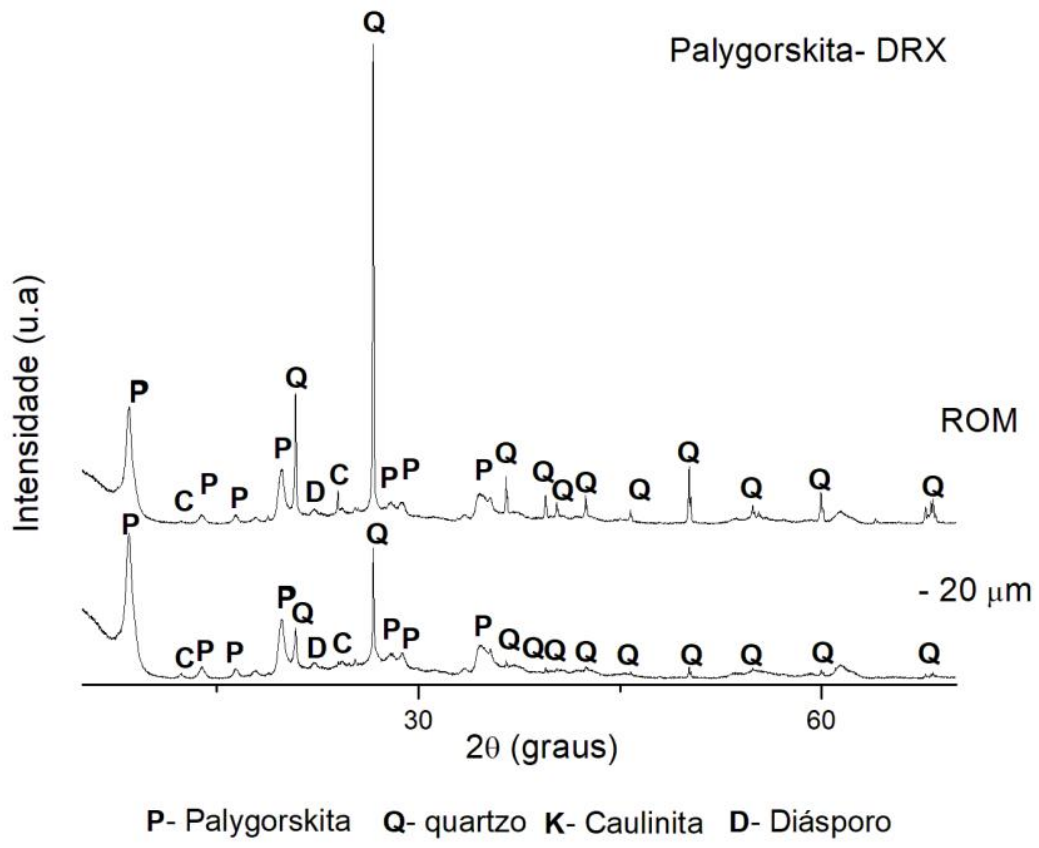

Figura 15-Difratogramas de raios $X$ das amostras Run of mine $(R O M)$ e $<20 \mu m$

É verificado que após o beneficiamento, houve um aumento relativo dos picos relacionados à palygorskita, e uma consequentemente diminuição dos picos referentes ao quartzo, caulinita e diásporo, indicando que as etapas prévias do beneficiamento promoveram maior grau de pureza a palygorskita.

Resultados similares foram encontrados por Simões (2017), onde foram observados picos característicos da palygorskita e caulinita, quartzo e goethita que são considerados contaminantes da amostra. Os picos dessas impurezas também diminuíam após as etapas de moagem, classificação granulométrica à úmido e separação magnética, corroborando a importância do beneficiamento da amostra.

\subsection{3.}

\section{Fluorescência de raios $\mathrm{X}$ - FRX}

A composição química elementar da palygorskita convertida em teores de óxidos foi determinada por meio da técnica de fluorescência de raios $X(F R X)$, apresentados na Tabela 14 para a amostra menor que $20 \mu \mathrm{m}$. 
Tabela 14- Composição química elementar da palygorskita $(<20 \mu \mathrm{m})$

\begin{tabular}{lllllllllll}
\hline \multirow{2}{*}{ Mineral } & \multicolumn{10}{c}{ Óxidos (\% p/p) } \\
\cline { 2 - 9 } & $\mathrm{Na}_{2} \mathrm{O}$ & $\mathrm{MgO}$ & $\mathrm{Al}_{2} \mathrm{O}_{3}$ & $\mathrm{SiO}_{2}$ & $\mathrm{~K}_{2} \mathrm{O}$ & $\mathrm{CaO}$ & $\mathrm{TiO}_{2}$ & $\mathrm{MnO}$ & $\mathrm{Fe}_{2} \mathrm{O}_{3}$ & ${ }^{*} \mathrm{PPC}$ \\
\hline $\begin{array}{l}\text { Fração } \\
<20 \mu \mathrm{m}\end{array}$ & 0,14 & 5,7 & 14,2 & 53,8 & 2,2 & 0,18 & 0,52 & 0,14 & 6,8 & 16,3 \\
\hline
\end{tabular}

Onde PPC é a perda por calcinação da amostra que foi feita em mufla. Foram separadas alíquotas da amostra, colocadas na mufla a $1000^{\circ} \mathrm{C}$ por 16 horas e após resfriamento foram pesadas para verificar a perda por calcinação

Através do resultado da composição química da palygorskita, é possível obter algumas informações relevantes. Os altos teores de óxido de silício $\left(\mathrm{SiO}_{2}\right)$ e óxido de alumínio $\left(\mathrm{Al}_{2} \mathrm{O}_{3}\right)$ indicam que a amostra é majoritariamente composta por palygorskita, já que o silício e o magnésio são elementos presentes na estrutura da palygorskita. A presença de $\mathrm{CaO}$ pode estar relacionada às impurezas como carbonatos, por exemplo. O potássio $\left(\mathrm{K}^{+}\right)$funciona como cátion de compensação da rede da palygorskita e o titânio $\left(\mathrm{Ti}^{4+}\right)$ seria uma impureza presente (Baltar et al., 2009).

As composições químicas também indicam que diferentemente de outras amostras de palygorskita reportadas na literatura o potássio é o principal cátion de compensação da estrutura (Grim, 1968), assim como o ferro que é um componente importante das camadas octaédricas. Para ser consideradas ricas em ferro, o teor dele deve ser maior do que o de alumínio, portanto a amostra em questão pode ser considerada levemente ferruginosa (Suárez e GarciaRomero,2006).

Os resultados encontrados estão em conformidade com os encontrados na literatura obtidos por Simões (2017), onde os teores de óxidos de silício, de alumínio e de magnésio foram 50,5, 15,5 e 7,1, respectivamente, e com Galan \& Singer, (2011), onde os teores dos óxidos de silício, alumínio e magnésio variam de 42,1 a 75,3, 2,41 a 24,4 e 2,33 a 22,9 \% em peso, respectivamente. A perda por calcinação (PPC) também está dentro do estipulado pela literatura, o valor comum em PCC para este argilomineral normalmente é de 8 a 18\% (Silva,2014). 


\subsection{4.}

\section{Microscopia eletrônica de varredura - MEV}

Com o microscópio eletrônico de varredura é possível avaliar morfologicamente e verificar a presente do íon Nd (III) após a adsorção com a palygorskita.

A morfologia da palygorskita de Boa vista II (Figura 16) foi analisada por meio de MEV, possibilitando caracterizar este material com morfologia fibrosa, além disso, verificou-se aglomerados de fitas e agulhas com comprimentos variados, essas características são inerentes a amostra de palygorskita estudada (Fangqun et al.,2009).
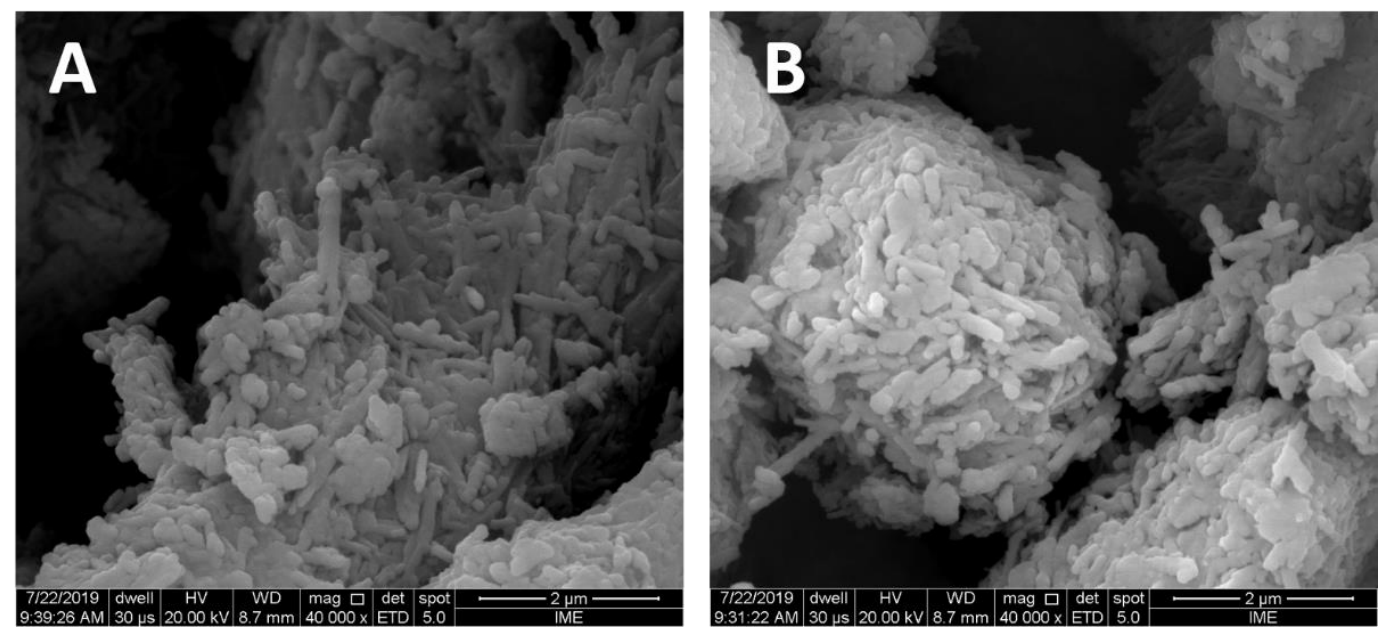

Figura 16- Imagens obtidas por MEV da palygorskita antes da adsorção

\subsection{5.}

\section{Capacidade de troca catiônica - CTC}

A capacidade de troca catiônica foi calculada por meio do índice de azul de metileno (IAM), onde $V$ é o volume em $\mathrm{ml}$ gasto na titulação. Quanto maior o volume gasto, maior é a capacidade de troca catiônica da amostra. A CTC da amostra de palygorskita BV II foi de $28 \mathrm{meq} / 100 \mathrm{~g}$ de amostra. Esse valor está dentro do previsto pela literatura, onde para a palygorskita, a CTC é estimada entre 20 e $50 \mathrm{meq} / 100 \mathrm{~g}$ de amostra (Luz \& Lins,2005).

A CTC estimada, é alcançada quando a saturação é atingida, dessa maneira um halo ao redor da gota do corante é depositado no papel filtro é alcançado 
representando desta maneira a viragem no ponto final da titulação do argilomineral como representado na Figura 17.
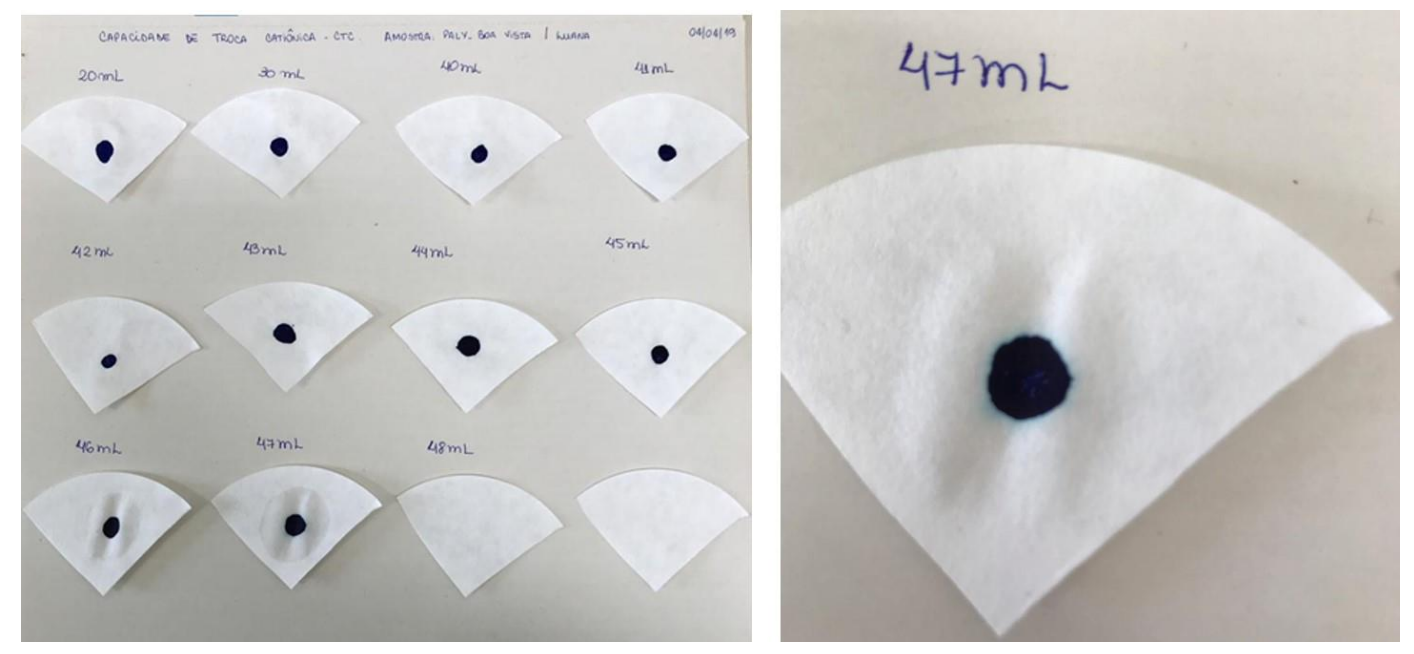

Figura 17- Formação do halo para o azul de metileno para estimativa do valor de

Capacidade de troca catiônica

\subsection{6. \\ Propriedades texturais}

As propriedades texturais da amostra de palygorskita foram obtidas por meio da fissisorção de $\mathrm{N}_{2}$. A área superficial da amostra é de $118,42 \mathrm{~m}^{2} / \mathrm{g}$ e o tamanho médio dos poros é de 4,64 nm. Este tamanho médio dos poros caracteriza a palygorskita sendo um material mesoporoso de acordo com as normas da IUPAC (1982), que abrange poro de largura interna entre 2 e $50 \mathrm{~nm}$.

Chen \& Wang (2007) verificaram através de seu estudo de adsorção de Chumbo utilizando a palygorskita como adsorvente que este argilomineral possuía 46,66 m²/g. Em comparação com a palygorskita do presente estudo é possível afirmar que esta possui elevada área superficial.

\subsection{7.}

\section{Análise Termogravimétrica (TG-DTG)}

O comportamento térmico da amostra BV-II foi avaliado com o objetivo de estudar a sua estabilidade térmica mediante a variação de temperatura. Dessa maneira, através da análise termogravimétrica uma curva de decomposição térmica foi gerada em percentual de perda mássica em função da temperatura (Fifield e Kealey,2000). 
A Figura 18 representa a curva termogravimétrica e sua respectiva derivada. É possível observar três principais eventos decorrentes da perda de massa em função da temperatura.

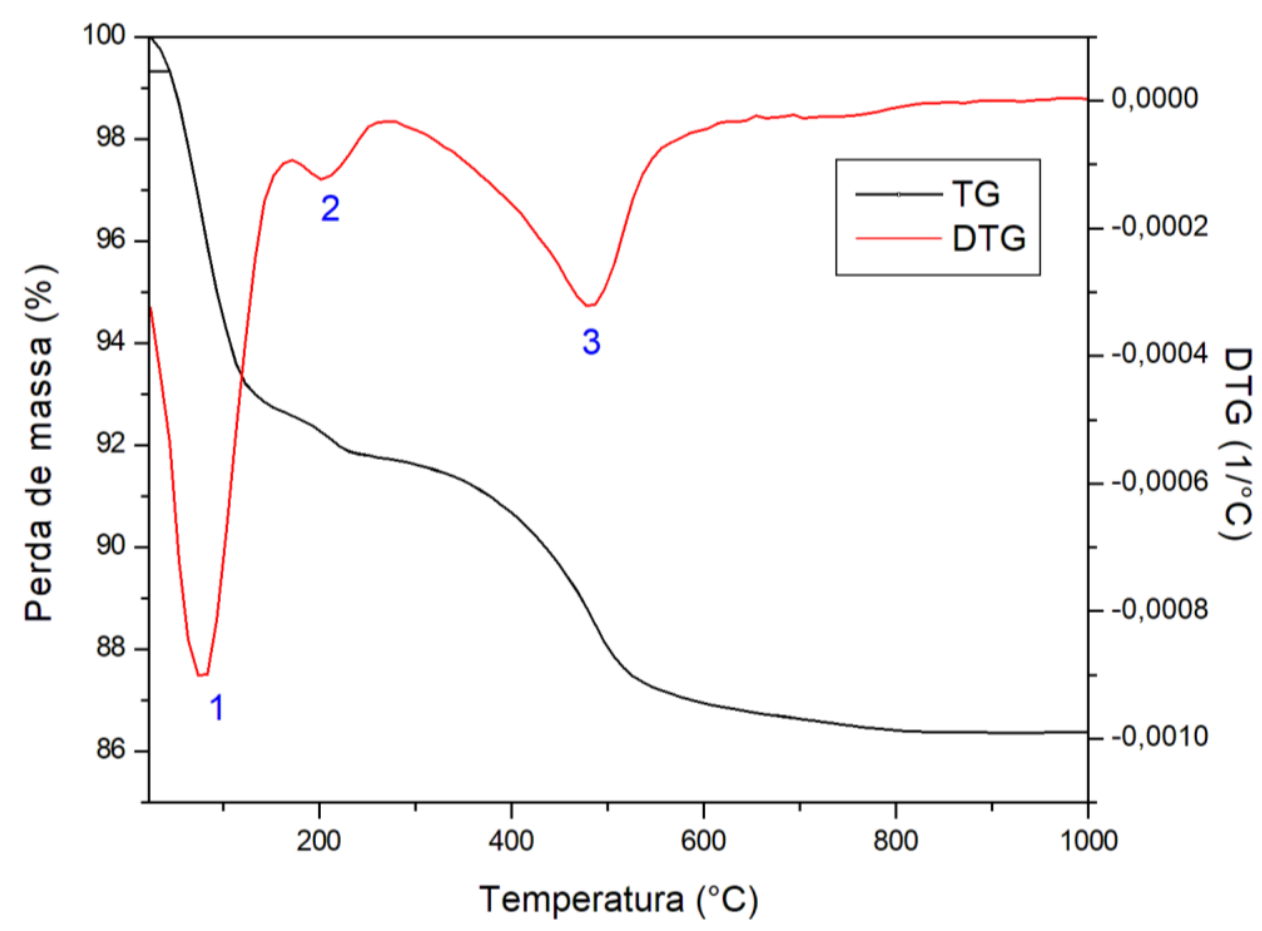

Figura 18- Curva termogravimétrica (TG) e sua derivada (DTG) da amostra de palygorskita

Para elucidar as termo decomposições a curva de DTG apresenta três eventos bem definidos, onde pode-se retirar informações relevantes. A primeira delas representada no gráfico por (1) refere-se à primeira desidroxilação que está associada à água de umidade ocorrendo por volta de $84^{\circ} \mathrm{C}$, esta água é a correspondente a água coordenada a cátions da camada octaédrica. O ponto (2) associa-se a segunda desidroxilação que acontece em $208^{\circ} \mathrm{C}$ e está relacionada à liberação da água zeolítica que está presente nos canais da palygorskita no qual interage tanto com a molécula de $\mathrm{H}_{2} \mathrm{O}$ coordenada quanto a camada tetraédrica. O terceiro evento relevante a curva termogravimétrica ocorre devido à desidroxilação da água estrutural do argilomineral, ocorrendo por volta da temperatura de $492^{\circ} \mathrm{C}$, sendo irreversível. Reações endotérmicas são observadas nos três pontos, que corroboram as desidratações observadas nos eventos pontuados. 


\subsection{8. \\ Potencial Zeta}

Objetivando avaliar a possível variação nas propriedades eletrocinéticas da palygorskita, decorrente da presença de $\mathrm{Nd}$ (III) em diferentes valores de $\mathrm{pH}$, e assim determinar se a mudança na carga superficial do adsorvente está relacionada à adsorção destes íons, estudos de medidas eletroforética foram realizados, visto que estes podem indicar a interação entre as espécies metálicas e os sítios ativos disponíveis do argilomineral. Os respectivos valores de potencial zeta foram calculados, a fim de examinar os possíveis mecanismos de adsorção e fornecer informações sobre a carga efetiva líquida na superfície da palygorskita.

A Figura 19 ilustra as curvas de potencial zeta referentes a palygorskita para diferentes concentrações de $\mathrm{KCl}$ em função de uma faixa de $\mathrm{pH}$ variando de 2 a 10.

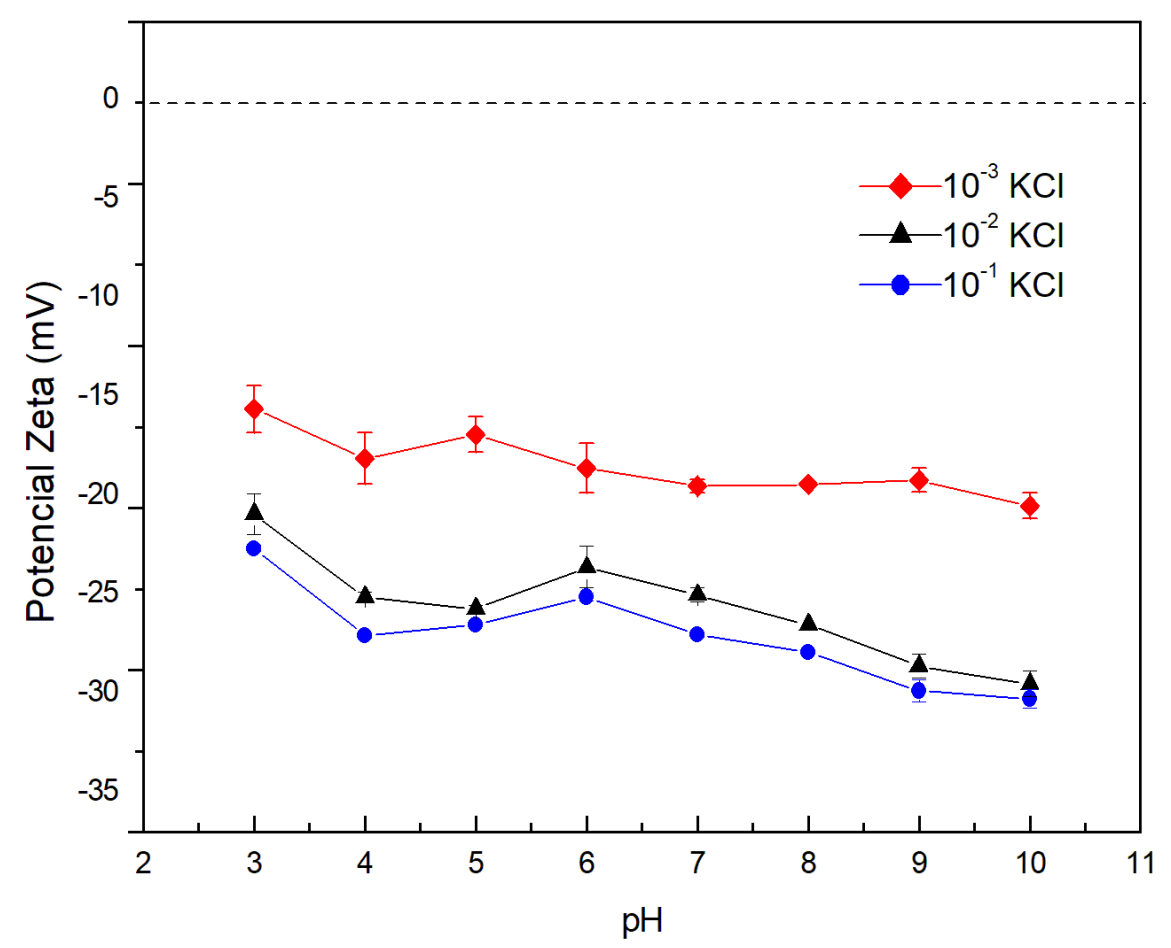

Figura 19- Potencial zeta da palygorskita in natura para três concentrações de eletrólitos indiferentes

Nas curvas de potencial zeta para a palygorskita (Figura 19), foram encontrados valores negativos em toda a faixa de $\mathrm{pH}$ estudado, sendo determinada assim uma carga negativa na superfície do argilomineral em solução aquosa. Resultados similares são apontados na literatura. (Middea et al (2013), Liang et al (2013), Liu et al (2008), Gan et al (2009), Middea et al (2018)). 
Essa característica de carga superficial negativa pode estar associada a dois eventos, sendo eles: a desprotonação dos sítios ativos da palygorskita na forma dos grupos silanóis (-Si-OH) devido as características do cristal. A outra explicação pode vir do fato das substituições isomórficas entre $\mathrm{Si}(\mathrm{IV})$ e $\mathrm{Al}(\mathrm{III})$ e $\mathrm{Al}(\mathrm{III})$ e $\mathrm{Mg}$ (II) e $\mathrm{Fe}(\mathrm{II})$ na palygorskita.

A palygorskita é carregada negativamente para a extensa faixa de $\mathrm{pH}$ estudada e apresenta uma diminuição da magnitude do potencial quando a concentração de eletrólitos foi elevada de $10^{-3} \mathrm{M}$ e $10^{-2} \mathrm{M}$. A diminuição do perfil potencial zeta está associada com o efeito de compressão da dupla camada elétrica, e pela acumulação de contra-íons, causada pelo aumento da força iónica do meio (Hunter,2013).

Com a finalidade de adquirir mais informações a respeito das propriedades eletrocinéticas do íon metálico estudado, a avaliação das medidas de potencial zeta também foram realizadas para o óxido de neodímio como ilustra a Figura 20. Para este ensaio, diferentes concentrações de $\mathrm{KCl}$ em função de uma faixa de $\mathrm{pH}$ variando de 2 a 10 foi utilizada.

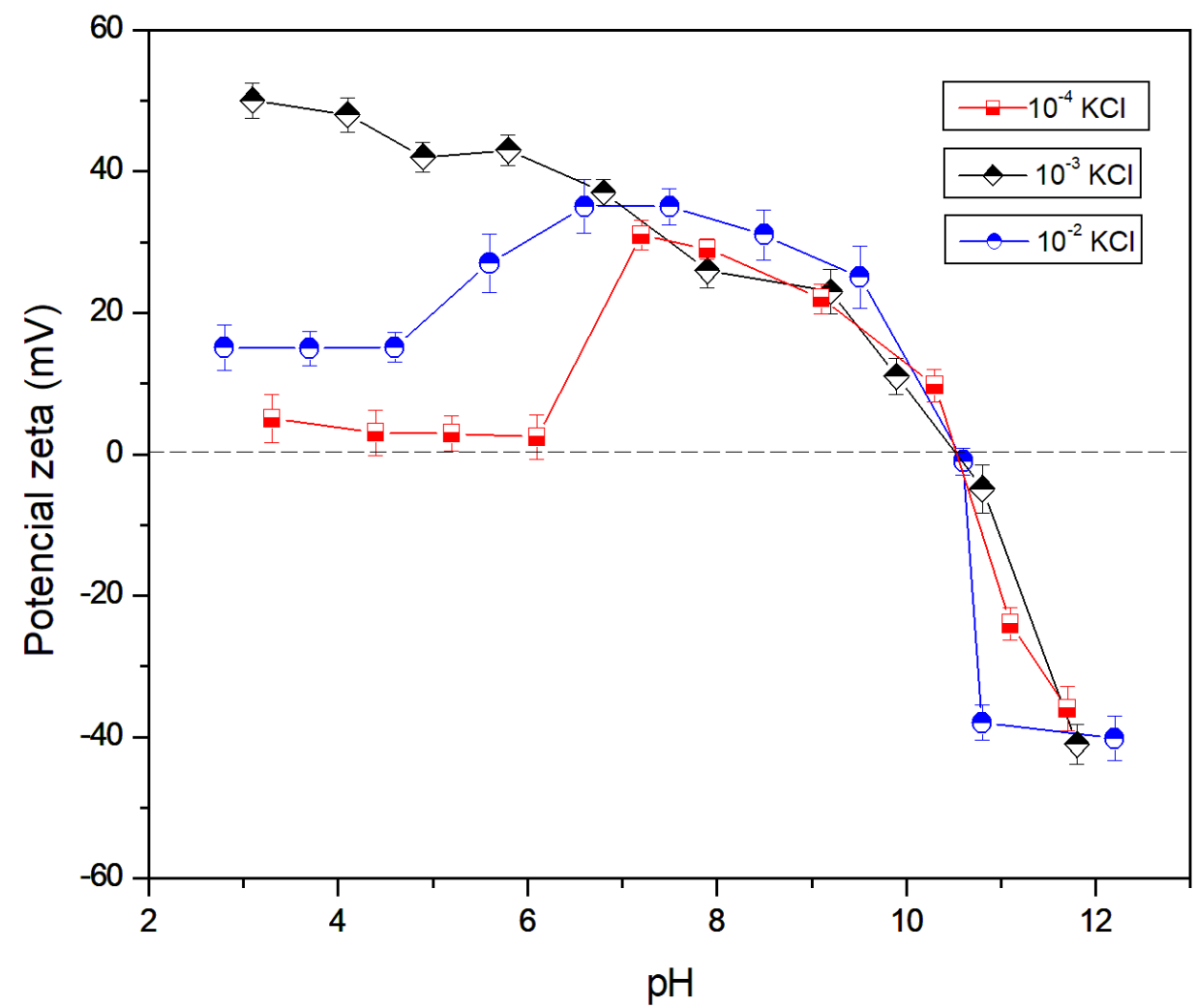

Figura 20-Potencial zeta do óxido de neodímio para três concentrações de eletrólitos indiferentes 
Informações a respeito das medidas de carga superficial do neodímio e seus compostos, ainda são escassas na literatura. Segundo Kosmulski (2016), o neodímio forma vários hidróxidos no estado de oxidação +3 . O ponto isoelétrico do óxido de neodímio não é documentado na literatura em comparação com os óxidos de outras espécies metálicas. Desta maneira, a fim de verificar e analisar para melhor compreensão dessas medidas, a Figura 20 elucida que para os experimentos relativos a avaliação das curvas de potencial zeta na presença de eletrólito indiferente apontam que para o óxido de neodímio o ponto isoelétrico encontrado é em torno de 10,4. Além disso, a pesquisa realizada na literatura mostra que esta informação é uma contribuição significativa no que diz respeito a mobilidade eletroforética de produtos que contem neodímio, em particular do óxido de neodímio, uma vez que a literatura não apresenta resultados referentes a este assunto, corroborado por Kosmulski (2016) que reporta a não incidência deste resultado.

A Figura 21 mostra as curvas de potencial zeta em função do $\mathrm{pH}$ para a palygorskita antes e após a adsorção de $\mathrm{Nd}$ (III) para a faixa de pH entre 2,0 e 11. Como forma de avaliar as mudanças nos padrões eletrocinéticos do argilomineral na presença do íon metálico o $\mathrm{KCl}$ foi eleito como eletrólito indiferente. 


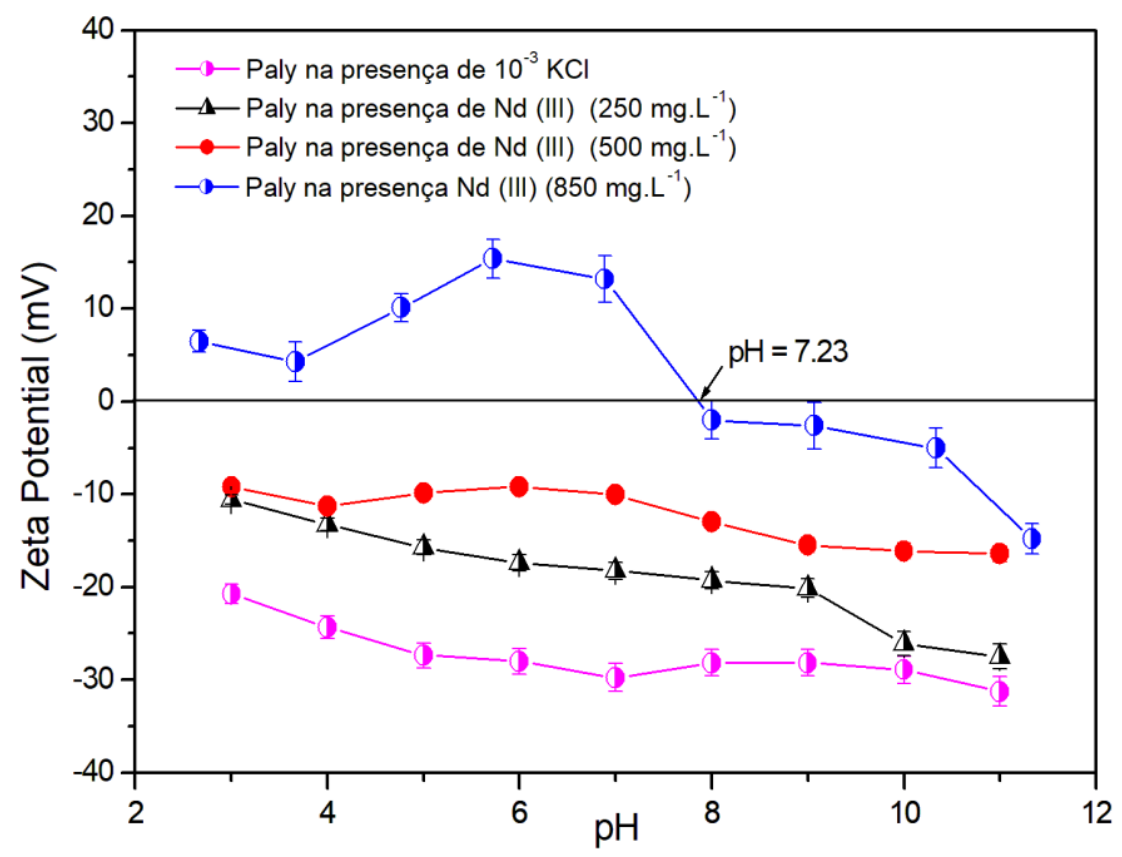

Figura 21- Curva de potencial zeta antes e após a adsorção com diferentes concentrações de neodímio (pH:5; tempo de contato:60 min; velocidade de agitação:150 rpm)

Segundo Fenter et al (2000), interações entre minerais e metais podem ser suscetíveis a variações nas espécies de superfície e carga dependentes do $\mathrm{pH}$. Evidentemente, a adsorção de neodímio modifica as curvas de potencial zeta, o que pode ser ocasionado pela captação específica que pode estar ocorrendo nos sítios ativos da palygorskita.

Após a adsorção de Neodímio nas concentrações de $250-890 \mathrm{mg} / \mathrm{L}$, é possível comparar as curvas do potencial zeta da palygorskita in natura e da amostra com interação com íon metálico. É possível observar que o potencial é reduzido. A principal razão é que o potencial zeta da palygorskita in natura pode ser neutralizado após a captura dos íons metálicos.

A presença de íons metálicos pode causar uma possível reversão de carga no perfil das medidas dos padrões eletrocinéticos e pode estar correlacionada com a especiação deste metal em solução aquosa. Foi verificado que para diferentes concentrações dos íons metálicos as curvas de potencial zeta ficaram menos negativas. Para a adsorção do neodímio utilizando concentração de $890 \mathrm{mg} / \mathrm{L}$ houve reversão de carga. O ponto isoelétrico encontrado foi em torno de 7,25. 
Segundo Stumm (1992), o incremento do valor de pH pode ocasionar na hidrólise do íon metálico hidratado. Mackenzie \& O’Brien (1969), reporta que íons hidratados livres, por exemplo $\mathrm{Al}^{3+}$ não ocasionam reversão de carga, porém, se o adsorvente possuir uma carga total negativa, este sinal do potencial poderá ser revertido no momento em que os íons hidrolisados e os hidróxidos metálicos forem precipitados na superfície do adsorvente.

Verificou-se através da análise do potencial zeta que há o efeito da atração eletrostática entre a palygorskita in natura e o neodímio, e essa interação fará com que o contato dos íons metálicos com a palygorskita seja propício para a adsorção. Os resultados dos estudos eletrocinéticos podem demonstrar claramente que existe uma mudança nos valores de potencial zeta de uma amostra mineral após interação com os íons metálicos adsorvidos na superfície da amostra. Os ensaios de potencial zeta ajudam também a elucidar os mecanismos envolvidos na interação dos íons metálicos na superfície mineral.

\subsection{9.}

Espectroscopia no infravermelho por transformada de Fourier (FTIR)

Os espectros no infravermelho da palygorskita in natura e da palygorskita após a interação com os íons metálicos na faixa de 400 a $4000 \mathrm{~cm}^{-1}$ foram analisados objetivando a identificação dos grupos funcionais presentes no argilomineral, além do entendimento das informações dos grupamentos que são responsáveis pela captação dos íons metálicos, esta técnica pode ser considerada um complemento da difratometria de raios $X$ (DRX).

A Figura 22 apresenta os espectros relacionados ao argilomineral. Já os grupos funcionais correspondentes aos números de ondas estão apresentados na Tabela 15. 


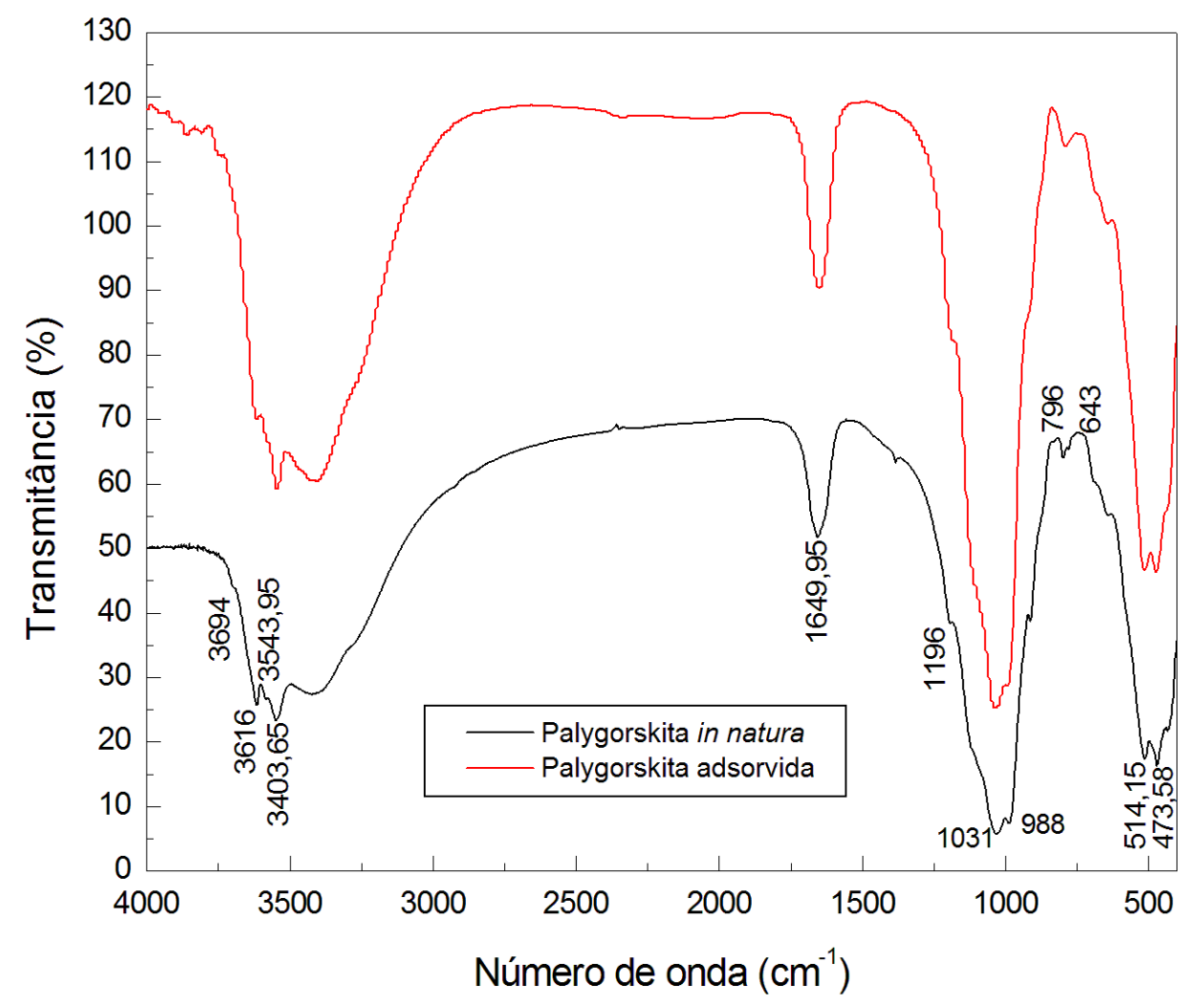

Figura 22-FTIR espectro da palygorskita antes e após o contato com o Nd (III)

A caracterização da palygorskita via espectroscopia infravermelha mostrou diferentes bandas. Na Figura 22, observa-se que na banda correspondente a 3694 $\mathrm{cm}^{-1}$ o grupo funcional que pode ser relacionado ao estiramento vibracional do grupo $\mathrm{Mg}-\mathrm{OH}$. Bandas características da palygorskita são observadas em 3616 $\mathrm{cm}^{-1}$ que corresponde ao estiramento $\mathrm{Al}-\mathrm{OH}$. Perfis similares também são reportados por Suárez \& Romero (2006). Na faixa próxima a 3403,65 características das moléculas de água de coordenação e água zeolítica são encontradas por (Cheng et al.,2011; Suárez \& Romero,2006). A banda correspondente a 1649,95 $\mathrm{cm}^{-1}$ pode ser atribuída a deformação das moléculas de água (Zhu et al.,2015), enquanto que em $1031 \mathrm{~cm}^{-1}$ é característico do estiramento vibracional Si-O-Si, e $988 \mathrm{~cm}^{-1}$ é atribuída a deformação Al-OH-Al (Cheng et al.,2011). A banda em $797 \mathrm{~cm}^{-1}$ é referente a vibração da ligação Si-O (He et al.,2018). As bandas em 643, 514,5, 473,58 $\mathrm{cm}^{-1}$ são devido a vibração SiO-Si (Cheng et al.,2011). 
Tabela 15- Grupos funcionais correspondentes as bandas de absorção apresentados no espectro de FTIR

\begin{tabular}{cc}
\hline Número de onda $\left(\mathrm{cm}^{-1}\right)$ & Grupos funcionais correspondentes \\
\hline 3694 & $\begin{array}{r}\text { Estiramento vibracional do grupo } \mathrm{Mg}-\mathrm{OH} \\
\text { Estiramento vibracional do grupo OH (banda } \\
\text { característica da palygorskita) }\end{array}$ \\
Faixa próxima de 3403,65 & $\begin{array}{c}\text { Águas de coordenação e zeolíticas } \\
1649,95\end{array}$ \\
1031 & Deformação angular das moléculas de água \\
Faixa próxima de 1031 a 988 & Eeformação do grupo Al-O-H \\
Faixa próxima de 798-641 & Correspondente ao quartzo. \\
\hline
\end{tabular}

\section{2.}

\section{Ensaios de adsorção}

A partir dos experimentos realizados em batelada foi possível obter informações preliminares importantes a respeito da adsorção do neodímio em solução aquosa. Um estudo das principais variáveis que afetam o processo de adsorção foi avaliado objetivando a determinação das condições mais adequadas para alcançar maior eficiência para remoção do neodímio utilizando a palygorskita como adsorvente.

\subsection{1.}

\section{Influência da concentração do adsorvente}

A concentração de adsorvente é uma variável importante para o estudo da adsorção, pois determina o nível de captação do metal na solução aquosa. Desta maneira, para maximizar as interações entre os íons metálicos e os sítios de adsorção é necessária uma dosagem ótima do adsorvente. Assim a porcentagem de remoção e a capacidade de captação do neodímio em função da concentração da palygorskita são mostradas na Figura 23. 


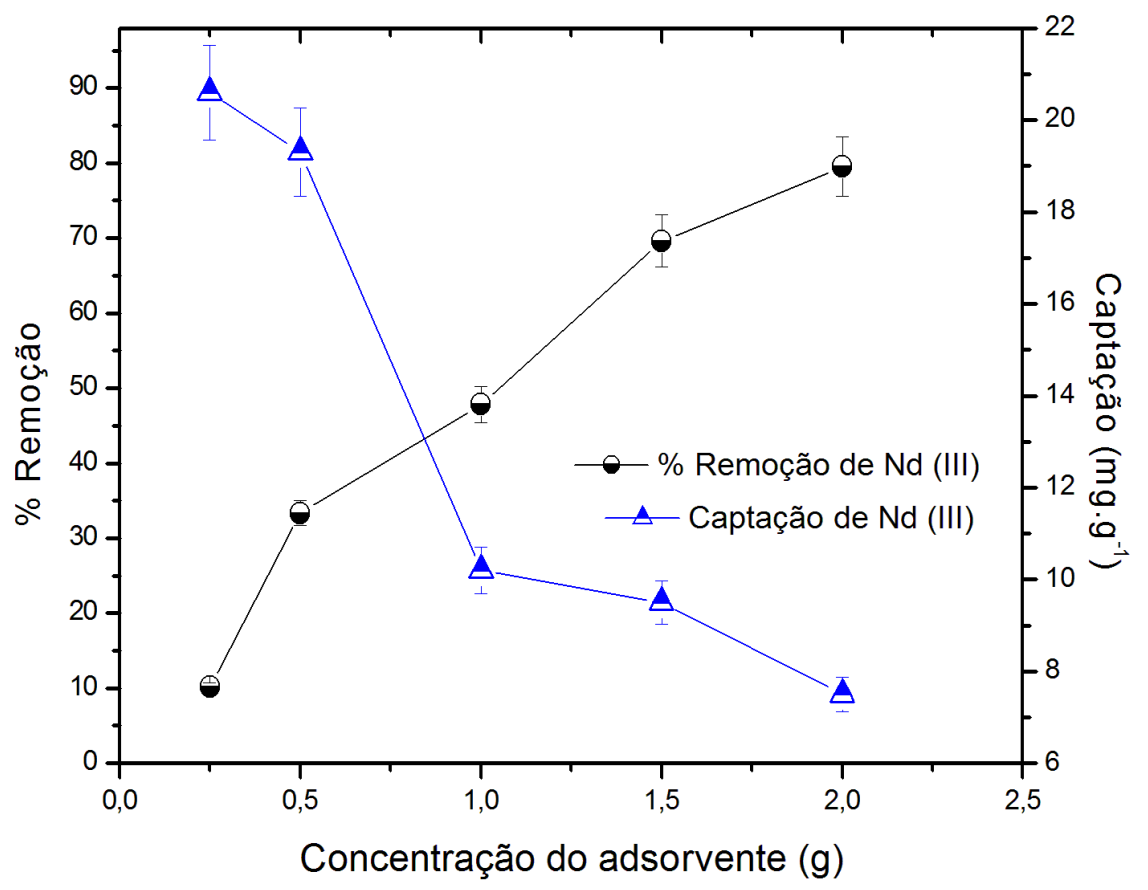

Figura 23- Influência da concentração do adsorvente

É verificado que o incremento da concentração de palygorskita de $0,5 \mathrm{~g}$ para $2 \mathrm{~g}$ aumentou a porcentagem de remoção de $\mathrm{Nd}$ (III), configurando uma relação diretamente proporcional entre os dois parâmetros. Este é um resultado esperado pois, em geral, à medida que a quantidade de adsorvente se torna maior, a quantidade adsorvida pelo soluto também aumenta, consequentemente a disponibilidade de sítios ativos também aumenta, portanto, essas partículas conectam mais íons as suas superfícies.

He et al (2018) realizou um estudo de adsorção para avalizar a capacidade de adsorção da palygorskita em azul de metileno em água, e observou porcentagem de remoção análoga a encontrada para Nd (III), próxima de 83\%, enquanto que para o $\mathrm{Nd}$ (III) a porcentagem de remoção foi de $79,92 \%$ utilizando $2 \mathrm{~g}$ de palygorskita como adsorvente apresentada neste trabalho.

Tan et al (2009) tem reportado observações similares para o Eu (III), onde a porcentagem de remoção incrementa com o aumento da concentração do adsorvente.

O estudo realizado por Potgieter et al (2006), para remoção de $\mathrm{Pb}$ (II), $\mathrm{Ni}$ (II), $\mathrm{Cr}$ (VI) e Cu (II) a partir de soluções aquosas utilizando palygorskita como adsorvente também apresentou semelhanças. Os resultados obtidos corroboram o fato de que o aumento da quantidade de palygorskita aumenta a porcentagem de remoção de $\mathrm{Ni}$ (II), assim como para $\mathrm{Pb}$ (II), $\mathrm{Cr}$ (VI) e Cu (II). 
Com o incremento da concentração do adsorvente evidentemente há o aumento do número de sítios ativos disponíveis, o que consequentemente, leva a um aumento na porcentagem de remoção. Obstante a este fato, quando a maioria dos sítios ativos desocupados aumenta, o resultado é uma diminuição da capacidade de adsorção (Zhang et al.,2016).

Perfis similares também são encontrados na literatura observados por autores diferentes que investigaram a adsorção de íons metálicos por diversos adsorventes, como: material compósito composto por quitosana e ferro [ChiFer (III)] para a recuperação de Nd (III) (Demey et al.,2018), microalgas verdes (Chlorella Vulgaris) para a recuperação de $\mathrm{Nd}$ (III) a partir de uma solução aquosa derivada de imãs de disco rígido (Kucuker et al.,2017), gel de lignina na remoção de chumbo (Ogunsile \& Bamgboye,2017).

Evidentemente, a porcentagem de remoção tal qual a capacidade de captação do íon metálico é sensível a mudanças de dosagens do adsorvente utilizado. Portanto, esta variável foi estudada com o objetivo de otimizar o processo de adsorção.

\subsection{2.}

\section{Influência do pH}

O pH é um parâmetro fundamental no processo de adsorção em solução, já que determina a carga superficial do adsorvente, além de ser importante pois controla a adsorção do metal nas interfaces entre o adsorvente e o adsorvato. $O$ equilíbrio do sistema, é dado pelas seguintes equações (33,34 e 35).

$$
\begin{gathered}
\mathrm{B}-H \Leftrightarrow B^{-}+H^{+} \\
k_{a}=\frac{\left[B^{-}\right] x\left[H^{+}\right]}{\left[B^{-}\right]} \\
p k_{a}-p H=\log \frac{[B-H]}{B^{-}}
\end{gathered}
$$

Através das equações acima, infere-se que para valores de $\mathrm{pH}$ inferiores ao de $\mathrm{pK}_{\mathrm{a}}$, o equilíbrio desloca-se para a esquerda, consequentemente consumindo prótons e aumentando o $\mathrm{pH}$ até que este valor seja igual ao de $\mathrm{pK}_{\mathrm{a}} . \mathrm{O}$ contrário acontece quando o $\mathrm{pH}$ da solução for maior do que o $\mathrm{pK}_{\mathrm{a}}$. 
Para valores de $\mathrm{pH}$ maiores do que os de $\mathrm{pK}_{\mathrm{a}}$, os sítios encontram-se dissociados, o que pode levar a troca de prótons com íons metálicos da solução. Quando valores de pH são menores do que os de $\mathrm{pK}_{\mathrm{a}}$, o fenômeno de complexação também pode ocorrer (Fourest \& Volesky,1995).

A magnitude da importância do efeito que o pH representa para a adsorção pode ser descrita em termos das interações eletroestáticas entre o adsorvente e o adsorvato. (Bautista-Toledo et al.,2005).

$\mathrm{O} \mathrm{pH}$ do qual o ponto de carga zero $\left(\mathrm{pH}_{\mathrm{PzC}}\right)$ é o $\mathrm{pH}$ abaixo daquele em que a superfície do adsorvente é positiva, enquanto que acima deste valor é negativa. (Ayraci et al.,2005). A importância desta variável na adsorção é que as cargas do adsorvato e do adsorvente devem ser opostas para que haja uma maior interação eletrostática entre ambos, pois, se as cargas forem iguais, o processo de adsorção será prejudicado, havendo assim uma repulsão eletrostática.

No que diz respeito a remoção de ions metálicos, é de fundamental importância conhecer quais tipos de espécies metálicas estão presentes no meio. A especiação dos metais é dependente do $\mathrm{pH}$ e sua variação vai favorecer a formação de uma espécie em relação a outras, desta maneira, convém analisar este dado.

Segundo Vijayaraghavan \& Yun (2008) a carga da superfície tende a ficar negativa até que os grupos funcionais estejam desprotonados, favorecendo a atração eletrostática e de adsorção de cátions. As concentrações de equilíbrio na fase aquosa de espécies de neodímio são avaliadas usando a técnica de equilíbrio de reação química apropriada para entender a distribuição de várias formas de íons de $\mathrm{Nd}$ (III) em solução. Os cátions de neodímio são conhecidos por existir nas seguintes formas, dependendo do $\mathrm{pH}$ da solução aquosa. O mecanismo de reação proposto por Park \&Tavlarides (2010) segue:

$$
\begin{gathered}
\mathrm{Nd}^{3+}+\mathrm{H}_{2} \mathrm{O} \Leftrightarrow \mathrm{Nd}(\mathrm{OH})_{2}+\mathrm{H}^{+} \quad \log \mathrm{K}=-8 \\
\mathrm{Nd}^{3+}+2 \mathrm{H}_{2} \mathrm{O} \Leftrightarrow \mathrm{Nd}(\mathrm{OH})_{2}^{+}+2 \mathrm{H}^{+} \log \mathrm{K}=-16,7 \\
\mathrm{Nd}^{3+}+3 \mathrm{H}_{2} \mathrm{O} \Leftrightarrow \mathrm{Nd}(\mathrm{OH})_{3}+3 \mathrm{H}^{+} \log \mathrm{K}=-26,5 \\
\mathrm{Nd}^{3+}+4 \mathrm{H}_{2} \mathrm{O} \Leftrightarrow \mathrm{Nd}(\mathrm{OH})_{4}+4 \mathrm{H}^{+} \log \mathrm{K}=-37,1
\end{gathered}
$$

As Figura 24,Figura 25,e Figura 26 mostram os respectivos diagramas de especiação do $\mathrm{Nd}$ (III), em concentrações diferentes, calculada com as constantes termodinâmicas foram elaborados pelo software make equilibrium diagrams using sophisticated algorithms (MEDUSA). Evidentemente, é perceptível através dos gráficos que há um deslocamento na formação dos primeiros hidróxidos 
complexos das espécies de $\mathrm{Nd}$ (III) à medida que a concentração é variada, entre $250 \mathrm{mg} / \mathrm{L}\left(1,7 \times 10^{-3} \mathrm{~mol} / \mathrm{L}\right), 500 \mathrm{mg} / \mathrm{L}\left(4,8 \times 10^{-3} \mathrm{~mol} / \mathrm{L}\right) 890 \mathrm{mg} / \mathrm{L}\left(6,2 \times 10^{-3} \mathrm{~mol} / \mathrm{L}\right)$. Estas foram as concentrações utilizadas nos ensaios de adsorção.

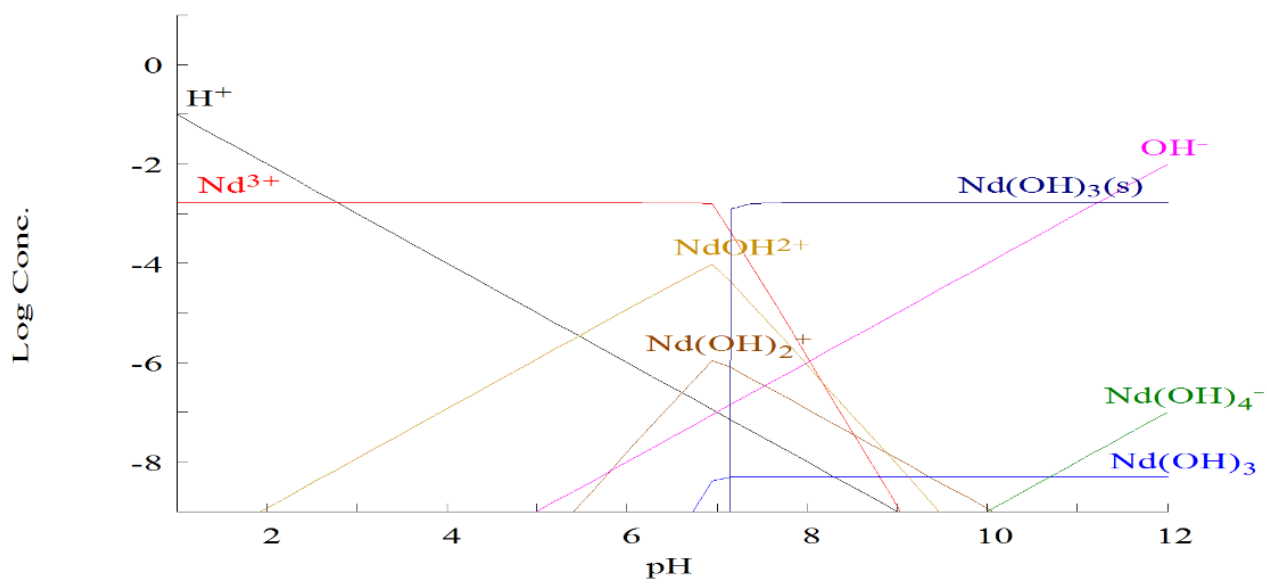

Figura 24- Diagrama de distribuição de espécies do Nd (III) em solução aquosa na concentração de $1,7 \times 10^{-3} \mathrm{~mol} / \mathrm{L}$

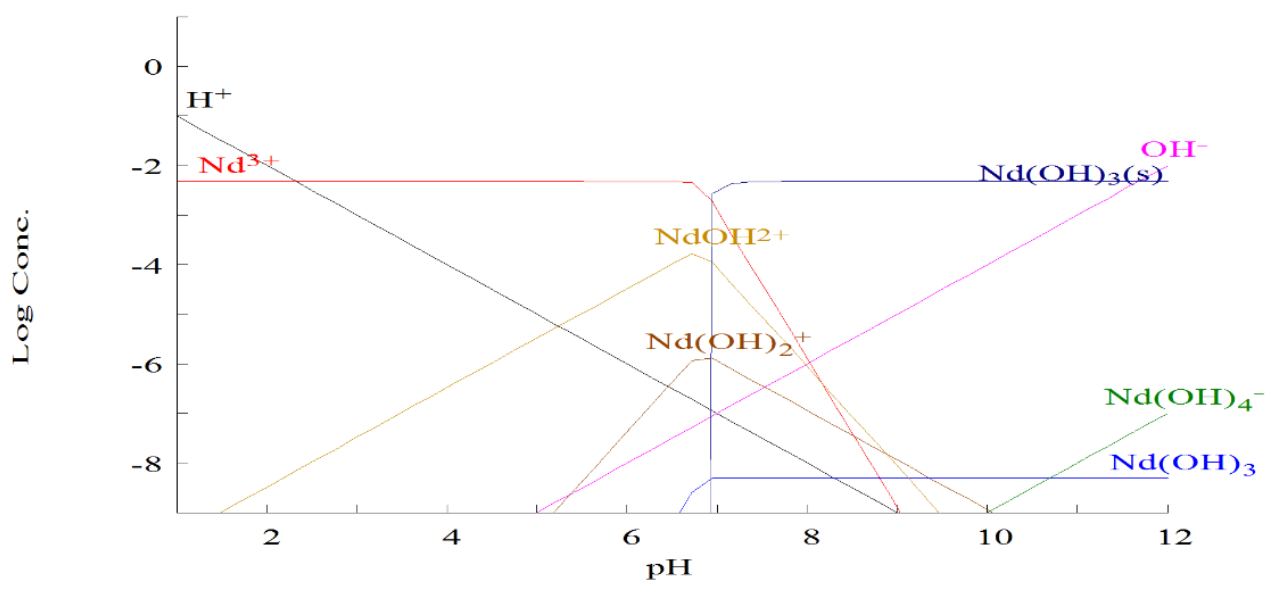

Figura 25- Diagrama de distribuição de espécies do Nd (III) em solução aquosa na concentração de $4,8 \times 10^{-3} \mathrm{~mol} / \mathrm{L}$ 


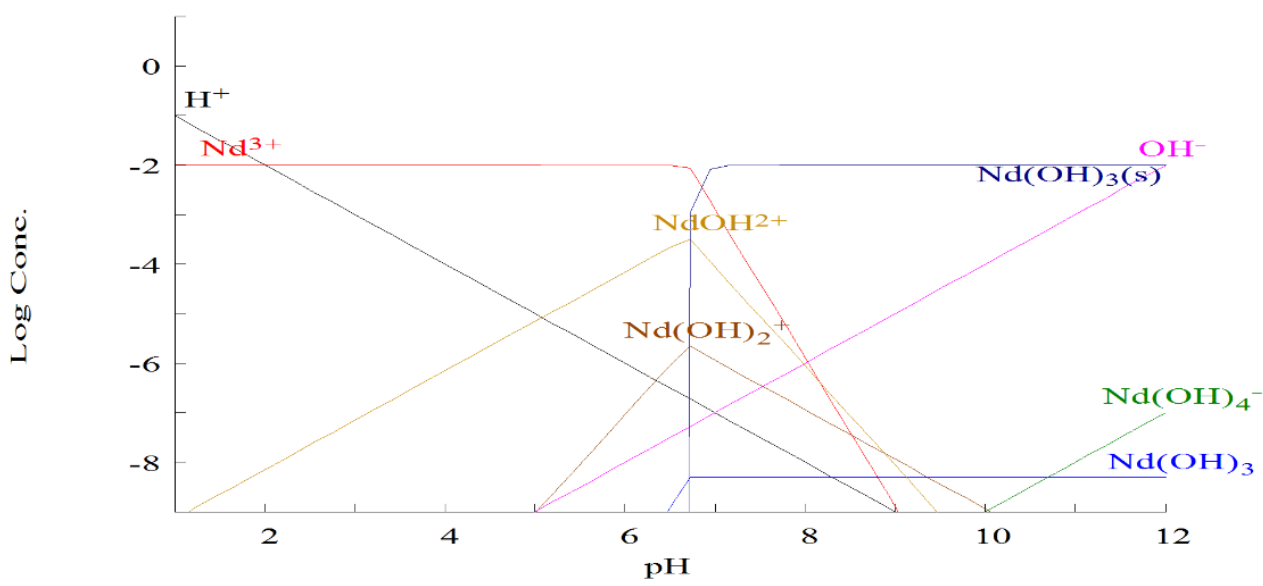

Figura 26- Diagrama de distribuição de espécies do Nd (III) em solução aquosa na concentração $6,2 \times 10^{-3} \mathrm{~mol} / \mathrm{L}$

As espécies de íons de neodímio na solução aquosa avaliadas usando as análises mostram que $\mathrm{Nd}$ (III) é a principal espécie em solução ácida, e a formação de $\mathrm{Nd}(\mathrm{OH})_{2}$ ocorre acima de $\mathrm{pH} 5,5$. A hidrólise acontece muito rapidamente em uma estreita faixa de $\mathrm{pH}$ de $\mathrm{Nd}(\mathrm{III})$ a $\mathrm{Nd}(\mathrm{OH})_{3}$, com evidência de espécies intermediárias como $\mathrm{Nd}(\mathrm{OH})_{2}$ ou $\mathrm{Nd}(\mathrm{OH})^{2+}$.(Park \& Tavlarides, 2010).

Segundo o diagrama de distribuição de espécies do $\mathrm{Nd}$ (III) a formação dos primeiros hidróxidos complexos se dá em pH ácido dependendo da concentração a ser utilizada. Quanto maior a concentração de neodímio em solução, há formação de hidróxido complexo de neodímio, que não são predominantes, mas a máxima concentração ocorre em pH mais baixo e a precipitação por sua vez ocorre em $\mathrm{pH}$ mais baixo. A predominância das espécies hidrolisadas de $\mathrm{Nd}$ desloca-se para valores de $\mathrm{pH}$ mais básicos à medida que a concentração do íon em solução aquosa aumenta. O neodímio como espécie pura $\left(\mathrm{Nd}^{3+}\right)$ pode eventualmente começar a desaparecer, indicando que com o aumento da concentração dos íons metálicos existe a possibilidade do aparecimento dos hidróxidos de neodímio em sua forma $\mathrm{Nd}(\mathrm{OH})_{3}(\mathrm{~s})$. Esse indicativo termodinâmico verificado através dos diagramas de especiação pode estar correlacionada com as curvas de potencial zeta representadas na Figura 21. A medida em que a concentração aumentou de $250 \mathrm{mg} / \mathrm{L}$ para $890 \mathrm{mg} / \mathrm{L}$ os potencias foram ficando menos negativo até alcançar uma reversão de carga ao redor de 7,23 na concentração de $890 \mathrm{mg} / \mathrm{L}$ o que sugere que na presença de palygorskita houve algum tipo de interação. O hidróxido de neodímio pode apresentar uma reversão de carga em valores de pH próximo ao do óxido, dessa maneira essa reversão também pode correlacionar-se aos diagramas de especiação. É verificado que o 
hidróxido complexo na forma $\mathrm{Nd}(\mathrm{OH})_{3}$ aparece em uma faixa estreita em que $\mathrm{Nd}(\mathrm{OH})_{3}(\mathrm{~s})$ também aparece indicando que esta espécie possa estar heterocoagulado na superfície do mineral.

Similaridades também foram reportadas entre a dependência do $\mathrm{pH}$ e a adsorção para lantanídeos (III) (Wang et al.,2006; Pathak et al.,2007; Kosmulski 1997). Estes resultados são consistentes com os comentários anteriores sobre a química dos grupos reativos e as espécies metálicas.

Nos ensaios de adsorção de íons metálicos, altos valores de $\mathrm{pH}$ devem ser evitados objetivando a não ocorrência de precipitação dos metais, e por conseguinte a percepção entre os fenômenos de adsorção e precipitação sejam distinguidas.

Pode ser verificado a partir dos resultados demonstrados na Figura 27 que os melhores resultados para o Nd (III) ocorreram em pH 5. Gok (2014) verificou um pH onde se observou que a melhor captação de íons $\mathrm{Nd}$ (III) acontecia em 5,5 utilizando um adsorvente magnético de nano hydroxiapatita corroborando a concordância com o que é reportado na literatura.

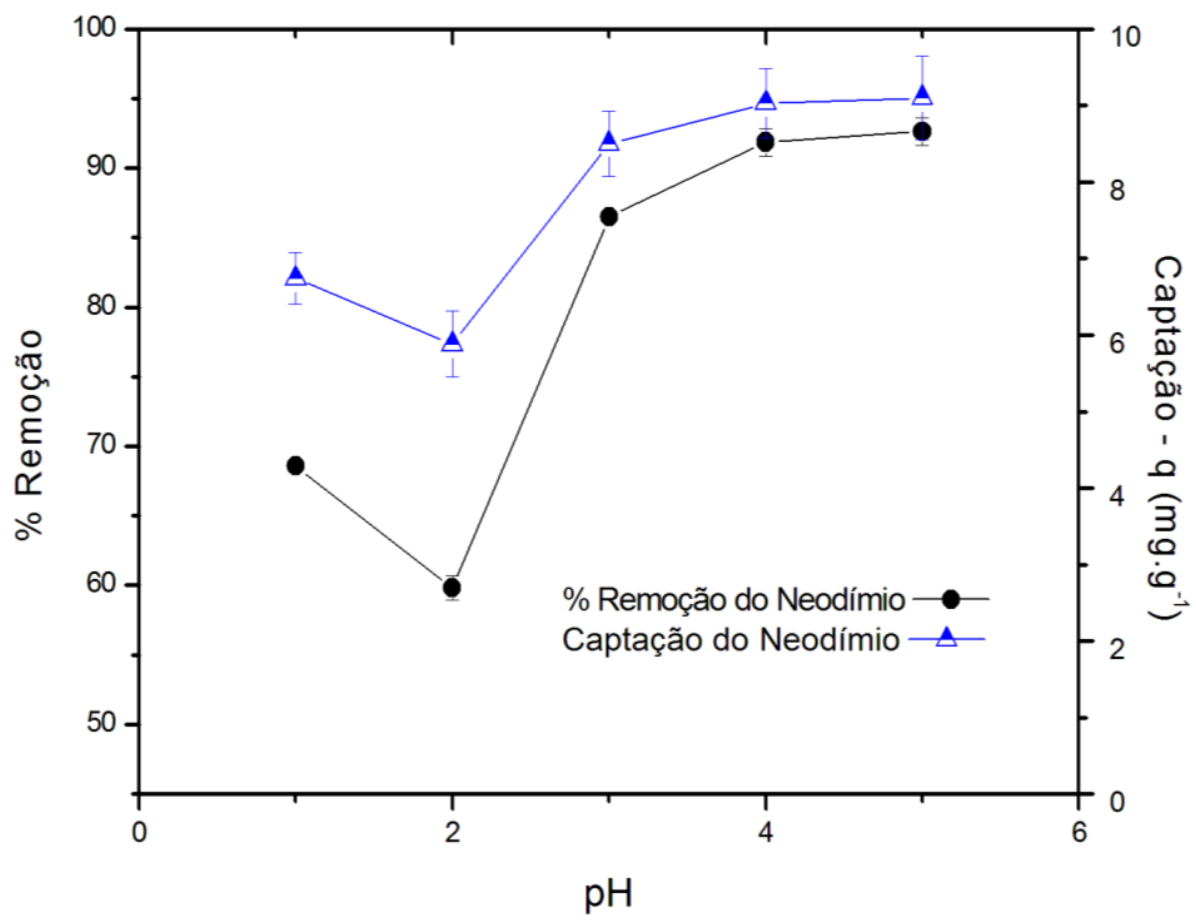

Figura 27- Influência do pH na adsorção do Nd (III)

A porcentagem de remoção da espécie metálica $\mathrm{Nd}$ (III) foi calculada mediante a Equação 36: 


$$
\% \text { Remoção }=\frac{C_{i}-C_{e}}{C i} \times 100
$$

A valores atribuídos a um pH 4 a remoção foi de $91,86 \%$ enquanto a um pH 5 a porcentagem de remoção alcançada foi de $92,62 \%$. A máxima remoção de Nd (III) por Sargassum sp., (Oliveira,2011) está em consonância com o pH de adsorção do Nd (III) utilizando palygorskita como adsorvente.

Observa-se que um incremento no $\mathrm{pH}$ leva a um aumento na porcentagem de remoção do metal, contudo valores maiores valores de $\mathrm{pH}$ podem levar a precipitação do íon metálico, fato este que levou a não utilização de uma faixa abrangente de $\mathrm{pH}$. Em baixo valor de $\mathrm{pH}$ há forte competição entre os íons de hidrogênio e os íons metálicos para os sítios ativos.

Romera et al.,(2007) realizaram uma série de testes de biossorção utilizando 6 algas diferentes a valores de $\mathrm{pH}$ entre 2 e 6 e relataram que $\mathrm{opH}$ afetou a eficiência de biossorção em todas as seis algas similarmente, com maior atração elétrica a ions de metal carregados positivamente ocorrendo em valores de $\mathrm{pH}$ mais altos.

Sabe-se que as argilas possuem carga superficial negativa, por conseguinte à medida que o pH muda, a carga superficial também se altera, e a sorção de espécies carregadas é afetada (atração entre o íon metálico carregado positivamente e a superfície da argila carregada negativamente). É concebível que em valores baixos de $\mathrm{pH}$, onde há um excesso de íons $\mathrm{H}_{3} \mathrm{O}^{+}$em solução, existe uma competição entre os íons de hidrogênio e os íons metálicos carregados positivamente para os locais de adsorção disponíveis na superfície da argila carregada.

À medida que o pH aumenta e o equilíbrio entre $\mathrm{H}_{3} \mathrm{O}^{+} \mathrm{e} \mathrm{OH}$ se tornam mais igualitários, os íns metálicos carregados positivamente na solução são adsorvidos na superfície negativa da argila e, assim, a porcentagem de remoção dos íons metálicos aumenta.

Coetzee et al. (2003) e Potgieter et al (2006) observaram o mesmo comportamento utilizando a palygorskita como adsorvente para metais. Por outro lado, a precipitação de hidróxidos metálicos também pode ocorrer à medida que o pH da solução torna-se de neutro a ligeiramente básico, o que levará a uma diminuição correspondente na quantidade de íons metálicos adsorvidos na argila. 


\subsection{3.}

\section{Influência da concentração inicial do íon metálico}

A concentração inicial dos íons metálicos é uma variável importante para realização e eficiência do processo de adsorção. Segundo Demey et al.,(2018) o aumento da concentração do íon metálico aumenta progressivamente a remoção do metal até atingir um patamar de saturação.

A modelagem juntamente com a análise dos dados de equilibro permitem o desenvolvimento das isotermas de adsorção que são cruciais na tradução de resultados laboratoriais para aplicações reais, pois auxiliam na compreensão dos mecanismos do processo, na análise de dados experimentais, na previsão de respostas a condições operacionais e na otimização de processos (Vijayaraghavan \& Yun,2010).

Os modelos de isotermas de adsorção são amplamente utilizados para fornecer informações sobre a quantidade de íons adsorvidos por um determinado adsorvente e sobre a interação entre os adsorventes e o adsorvato. (Bharathi \& Ramesh,2013).

O método dos mínimos quadrados é utilizado para ajustar pontos experimentais ao cálculo teórico. Este método minimiza a soma dos quadrados de erros entre pontos experimentais e teóricos. Na modelagem de adsorção, as isotermas são dadas usualmente em sua forma linearizada. Como a linearização dos dados transformados implica na alteração de distribuição do erro, ou seja, se os erros do modelo não linear satisfazem as suposições usuais de normalidade, independência e homogeneidade da variância, os erros do novo modelo, em geral, não satisfazem tais suposições (Foo \& Hameed,2010).

Dessa maneira, neste estudo foi comparado os modelos linearizados tanto como não linearizados. A regressão não linear oferece a possibilidade de um ajuste mais rigoroso. Para o ajuste de dados foram empregadas regressões lineares e não lineares baseadas no método dos mínimos quadrados para determinar os parâmetros das isotermas linearizadas e não linearizadas.

Para medir a qualidade do ajuste, foram utilizadas várias funções de erro, que incluem o coeficiente de correlação $\left(R^{2}\right)$ e o erro médio quadrático residual (RMSE) definidos pelas seguintes expressões:

$$
R^{2}=1-\frac{\sum_{i=1}^{i=n}\left(q_{\text {exp }, i}-q_{c a l c, i}\right)^{2}}{\sum_{i=1}^{n}\left(q_{\text {exp }, i}-\bar{q}_{\text {exp }}\right)^{2}}
$$


Onde:

$q_{\text {exp,i }}:$ Valores de $q_{\mathrm{e}}$ obtidos experimentalmente

$\bar{q}_{\text {exp }}:$ Média dos valores de $q_{\mathrm{e}}$ obtidos experimentalmente

$q_{c a l c, i}$ :valores de $q_{e}$ calculados do modelo.

Usualmente a valores de $\mathrm{R}^{2}$ próximo de um indicam que o modelo está bem ajustado.

O erro da raiz quadrada média residual (RMSE), é um ajuste onde utiliza-se a raiz do erro quadrático da diferença entre a predição e dos valores reais.

$$
R M S E=\sqrt{\frac{1}{n_{e}-2} \sum\left(q_{\text {exp }, i}-q_{c a l c, i}\right)^{2}}
$$

Onde:

$q_{\text {exp,i }}:$ Valores de $q_{\mathrm{e}}$ obtidos experimentalmente

$q_{\text {calc,i }}:$ Valores de $q_{\mathrm{e}}$ calculados do modelo.

Valores de RMSE menores indicam melhor ajuste da curva. Os parâmetros dos modelos de isotermas de adsorção foram estimados através do software OriginPro 6.0.

A Figura 28 representa a isoterma de adsorção dos cátions metálicos do $\mathrm{Nd}$ (III), em que, no eixo das ordenadas, estão plotadas as quantidades de íon adsorvido por unidade de massa do adsorvente $\left(q_{\mathrm{e}}\right)$, enquanto que, no eixo das abcissas tem-se a concentração de $\mathrm{Nd}$ (III) em solução após o equilíbrio $\left(\mathrm{C}_{\mathrm{e}}\right)$. Os experimentos foram realizados para uma faixa de concentração inicial que abrange de 40 a 890 mg/L, mantendo constantes os demais parâmetros. 


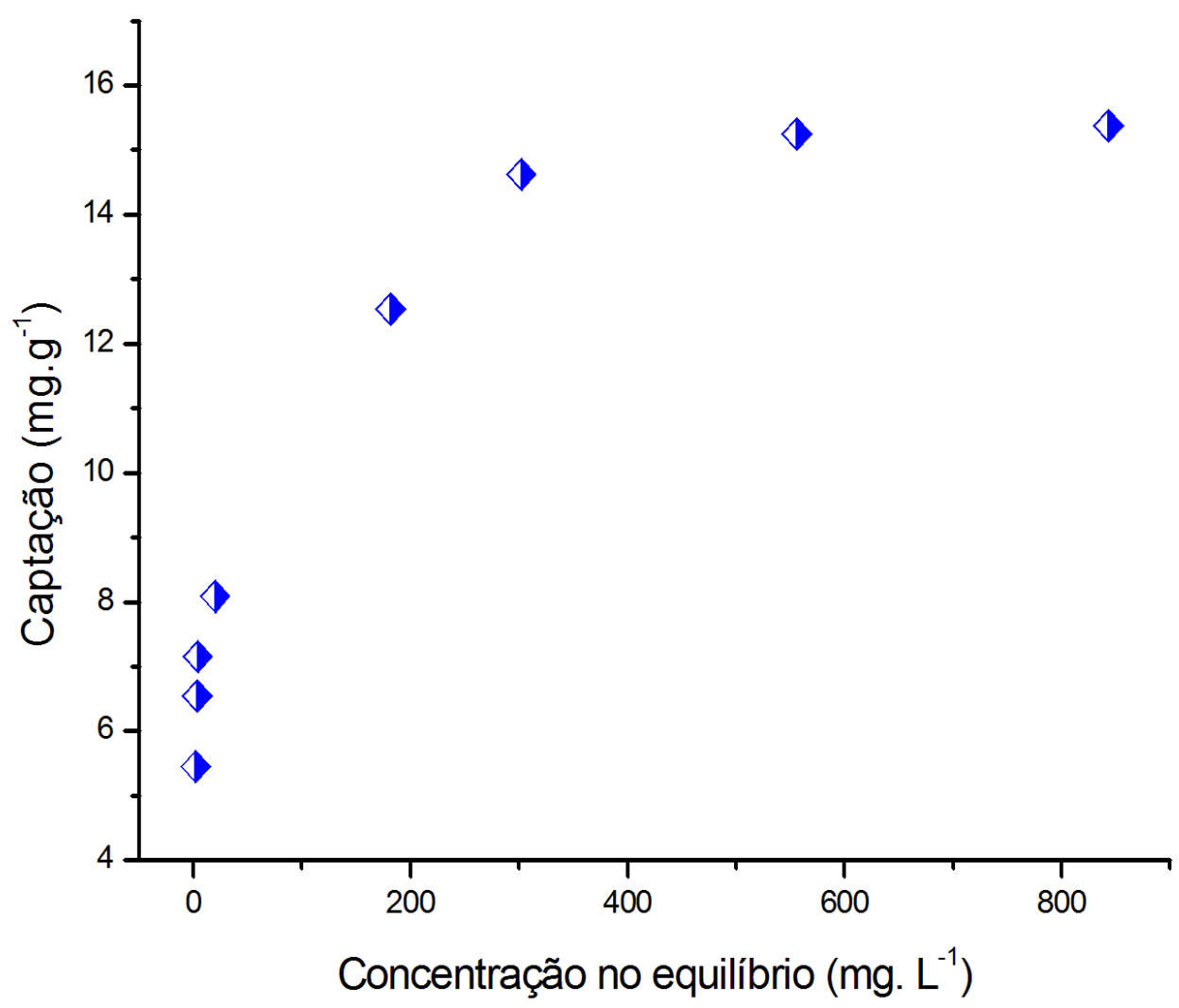

Figura 28- Isoterma de adsorção em função da concentração de equilíbrio do $\mathrm{Nd}$ (III). (pH: 5 ; concentração inicial de palygorskita: $2 \mathrm{~g}$; temperatura: $30^{\circ} \mathrm{C}$; Tempo de contato: $60 \mathrm{~min})$

Podemos observar a partir da Figura 28 que para valores da concentração inicial de íon metálico de $890 \mathrm{mg} / \mathrm{L}$ o valor de $q_{e}$ encontrado foi de $15,375 \mathrm{mg} / \mathrm{g}$ de $\mathrm{Nd}$ (III).

Nessa perspectiva, vários modelos são propostos para descrever isotermas e eles são comprovadamente bem-sucedidos para o mecanismo de sorção (Liu e Liu,2008). Mesmo que sejam modelos empíricos com relações matemáticas simples, caracterizados pelo número de parâmetros ajustáveis, eles geralmente dão boa descrição do comportamento experimental sobre uma grande variedade de condições de operação (Esposito et al.,2002; Vijayaraghavan \& Yun,2008).

Para esta pesquisa os dados foram ajustados segundo as equações de Langmuir, Freundlich, Tenkim, Dubinin Radushkevich, Redlich-Peterson e Sips. 


\section{ISOTERMA DE LANGMUIR}

Evidentemente é um dos modelos mais tradicionais, para a representação dos processos de sorção. Segundo Cooney (1998), as suposições decorrentes da equação de Langmuir, são explicadas a partir das considerações feitas em decorrência do seu desenvolvimento. O contato de uma solução aquosa com um adsorvente, depois de um certo período de tempo atinge um equilíbrio, que nada mais é do que a igualdade da velocidade das moléculas ou íons que são adsorvidos na superfície do adsorvente, isto significa que se a velocidade (taxa) é proporcional à concentração do adsorvato na solução aquosa $\left(\mathrm{C}_{\mathrm{e}}\right)$.

Além disso, pode-se admitir o fato de que a cobertura da camada superficial se dá de maneira monoelementar, isto é, somente é possível a formação de uma monocamada na superfície externa do adsorvente, contendo um número finito de locais idênticos e após isso nenhuma adsorção adicional ocorre.

Dessa maneira, a isoterma de Langmuir baseia-se em três hipóteses, a saber: a sorção é limitada à cobertura monocamada, todos os sítios superficiais são semelhantes e só podem acomodar um átomo adsorvido e a capacidade de uma molécula ser adsorvida em um determinado local é independente de sua ocupação. Dentro do modelo de Langmuir, a capacidade de saturação $q_{\max }$ deve coincidir com a saturação de um número fixo de locais de superfície idênticos representando a distribuição de equilíbrio dos íons metálicos entre as fases sólida e líquida, onde assume energias uniformes de adsorção na superfície e nenhuma transmigração de adsorvato no plano da superfície (Hall et al.,1966).

Os ajustes dos dados de adsorção do neodímio às equações linearizadas e não linearizadas dos modelos de Langmuir encontram-se nas Figura 29 e Figura 30 respectivamente. 


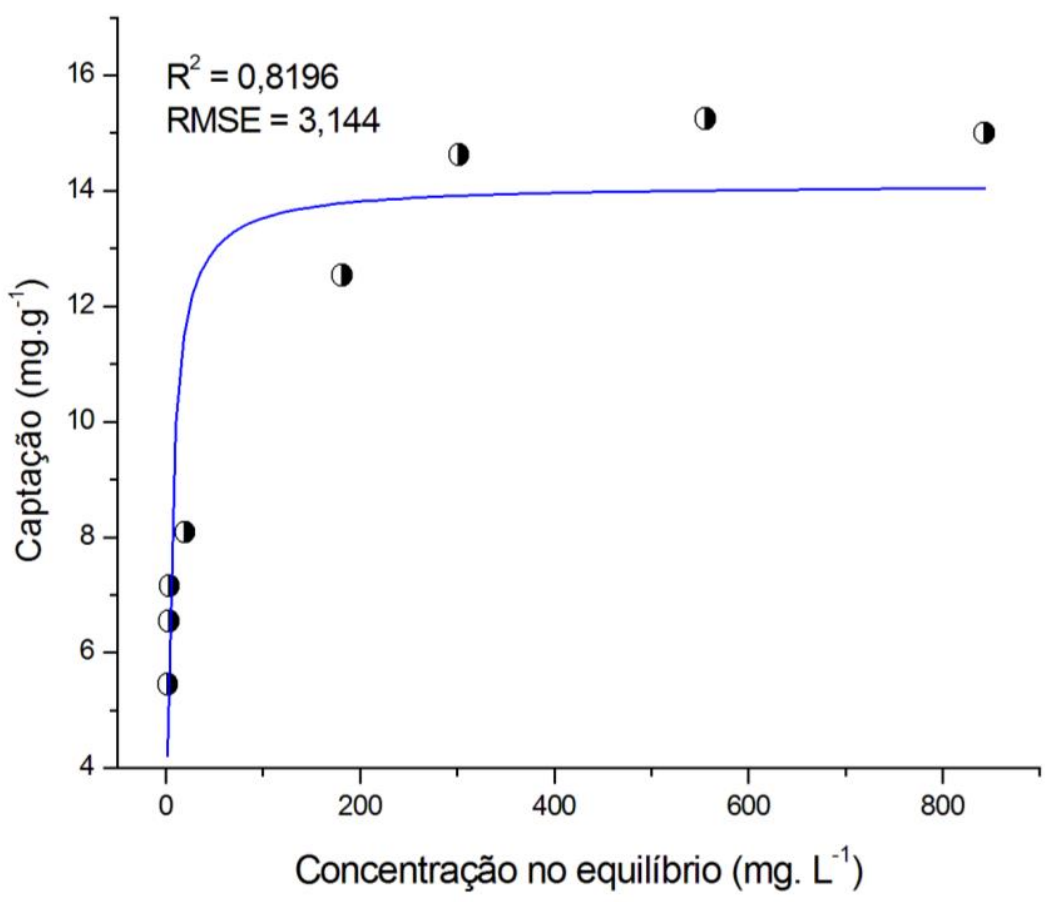

Figura 29- Isoterma de Langmuir para o neodímio na forma não linearizada $\mathrm{pH}$ : 5; Concentração inicial de palygorskita: $2 \mathrm{~g}$; temperatura: $30^{\circ} \mathrm{C}$; tempo de contato: $60 \mathrm{~min}$ )

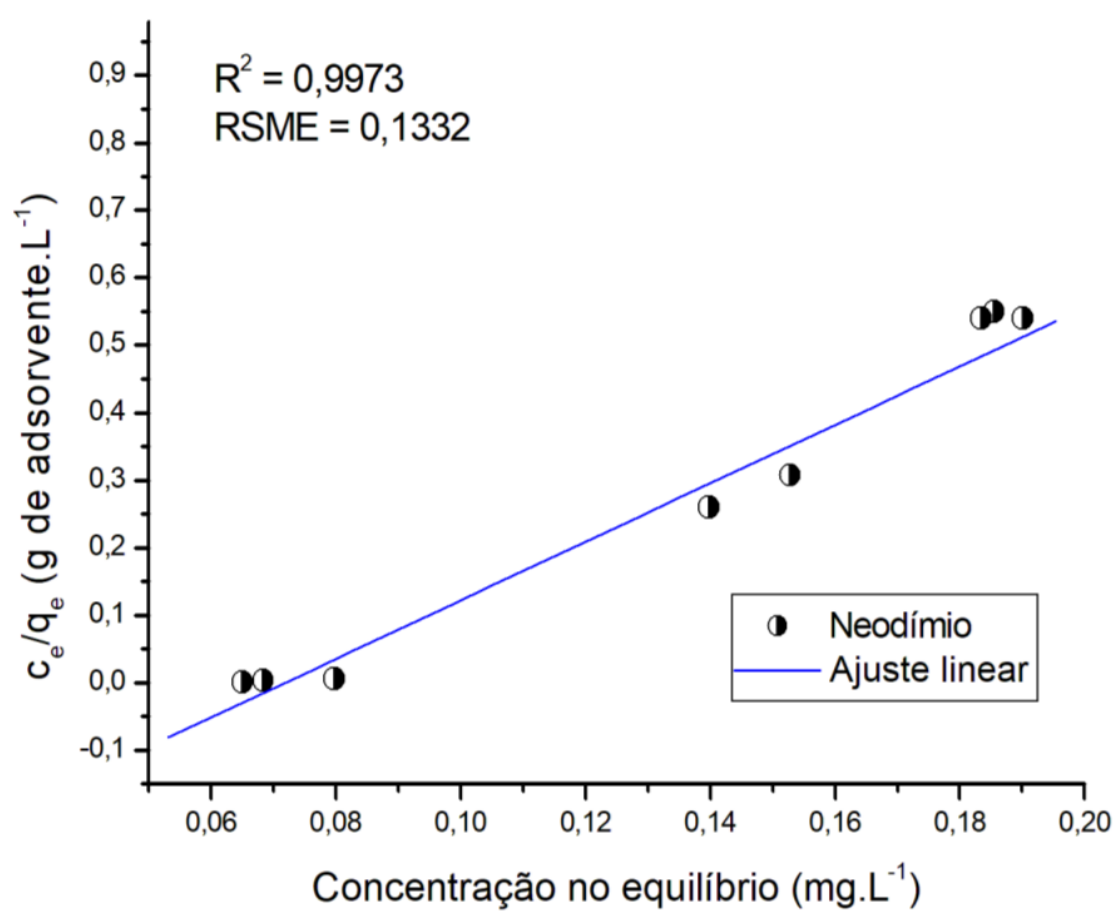

Figura 30-Isoterma de Langmuir linearizada para neodímio $(\mathrm{pH}$ : 5; Concentração inicial de palygorskita: $2 \mathrm{~g}$; temperatura: $30^{\circ} \mathrm{C}$; tempo de contato: $60 \mathrm{~min}$ ) 
Nessa perspectiva, como visto anteriormente através da equação 8 é possível expressar a isoterma de Langmuir linearizada e determinar os parâmetros $C_{e}, q_{\max } e K_{L}$ através da inclinação e interceptação do gráfico linearizado de Langmuir apresentados na Tabela 16

Tabela 16- Constantes de adsorção para Neodímio a $30^{\circ} \mathrm{C}$

\begin{tabular}{ccccc}
\hline & \multicolumn{4}{c}{ Parâmetros } \\
\cline { 2 - 5 } Modelo & $\mathbf{q}_{\text {máx }}(\mathbf{m g} / \mathbf{L})$ & $\mathbf{K}_{\mathbf{L}}(\mathbf{L} / \mathbf{m g})$ & $\mathbf{R}^{\mathbf{2}}$ & $\mathbf{R M S E}$ \\
Ajuste Linear & 15,46 & 0,077 & 0,99725 & 1,1131 \\
Ajuste não linear & 14,11 & 0,069 & 0,81968 & 3,144 \\
\hline
\end{tabular}

O valor da capacidade máxima de captação obtido para esta pesquisa

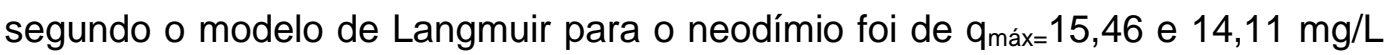
respectivamente segundo os ajustes linear e não linear.

Perfis similares são apontados em estudos como o de Demey et al., (2018) que estudaram vários modelos de isotermas para descrever o equilíbrio da sorção de íons $\mathrm{Nd}$ (III). Utilizando como adsorvente um material sintetizado que contém quitosana e Fe (III), sob temperatura de $20^{\circ} \mathrm{C}$, tempo de contato de $72 \mathrm{~h}, \mathrm{pH}=4$, $1 \mathrm{~g} / \mathrm{L}$ do adsorvente e variando a concentração inicial do íon metálico de 5 a 400 $\mathrm{mg} / \mathrm{L}$ obtiveram capacidade máxima de saturação da monocamada de Langmuir $q_{\text {máx }}=13,8 \mathrm{mg} / \mathrm{L}$, semelhante a apresentada neste trabalho.

Butnariu et al.,(2015) estudaram a adsorção de Neodímio a partir de matéria orgânica natural. O valor de $q_{\text {máx }}$ encontrado foi de $10,75 \mathrm{mg} / \mathrm{L}$, os parâmetros $\mathrm{K}_{\mathrm{L}}=$ 0,349 foi semelhante se comparado com a utilização da palygorskita, e o $R^{2}$ foi de 0,9980 demonstrando um bom ajuste dos dados para este modelo.

No entanto, estudos reportam outros adsorventes os quais possuem uma capacidade de captação maior que a da palygorskita. Gok (2014), estudou a sorção de Neodímio utilizando adsorvente magnético de nanohidroxiapatita variando uma faixa de concentração do íon metálico que ia de 10 a $500 \mathrm{mg} / \mathrm{L}$ utilizando $25 \mathrm{mg}$ do adsorvente a um pH 5,5, temperatura de $25^{\circ} \mathrm{C}$ e tempo de contato de 120 min e obteve um valor de $q_{\text {máx }}=323 \mathrm{mg} / \mathrm{L}$, o modelo de Langmuir o que mais se ajustou aos dados experimentais, obtendo um $R^{2}=0,997$ e um $K_{L}$ $=4,84 \times 10^{-2} \mathrm{~L} / \mathrm{mg}$. 
As características essenciais da isoterma de Langmuir podem ser expressas em termos do parâmetro $R_{L}$, que é uma constante adimesional chamada fator de separação ou parâmetro de equilíbrio (Weber; Chakravorti,1974). Ele indica se o processo de sorção é ou não favorável e é dado pela seguinte expressão:

$$
R_{L}=\frac{1}{1+C_{o} b}
$$

Onde: "b" é a constante de Langmuir e $\mathrm{C}_{\circ}$ é a concentração inicial do metal Para valores de:

- $R_{L}>1$ indica que a natureza da adsorção é desfavorável;

- $R_{L}=1$, indica que a natureza da adsorção é linear;

- $0<R_{L}<1$ indica que a natureza de sorção é favorável;

- $R_{L}=0$ indica que a natureza de sorção é irreversível;

Os valores de $R_{L}$ para o Neodímio calculado foi de $0,1113 \mathrm{mg} / \mathrm{L}$ corroborando que os dados foram bem ajustados ao modelo de Langmuir, e estão de acordo com os resultados obtidos na literatura.

\section{ISOTERMA DE FREUNDLICH}

Desenvolvido com o objetivo de estudar empiricamente a adsorção de gases em superfícies sólidas (Sparks,2003). Tal qual o de Langmuir, o modelo de Freundlich vem sendo amplamente utilizado para descrever a adsorção de íons metálicos com diferentes adsorventes.

Comumentemente utilizado para descrever as características de adsorção para superfícies heterogêneas (Dada et al.,2012), este modelo assume que os sítios que possuem sítios de ligação com maior afinidade são ocupados primeiro. (Vijayaraghavan,2015).

As Figura 31 e Figura 32 apresentam as isotermas de adsorção para o neodímio, segundo o modelo de Freundlich não linearizadas e linearizadas respectivamente. 


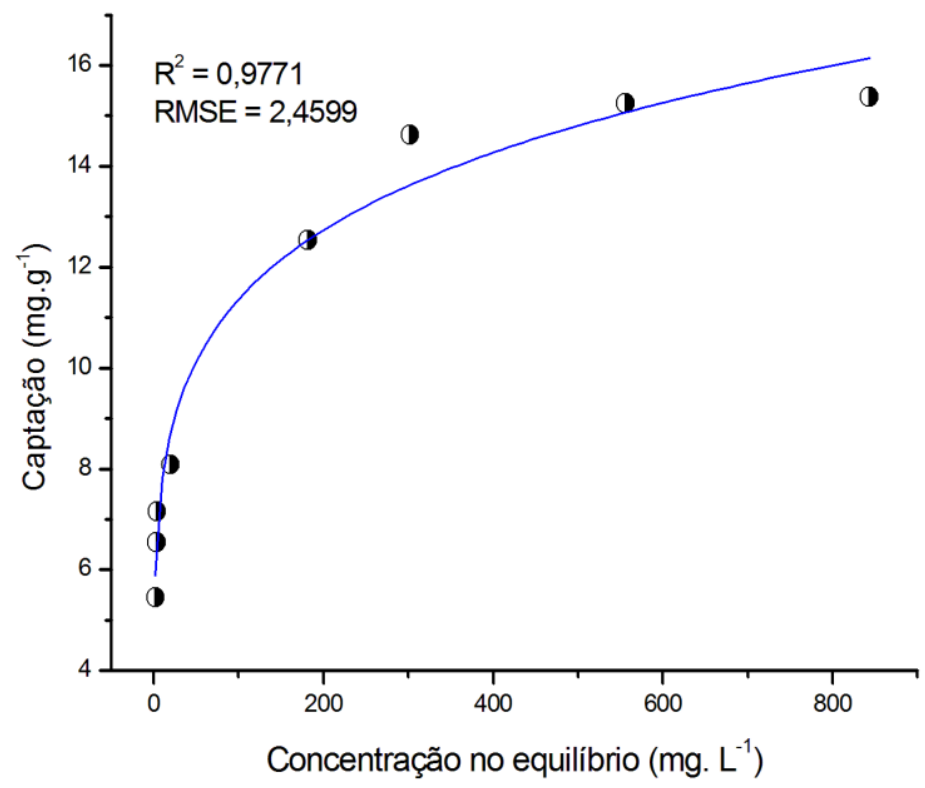

Figura 31- Isoterma de Freundlich para o neodímio na forma não linearizada pH: 5;

Concentração inicial de palygorskita: $2 \mathrm{~g}$; temperatura: $30^{\circ} \mathrm{C}$; tempo de contato: $60 \mathrm{~min}$ )

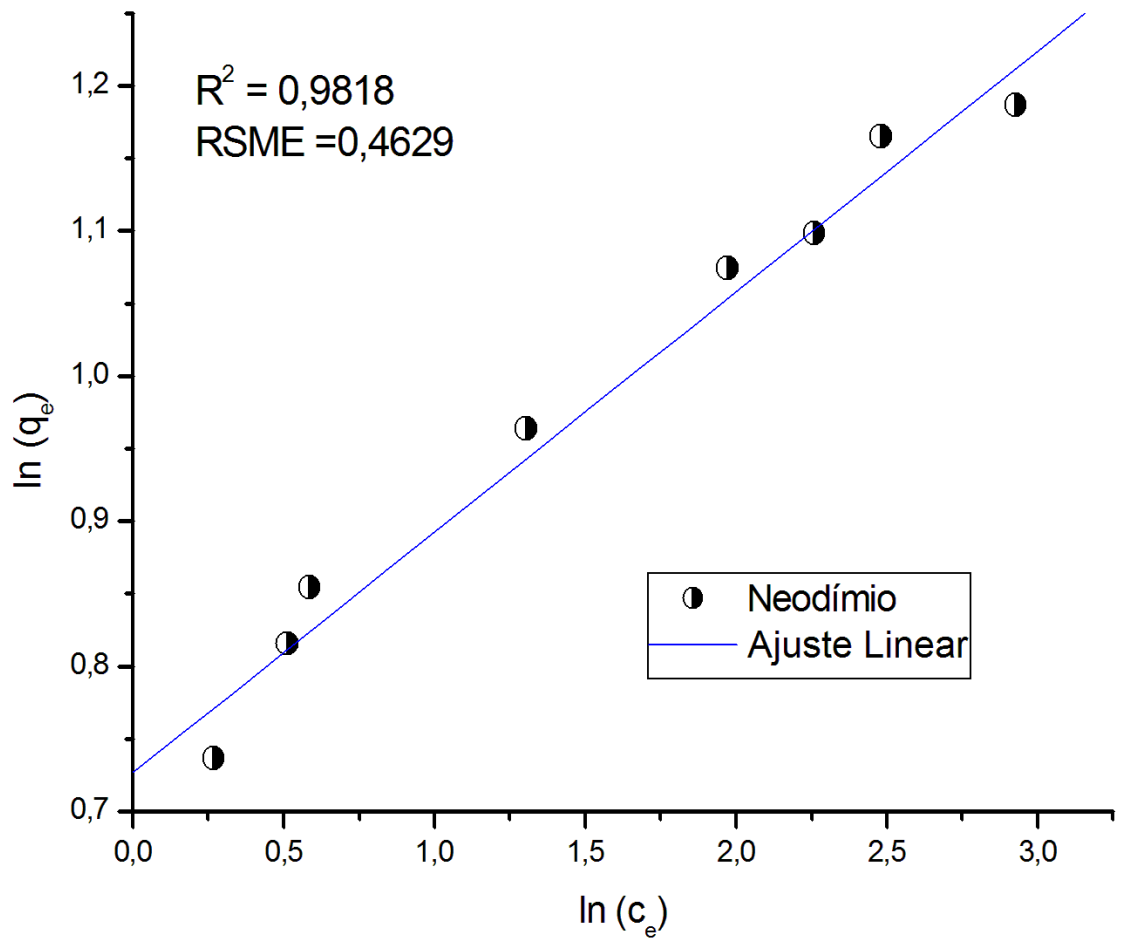

Figura 32-Isoterma de Freundlich para o neodímio na forma linearizada $\mathrm{pH}$ : 5; Concentração inicial de palygorskita: $2 \mathrm{~g}$; temperatura: $30^{\circ} \mathrm{C}$; tempo de contato: $60 \mathrm{~min}$ ) 
Através da Equação 10 a construção da isoterma segundo o modelo de Freundlich é possível. Em pH 5 ambas as constantes atingiram valores máximos. Os parâmetros do modelo calculados por análise de regressão linear e não linear estão listados na Tabela 17, assim como as suas respectivas funções erros associados.

Tabela 17- Constantes de adsorção de Freundlich para neodímio a $30^{\circ} \mathrm{C}$

\begin{tabular}{ccccc}
\hline Modelo & \multicolumn{4}{c}{ Parâmetros } \\
\cline { 2 - 5 } & $\mathbf{K}_{\mathbf{F}}(\mathbf{L} / \mathbf{g})$ & $\mathbf{1 / n}$ & $\mathbf{R}^{\mathbf{2}}$ & RMSE \\
Ajuste não Linear & 5,32 & 0,17 & 0,9771 & 2,4599 \\
Ajuste Linear & 5,33 & 0,19 & 0,9818 & 0,4629 \\
\hline
\end{tabular}

A magnitude dos parâmetros $K_{F}$ e $n$, mostram que é possível uma fácil separação do íon metálico da solução aquosa e uma alta capacidade de adsorção. Analisando o pressuposto sugerido por este modelo, é possível compreender através da análise dos seus parâmetros a respeito da sorção estudada. Para o neodímio, o valor de $n$ encontrado é de 5,26 e 6,07 respectivamente para os ajustes linear e não linear, o que sugere a afinidade do adsorvente e o íon metálico.

Por meio do ajuste de regressão linear, a equação ajustada para o modelo linear apresentou $\mathrm{R}^{2}=0,9818$ o que mostra uma afinidade tão compatível do modelo de Freundlich quanto ao de Langmuir.

Os resultados encontrados no presente estudo estão consonantes com os reportados na literatura. Lajevardi et al.,(2015) em seu estudo sobre adsorção de $\mathrm{Nd}$ (III) utilizando um adsorvente nanoporoso de Fe-MCM-41 constatou que a isoterma de Freundlich também se adequou aos dados experimentais, o parâmetro $1 / n$ obtido em sua pesquisa foi de 0,72 indicando um processo favorável para a adsorção.

Wang et al.,(2013) verificou que ao empregar 0,04g de alginato de cálcio (ALG) e y-ácido poliglutâmico (PGA) em pH 4 para adsorção de $\mathrm{Nd}$ (III) o valor de 1/n para o modelo de Freundlich obtido foi de 0,24 e um $\mathrm{R}^{2}$ de 0,92 corroborando o ajuste favorável da adsorção segundo este modelo. 


\section{ISOTERMA DE TEMKIN}

Essa isoterma contém um fator que explicitamente leva em conta as interações adsorvente-adsorvato. Ao ignorar o valor extremamente baixo e grande de concentrações, o modelo assume que o calor de adsorção (função da temperatura) de todas as moléculas na camada diminuiria linearmente em vez de logarítmica com cobertura.

A Figura 33 e Figura 34 mostra o perfil desta isoterma com seus respectivos ajustes não linear e linear.

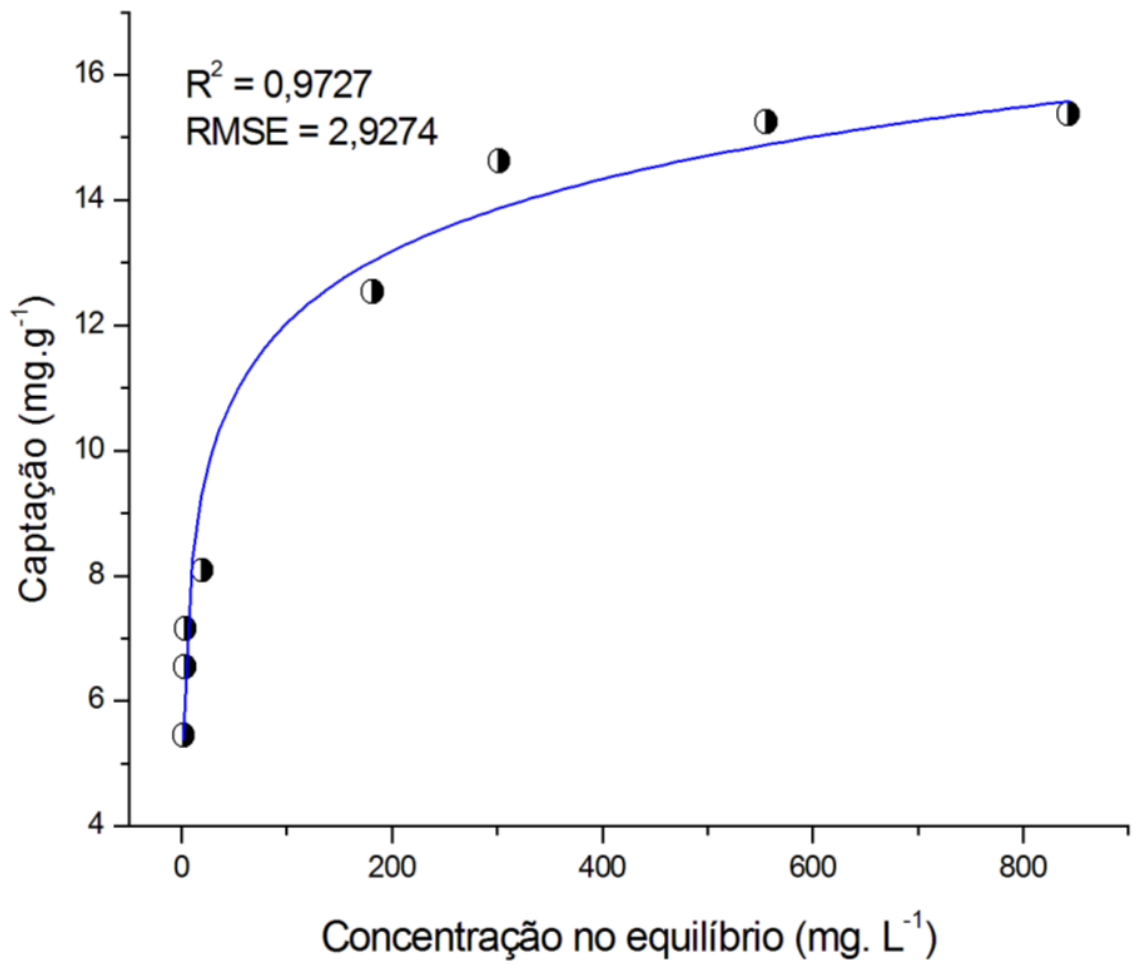

Figura 33 Isoterma de Temkin para o neodímio na forma não linearizada $(\mathrm{pH}: 5$; Concentração inicial de palygorskita: $2 \mathrm{~g}$; temperatura: $30^{\circ} \mathrm{C}$; tempo de contato: $60 \mathrm{~min}$ ) 


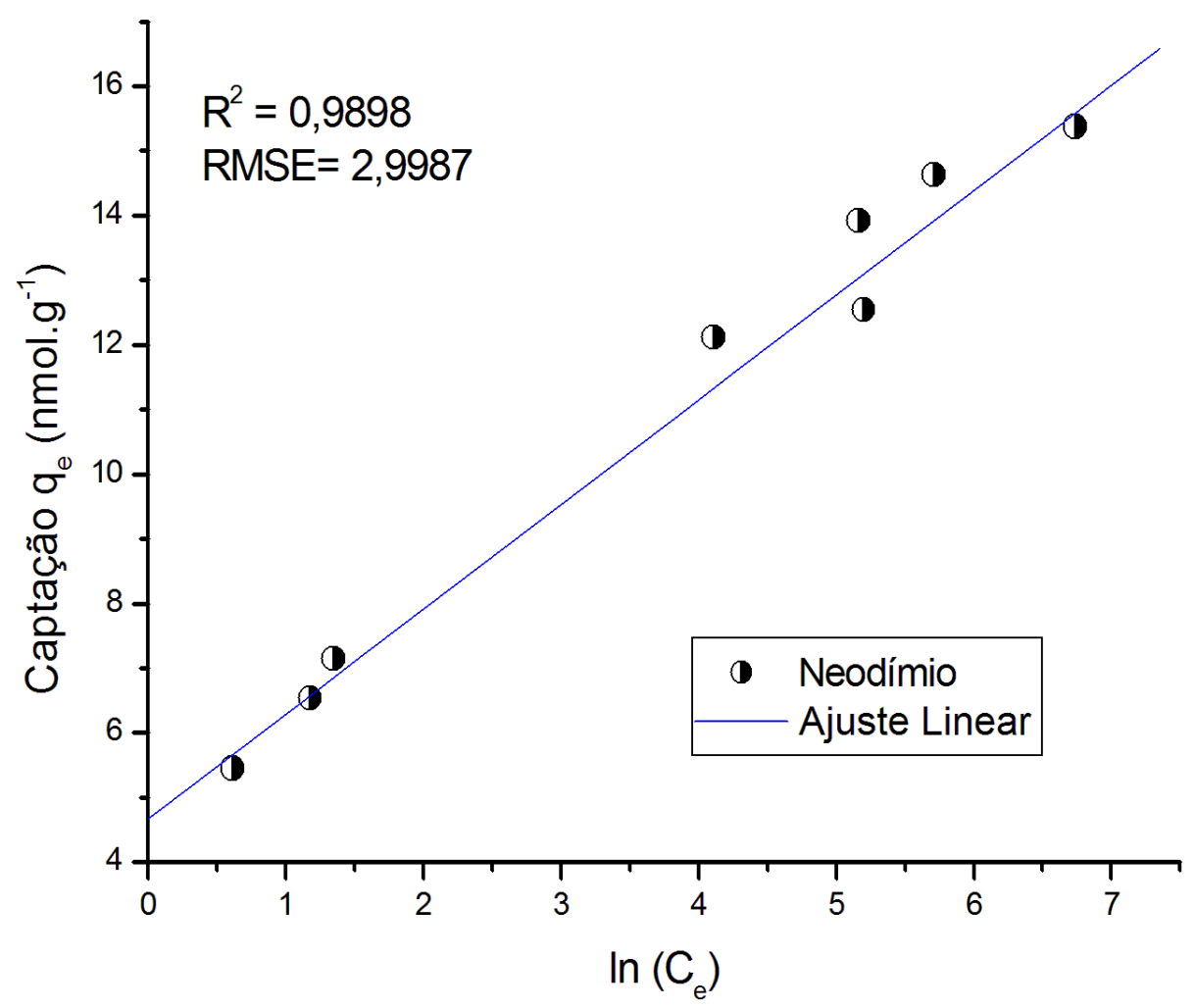

Figura 34 Isoterma de Temkin para o neodímio na forma linearizada $(\mathrm{pH}: 5$; Concentração inicial de palygorskita: $2 \mathrm{~g}$; temperatura: $30^{\circ} \mathrm{C}$; tempo de contato: $60 \mathrm{~min}$ )

Através dos ajustes dos dados experimentais e dos gráficos foi possível estimar os seguintes valores das constantes que serão apresentadas na Tabela 18

Tabela 18- Constantes de adsorção de Temkin para neodímio a $30^{\circ} \mathrm{C}$

\begin{tabular}{ccccc}
\hline \multirow{2}{*}{ Modelo } & \multicolumn{4}{c}{ Parâmetros } \\
\cline { 2 - 5 } & $\mathbf{A}_{\mathbf{T}}(\mathbf{L} / \mathbf{m o l})$ & $\mathbf{b}_{\mathbf{T}}$ & $\mathbf{R}^{\mathbf{2}}$ & RMSE \\
Ajuste não Linear & 13,77 & 57196,70 & 0,9727 & 2,9274 \\
Ajuste Linear & 17,88 & 1556,28 & 0,9898 & 2,9274 \\
\hline
\end{tabular}

Segundo Kim (2004) este tipo de isoterma é mais adequada à descrição de processos de adsorção em meio gasoso, já que fatores que influenciam na complexidade dos sistemas em meio aquoso não são considerados no desenvolvimento como o pH e até mesmo a solubilidade do soluto no meio líquido. Apesar disso, foi possível inferir através do erro $\mathrm{R}^{2}$ que os dados experimentais se adequaram bem ao ajuste linear. Contudo, quando comparado ao ajuste não linear, percebe-se uma discrepância quanto a constante $\mathrm{b}_{\mathrm{T}}$. 


\section{ISOTERMA DE DUBININ-RADUSHKEVICH}

Este modelo, é utilizado para estimar a energia livre aparente de adsorção, propõe uma Equação 14 para avaliar o mecanismo de adsorção assumindo uma superfície heterogênea. Nas Figura 35 e Figura 36 estão a análise de dados ajustados nas suas formas linear e não linear.

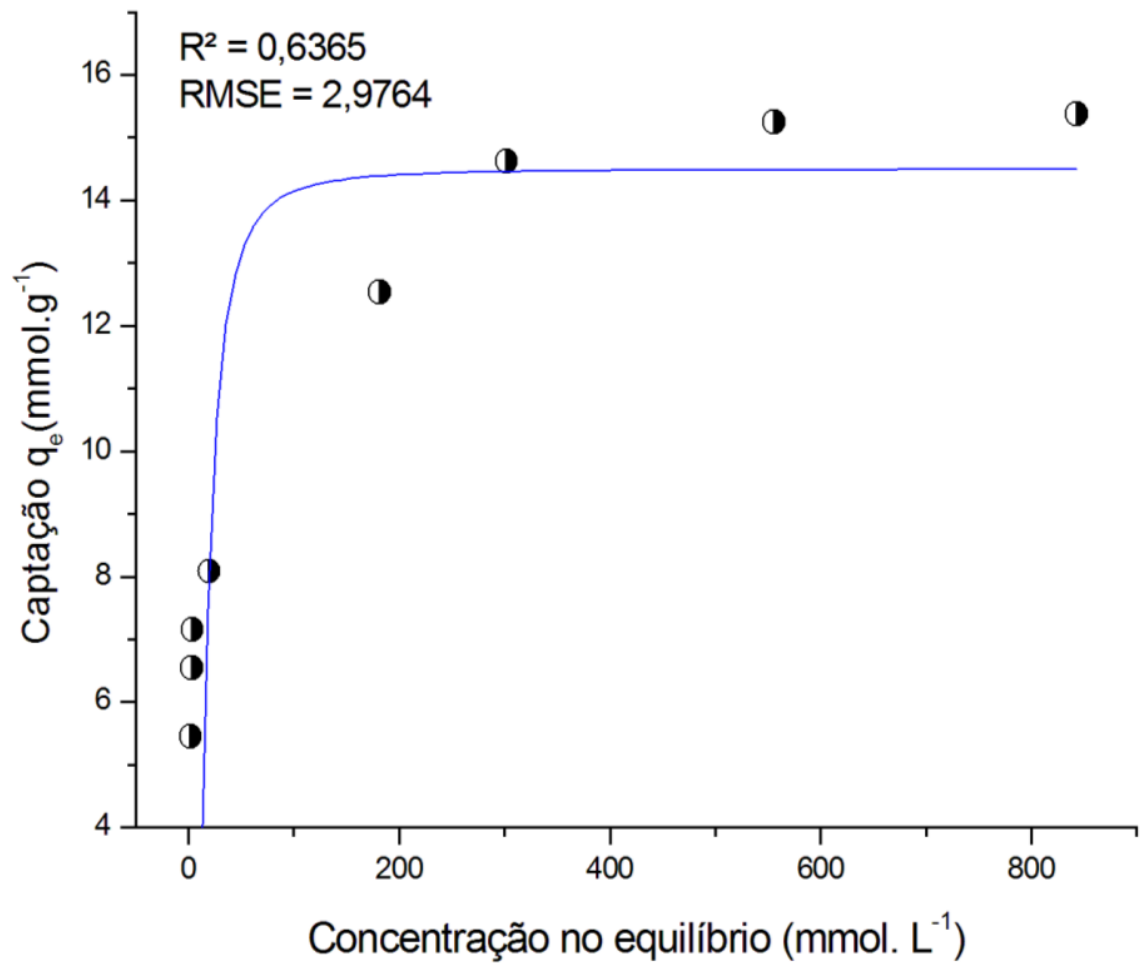

Figura 35 Isoterma de Dubinin-Radushkevich para o neodímio na forma não linearizada ( $\mathrm{pH}$ : 5 ; Concentração inicial de palygorskita: $2 \mathrm{~g}$; temperatura: $30^{\circ} \mathrm{C}$; tempo de contato: $60 \mathrm{~min})$ 


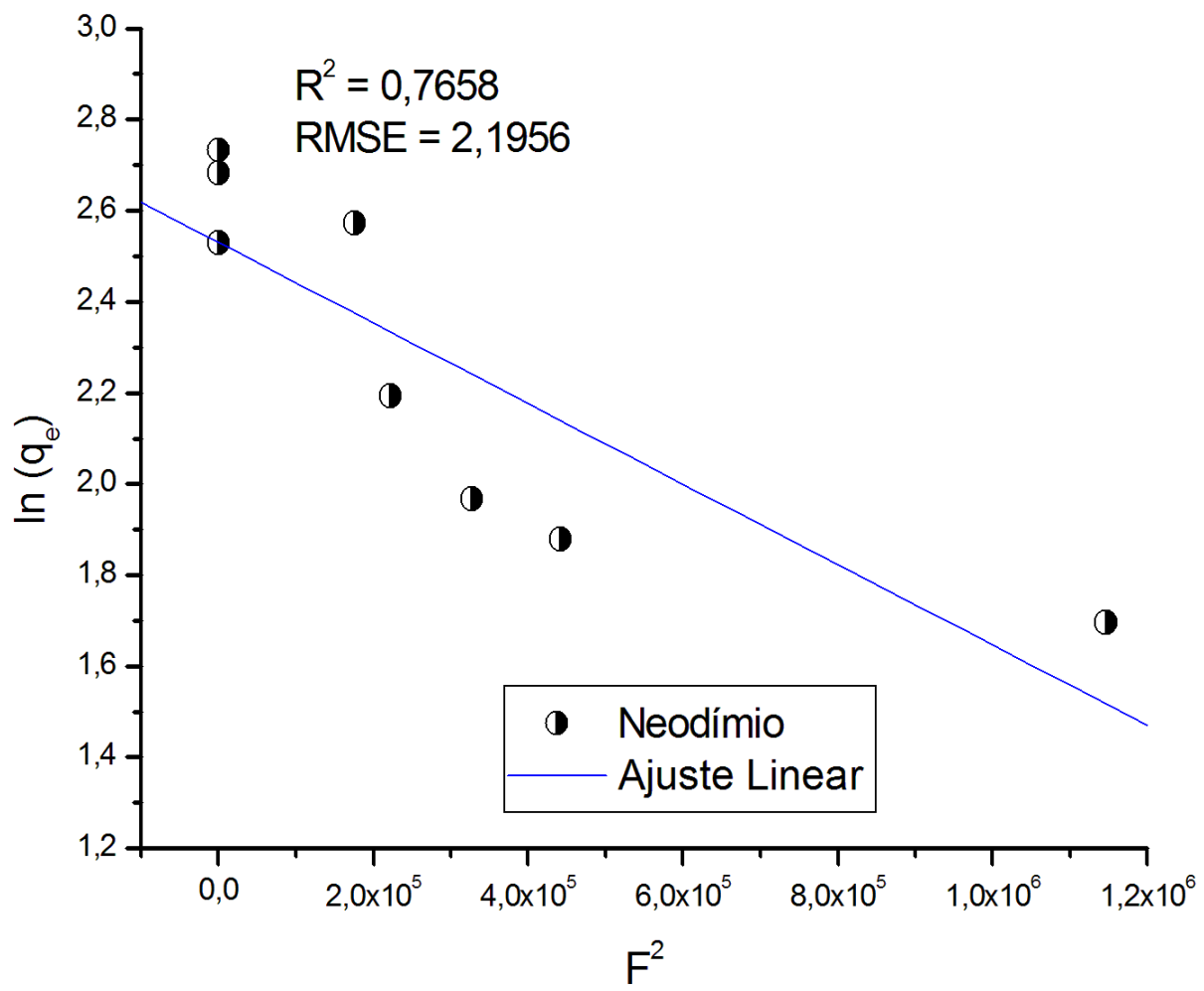

Figura 36- Isoterma de Dubinin-Radushkevich para o neodímio na forma linearizada (pH: 5; Concentração inicial de palygorskita: $2 \mathrm{~g}$; temperatura: $30^{\circ} \mathrm{C}$; tempo de contato: 60 $\min )$

As constantes de adsorção associadas a isoterma de Dubinin Radushkevich estão apresentadas na Tabela 19

Tabela 19- Constantes de adsorção de Dubinin- Radushkevich para neodímio a $30^{\circ} \mathrm{C}$

\begin{tabular}{ccccc}
\hline Modelo & \multicolumn{4}{c}{ Parâmetros } \\
\cline { 2 - 5 } & $\mathbf{Q}_{\mathbf{m a x}}(\mathbf{m m o l} \mathbf{g})$ & $\boldsymbol{\beta}\left(\mathbf{m m o l}^{2} \cdot \mathbf{K J}^{-2}\right)$ & $\mathbf{R}^{\mathbf{2}}$ & $\mathbf{R M S E}$ \\
Ajuste não Linear & 0,014 & $4,00 \times 10^{-5}$ & 0,6365 & 2,9764 \\
Ajuste Linear & 0,012 & $9,00 \times 10^{-7}$ & 0,7658 & 2,1956 \\
\hline
\end{tabular}

$O$ valor calculado para a constante $E_{s}$ na temperatura de $30^{\circ} \mathrm{C}$ foi de 16,1 $\mathrm{KJ} / \mathrm{mol}$ indicando que um processo de adsorção química é pode ser um dos mecanismos predominantes. 


\section{ISOTERMA DE SIPS}

Sips (1948) combinou as características das equações de Langmuir e Freundlich para prever os sistemas heterogêneos de sorção e também para evitar a restrição da concentração de adsorvato crescente associada ao modelo de isoterma de Freundlich.

As Figura 37 e Figura 38 representam o ajuste de dados da isoterma de sips em suas formas não linear e linear.

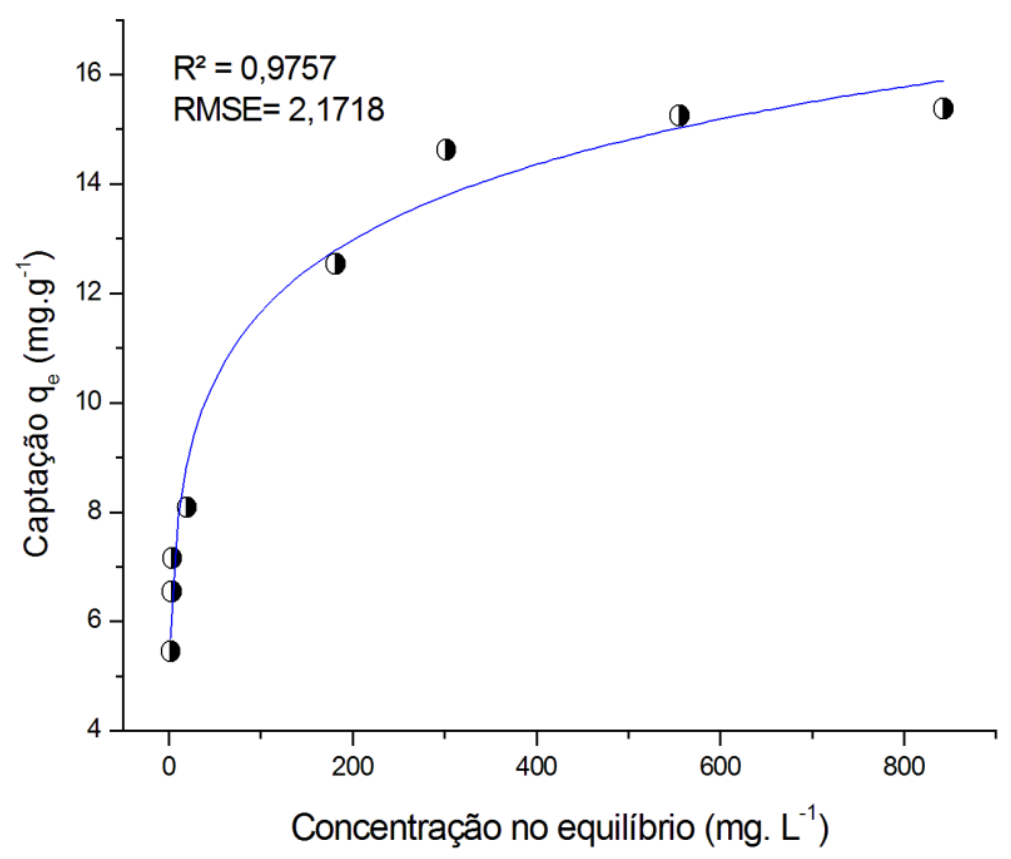

Figura 37 Isoterma de sips para o neodímio na forma não linearizada $(\mathrm{pH}$ : 5; Concentração inicial de palygorskita: $2 \mathrm{~g}$; temperatura: $30^{\circ} \mathrm{C}$; tempo de contato: $60 \mathrm{~min}$ ) 


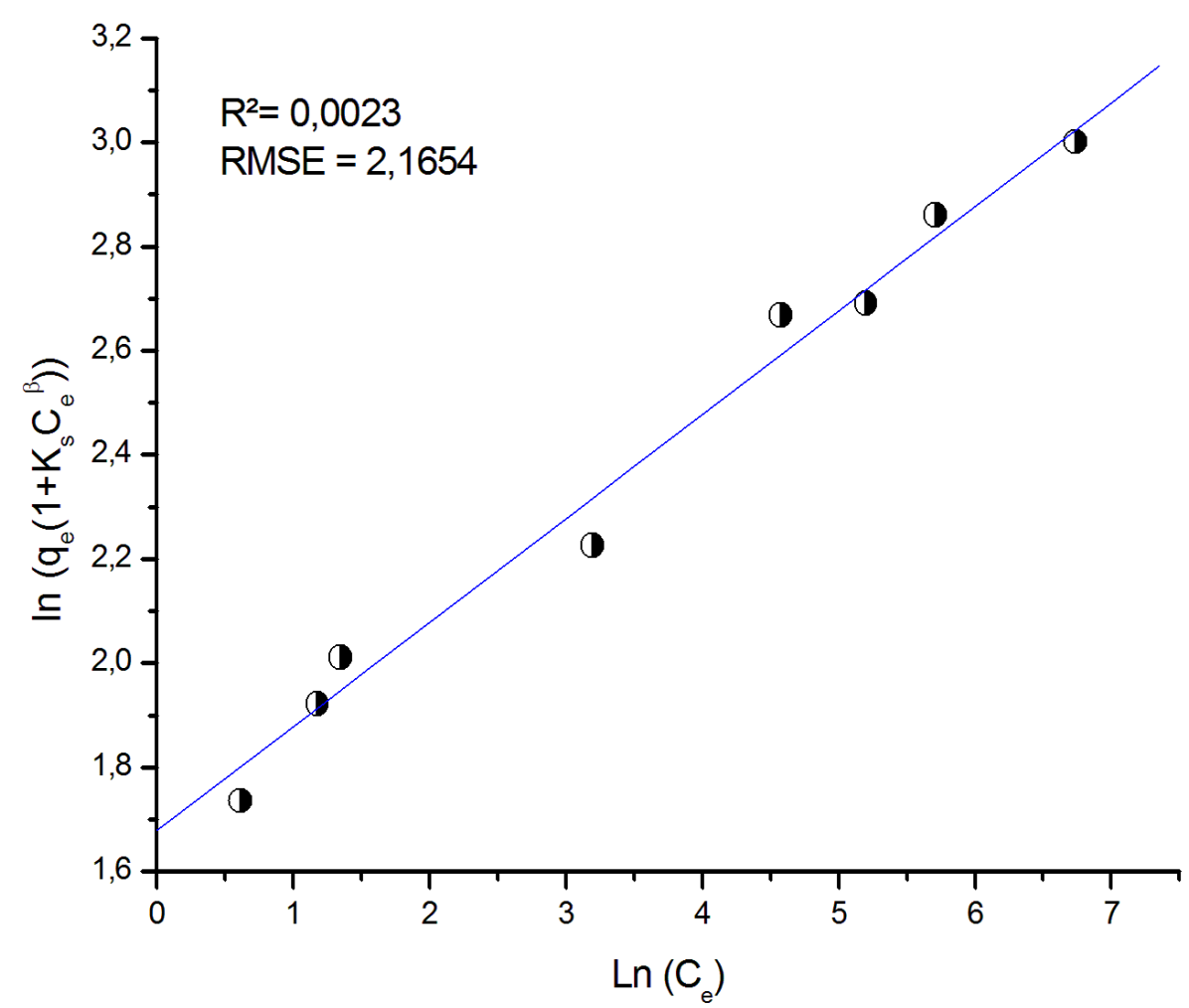

Figura 38 Isoterma de sips para o neodímio na forma linearizada $(\mathrm{pH}: 5$; Concentração inicial de palygorskita: $2 \mathrm{~g}$; temperatura: $30^{\circ} \mathrm{C}$; tempo de contato: $60 \mathrm{~min}$ )

As constantes são avaliadas de maneira pseudo linear já que as constantes da forma linear são desconhecidas. As constantes de adsorção associadas a isoterma de Sips através do ajuste não linear estão apresentadas na Tabela 20

Tabela 20- Constantes de adsorção de Sips não linear para neodímio a $30^{\circ} \mathrm{C}$

\begin{tabular}{cccccc}
\hline \multirow{2}{*}{ Modelo } & \multicolumn{5}{c}{ Parâmetros } \\
\cline { 2 - 6 } Ajuste não Linear & $\mathbf{Q}_{\text {sat }}(\mathbf{L} / \mathbf{g})$ & $\mathbf{K}_{\mathbf{s}}(\mathbf{L} / \mathbf{m g})$ & $\mathbf{n}$ & $\mathbf{R}^{\mathbf{2}}$ & $\mathbf{R M S E}$ \\
& 35,91 & 0,1630 & 0,2348 & 0,9757 & 2,1718 \\
\hline
\end{tabular}




\section{ISOTERMA DE REDLICH-PETTERSON}

As curvas em seus respectivos ajustes não linear e linear para a isoterma de Redlich-Petterson estão graficadas e representadas nas Figura 39 e Figura 40.

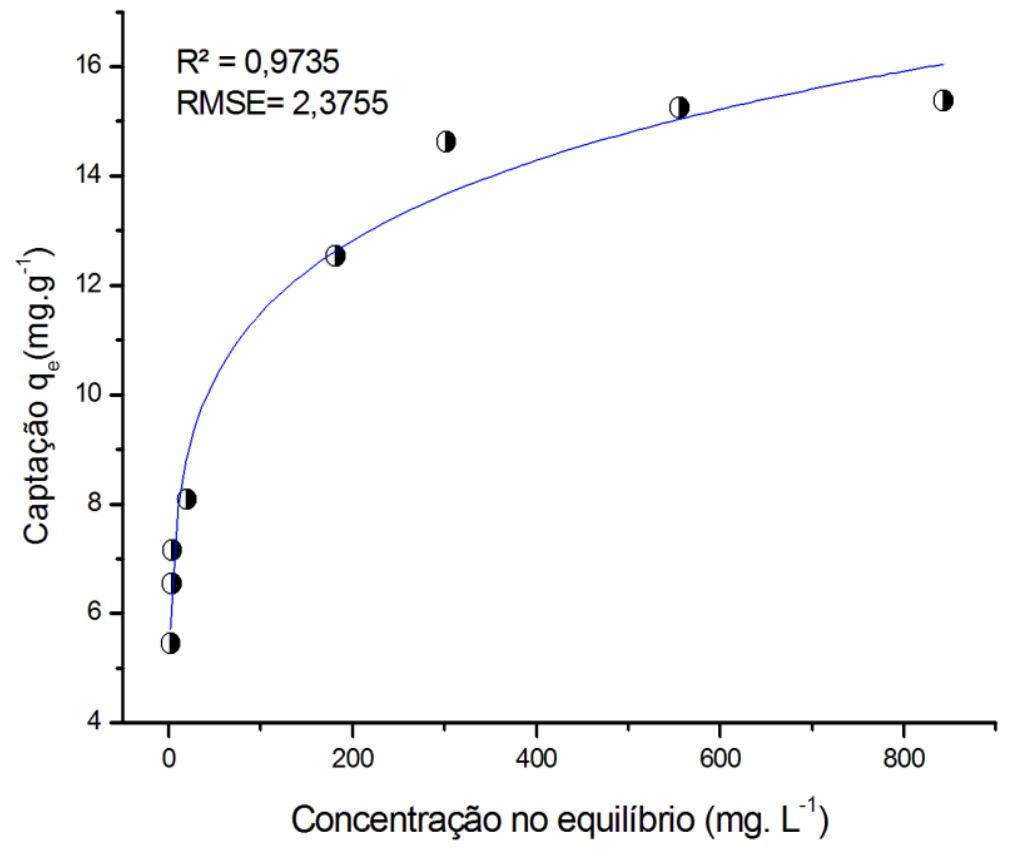

Figura 39 Isoterma de Redlich-Peterson para o neodímio na forma não linearizada $\left(\mathrm{pH}\right.$ : 5; Concentração inicial de palygorskita: $2 \mathrm{~g}$; temperatura: $30^{\circ} \mathrm{C}$; tempo de contato: 60 $\min )$ 


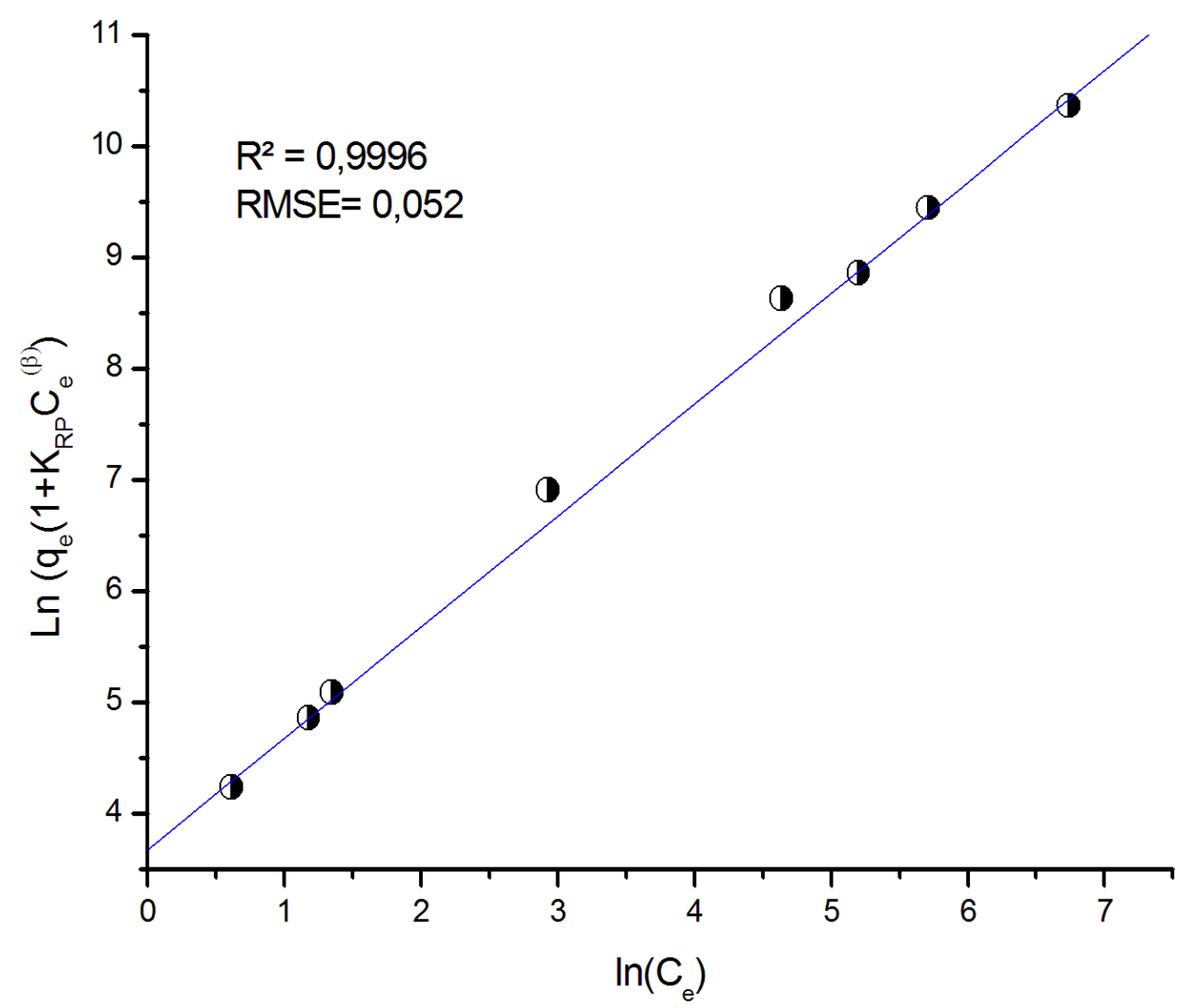

Figura 40 Isoterma de Redlich-Peterson para o neodímio na forma linearizada $(\mathrm{pH}$ : 5; Concentração inicial de palygorskita: $2 \mathrm{~g}$; temperatura: $30^{\circ} \mathrm{C}$; tempo de contato: $60 \mathrm{~min}$ )

As constantes são avaliadas de maneira pseudo linear já que as constantes da forma linear são desconhecidas. As constantes de adsorção associadas a isoterma de Redlich-Peterson através do ajuste não linear estão apresentadas na Tabela 21.

Tabela 21 Constantes de adsorção de Redlich-Peterson não linear para neodímio a $30^{\circ} \mathrm{C}$

\begin{tabular}{cccccc}
\hline \multirow{2}{*}{ Modelo } & \multicolumn{5}{c}{ Parâmetros } \\
\cline { 2 - 6 } Ajuste não Linear & $\mathbf{K}_{\mathbf{R P}}$ & $\mathbf{B}$ & $\mathbf{a}_{\mathbf{R P}}$ & $\mathbf{R}^{\mathbf{2}}$ & $\mathbf{R M S E}$ \\
& 39,14 & 0,8446 & 6,9442 & 0,9735 & 2,3755 \\
\hline
\end{tabular}

\section{ISOTERMAS COM MELHORES AJUSTES EXPERIMENTAIS}

O modelo de isoterma que mais se ajustou aos dados experimentais foi o de Langmuir que apresentou o maior coeficiente de correlação $R^{2}$ no valor de 0,9973 , 
sugerindo que a adsorção é realizada em monocamada. A Tabela 22 apresenta os dados de maneira resumida dos modelos de isotermas utilizados neste trabalho.

Tabela 22- Resumo dos parâmetros das isotermas utilizadas

\begin{tabular}{|c|c|c|c|c|c|}
\hline & $\begin{array}{c}\text { Temperatura } \\
\left({ }^{\circ} \mathrm{C}\right)\end{array}$ & $Q_{m}(m g / g)$ & $\mathbf{b}\left(\mathbf{L} \mathbf{~ m g}^{-1}\right)$ & $\mathbf{R}^{2}$ & RMSE \\
\hline Langmuir & 30 & 15.46 & 0.071 & 0,9973 & 1,1131 \\
\hline \multirow[t]{2}{*}{ Freundlich } & $\begin{array}{c}\text { Temperatura } \\
\left({ }^{\circ} \mathbf{C}\right)\end{array}$ & $K_{F}\left(L . g^{-1}\right)$ & $\mathbf{N}$ & $\mathbf{R}^{2}$ & RMSE \\
\hline & 30 & 5,33 & 5,26 & 0,9818 & 0,4629 \\
\hline \multirow[t]{2}{*}{ Temkin } & $\begin{array}{c}\text { Temperatura } \\
\left({ }^{\circ} \mathbf{C}\right)\end{array}$ & $\mathrm{A}\left(\mathrm{L} . \mathrm{mol}^{-1}\right)$ & $\mathbf{b}_{\mathrm{T}}$ & $\mathbf{R}^{2}$ & RMSE \\
\hline & 30 & 17,88 & 1529,84 & 0,9898 & 2,9274 \\
\hline \multirow[t]{2}{*}{$\begin{array}{c}\text { Dubinin- } \\
\text { Radushkevic } \\
\mathbf{h}\end{array}$} & $\begin{array}{c}\text { Temperatura } \\
\left({ }^{\circ} \mathbf{C}\right)\end{array}$ & $\mathrm{q}_{\mathrm{DR}}(\mathrm{mmol} /)$ & $\beta\left(\mathrm{mmol}^{2} . \mathrm{KJ}^{2}\right)$ & $\mathbf{R}^{2}$ & RMSE \\
\hline & 30 & 0,012 & $9.0 \times 10^{-9}$ & 0,7658 & 2,1956 \\
\hline \multirow[t]{2}{*}{ Sips } & $\begin{array}{c}\text { Temperatura } \\
\left({ }^{\circ} \mathbf{C}\right)\end{array}$ & Qsat(L/g) & $\mathrm{Ks}(\mathrm{L} / \mathrm{mg})$ & $\mathbf{R}^{2}$ & RMSE \\
\hline & 30 & 35,91 & 0,1630 & 0,9757 & 2,1718 \\
\hline \multirow[t]{2}{*}{$\begin{array}{l}\text { Redilich- } \\
\text { Peterson }\end{array}$} & $\begin{array}{c}\text { Temperatura } \\
\left({ }^{\circ} \mathrm{C}\right)\end{array}$ & KRP & $\beta$ & $\mathbf{R}^{2}$ & RMSE \\
\hline & 30 & 39,14 & 0,8446 & 0,9735 & 2,3755 \\
\hline
\end{tabular}

6.3.

\section{Cinética de adsorção e tempo de equilíbrio}

Os parâmetros cinéticos representam importante papel nos processos de sorção para prever a taxa de adsorção e fornecer informações importantes sobre a modelagem do processo. Portanto, a cinética da adsorção para captação do $\mathrm{Nd}$ (III) foi investigada e interpretada aplicando os modelos cinéticos de pseudo primeira ordem e pseudo segunda ordem (Ghaedi et al.,2010).

Dessa maneira, dados cinéticos para a adsorção foram obtidos para diferentes tempos de contato e foram aplicados para avaliação da cinética de adsorção. O resultado obtido para o neodímio está representado na Figura 41. 


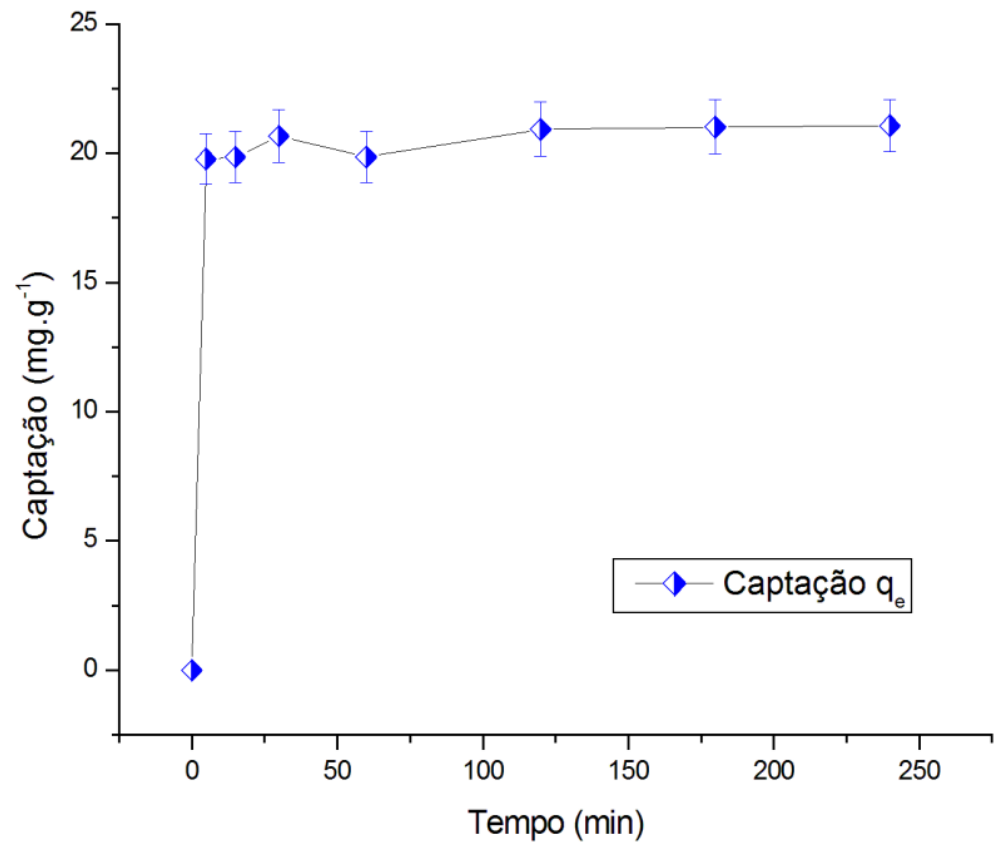

Figura 41- Influência do tempo de equilíbrio na adsorção de Nd (III) por palygorskita. (Concentração inicial de íon metálico: $2 \times 10^{3} \mathrm{mg} / \mathrm{L}$; $\mathrm{pH}$ : 5 ; concentração inicial de palygorskita: $2 \mathrm{~g}$; temperatura: $30^{\circ} \mathrm{C}$ )

O rápido equilíbrio de adsorção é uma indicação de que a superfície do adsorvente está prontamente disponível para adsorção. Sendo assim, o efeito do tempo de contato verificado aponta para uma quantidade crescente nos primeiros minutos de contato entre o adsorvente e o íon metálico. Observa-se que nos primeiros 5 minutos atingiu-se uma boa captação dos íons pelo adsorvente, e o equilíbrio é atingido após os 120 minutos onde ocorre uma captação de 21,01 mg/L.Tendências similares são apontadas na literatura.

Gok (2014), realizou estudo cinético para recuperação de neodímio e samário, através de nano-hidroxiapatita magnética e concluiu que a concentração de metal na solução diminuía nos primeiros minutos e que a partir dos $30 \mathrm{~min}$ a sorção aumentava gradualmente com o aumento do tempo de contato atingindo o equilíbrio após os 150 minutos.

Park \& Tavlarides (2010) reporta em seu estudo sobre a adsorção de neodímio utilizando adsorvente funcionalizado de fósforo, que durante os primeiros 5 minutos foi verificado uma rápida adsorção e após um período de 60 minutos a concentração dos metais permaneceu quase constante alcançando o equilíbrio. 
A fim de investigar as características do processo de adsorção e a etapa controladora da taxa potencial (reação química, controle de difusão, transferência de massa), os dados cinéticos foram analisados utilizando dois modelos cinéticos. Sendo eles o de pseudo primeira ordem e pseudo segunda ordem, respectivamente. Dessa maneira, a validade destes modelos foi testada pela linearização da curva e parâmetros da Equação 27 para o modelo da pseudo primeira ordem, e Equação 31 para o modelo de pseudo segunda ordem.

Os valores do coeficiente de correlação de cada modelo foram comparados a fim de serem avaliados quantitativamente. As Figura 42 e Figura 43 ilustram os plotes lineares de pseudo primeira ordem e pseudo segunda ordem, respectivamente.

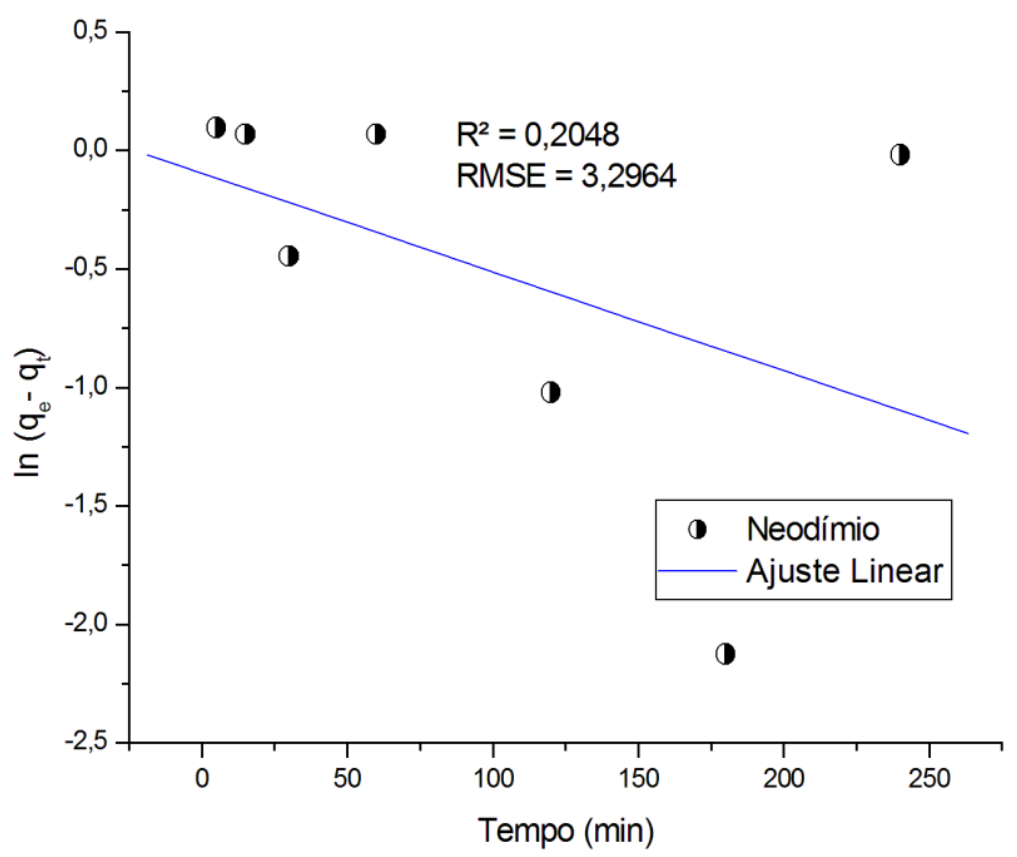

Figura 42- Modelo cinético de pseudo-primeira ordem linearizado aplicado a adsorção de Nd (III) adsorvido por palygorskita. 


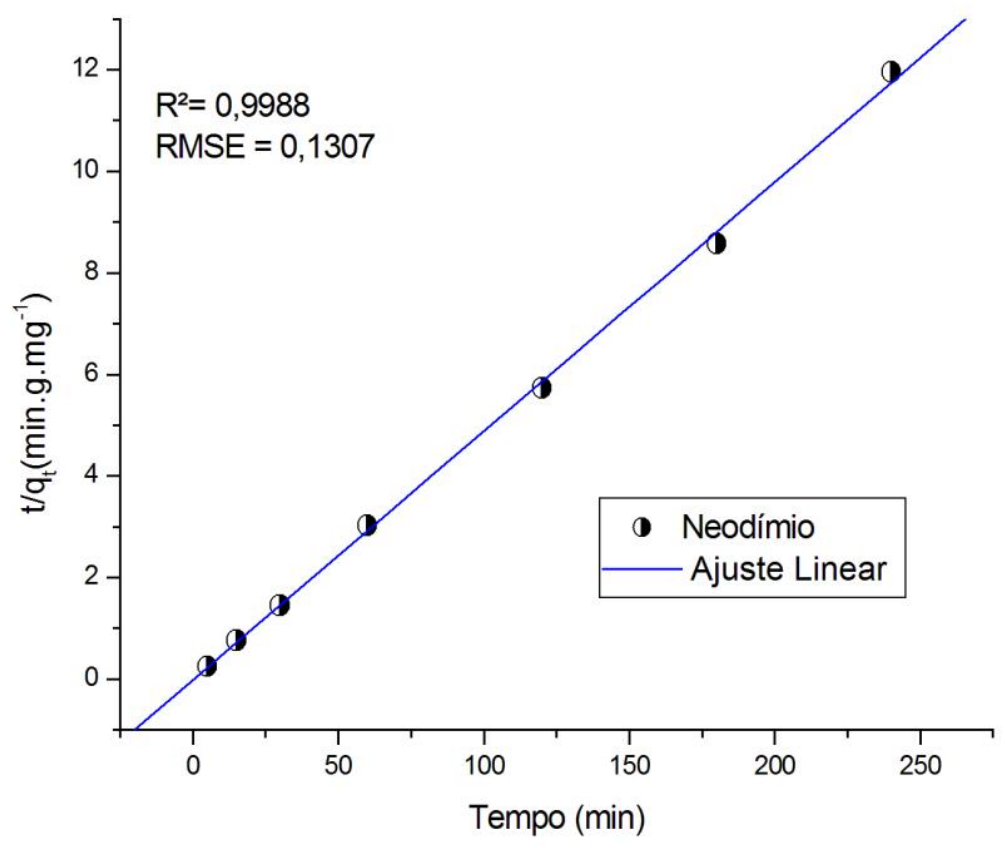

Figura 43- Modelo cinético de pseudo-segunda ordem linearizado aplicado a adsorção de $\mathrm{Nd}$ (III) adsorvido por palygorskita.

Os valores do coeficiente de correlação $\mathrm{R}^{2}$, RMSE e os parâmetros do modelo de taxa de primeira e segunda ordem são reportados nas Tabela 23 e Tabela 24

Tabela 23- Parâmetros referentes a cinética de pseudo primeira ordem

\begin{tabular}{ccccc}
\hline \multirow{2}{*}{ Adsorvato } & \multicolumn{4}{c}{ Parâmetros } \\
\cline { 2 - 5 } Neodímio & $\mathbf{K}_{\mathbf{1}}\left(\mathbf{g} \cdot \mathbf{m g}^{-1} \cdot \mathbf{m i n}\right)$ & $\mathbf{q}_{\mathbf{e}}(\mathbf{m g} / \mathbf{L})$ & $\mathbf{R}^{\mathbf{2}}$ & RMSE \\
& 0,0096 & 1,0042 & 0,2048 & 3,2964 \\
\hline
\end{tabular}

Tabela 24- Parâmetros referentes a cinética de pseudo segunda ordem

\begin{tabular}{cccccc}
\hline \multirow{2}{*}{ Adsorvato } & \multicolumn{5}{c}{ Parâmetros } \\
\cline { 2 - 6 } Neodímio & $\mathbf{K}_{\mathbf{2}}\left(\mathbf{g} \cdot \mathbf{m g}^{-1} \cdot \mathbf{m i n}\right)$ & $\mathbf{q}_{\mathrm{e}, \mathbf{e x p}}(\mathbf{m g} \mathbf{L})$ & $\mathbf{q}_{\mathbf{e}, \text { cal }}(\mathbf{m g} \mathbf{/ L})$ & $\mathbf{R}^{\mathbf{2}}$ & $\mathbf{R M S E}$ \\
& 0,1656 & 21,02 & 20,41 & 0,9988 & 0,1307 \\
\hline
\end{tabular}

De acordo com a análise dos resultados, os coeficientes de correlação da taxa do modelo cinético de pseudo segunda ordem para Nd (III). são significativamente maiores que os encontrados para o modelo de pseudo primeira ordem, apresentando para os dados experimentais um melhor coeficiente de correlação $\left(R^{2}=0,9988\right)$ frente ao outro modelo estudado. Os valores de 
quantidade de $\mathrm{Nd}$ (III) adsorvido no equilíbrio $\left(\mathrm{q}_{\mathrm{e}}\right.$ ) também demonstram que o modelo de pseudo segunda ordem descreve bem o comportamento cinético de sorção do sistema avaliado. Os dados avaliados a partir da Tabela 24 demonstram que os valores obtidos experimentalmente de $q_{e} e$ os valores calculados de $q_{e}$ descrevem uma boa concordância uma vez que os valores teóricos destes se aproximam dos resultados experimentais.

Isto indica que o modelo de pseudo segunda ordem descreve e é mais adequado para interpretação dos dados cinéticos e do mecanismo de adsorção. Por levar em consideração os sítios ativos do adsorvente e a concentração dos íons metálicos, este modelo propõe que a velocidade de adsorção é dependente da quantidade de íons na superfície do adsorvente e da quantidade de ions adsorvido no equilíbrio, evidenciando que o mecanismo de velocidade é a adsorção química (reação química).

Em geral, para adsorção por um mecanismo de troca de cátions, íons metálicos com maior valência podem ser trocados mais facilmente porque a afinidade entre adsorvente e adsorvato depende fortemente da estrutura eletrônica de valência e do raio iônico hidratado do íon metálico.

\subsection{1. Influência da temperatura}

A influência da temperatura nos processos de sorção foi avaliada com o intuito de determinar a alteração que esta variável iria produzir no que se refere a capacidade de adsorção. Nos processos de sorção um aumento na temperatura pode afetar solubilidade e o potencial químico do adsorvato (Khattri \& Singh,1999).A desobstrução de poros ocasionado pela elevação da temperatura é outro efeito importante que pode ocorrer uma vez que este parâmetro é variado, o que permite a penetração de moléculas maiores do adsorvato no adsorvente. $O$ efeito da temperatura foi avaliado ao longo do tempo no intervalo de 20 a $40{ }^{\circ} \mathrm{C} \mathrm{e}$ está ilustrado na Figura 44. 


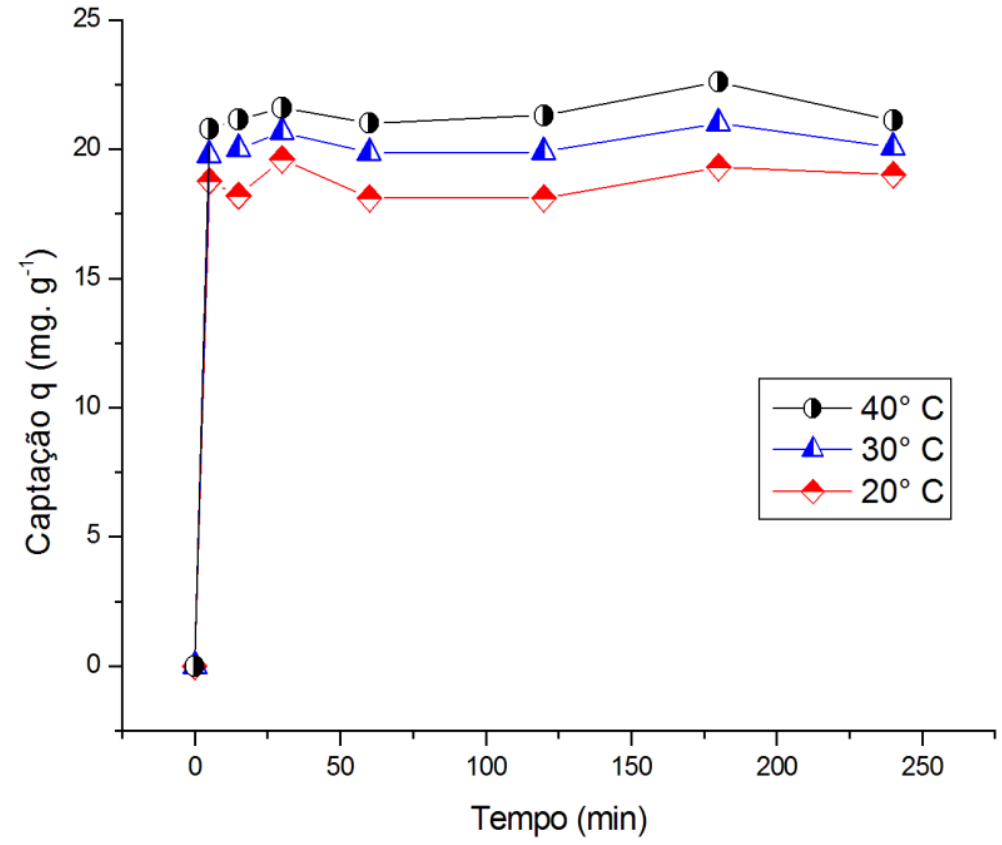

Figura 44- Influência da temperatura no processo de adsorção de Nd (III) utilizando palygorskita como adsorvente em diferentes temperaturas

A Figura 44 ilustra o perfil da variação da temperatura com o tempo. A quantidade captada é elevada com o incremento da temperatura de 19,3 a $20^{\circ} \mathrm{C}$ para 22,6 a $40{ }^{\circ} \mathrm{C}$. É evidente que em temperaturas mais altas a capacidade de sorção é otimizada (Vijayaraghavan \& Yun,2007b), contudo esse acréscimo da temperatura pode causar danos físicos ao adsorvente.

Na Figura 45 observaremos o ajuste linear da variação da temperatura na adsorção do neodímio em função do modelo cinético de pseudo segunda ordem que melhor se ajustou aos dados experimentais. 


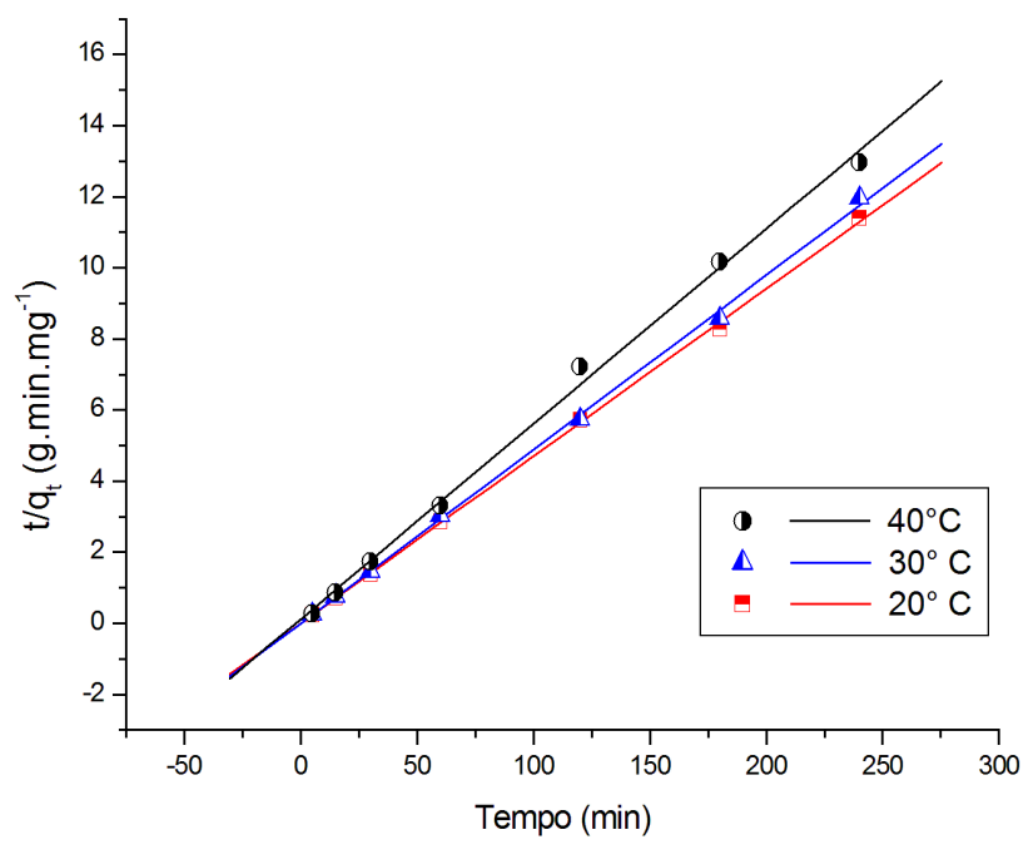

Figura 45- Modelo cinético de pseudo segunda ordem linearizado aplicado a adsorção de neodímio utilizando a palygorskita como adsorvente a diferentes temperaturas

$\mathrm{Na}$ Tabela 25, estão reportados os valores dos parâmetros que se referem a cada temperatura estudada segundo os modelos cinéticos estudados ajustados em sua forma linearizada. Através do coeficiente de correlação $\left(R^{2}\right)$ é possível corroborar que o modelo de pseudo segunda ordem foi o que melhor se ajustou aos dados experimentais.

Tabela 25- Parâmetros relacionados a cada temperatura referentes ao modelo cinético de pseudo segunda ordem em sua forma linearizada

\begin{tabular}{ccccc}
\hline $\mathbf{T}(\mathbf{K})$ & $\mathbf{K}_{\mathbf{1}}\left(\mathbf{m i n}^{-\mathbf{1}}\right)$ & $\mathbf{R}_{\mathbf{1}}{ }^{2}$ & $\begin{array}{c}\mathbf{K}_{\mathbf{2}} \\
\left.\mathbf{( g \cdot \mathbf { m g } ^ { - 1 } \cdot \mathbf { m i n }} \mathbf{- 1}\right)\end{array}$ & $\mathbf{R}_{\mathbf{2}}{ }^{\mathbf{1}}$ \\
\hline 293 & 0,00063 & 0,0032 & 0,02637 & 0,9972 \\
303 & 0,0096 & 0,2048 & 0,1656 & 0,9989 \\
313 & 0,0018 & 0,0119 & 0,5546 & 0,9995 \\
\hline
\end{tabular}

Os dados listados na Tabela 25 mostram que os valores da constante de taxa sofreram um acréscimo de 0,026 para $0,555 \mathrm{~g} \cdot \mathrm{mg}^{-1} \cdot \mathrm{min}^{-1}$ com o aumento da temperatura, fato este que sugere que com o aumento deste parâmetro de $293 \mathrm{~K}$ 
para 313K, a adsorção é mais rápida. No equilíbrio, tem-se que a capacidade do adsorvente não é muito afetada por esse incremento. Segundo Mckay, et al (1997) em sistemas onde a fisissorção é predominante, o aumento da temperatura incrementa a taxa de aproximação ao equilíbrio. Djeribi \& Hamdaoui (2008), reportam que com o aumento da temperatura incrementa-se a taxa de difusão do sorvato em toda a camada limite externa e no interior dos poros do sorvente. Observa-se que uma simples elevação de temperatura geralmente exerce uma influência sobre as velocidades das reações, exaltando os movimentos intermoleculares e intramoleculares, facilitando os reagrupamentos dos constituintes do sistema em novas moléculas. As novas moléculas do sistema, mesmo aquelas cuja transformação se faz com desprendimento de uma certa energia de ativação (Adamian \& Almendra,2002). Para determinar a energia de ativação do sistema de adsorção estudado, empregou-se a equação de Arrhenius (Equação 38) que fornece uma correlação entre a constante de velocidade da reação $\mathrm{K}_{2}$ com a temperatura.

O aumento da constante com o acréscimo da temperatura pode ser descrito através da Equação 39:

$$
k=k_{0} \exp ^{\left(\frac{-E a}{R T}\right)}
$$

Onde $\mathrm{k}$ é a constante de taxa da sorção $\left(\mathrm{g} \cdot \mathrm{mg}^{-1} \cdot \mathrm{min}^{-1}\right), \mathrm{k}_{\circ}$ é o fator independente da temperatura $\left(\mathrm{g} \cdot \mathrm{mg}^{-1} \cdot \mathrm{min}^{-1}\right)$, EA é a energia de ativação da sorção $(\mathrm{KJ} / \mathrm{mol})$, R é a constante dos gases $\left(8,314 \mathrm{~J} \cdot \mathrm{mol}^{-1} \cdot \mathrm{K}^{-1}\right)$ e $\mathrm{T}$ é a temperatura da solução $(\mathrm{K})$.

A Figura 46 representa graficamente a relação entre $\operatorname{lnK}_{2}$ e $T$ na forma da equação de Arrhenius. 


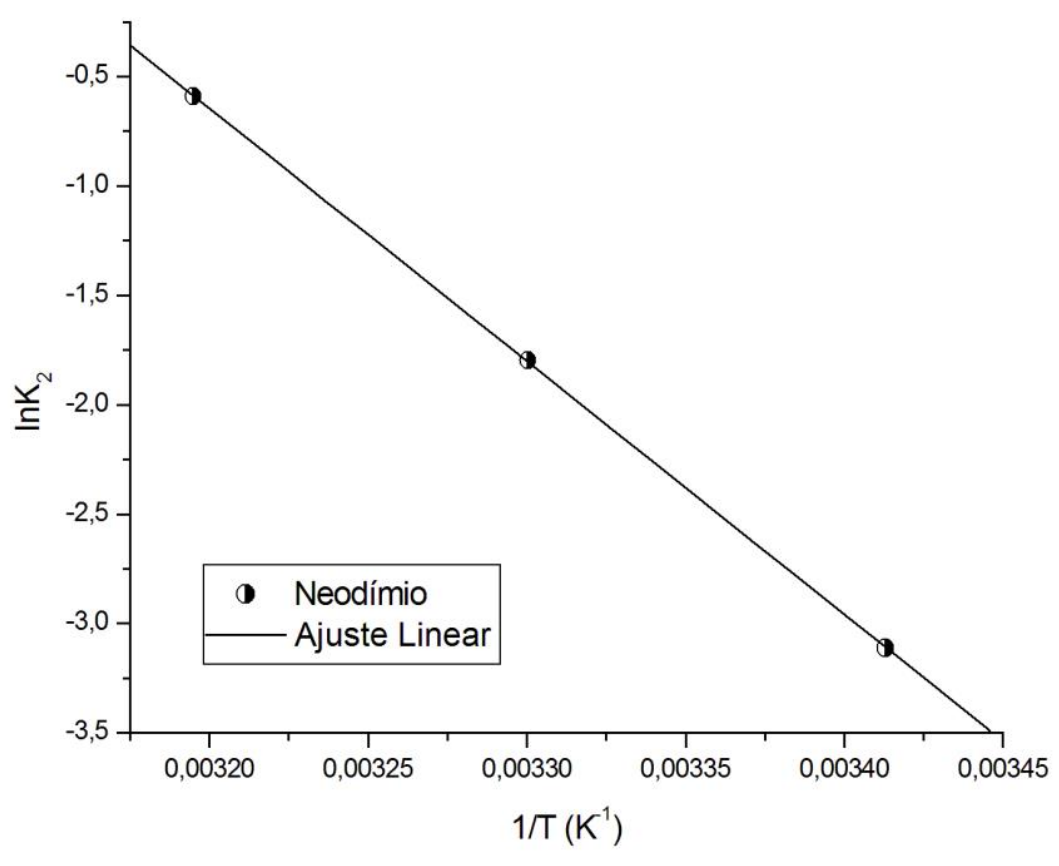

Figura 46- Curva de Arrhenius para o Neodímio

A energia de ativação representa a energia que deve ser fornecida aos reagentes, neste caso os íons metálicos e o adsorvente, para permitir-lhes transpor a barreira do potencial que se opõe à sua reorganização, no sentido de dar origem ao produto da reação de adsorção, ou seja, o adsorvente carregado com os íons metálicos. Segundo Smith et al (1981), a magnitude da energia de ativação poderia dar uma idéia sobre o tipo de adsorção que pode estar ocorrendo no processo, seja ela de natureza química ou física. Na adsorção física o equilíbrio é rapidamente alcançado e facilmente reversível, devido a uma necessidade baixa de energia. A energia de ativação para adsorção física não é maior que $4,2 \mathrm{KJ} / \mathrm{mol}$, já que as forças envolvidas na adsorção física são fracas. A adsorção química é específica e implica em forças mais fortes do que a adsorção física na ordem de 8,4 a $98,7 \mathrm{KJ} / \mathrm{mol}$ (Sag \& Kutsal,2000).

Os valores de energia de ativação e $\mathrm{K}_{0}$ para os íons $\mathrm{Nd}$ (III) os quais foram de $96,18 \mathrm{KJ} / \mathrm{mol}$ e $6,28 \times 10^{15} \mathrm{~g} \cdot \mathrm{mg}^{-1} \cdot \mathrm{min}^{-1}$ respectivamente. Estes resultados sugerem que a adsorção deste íon utilizando palygorskita como adsorvente é predominantemente um mecanismo de natureza química, ou seja, onde predominam-se forças específicas mais fortes, tais como as que se manifestam durante a formação de ligações químicas. Na adsorção química somente são possíveis camadas adsorvidas monomoleculares, sendo relativamente lento e 
pouco reversível. Contudo, diferenciar estes tipos de adsorção, já que em certos casos, os dois tipos podem ocorrer simultaneamente.

\subsection{2.}

\section{Parâmetros termodinâmicos}

Considerações termodinâmicas de um processo de adsorção são necessárias para concluir se o processo é espontâneo ou não. A mudança de energia livre de Gibbs, $\Delta G^{\circ}$ é uma indicação da espontaneidade de uma reação química e, portanto, é um critério importante para a espontaneidade. Ambos os fatores de entalpia $\Delta \mathrm{H}^{\circ}$ e $\Delta \mathrm{S}^{\circ}$ devem ser considerados para determinar a energia livre de Gibbs no processo. As reações ocorrem espontaneamente a uma determinada temperatura, se $\Delta G^{\circ}$ for uma quantidade negativa. A energia livre de um processo de adsorção está relacionada à constante de equilíbrio pela equação de Van't Hoff.

$$
\ln K=\frac{\Delta \mathrm{S}^{\circ}}{R}-\frac{\Delta \mathrm{H}^{\circ}}{R T}
$$

A constante de equilíbrio (K) é utilizado na equação que segue para determinar o valor da energia livre de Gibbs.

$$
\Delta G^{\circ}=-R T \ln K
$$

Os valores de $\Delta \mathrm{S}^{\circ}$ e $\Delta \mathrm{H}^{\circ}$ são obtidos através do intercepto e da inclinação do gráfico linearizado de Van't Hoff de InK versus 1/T.

A avaliação destes parâmetros é de grande importância para o entendimento do processo de sorção que está ocorrendo. Desta maneira, a fim de se determinar os valores de $\Delta \mathrm{H}^{\circ}$ e $\Delta \mathrm{S}^{\circ}$ foi determinada a partir de diferentes temperaturas, com o objetivo de identificar a influência destes parâmetros na adsorção. Para cada temperatura, a concentração inicial de íons Nd (III) foi variada de 40 a $890 \mathrm{mg} / \mathrm{L}$ fixando os valores de $\mathrm{pH}$ (5), tempo de contato (60 min) e velocidade de agitação (150 rpm).

Os resultados dos valores de $\mathrm{K}$ estão listados na Tabela 26 que mostra que o aumento da temperatura causa o acréscimo da constante de Langmuir, o que indica que a adsorção é favorecida devido ao aumento da taxa de sorção dos íons $\mathrm{Nd}$ (III), e aumento da capacidade de captação. 
Tabela 26- Parâmetros referentes a cada temperatura estudada

\begin{tabular}{cccc}
\hline $\begin{array}{c}\text { Temperatura } \\
(\mathrm{K})\end{array}$ & $\begin{array}{c}\text { Constante de } \\
\text { Langmuir } \\
(\mathbf{L} / \mathbf{g})\end{array}$ & $\begin{array}{c}\text { Constante de } \\
\text { Langmuir } \\
(\mathbf{L} / \text { mol) }\end{array}$ & $\begin{array}{c}\text { Capacidade de } \\
\text { captação } \\
(\mathbf{m g} / \mathbf{L})\end{array}$ \\
\hline 293 & 0,069 & 29809,04 & 15,3947 \\
303 & 0,077 & 33678,35 & 15,4650 \\
313 & 0,108 & 46817,70 & 17,2899 \\
\hline
\end{tabular}

Perfis similares são reportados por Sekar et al (2004) que realizou estudo de adsorção de chumbo em carvão ativado. Tem-se que a maior capacidade de captação ocorre a uma temperatura de $313 \mathrm{~K}\left(40^{\circ} \mathrm{C}\right)$.

A entalpia de adsorção pode ser determinada através do plote gráfico (InK vs 1/T) da equação de Van't Hoff, representado pela Figura 47.

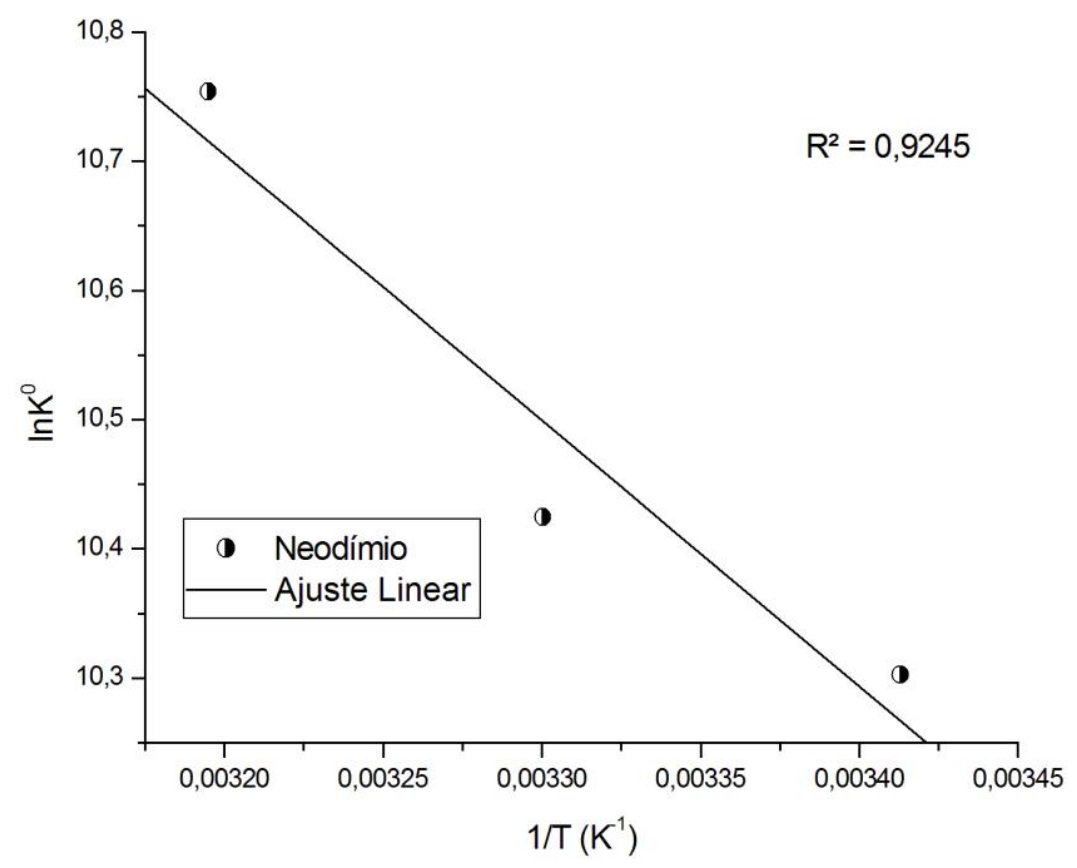

Figura 47- Relação entre a constante de equilíbrio de Langmuir (L/mol) e temperatura na adsorção de Nd (III) em palygorskita

Dessa forma, os valores encontrados de entalpia $\left(\Delta H^{\circ}\right)$ e entropia $\left(\Delta S^{\circ}\right)$ através do intercepto e inclinação do gráfico de $\operatorname{InK}^{\circ}$ vs $1 / T$ foram de 17,12 KJ.mol.K $\mathrm{K}^{-1}$ e $143,78 \mathrm{~J} . \mathrm{mol}^{-1}$. O valor positivo de $\Delta \mathrm{H}^{\circ}$ sugere que o processo de adsorção tem natureza endotérmica. Já o valor positivo de $\Delta S^{\circ}$ confirma a 
alteração da estrutura do adsorvente. Os valores encontrados para os parâmetros termodinâmicos correspondente a cada temperatura estão listados na Tabela 27.

Tabela 27- Parâmetros termodinâmicos

\begin{tabular}{|c|c|c|c|}
\hline $\mathbf{T}(\mathrm{K})$ & $\Delta G^{\circ}(\mathrm{KJ} / \mathrm{mol})$ & $\Delta H^{\circ}(\mathrm{KJ} / \mathrm{mol})$ & $\Delta \mathrm{S}^{\circ}\left(\right.$ J.mol.K $\left.{ }^{-1}\right)$ \\
\hline 293 & $-25,09$ & & \\
\hline 303 & $-26,27$ & 17,12 & 143,78 \\
\hline 313 & $-27,99$ & & \\
\hline
\end{tabular}

Os valores de $\Delta G^{\circ}$ negativos encontrados indicam que o processo de adsorção é espontâneo e apresenta alta afinidade dos íons neodímio pela palygorskita.

Galhoum et al (2016) reportou resultados similares em seu estudo sobre a captação de $\mathrm{Nd}$ (III) e Yb (III). Utilizando como adsorvente a Alanina, o autor encontrou valores de $\Delta \mathrm{G}^{\circ}$ de $-23,45 \mathrm{KJ} / \mathrm{mol}$ assim como $27,76 \mathrm{KJ} / \mathrm{mol}$ para $\Delta \mathrm{H}^{\circ}$ e $171 \mathrm{~J} \cdot \mathrm{mol}^{-1} \cdot \mathrm{k}^{-1}$ para $\Delta \mathrm{S}^{\circ}$, sugerindo processo espontâneo e endotérmico da sorção do neodímio. 


\section{7 \\ Conclusões}

O presente estudo avaliou a captação dos íons metálicos Nd (III) a partir de soluções aquosas utilizando como adsorvente o argilomineral palygorskita. A escolha do íon metálico estudado se deu convenientemente em um contexto onde a demanda por ETRs é cada vez mais crescente e sua utilização cresce exponencialmente em dispositivos eletrônicos devido as suas excelentes propriedades ópticas.

De forma a elucidar os resultados desta pesquisa, foi possível concluir:

- No que tange as operações unitárias do processo de beneficiamento da amostra de palygorskita os resultados provenientes da caracterização mostraram que as etapas de moagem, classificação granulométrica à úmido e separação magnética conferiram ao argilomineral maior grau de pureza.

- As caracterizações permitiram o conhecimento das propriedades da amostra estudada, de forma que foi verificada a presença de palygorskita, diásporo, caulinita e quartzo por meio da técnica de $\mathrm{DRX}$. A composição química obtida através do FRX corroborou através dos teores de óxidos a presença de palygorskita na amostra estudada.

- Os resultados da microscopia eletrônica de varredura mostraram a morfologia fibrosa e aspecto de fitas e agulhas característico do argilomineral estudado.

- Estudos eletrocinéticos explicitaram a obtenção das curvas de potencial zeta, e a consequente avaliação da carga superficial das partículas do adsorvente em estudo. Utilizando como eletrólito indiferente o $\mathrm{KCl}$ a palygorskita in natura apresentou carga superficial negativa em toda faixa de $\mathrm{pH}$ corroborando o fato de ser uma boa adsorvedora de cátions. A interação com os íons metálicos de $\mathrm{Nd}$ (III) fez com que o ponto isoelétrico da palygorskita fosse medido em torno de 7,5 . 
- Nas faixas de $\mathrm{pH}$ estudadas, foi possível determinar o ponto isoelétrico do óxido de neodímio, pouco documentado na literatura de forma a compreender como se dá a adsorção para este íon metálico. O valor encontrado do PIE para o óxido foi de em torno de 10,4

- A correlação dos diagramas de especiação com as curvas de potencial zeta permitiram a verificação da interação que possivelmente é de ordem especifica entre a palygorskita e o $\mathrm{Nd}(\mathrm{III})$.

- Os ensaios de adsorção em batelada revelaram que a captação máxima para a adsorção de neodímio em palygorskita foi de 15,39 $\mathrm{mg} / \mathrm{L}$ a $30^{\circ} \mathrm{C} \mathrm{em} \mathrm{pH} 5$.

- A capacidade de captação do neodímio utilizando o argilomineral palygorskita é sensível a todas as variáveis estudadas, tais como: a concentração do adsorvente, o pH do meio, e a concentração do íon metálico, obtendo maior eficiência em $\mathrm{pH} 5$, e utilizando concentração inicial de adsorvente: $2 \mathrm{~g}$.

- Considerando a faixa inicial de concentração dos ions metálicos utilizados neste trabalho tem se que os dados experimentais do processo de adsorção em batelada foram melhor ajustados ao modelo de Langmuir apresentando coeficiente de regressão $R^{2}=$ 0,9973 e RMSE:1,1131. As constantes encontradas pelo modelo foram respectivamente: $K_{L}: 0,077$, e $R_{L}$ de $0,1113 \mathrm{mg} / L$ corroborando que os dados foram bem ajustados ao modelo de Langmuir, e estão de acordo com os resultados obtidos na literatura.

- Apesar do modelo de isoterma de Langmuir ter melhores resultados dos ajustes experimentais, foi verificado que Freundlich que obteve $\left(R^{2}: 0,9771\right)$ e Temkin ( $\left.R^{2}: 0,9727\right)$ também se ajustaram bem aos dados experimentais, assim como os modelos que são considerados variações dos de Langmuir como o de Redlich- Petterson que alcançou ( $R^{2}:$ 0,9757). Já o modelo de isoterma de DubininRadushkevich não obteve tanto êxito comparado aos demais $\left(R^{2}\right.$ : 0,6365).

- Dos dois modelos cinéticos estudados para a adsorção de neodímio em palygorskita, o melhor ajuste dos dados experimentais se deu através do modelo de pseudo segunda ordem apresentando 
coeficiente de regressão $R^{2}$ de 0,9988 e RMSE de 0,1307 e constante cinética $\mathrm{K}_{2}$ de 0,1656.

- No que se refere ao estudo da influência da temperatura foi possível obter um valor de energia de ativação de e $\mathrm{K}_{0}$ para os íons $\mathrm{Nd}$ (III) os quais foram de $96,18 \mathrm{KJ} / \mathrm{mol}$ e $6,28 \times 1015$ g.mg- ${ }^{-1} \cdot \mathrm{min}^{-1}$ respectivamente. Estes resultados sugerem que a adsorção deste íon utilizando palygorskita como adsorvente sugere que a etapa controladora da taxa é de natureza química. Além disso através deste estudo foi possível corroborar o melhor ajuste dos dados do modelo de pseudo segunda ordem, apresentando um aumento das constantes de taxa $\left(\mathrm{K}_{2}\right)$ conforme aumentava a temperatura de $293 \mathrm{~K}$ a $313 \mathrm{~K}$.

- Análises dos parâmetros termodinâmicos viabilizaram o conhecimento da espontaneidade do processo de adsorção. Os valores na $303 \mathrm{~K}$ de $\Delta \mathrm{G}^{\circ}$ de $-26,27 \mathrm{KJ} / \mathrm{mol}, \Delta \mathrm{H}^{\circ}: 17,12 \mathrm{KJ} / \mathrm{mol}$ e $\Delta \mathrm{S}^{\circ}$ de 143,78 J.mol. $\mathrm{K}^{-1}$ indicaram a espontaneidade do processo, a sua natureza endotérmica e a irreversibilidade do processo de adsorção de neodímio em palygorskita. 
8 Recomendações para trabalhos futuros

Para o prosseguimento do estudo da adsorção de neodímio utilizando palygorskita como adsorvente são sugeridos os seguintes trabalhos de pesquisa:

- Estudo experimental a ser realizado em coluna;

- Estudos de dessorção e regeneração do adsorvente;

- Estudos utilizando efluentes reais contendo Nd (III). 
9

\section{Referências bibliográficas}

ABO-FARHA, S. A. et al. Removal of some heavy metal cations by synthetic resin purolite C100. Journal of hazardous materials, v. 169, n. 1-3, p. 190-194, 2009.

ABREU, S. F. Recursos minerais do Brasil. 2 ed São Paulo/ Rio de Janeiro: Edgard Blücher, p. 324, 1973

ADAMIAN, Rupen; ALMENDRA, Ericksson. Físico-química: uma aplicação aos materiais. COPPE/UFRJ, 2002.

ADAMSON, Arthur W. et al. Physical chemistry of surfaces. New York: Interscience, 1967.

AJMAL, Mohammad et al. Adsorption studies on Citrus reticulata (fruit peel of orange): removal and recovery of $\mathrm{Ni}$ (II) from electroplating wastewater. Journal of hazardous materials, v. 79, n. 1-2, p. 117-131, 2000.

AKSU, Z. Determination of the equilibrium, kinetic and thermodynamic parameters of the batch biosorption of nickel (II) ions onto Chlorella vulgaris. Process Biochemistry, v. 38, n. 1, p. 89-99, 2002.

ALBANEZ, Nelma Elisa Farias Kunrath. Preparação e caracterização de nanocompósitos preparados com argilas esmectitas (bentonita), amido e sacarose. 2008. Tese de Doutorado. Universidade de São Paulo.

ALBERS, A. P. F. et al. Um método simples de caracterização de argilominerais por difração de raios X. Cerâmica, v. 48, n. 305, p. 34-37, 2002.

ALTIN, Orhan; ÖZBELGE, H. Önder; DOĞU, Timur. Use of general purpose adsorption isotherms for heavy metal-clay mineral interactions. Journal of Colloid and Interface Science, v. 198, n. 1, p. 130-140, 1998.

ALVES. Adsorção em carvão ativado e outros materiais. Artigo científico. PUC Rio - 2014. Outubro 2005.

ANASTOPOULOS, Ioannis; BHATNAGAR, Amit; LIMA, Eder C. Adsorption of rare earth metals: A review of recent literature. Journal of Molecular Liquids, v. 221, p. 954-962, 2016.

ASNIN, Leonid; KACZMARSKI, Krzysztof; GUIOCHON, Georges. Empirical development of a binary adsorption isotherm based on the single-component isotherms in the framework of a two-site model. Journal of Chromatography A, v. 1138, n. 1-2, p. 158-168, 2007.

AYRANCI, Erol; HODA, Numan; BAYRAM, Edip. Adsorption of benzoic acid onto high specific area activated carbon cloth. Journal of colloid and interface science, v. 284, n. 1, p. 83-88, 2005.

AZIZIAN, Saeid; BASHIRI, Hadis. Adsorption kinetics at the solid/solution interface: statistical rate theory at initial times of adsorption and close to equilibrium. Langmuir, v. 24, n. 20, p. 11669-11676, 2008. 
AZIZIAN, Saeid; HAERIFAR, Monireh; BASHIRI, Hadis. Adsorption of methyl violet onto granular activated carbon: Equilibrium, kinetics and modeling. Chemical Engineering Journal, v. 146, n. 1, p. 36-41, 2009.

BALTAR, Carlos Adolpho Magalhães et al. Influence of morphology and surface charge on the suitability of palygorskite as drilling fluid. Applied Clay Science, v. 42, n. 3-4, p. 597-600, 2009.

BANSAL, Roop Chand; GOYAL, Meenakshi. Activated carbon adsorption. CRC press, 2005.

BARROS, A. R. B.; MOREIRA, R. F. P. M.; JOSÉ, H. J. Remoção de metais em água utilizando diversos adsorventes. Revista tecnológica, p. 65-72, 2000.

BAUTISTA-TOLEDO, I. et al. Bisphenol A removal from water by activated carbon. Effects of carbon characteristics and solution chemistry. Environmental science \& technology, v. 39, n. 16, p. 6246-6250, 2005.

BEAUFORD, R. An Introduction to the Geology of Rare Earth Elements and Associated Mineral Ores. Retrieved from: rareearthelements. us/ree_geology, 2010.

BHARATHI, K. S.; RAMESH, S. T. Removal of dyes using agricultural waste as low-cost adsorbents: a review. Applied Water Science, v. 3, n. 4, p. 773-790, 2013.

BIRUNGI, Z. S.; CHIRWA, E. M. N. The kinetics of uptake and recovery of lanthanum using freshwater algae as biosorbents: comparative analysis. Bioresource technology, v. 160, p. 43-51, 2014.

BLANCHARD, G.; MAUNAYE, M.; MARTIN, G. Removal of heavy metals from waters by means of natural zeolites. Water research, v. 18, n. 12, p. 1501-1507, 1984.

BOTERO, Ana Elisa C.; TOREM, Maurício Leonardo; DE MESQUITA, Luciana Maria S. Surface chemistry fundamentals of biosorption of Rhodococcus opacus and its effect in calcite and magnesite flotation. Minerals Engineering, v. 21, n. 1, p. 83-92, 2008.

BOURLIVA, A. et al. Removal of $\mathrm{Cu} 2+$ and $\mathrm{Ni2}+$ ions from aqueous solutions by adsorption onto natural palygorskite and vermiculite. Clay Minerals, v. 53, n. 1, p. 1-15, 2018.

BUENO, B. Y. M. et al. Biosorption of lead2+, chromium3+ and copper2+ by R. opacus: Equilibrium and kinetic studies. Minerals Engineering, v. 21, n. 1, p. 6575, 2008.

BUTNARIU, Monica et al. Remediation of rare earth element pollutants by sorption process using organic natural sorbents. International journal of environmental research and public health, v. 12, n. 9, p. 11278-11287, 2015.

CARRETERO, M. Isabel; POZO, Manuel. Clay and non-clay minerals in the pharmaceutical industry: Part I. Excipients and medical applications. Applied Clay Science, v. 46, n. 1, p. 73-80, 2009.

CAYLLAHUA, Javier Enrique Basurco.FLOTAÇÃO BIOSORTIVA DE NÍQUEL E ALUMÍNIO USANDO A CEPA RHODOCOCCUS OPACUS.2008. $159 \mathrm{f}$. Dissertação (Mestrado) - Curso de Pós Graduação em Engenharia Química e de Materiais, Departamento de Materiais e Processos Químicos e Metalúrgicos, Pontifícia Católica Universidade, Rio de Janeiro, 2008.

CHANG, Po-Hsiang et al. Interaction of ciprofloxacin and probe compounds with palygorskite PFI-1. Journal of hazardous materials, v. 303, p. 55-63, 2016. 
CHEN, Arh-Hwang et al. The chemically crosslinked metal-complexed chitosans for comparative adsorptions of $\mathrm{Cu}$ (II), $\mathrm{Zn}$ (II), Ni (II) and Pb (II) ions in aqueous medium. Journal of Hazardous Materials, v. 163, n. 2-3, p. 1068-1075, 2009.

CHEN, Hao; WANG, Aiqin. Kinetic and isothermal studies of lead ion adsorption onto palygorskite clay. Journal of Colloid and Interface Science, v. 307, n. 2, p. 309-316, 2007.

CHENG, Hongfei et al. Infrared transmission and emission spectroscopic study of selected Chinese palygorskites. Spectrochimica Acta Part A: Molecular and Biomolecular Spectroscopy, v. 83, n. 1, p. 518-524, 2011.

CHOUDHARY, Bharat; PAUL, Debajyoti. Isotherms, kinetics and thermodynamics of hexavalent chromium removal using biochar. Journal of Environmental Chemical Engineering, v. 6, n. 2, p. 2335-2343, 2018.

CHOY, Jin-Ho et al. Clay minerals and layered double hydroxides for novel biological applications. Applied Clay Science, v. 36, n. 1-3, p. 122-132, 2007.

$\mathrm{CHU}$, Steven (Ed.). Critical materials strategy. DIANE Publishing, 2011.

COELHO, Antonio C. Vieira; DE SSANTOS, P.; DE SSANTOS, H. Argilas especiais: o que são, caracterização e propriedades. Química Nova, v. 30, n. 1, p. 146, 2007.

COETZEE, P. P. et al. Characterisation of selected South African clays for defluoridation of natural waters. Water Sa, v. 29, n. 3, p. 331-338, 2003.

COONEY, David O. Adsorption design for wastewater treatment. CRC press, 1998.

COVELO, E. F.; VEGA, F. A.; ANDRADE, M. L. Simultaneous sorption and desorption of $\mathrm{Cd}, \mathrm{Cr}, \mathrm{Cu}, \mathrm{Ni}, \mathrm{Pb}$, and $\mathrm{Zn}$ in acid soils: I. Selectivity sequences. Journal of hazardous materials, v. 147, n. 3, p. 852-861, 2007.

CRISS, J. W. Particle size and composition effects in X-ray fluorescence analysis of pollution samples. Analytical Chemistry, v. 48, n. 1, p. 179-186, 1976.

CULLITY, Bernard Dennis; GRAHAM, Chad D. Introduction to magnetic materials. John Wiley \& Sons, 2011.

DADA, A. O. et al. Langmuir, Freundlich, Temkin and Dubinin-Radushkevich isotherms studies of equilibrium sorption of $\mathrm{Zn}^{2+}$ unto phosphoric acid modified rice husk. IOSR Journal of Applied Chemistry, v. 3, n. 1, p. 38-45, 2012.

DEDAVID, Berenice Anina; GOMES, Carmem Isse; MACHADO, Giovanna. Microscopia eletrônica de varredura: aplicações e preparação de amostras: materiais poliméricos, metálicos e semicondutores. EdiPUCRS, 2007.

DEMEY, Hary et al. Neodymium recovery by chitosan/iron (III) hydroxide [ChiFer (III)] sorbent material: Batch and column systems. Polymers, v. 10, n. 2, p. 204, 2018.

DJERIBI, Rabiaa; HAMDAOUI, Oualid. Sorption of copper (II) from aqueous solutions by cedar sawdust and crushed brick. Desalination, v. 225, n. 1-3, p. 95112, 2008.

DOMINGUES, V. M. F. Utilização de um produto natural (cortiça) como adsorvente de pesticidas piretróides em águas. 2005. 224 f. Tese (Doutorado em Engenharia Química) - Faculdade de Engenharia da Universidade do Porto, Porto. 2005 
DU, Xiaoyue; GRAEDEL, Thomas E. Global in-use stocks of the rare earth elements: a first estimate. Environmental science \& technology, v. 45, n. 9, p. 4096-4101, 2011.

ELISEEVA, Svetlana V.; BÜNZLI, Jean-Claude G. Rare earths: jewels for functional materials of the future. New Journal of Chemistry, v. 35, n. 6, p. 11651176, 2011.

EMSLEY, John. Nature's building blocks: an AZ guide to the elements. Oxford University Press, 2011.

Encyclopaedia Britannica Online, Neodymium (Nd), chemical element, a rare-earth metal of the lanthanide series of the periodic table. 2013. Disponivel em: <https://www.britannica.com/science/neodymium>. Acesso em: 13 maio 2019.

ERDÓCIA, Félix Anderson Barros et al. Difração de Raios X em Minerais de Bauxita e Análise através de Refinamento pelo Método de Rietveld. 2011.

ESPOSITO, A.; PAGNANELLI, F.; VEGLIÒ, Francesco. pH-related equilibria models for biosorption in single metal systems. Chemical Engineering Science, v. 57, n. 3, p. 307-313, 2002.

FEBRIANTO, Jonathan et al. Equilibrium and kinetic studies in adsorption of heavy metals using biosorbent: a summary of recent studies. Journal of hazardous materials, v. 162, n. 2-3, p. 616-645, 2009.

FENG, H. O. N. G. Rare earth: production, trade and demand. Journal of Iron and Steel Research, International, v. 13, p. 33-38, 2006.

FENTER, P. et al. Surface speciation of calcite observed in situ by high-resolution X-ray reflectivity. Geochimica et Cosmochimica Acta, v. 64, n. 7, p. 1221-1228, 2000.

FIFIELD, F. W.; KEALEY, D. Principle and practice of analytical chemistry 3rd Edition. 2000.

FLOODY, M. Calabi et al. Natural nanoclays: applications and future trends-a Chilean perspective. Clay Minerals, v. 44, n. 2, p. 161-176, 2009.

FOO, Keng Yuen; HAMEED, Bassim $\mathrm{H}$. Insights into the modeling of adsorption isotherm systems. Chemical engineering journal, v. 156, n. 1, p. 2-10, 2010.

FOUREST, Eric; VOLESKY, Bohumil. Contribution of sulfonate groups and alginate to heavy metal biosorption by the dry biomass of Sargassum fluitans. Environmental Science \& Technology, v. 30, n. 1, p. 277-282, 1995.

FREITAS, Renato Pereira. Aplicações de técnicas nucleares e espectroscopia molecular em Arqueometria. 2014. Tese de Doutorado. Universidade Federal do Rio de Janeiro.

Freundlich, H.M.F. Over the adsorption in solution. Journal Physical Chemistry. 57 385-470, 1907.

GADD, Geoffrey Michael. Biosorption: critical review of scientific rationale, environmental importance and significance for pollution treatment. Journal of Chemical Technology \& Biotechnology: International Research in Process, Environmental \& Clean Technology, v. 84, n. 1, p. 13-28, 2009.

GALHOUM, Ahmed A. et al. Alanine and serine functionalized magnetic nanobased particles for sorption of $\mathrm{Nd}$ (III) and $\mathrm{Yb}$ (III). Advances in environmental research, v. 5, n. 1, p. 1-18, 2016.

GAN, Fangqun et al. Removal of phosphate from aqueous solution by thermally treated natural palygorskite. Water Research, v. 43, n. 11, p. 2907-2915, 2009. 
GHAEDI, Mehrorang et al. Equilibrium, thermodynamic, and kinetic studies on lead (II) biosorption from aqueous solution by Saccharomyces cerevisiae biomass. CLEAN-Soil, Air, Water, v. 38, n. 9, p. 877-885, 2010.

GILES, Charles H.; SMITH, David; HUITSON, Alan. A general treatment and classification of the solute adsorption isotherm. I. Theoretical. Journal of colloid and interface science, v. 47, n. 3, p. 755-765, 1974.

GOBBO, Luciano de Andrade. Aplicação da difração de raios - $X$ e método de Rietveld no estudo de cimento portland. 2009. $273 \mathrm{f}$. Tese (Doutorado) - Curso de Pós Graduação em Recursos Minerais e Hidrogeologia, Universidade de São Paulo, São Paulo, 2009.

GOK, Cem. Neodymium and samarium recovery by magnetic nanohydroxyapatite.Journal of Radioanalytical and Nuclear Chemistry, v. 301, n. 3, p. 641-651, 2014.

GOMES, Celso de Sousa Figueiredo; SILVA, João Baptista Pereira. Minerals and clay minerals in medical geology. Applied Clay Science, v. 36, n. 1-3, p. 4-21, 2007.

GONZALEZ, F.; PESQUERA, C.; BENITO, I. A study by thermal analysis of the reversible folding in palygorskite under vacuum thermal treatment. Thermochimica acta, v. 223, p. 83-91, 1993.

GRANADOS-CORREA, F. et al. Adsorption behaviour of La (III) and Eu (III) ions from aqueous solutions by hydroxyapatite: kinetic, isotherm, and thermodynamic studies. Journal of Chemistry, v. 2013, 2012.

GRIM, Ralph E. Clay mineralogy. LWW, 1953.

GUERRA, D. L. et al. Aplicação de Al-PILC na adsorção de $\mathrm{Cu}^{2+}, \mathrm{Ni}^{2+}$ e $\mathrm{Co}^{2+}$ utilizando modelos físico-químicos de adsorção.Eclética Química, 2007.

GUGGENHEIM, Stephen; KREKELER, Mark PS. The structures and microtextures of the palygorskite-sepiolite group minerals. In: Developments in Clay Science. Elsevier, 2011. p. 3-32.

HALL, Kenneth R. et al. Pore-and solid-diffusion kinetics in fixed-bed adsorption under constant-pattern conditions. Industrial \& Engineering Chemistry Fundamentals, v. 5, n. 2, p. 212-223, 1966.

HE, Dengliang et al. Adsorption properties and mechanism of purified palygorskite on methylene blue. Arabian Journal of Geosciences, v. 11, n. 21, p. 658, 2018.

HEIVILIN, F. G.; MURRAY, H. H. Hormites: palygorskite (attapulgite) and sepiolite. Industrial Minerals and Rocks (ed. Carr, DD) Littleton, Colarado, Society of Mining, Metallurgy, and Exploration, Inc, p. 249-154, 1994.

HILL, A.V. The possible effects of the aggregation of the molecules of haemoglobin on its dissociation curves. Journal of Physiology, 40, 4-7. (1910)

HO, Y. S.; NG, J. C. Y.; MCKAY, G. Kinetics of pollutant sorption by biosorbents. Separation and purification methods, v. 29, n. 2, p. 189-232, 2000.

HUANG, Jianhua et al. Adsorption studies of a water soluble dye, Reactive Red MF-3B, using sonication-surfactant-modified attapulgite clay. Journal of Hazardous Materials, v. 143, n. 1-2, p. 541-548, 2007.

HUGGINS, Charles W.; SHELL, Haskiel Roy; DENNY, Marion V. Properties of palygorskite, an asbestiform mineral. Bureau of Mines, 1962.

HUMPHRIES, Marc. Rare earth elements: the global supply chain. Diane Publishing, 2010. 
HUNTER, Robert J. Zeta potential in colloid science: principles and applications. Academic press, 2013.

IONASHIRO, Massao; GIOLITO, I. Fundamentos da termogravimetria, análise térmica diferencial, calorimetria exploratória diferencial. São Paulo: Giz Editorial, 2005.

JIMENEZ, Ricardo Sarti; DAL BOSCO, Sandra Maria; CARVALHO, Wagner Alves. Remoção de metais pesados de efluentes aquosos pela zeólita natural escolecitainfluência da temperatura e do pH na adsorção em sistemas monoelementares. Química Nova, v. 27, n. 5, p. 734-738, 2004.

JOVANOVIC, D. S. Physical adsorption of gases. I. Isotherms for monolayer and multilayer adsorption. Kolloid-Zeitschrift and Zeitschrift Fur Polymere, v. 235, n. 1, p. 1203, 1969.

K. C., KAMALA C.T, CHARY N.S., SASTRY A.R.K., Nageswara R., Vairamani M. Removal of lead from aqueous solutions using na immobilized biomaterial derived from a plant biomass. J. Hazard Mater., B108, 111-117, 2004.

KEDARI, C. S.; DAS, S. K.; GHOSH, S. Biosorption of long lived radionuclides using immobilized cells of Saccharomyces cerevisiae. World Journal of Microbiology and Biotechnology, v. 17, n. 8, p. 789-793, 2001.

KELLY, Errol G.; SPOTTISWOOD, David J. Introduction to mineral processing. 1982.

KHAN, Abdul R.; AL-WAHEAB, I. R.; AL-HADDAD, A. A generalized equation for adsorption isotherms for multi-component organic pollutants in dilute aqueous solution. Environmental technology, v. 17, n. 1, p. 13-23, 1996.

KHATTRI, S. D.; SINGH, M. K. Colour removal from dye wastewater using sugar cane dust as an adsorbent. Adsorption science \& technology, v. 17, n. 4, p. 269282, 1999.

KIM, Christopher S.; RYTUBA, James J.; BROWN JR, Gordon E. EXAFS study of mercury (II) sorption to Fe-and Al-(hydr) oxides: I. Effects of $\mathrm{pH}$. Journal of colloid and interface science, v. 271, n. 1, p. 1-15, 2004.

KOBLE, Robert A.; CORRIGAN, Thomas E. Adsorption isotherms for pure hydrocarbons. Industrial \& Engineering Chemistry, v. 44, n. 2, p. 383-387, 1952.

KOSMULSKI, Marek. Adsorption of trivalent cations on silica. Journal of colloid and interface science, v. 195, n. 2, p. 395-403, 1997.

KOSMULSKI, Marek. Isoelectric points and points of zero charge of metal (hydr) oxides: 50 years after Parks' review. Advances in colloid and interface science, v. 238, p. 1-61, 2016.

KRISHNAMURTHY, Nagaiyar; GUPTA, Chiranjib Kumar. Extractive metallurgy of rare earths. CRC press, 2004.

KUCUKER, Mehmet Ali et al. Biosorption of neodymium on Chlorella vulgaris in aqueous solution obtained from hard disk drive magnets. PloS one, v. 12, n. 4, p. e0175255, 2017.

LAGERGREN, Stan. Zur theorie der sogenannten adsorption geloster stoffe. Kungliga svenska vetenskapsakademiens. Handlingar, v. 24, p. 1-39, 1898.

LAJEVARDI, Seyedeh Aseman; KHANLOU, Roghayeh Madadi Hamzeh; MANOOCHEHRI, Mahboobeh. Removal of Neodymium from Aqueous Solutions Using a New Fe-modified Nanoporous Adsorbent of Fe-MCM41.Journal Of Applied Chemical Research.Iran, p. 31-40. ago. 2015. 
LARGITTE, L.; PASQUIER, R. A review of the kinetics adsorption models and their application to the adsorption of lead by an activated carbon. Chemical Engineering Research and Design, v. 109, p. 495-504, 2016.

LEE, I.-Hsien; KUAN, Yu-Chung; CHERN, Jia-Ming. Equilibrium and kinetics of heavy metal ion exchange. Journal of the Chinese Institute of Chemical Engineers, v. 38, n. 1, p. 71-84, 2007.

LEWINSKY, Allison A. Hazardous materials and wastewater: treatment, removal and analysis. Nova Publishers, 2007.

LIANG, Xuefeng et al. Heavy metal adsorbents mercapto and amino functionalized palygorskite: preparation and characterization. Colloids and Surfaces A: Physicochemical and Engineering Aspects, v. 426, p. 98-105, 2013.

LIDE, David R. (Ed.). CRC handbook of chemistry and physics. CRC press, 2004.

LIMOUSIN, G. et al. Sorption isotherms: A review on physical bases, modeling and measurement. Applied geochemistry, v. 22, n. 2, p. 249-275, 2007.

LIU, Yu; LIU, Ya-Juan. Biosorption isotherms, kinetics and thermodynamics. Separation and Purification Technology, v. 61, n. 3, p. 229-242, 2008.

LIU, Yushan et al. Attapulgite-Fe3O4 magnetic nanoparticles via co-precipitation technique. Applied Surface Science, v. 255, n. 5, p. 2020-2025, 2008.

LUZ, Adão Benvindo da; LINS, Fernando Antonio Freitas. Rochas \& minerais industriais: usos e especificações. CETEM/MCT, 2005.

M.J. Ahmed, Application of agricultural based activated carbons by microwave and conventional activations for basic dye Adsorption: review,J. Environ.Chemical Eng. 4 p.89-99.(2016)

MACKENZIE, J. M. W.; O'BRIEN, R. T. Zeta potential of quartz in the presence of nickel (II) and cobalt (II). Trans. AIME, v. 244, p. 168-173, 1969.

MALAMIS, S.; KATSOU, E. A review on zinc and nickel adsorption on natural and modified zeolite, bentonite and vermiculite: Examination of process parameters, kinetics and isotherms. Journal of hazardous materials, v. 252, p. 428-461, 2013.

MATOS, J. do R.; MERCURI, L.; BARROS, G. Análise térmica aplicada a fármacos e medicamentos. STORPIRTIS, S. et al. Biofarmacotécnica. Guanabara Koogan, p. 32-65, 2009.

MCKAY, Gordon; PORTER, John F. Equilibrium parameters for the sorption of copper, cadmium and zinc ions onto peat. Journal of Chemical Technology \& Biotechnology: International Research in Process, Environmental AND Clean Technology, v. 69, n. 3, p. 309-320, 1997.

MIDDEA, Antonieta et al. Evaluation of Fe (III) adsorption onto palygorskite surfaces. Applied Surface Science, v. 282, p. 253-258, 2013.

MIDDEA, Antonieta et al. Magnetic polystyrene-palygorskite nanocomposite obtained by heterogeneous phase polymerization to apply in the treatment of oily waters. Journal of Applied Polymer Science, v. 135, n. 15, p. 46162, 2018.

MOELLER, Therald. The Chemistry of the Lanthanides: Pergamon Texts in Inorganic Chemistry. Elsevier, 2013.

MURRAY, Haydn H. Traditional and new applications for kaolin, smectite, and palygorskite: a general overview. Applied clay science, v. 17, n. 5-6, p. 207-221, 2000. 
NASCIMENTO FILHO, VIRGÍLIO F. Técnicas analíticas nucleares de fluorescência de raios $X$ por dispersão de energia (EDXRF) e por reflexão total (TXRF).Piracicaba: Escola Superior de Agricultura Luiz de Queiroz, 1999.

NASEDKIN, V. V. et al. The crystal structure and chemistry of several palygorskite samples with different geneses. Crystallography Reports, v. 54 , n. 5 , p. 884 , 2009.

NASEEM, R.; TAHIR, S. S. Removal of Pb (II) from aqueous/acidic solutions by using bentonite as an adsorbent. Water Research, v. 35, n. 16, p. 3982-3986, 2001.

NASER, A. A. et al. Elaboration of impregnated composite for sorption of europium and neodymium ions from aqueous solutions. Journal of Industrial and Engineering Chemistry, v. 32, p. 264-272, 2015.

NEWMAN, David J.; CRAGG, Gordon M. Natural products as sources of new drugs over the last 25 years. Journal of natural products, v. 70 , n. 3, p. 461-477, 2007.

OGUNSILE, B. O.; BAMGBOYE, M. O. Biosorption of Lead (II) onto soda lignin gels extracted from Nypa fruiticans. Journal of environmental chemical engineering, v. 5, n. 3, p. 2708-2717, 2017.

OLIVEIRA, Robson Caldas de. Biossorção de terras-raras por Sargassum sp.: estudos preliminares sobre as interações metal-biomassa e a potencial aplicação do processo para a concentração, recuperação e separação de metais de alto valor agregado em colunas empacotadas. 2011. $190 \mathrm{f}$. Tese (Doutorado) - Curso de Química, Universidade Estadual Paulista, Araraquara, 2011

ÖZCAN, Adnan et al. Determination of the equilibrium, kinetic and thermodynamic parameters of adsorption of copper (II) ions onto seeds of Capsicum annuum. Journal of Hazardous Materials, v. 124, n. 1-3, p. 200-208, 2005.

PALMIERI, Mauricio C.; GARCIA JR, Oswaldo; MELNIKOV, Petr. Neodymium biosorption from acidic solutions in batch system. Process Biochemistry, v. 36, n. 5, p. 441-444, 2000.

PARK, Hyung-Jun; TAVLARIDES, Lawrence L. Adsorption of neodymium (III) from aqueous solutions using a phosphorus functionalized adsorbent. Industrial \& Engineering Chemistry Research, v. 49, n. 24, p. 12567-12575, 2010.

PARKS, George A. The isoelectric points of solid oxides, solid hydroxides, and aqueous hydroxo complex systems. Chemical Reviews, v. 65, n. 2, p. 177-198, 1965.

PATHAK, P. N.; CHOPPIN, G. R. Sorption of $\mathrm{Am}^{3+}$ cations on suspended silicate: effects of $\mathrm{pH}$, ionic strength, complexing anions, humic acid and metal ions. Journal of Radioanalytical and Nuclear Chemistry, v. 274 , n. 3, p. 517523, 2007.

PINO, Gabriela Alejandra Huamán. Biossorção de Metais Pesados Utilizando Pó da Casca de Coco Verde (Cocos nucifera). 2005. 113 f. Dissertação (Mestrado) - Curso de Pós Graduação em Engenharia Química e de Materiais, Pontifícia Católica Universidade, Rio de Janeiro, 2005.

PLAZINSKI, Wojciech; RUDZINSKI, Wladyslaw; PLAZINSKA, Anita. Theoretical models of sorption kinetics including a surface reaction mechanism: a review. Advances in colloid and interface science, v. 152, n. 1-2, p. 2-13, 2009. 
POTGIETER, J. H.; POTGIETER-VERMAAK, S. S.; KALIBANTONGA, P. D. Heavy metals removal from solution by palygorskite clay. Minerals Engineering, v. 19, n. 5, p. 463-470, 2006.

PREISINGER, Anton. Sepiolite and related compounds: its stability and application. Clays and Clay Minerals, v. 10, n. 1, p. 365-371, 1961.

RIAÑO, Sofía; BINNEMANS, Koen. Extraction and separation of neodymium and dysprosium from used NdFeB magnets: an application of ionic liquids in solvent extraction towards the recycling of magnets. Green Chemistry, v. 17, n. 5, p. 2931-2942, 2015.

ROMERA, E. et al. Comparative study of biosorption of heavy metals using different types of algae. Bioresource technology, v. 98, n. 17, p. 3344-3353, 2007.

RUIZ-HITZKY, Eduardo et al. Advanced materials and new applications of sepiolite and palygorskite. In: Developments in Clay Science. Elsevier, 2011. p. 393-452.

SAĞ, Yeşim; KUTSAL, Tülin. Determination of the biosorption heats of heavy metal ions on Zoogloea ramigera and Rhizopus arrhizus. Biochemical Engineering Journal, v. 6, n. 2, p. 145-151, 2000.

SAMPAIO, João Alves; FRANÇA, Silvia Cristina Alves; BRAGA, Paulo Fernando Almeida.Tratamento de minérios: práticas laboratoriais. CETEM/MCT, 2007.

SANDAU, E. et al. Heavy metal sorption by marine algae and algal by-products. Acta biotechnologica, v. 16, n. 2-3, p. 103-119, 1996.

SCHONS, E. Fenômenos Interfaciais - aula 1: tipos e caracterização das interfaces. Curso de especialização em tratamento de minérios. Universidade Federal de Goiás. Catalão. 96 slides. Disponível em: < $<$ https://cetm_engminas.catalao.ufg.br/up/596/o/fen_int_1.pdf>.Acesso em $11 \mathrm{de}$ Abril de 2019.

SCHÜLER, Doris et al. Study on rare earths and their recycling. Öko-Institut eV Darmstadt, 2011.

SEKAR, M.; SAKTHI, V.; RENGARAJ, S. Kinetics and equilibrium adsorption study of lead (II) onto activated carbon prepared from coconut shell. Journal of colloid and interface science, v. 279, n. 2, p. 307-313, 2004.

SERRA, Osvaldo Antonio. Terras raras.[Editorial]: Brasil $X$ China. Journal of the Brazilian Chemical Society, v. 22, n. 5, p. 809-811, 2011.

SHANNON, Robert D. Revised effective ionic radii and systematic studies of interatomic distances in halides and chalcogenides. Acta crystallographica section A: crystal physics, diffraction, theoretical and general crystallography, v. 32, n. 5, p. 751-767, 1976.

SHARIFIPOUR, F. et al. Kinetics and thermodynamics of lead adsorption from aqueous solutions onto Iranian sepiolite and zeolite. International Journal of Environmental Research, v. 9, n. 3, p. 1001-1010, 2015.

SHARMA, Y. C. et al. Use of wollastonite in the removal of $\mathrm{Ni}$ (II) from aqueous solutions. Water, Air, and Soil Pollution, v. 49, n. 1-2, p. 69-79, 1990.

SHAW, Duncan James. Introdução à Química dos Colóides e de Superfícies. E. Blücher, 1975.

SILVA, M. L. G. Obtenção e caracterização de argila piauiense paligorskita (atapulgita) organofilizada para uso em formulações cosméticas. Teresina: UFPI, 2011. 
SILVA, Mirna Luciano de Gois da et al. The effect of natural and organophilic palygorskite on skin wound healing in rats. Brazilian Journal of Pharmaceutical Sciences, v. 49, n. 4, p. 729-736, 2013.

SILVA, Mirna Luciano de Gois et al. Palygorskite organophilic for dermopharmaceutical application. Journal of Thermal Analysis and Calorimetry, v. 115, n. 3, p. 2287-2294, 2014.

SILVERSTEIN, Roberto M.; BASSLER, G. C.; MORRILL, T. C. Identificação espectrométrica de compostos orgânicos. $5^{a}$ edição. Guanabora koogan SA, 1979.

SIMÕES, Karla Mayara Arguelles. Caracterização tecnológica e beneficiamento da palygorskita do piauí para aplicação como adsorvedor de chumbo e cádmio em efluentes. 2017. 102 f. Dissertação (Mestrado) - Curso de Pós Graduação em Química, Universidade Federal do Rio de Janeiro, Rio de Janeiro, 2017.

SING, Kenneth SW. Reporting physisorption data for gas/solid systems with special reference to the determination of surface area and porosity (Recommendations 1984). Pure and applied chemistry, v. 57, n. 4, p. 603-619, 1985.

SINGER, Arieh; HUERTOS, Emilio Galán; GALAN, Emilio (Ed.). Developments in Palygorskite-sepiolite Research: A new outlook on these nanomaterials. Elsevier, 2011.

SIPS, R. Combined form of Langmuir and Freundlich equations. J. Chem. Phys, v. 16, n. 429, p. 490-495, 1948.

SLAMOVA, R. et al. Clay minerals in animal nutrition. Applied Clay Science, v. 51, n. 4, p. 395-398, 2011.

SMITH, Joseph Mauk. Chemical engineering kinetics. 1981.

SONDI, Ivan; MILAT, Ognjen; PRAVDIĆ, Velimir. Electrokinetic potentials of clay surfaces modified by polymers. Journal of Colloid and Interface Science, v. 189, n. 1, p. 66-73, 1997.

SPARKS, D. L. Environmental soil chemistry. London: Academic Press,p 351, 2003

SPOSITO, Garrison et al. The surface chemistry of natural particles. Oxford University Press on Demand, 2004.

STUMM, Werner et al. Chemistry of the solid-water interface: processes at the mineral-water and particle-water interface in natural systems. John Wiley \& Son Inc., 1992.

SUÁREZ, Mercedes; GARCIA-ROMERO, Emilia. FTIR spectroscopic study of palygorskite: influence of the composition of the octahedral sheet. Applied Clay Science, v. 31, n. 1-2, p. 154-163, 2006.

TAN, Xiaoli et al. Adsorption of Eu (III) onto TiO2: effect of $\mathrm{pH}$, concentration, ionic strength and soil fulvic acid. Journal of hazardous materials, v. 168, n. 1, p. 458465, 2009.

TIAN, Miaomiao et al. Applications of the binary mixture of sec-octylphenoxyacetic acid and 8-hydroxyquinoline to the extraction of rare earth elements. Hydrometallurgy, v. 111, p. 109-113, 2012. 
TORAB-MOSTAEDI, Meisam et al. Biosorption of lanthanum and cerium from aqueous solutions by grapefruit peel: equilibrium, kinetic and thermodynamic studies. Research on Chemical Intermediates, v. 41, n. 2, p. 559-573, 2015.

TOTH, J. State equation of the solid-gas interface layers. Acta chim. hung., v. 69, p. 311-328, 1971.

TRIPATHY, Sushree Swarupa; RAICHUR, Ashok M. Abatement of fluoride from water using manganese dioxide-coated activated alumina. Journal of Hazardous Materials, v. 153, n. 3, p. 1043-1051, 2008.

UDDIN, Mohammad Kashif. A review on the adsorption of heavy metals by clay minerals, with special focus on the past decade. Chemical Engineering Journal, v. 308, p. 438-462, 2017.

ÜNLÜ, Nuri; ERSOZ, Mustafa. Adsorption characteristics of heavy metal ions onto a low cost biopolymeric sorbent from aqueous solutions. Journal of Hazardous Materials, v. 136, n. 2, p. 272-280, 2006.

USGS, 2013. Mineral commodity summaries 2013, United States Geological Survey. Available at: http://minerals.usgs.gov/minerals/pubs/mcs/ [Acesso em 15 de abril,2018].

VÁGVÖLGYI, Veronika et al. Dynamic and controlled rate thermal analysis of attapulgite. Journal of Thermal Analysis and Calorimetry, v. 92, n. 2, p. 589594, 2008.

VARELA, M. L. et al. Otimização de uma metodologia para análise mineralógica racional de argilominerais. 2005.

VARSHINI, C. J. S. et al. Screening of biowaste materials for the sorption of cerium (III) from aqueous environment. Research Journal of Pharmaceutical, Biological and Chemical Sciences, v. 5, n. 5, p. 402-408, 2014.

VARSHINI, J. S. C.; DAS, D.; DAS, N. Recovery of cerium (III) from electronic industry effluent using novel biohydrogel: Batch and column studies. Der Pharmacia Lettre, v. 7, p. 166-179, 2015.

VENEU, Diego Macedo. Tratamento de Soluções Aquosas Contendo Zinco, Cobre e Cádmio por Processo de Biossorção/Bioflotação. 2010. 224 f. Dissertação (Mestrado) - Curso de Pós Graduação em Engenharia Química e de Materiais, Pontifícia Católica Universidade, Rio de Janeiro, 2010.

VIJAYARAGHAVAN, K. Biosorption of lanthanide (praseodymium) using Ulva lactuca: mechanistic study and application of two, three, four and five parameter isotherm models. Journal of Environment \& Biotechnology Research, v. 1, n. 1, p. 10-17, 2015.

VIJAYARAGHAVAN, K.; BALASUBRAMANIAN, R. Single and binary biosorption of cerium and europium onto crab shell particles. Chemical Engineering Journal, v. 163, n. 3, p. 337-343, 2010.

VIJAYARAGHAVAN, K.; JEGAN, J. Entrapment of brown seaweeds (Turbinaria conoides and Sargassum wightii) in polysulfone matrices for the removal of praseodymium ions from aqueous solutions. Journal of Rare Earths, v. 33, n. 11, p. 1196-1203, 2015.

VIJAYARAGHAVAN, K.; YUN, Yeoung-Sang. Bacterial biosorbents and biosorption. Biotechnology advances, v. 26, n. 3, p. 266-291, 2008.

VIJAYARAGHAVAN, K.; YUN, Yeoung-Sang. Utilization of fermentation waste (Corynebacterium glutamicum) for biosorption of Reactive Black 5 from aqueous solution. Journal of Hazardous Materials, v. 141, n. 1, p. 45-52, 2007. 
WANG, Fuchun et al. Adsorption of rare earths (III) by calcium alginate-poly glutamic acid hybrid gels. Journal of Chemical Technology \& Biotechnology, v. 89, n. 7, p. 969-977, 2013.

WANG, X. et al. Sorption and complexation of Eu (III) on alumina: Effects of pH, ionic strength, humic acid and chelating resin on kinetic dissociation study.Applied radiation and Isotopes, v. 64, n. 4, p. 414-421, 2006.

WEBER, Thomas W.; CHAKRAVORTI, Ranjit K. Pore and solid diffusion models for fixed-bed adsorbers. AIChE Journal, v. 20, n. 2, p. 228-238, 1974.

WEDEPOHL, K. H. The Composition of the Continental Crust. Geochimica et Cosmochimica Acta№ 7, v. 59. ndash, v. 1232, p. 1217, 1995.

WILLS, Barry A.; FINCH, James. Wills' mineral processing technology: an introduction to the practical aspects of ore treatment and mineral recovery. Butterworth-Heinemann, 2015.

YAMAMOTO, Yukio et al. Current status of X-ray spectrometer development in the SELENE project. Advances in Space Research, v. 42, n. 2, p. 305-309, 2008.

YAO, Ting et al. Adsorption of Eu (III) on sulfonated graphene oxide: Combined macroscopic and modeling techniques. Journal of Molecular Liquids, v. 215, p. 443-448, 2016.

ZEWAIL, T. M.; YOUSEF, N. S. Kinetic study of heavy metal ions removal by ion exchange in batch conical air spouted bed. Alexandria Engineering Journal, v. 54, n. 1, p. 83-90, 2015.

ZHANG, Jing et al. Adsorption of methylene blue from aqueous solution onto multiporous palygorskite modified by ion beam bombardment: Effect of contact time, temperature, $\mathrm{pH}$ and ionic strength. Applied Clay Science, v. 83, p. 137143, 2013.

ZHANG, Lei; ZENG, Yuexian; CHENG, Zhengjun. Removal of heavy metal ions using chitosan and modified chitosan: A review. Journal of Molecular Liquids, $v$. 214, p. 175-191, 2016.

ZHAO, Feiping et al. An EDTA- $\beta$-cyclodextrin material for the adsorption of rare earth elements and its application in preconcentration of rare earth elements in seawater. Journal of colloid and interface science, v. 465, p. 215-224, 2016.

ZHOU, Li. Adsorption: Progress in Fundamental and Application Research: Selected Reports at the 4th Pacific Basin Conference on Adsorption Science and Technology: Tianjin, China, 22-26 May 2006. World Scientific, 2007.

ZHU, Ye Kai; CHEN, Da Jun. Effect of Sintering Temperature on the Structure and Properties of Attapulgite-Based Nanofibrous Membranes. In: Materials Science Forum. Trans Tech Publications Ltd, 2017. p. 1929-1934.

ZHU, Yongfeng; ZHENG, Yian; WANG, Aiqin. A simple approach to fabricate granular adsorbent for adsorption of rare elements. International journal of biological macromolecules, v. 72, p. 410-420, 2015. 